\title{
The SNAP Operating System Reference Manual
}

Jerome D. Sabuda, Joseph Polito, Jack L. Walker, Floyd H. Grant, III

Pritsker \& Associates, Inc.

West Lafayette, IN 47906

Prepared by

Sandia National Laboratories

Albuquerque, New Mexıco 87185 and Livermore, Calıfornı 94550

for the United States Department of Energy

under Contract DE-AC04-76DP00789 


\section{DISCLAIMER}

This report was prepared as an account of work sponsored by an agency of the United States Government. Neither the United States Government nor any agency Thereof, nor any of their employees, makes any warranty, express or implied, or assumes any legal liability or responsibility for the accuracy, completeness, or usefulness of any information, apparatus, product, or process disclosed, or represents that its use would not infringe privately owned rights. Reference herein to any specific commercial product, process, or service by trade name, trademark, manufacturer, or otherwise does not necessarily constitute or imply its endorsement, recommendation, or favoring by the United States Government or any agency thereof. The views and opinions of authors expressed herein do not necessarily state or reflect those of the United States Government or any agency thereof. 


\section{DISCLAIMER}

Portions of this document may be illegible in electronic image products. Images are produced from the best available original document. 


\section{NOTICE}

This report was prepared as an account of work sponsored by an agency of the United States Government. Neither the United States Government nor any agency thereof, or any of their employees, makes any warranty, expressed or implied, or assumes any legal liability or responsibility for any third party's use, or the results of such use, of any information, apparatus product or process disclosed in this report, or represents that its use by such third party would not infringe privately owned rights.

Available from GPO Sales Program

Division of Technical Information and Document Control

U.S. Nuclear Regulatory Commission

Washington, D.C. 20555

and

National Technical Information Service

Springfield, Virginia 22161 
ABSTRACT

The SNAP Operating System (SOS) is a FORTRAN 77 program which provides assistance to the safeguards analyst who uses the Safeguards Automated Facility Evaluation (SAFE) and the Safeguards Network Analysis Procedure (SNAP) techniques. Features offered by SOS are a data base system for storing a library of SNAP applications, computer graphics representation of SNAP models, a computer graphics editor to develop and modify SNAP models, a SAFE-to-SNAP interface, automatic generation of SNAP input data, and a computer graphics postprocessor for SNAP. The SOS Reference Manual provides detailed application information concerning sos as well as a detailed discussion of all sos components and their associated command input formats. Sos was developed for the U.S. Nuclear Regulatory Commission's Office of Nuclear Regulatory Research and the U.S. Naval Surface Weapons Center by Pritsker \& Associates, Inc., under contract to Sandia National Laboratories. 
TABLE OF CONTENTS

Page

LIST OF TABLES......................... iv

LIST OF PIGURES.......................... v

SECTION I. INTRODUCTION................... 1

SECTION II. SNAP OPERATING SYSTEM OVERVIEW......... 3

SNAP Model Library Manipulation................ 3

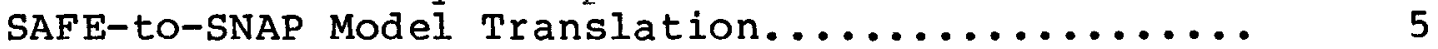

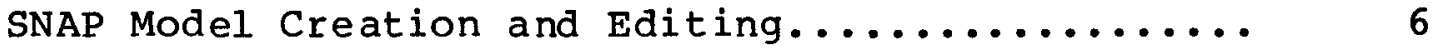

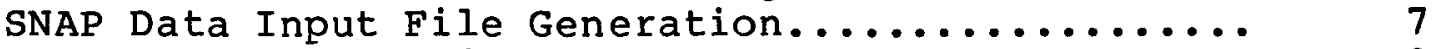

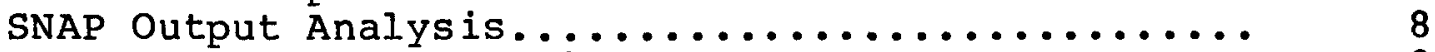

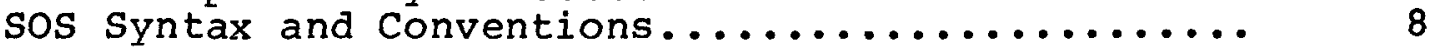

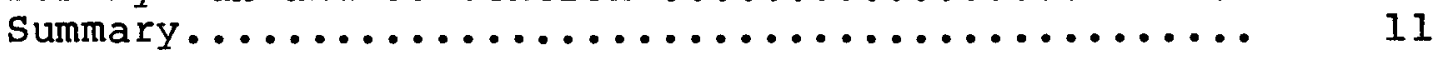

SECTION III. SOS EXECUTIVE................... 13

EXECUTIVE Command Descriptions.............. 16

SECTION IV. SOS LIBRARY MANIPULATION............. 20

sos Terminology......................... 22

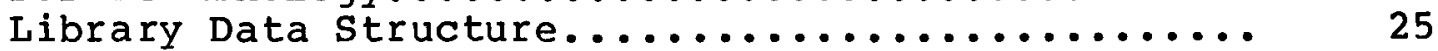

Library Command Syntax and Conventions........... 27

LIBRARY Command Descriptions................... 29

SECTION V. SAFE-TO-SNAP TRANSLATOR (TRANSLATE) ...... 50

TRANSLATE Command Descriptions.............. 54

SECTION VI. SNAP MODEL EDITOR (EDIT) ............ 60

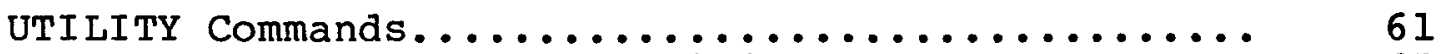

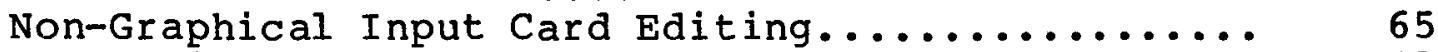

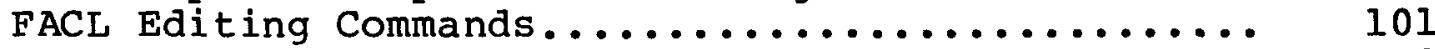

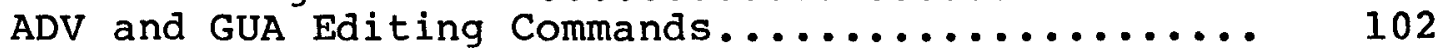

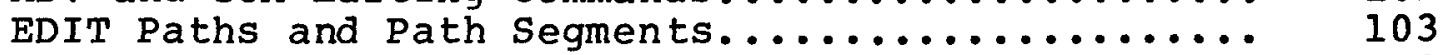

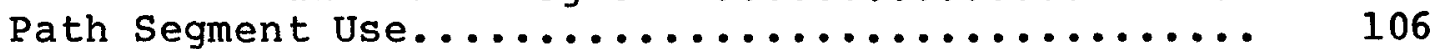

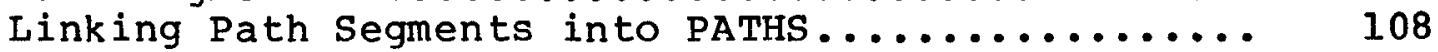

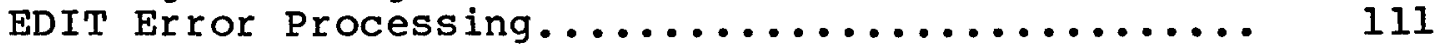

EDIT Command Syntax and Conventions............. 114

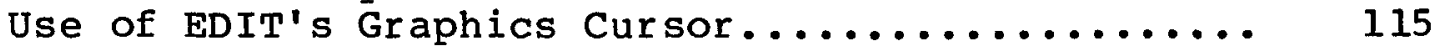

EDIT Command Descriptions.................. 116 
SECTION VII. SNAP DATA INPUT RECORD

GENERATOR (DATA) ................. 165

DATA Command Description................. 167

SECTION VIII. SNAP OUTPUT ANALYZER (ANALYZE) ....... 168

ANALYZE Command Syntax and Conventions.......... 172

ANALYZE Command Descriptions................. 175

SECTION IX. SUMMARY....................... 185

REFERENCES ............................ 186

APPENDIX A. SOS COMMAND SYNTAX SUMMARY........... 188

APPENDIX B. SOS DATA LIST DEFINITIONS............. 196 
2.1. Naming Conventions by Entry Type for Labels provided by sos......................... 12

6.1. The sos/EDIT Commands................... 118 
LIST OF FIGURES

Figure

Page

2.1. sos Overview......................... 4

3.1. Sos Functional schematic................ 13

4.1. sos Library structure................... 21

4.2. Sos Library Component Organization structure.. 26

5.1. TRANSLATE Command Hierarchy............. 51

6.1. EDIT Command Hierarchy................. 62

6.2. EDIT screen Configurations............... 64

6.3. Example TEXT Editing Session............. 67

6.4. Example EDIT Path Segment............... 107

6.5. The EDIT/ALARM Modular Subnetwork.......... 123

6.6. The EDIT/ATTACK Modular Subnetwork......... 133

6.7. The EDIT/COVER Modular Subnetwork........... 140

6.8. The EDIT/MERGE Modular Subnetwork.......... 150

6.9. The EDIT Graphical Paging system........... 154

6.10. Example EDIT Path Segment................. 158

6.11. The EDIT/PATROL Modular Subnetwork......... 166

7.1. DATA Command Hierarchy................. 170

8.1. ANALYZE Command Hierarchy.............. 171

8.2. ANALYZE Screen Configuration............. 173

8.3. ANALYZE Symbology.................. 176 
SECTION I

INTRODUCTION

The Snap Operating System (SOS) is an interactive computer software tool developed to assist the safeguards analyst in the building, maintaining, and analysis of SNAP simulation models. Sos was developed by Pritsker \& Associates, Inc. under contract to Sandia National Laboratories. The purpose of sos is to provide the analyst with support for his SNAP modeling efforts. SOS provides this support with five functions that address significant SNAP modeling tasks. These functions are:

* A library creation and maintenance capability to aid in the storage and maintenance of SNAP models;

* An editor to support the graphical creation and maintenance of SNAP network models and the specification of non-graphical data;

* A SAFE-to-SNAP translator to transform SAFE analysis data to a skeletal SNAP model to expedite building safeguards models;

* A SNAP input data record creator to generate the data for the SNAP analysis program from the graphical networks and non-graphical data stored in the library; and

* A SNAP output analysis package which consists of a graphical output illustrator to display trace characteristics of individual simulation runs.

This report is designed to be a reference manual and to provide reference support on the use of SOS. An SOS user's guide is also available to provide training in the use of sos (1). A working knowledge of SNAP (the Safeguards 


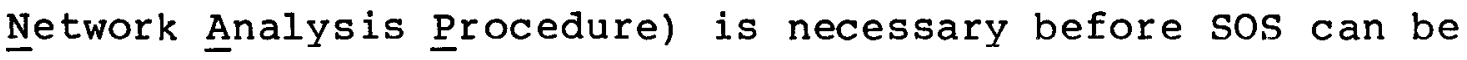
used constructively.(2) The next section of this report provides an overview of sos followed by discussion of the SOS EXECUTIVE processor in section III which ties all of the various sos components into a single comprehensive system. Sections IV through VIII provide a detailed discussion of the five sos components and their associated command input formats. A summary of all of the sos commands is provided in the Appendices as a quick command reference guide. The user should use this report as a reference manual for detailed application information concerning the SNAP Operating system.

The SNAP Operating System computer program is written in ANSI 177 FORTRAN, with Hollerith data, and is thus portable among many different computers. Its graphics capabilities are performed using the Graphics Compatibility System (GCS) which is a computer and graphics device independent software package: $(3,4)$ As of this writing, sos has been installed on CDC 6600 and VAX $11 / 780$ computers and has been used on Tektronix 4014, 4054, and 4112 graphics terminals. 
SECTION II

SNAP OPERATING SYSTEM OVERVIEW

The SNAP Operating System (SOS) provides the model developer with an integrated set of support functions for building and maintaining SNAP models as well as for displaying and evaluating SNAP model output. This section will provide the user with an overview of these capabilities. Details concerning command syntax and model structures will be provided in subsequent sections.

Figure 2.1 provides an overview of the SNAP Operating system in its entirety. Sos consists of five main functions designed to support model building tasks. These functions are available in the parallel structure indicated in Figure 2.1. There are commands associated with each function which are described in detail later in this manual.

SNAP Model Library Manipulation

The first function provided in sOS is a logical structure for developing and maintaining SNAP models in a library format. This function of sos consists of a set of interactive library manipulation commands through which the user may link up and define various SNAP scenarios. The user can maintain the following entities and submodels: 


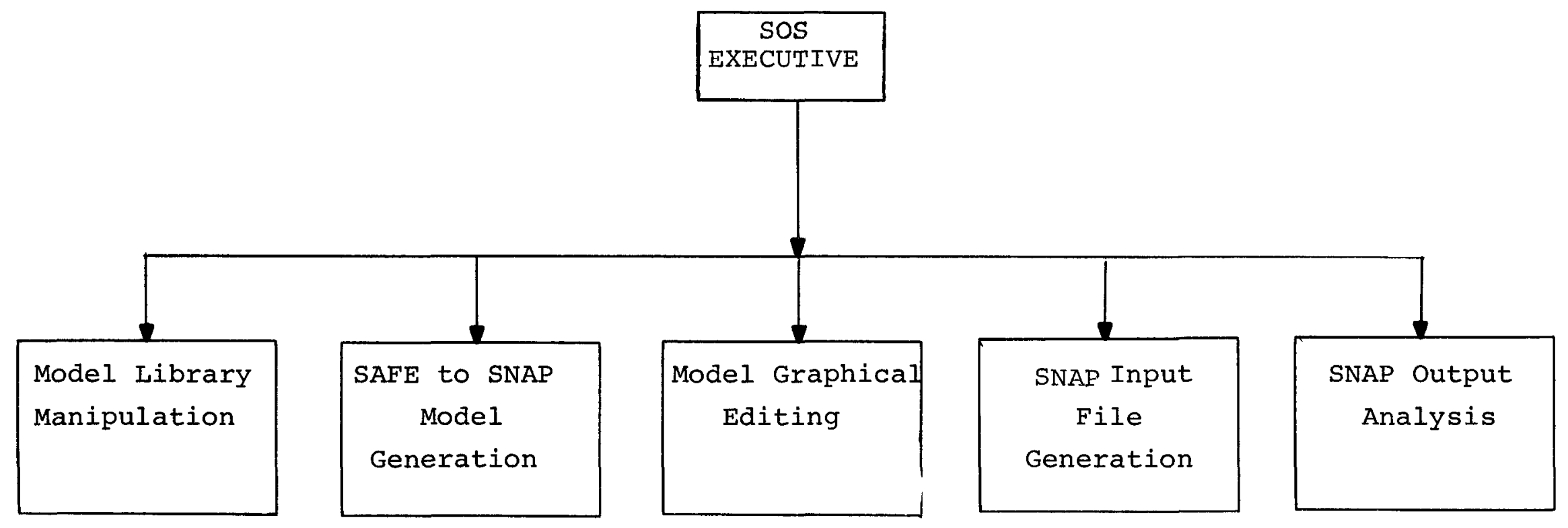

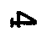

Figure 2.1. Sos Overview. 
1. Adversary submodels;

2. Guard submodels;

3. Facility submodels;

4. Status variable definitions;

5. SNAP trace output;

6. User function FORTRAN code; and

7. Other user defined data.

The user may link these entities together to form what are called scenarios. Each scenario consists of at least one of the above entities. Multiple scenarios are then grouped together within site applications in the library processor. The library processor also provides the capability to support multiple sites in a single library. The user may also maintain unlinked entities which are associated with no particular scenario, but which he wishes to keep for further reference or use.

\section{SAFE-to-SNAP Model Translation}

In the generation of SAFE models, $(5,6,7)$ much work is performed to characterize the facility through facility digitization. Additionally, outputs of the SAFE analysis procedure provide important information concerning likely adversary scenarios and the associated attack paths as well as guard response procedures. The TRANSLATE function in SOS provides for the automatic generation of SNAP models which 
emulate the SAFE model. TRANSLATE automatically provides the following items to the analyst:

1. A facility model based on the SAFE digitization;

2. A skeletal guard response model; and

3. An adversary attack scenario based on the SAFE analysis.

This function will greatly expedite the creation of basic SNAP models and will automate and formalize the interface between SAFE and SNAP.

\section{SNAP Model Creation and Editing}

This function of the sOs provides a SNAP model editor designed for the creation and modification of SNAP models. It allows the user to interactively build a SNAP model using computer aided graphics techniques. The user creates a model by directly positioning and linking up the various SNAP symbols. Two levels of commands are provided within the graphical editing capability. General data input is provided by which the user can simply position the symbols and link them together on the screen. Additionally, modular commands are provided through which the user can easily model recurring functions such as patrols, response to alarms, etc. These modular commands greatly expedite the development of SNAP models. 
While SNAP is a network/graphical simulation technique, there are certain data input elements which are not characterized by graphical symbols. These include the PARAMETER data cards, the ENGAGEMENT data card, etc. The EDIT/TEXT command in sos will allow the user to create these SNAP data elements for which there is no graphical symbol. This command will invoke an interactive input processor which is highly user friendly and allows the user to create these data elements. They include the following:

1. PARAMETER cards;

2. The ENGAGEMENT card;

3. PENG cards;

4. DENG cards;

5. The OBJECTIVE card;

6. BASE cards;

7. MACRO cards;

8. TIMER cards; and

9. STATUS VARIABLE cards.

This approach expedites the creation of SNAP models and gives the user a formalized means for creating and maintaining SNAP non-graphical data.

SNAP Data Input File Generation

To provide efficient storage of SNAP models, model data is stored in the sos model library in a condensed form which reflects graphical and SNAP data for SNAP elements. 
The DATA command is used to generate SNAP data input which is compatible with the SNAP simulation program. The DATA command generates SNAP data input files from the data stored in the sos library. The command is interactive and prompts the user for the definition of data associated with the SNAP data card as well as the particular scenario for which the data is to be generated in the sos library. A file is created which contains all of the SNAP data input for the identified scenario. This data file may then be fed into the SNAP program for subsequent simulation and analysis.

\section{SNAP Output Analys is}

In order to support the analysis of SNAP models, the graphical trace output function in sos allows the user to interactively display the execution trace of a SNAP model on the digitized representation of the facility. This aids not only in the presentation of SNAP results but also in the development of SNAP models by providing a convenient debugging aid which expedites the review of the SNAP trace. This graphical output illustrator is completely general and is tied to no particular facility.

sos syntax and Conventions

The sos provides a set of commands by which the user may execute the various functions required in SNAP model 
development and analysis. There are several conventions regarding the entry of sos commands and their associated syntax. The following provides a summary of general conventions which are applicable to all sos commands. Conventions specific to certain commands are discussed in the section describing that set of commands.

1. User input to SOS consists of commands, prompts and responses. An input line resembles FORTRAN NAMELIST input, e.g.:

command, prompt $=$ response, prompt $=$ response, etc.

The order of the prompts is significant only for some commands in the sos editor.

2. Commands and prompts are significant to four characters and may not be abbreviated.

3. Some prompts have defaults and need not be specified on the command line.

4. In issuing commands, the user has several options:

a. Type the command name only. The system will interactively request responses for all prompts, even those that have defaults. The user must input a response to each prompt.

b. Type all required prompts and responses on the command line and take defaults for others. No interactive prompting.

c. Type only some of the required prompts on the command line. The user will be prompted for the other required responses and will get defaults for any others not specified explicitly on the command line.

5. A command can be aborted any time by typing "CANC" for a prompt or a response. 
6. Some commands request additional information from the user interactively after the command has been issued.

7. When sos is ready for another command it prints "ENTER COMMAND".

8. Commas or blanks can be used as separators.

9. Any characters past a "\$" character will always be ignored.

10. The characters blank, comma, equals, and dash are sos separators. They can, however, be included in alphanumeric names (such as site names or passwords) by enclosing the names in double quotes (e.g., PASS="ONE,TWO"). The double quote notation must be used every time the name is specified.

11. The sos user will be using various alphanumeric identifiers--for site names, passwords, and node labels. There are certain 4-character reserved keywords used by sos that cannot be used as node labels or as the first 4 characters of a site name or password. If one of these keywords is used out of place, sos will provide an error message such as "ILLEGAL USE OF PROMPT NAME" or "RESPONSE UNRECOGNIZABLE." These reserved keywords are listed below:

$\begin{array}{lll}\text { ADEN } & \text { FSTA } & \text { READ } \\ \text { ADSC } & \text { GENA } & \text { RECO } \\ \text { ADSI } & \text { GENF } & \text { RENA } \\ \text { ANAL } & \text { GENG } & \text { RETA } \\ \text { ASSI } & \text { GET } & \text { REWI } \\ \text { BATL } & \text { LIBR } & \text { SAVE } \\ \text { CANC } & \text { LINK } & \text { SCNR } \\ \text { CLOS } & \text { MAXR } & \text { SELE } \\ \text { COMP } & \text { NEW } & \text { SITN } \\ \text { CURR } & \text { OLD } & \text { TRAN } \\ \text { DATA } & \text { PASS } & \text { TRCE } \\ \text { DELE } & \text { PATH } & \text { TYPE } \\ \text { EDIT } & \text { PRPA } & \text { UNLI } \\ \text { ENTR } & \text { PRTA } & \text { WRIT } \\ \text { FACL } & \text { PURG } & \\ \text { FILE } & \text { QUIT } & \end{array}$

12. Site names and passwords have only 8 significant characters. Any further characters are ignored. Passwords may be any combination of letters and numbers. Site names are any combination of 
letters and numbers with one restriction: they must contain at least one letter. Special characters should not be used in either site names or passwords (see 11 above).

13. There is a naming scheme for labels which are automatically generated by various sos

functions. The user should not use a label which could be generated by the system. The ranges of labels generated by sos are listed in Table 2.1 .

14. Commands are entered without reference to column headings. (8)

\section{Summary}

The SNAP library system is a set of interactive FORTRAN routines designed to provide the five functions described earlier which are necessary in building and maintaining SNAP models of safeguards systems. The various capabilities in sos are designed to be highly interactive and user friendly. Their use in SNAP application will provide more timely analysis results and easier data maintenance.

The following sections of this report will provide details concerning the use of each of the above functions. This will include a detailed description of command syntax, terminology, and conventions. 
Table 2.1. Naming Conventions by Entry Type for Labels Provided by sos

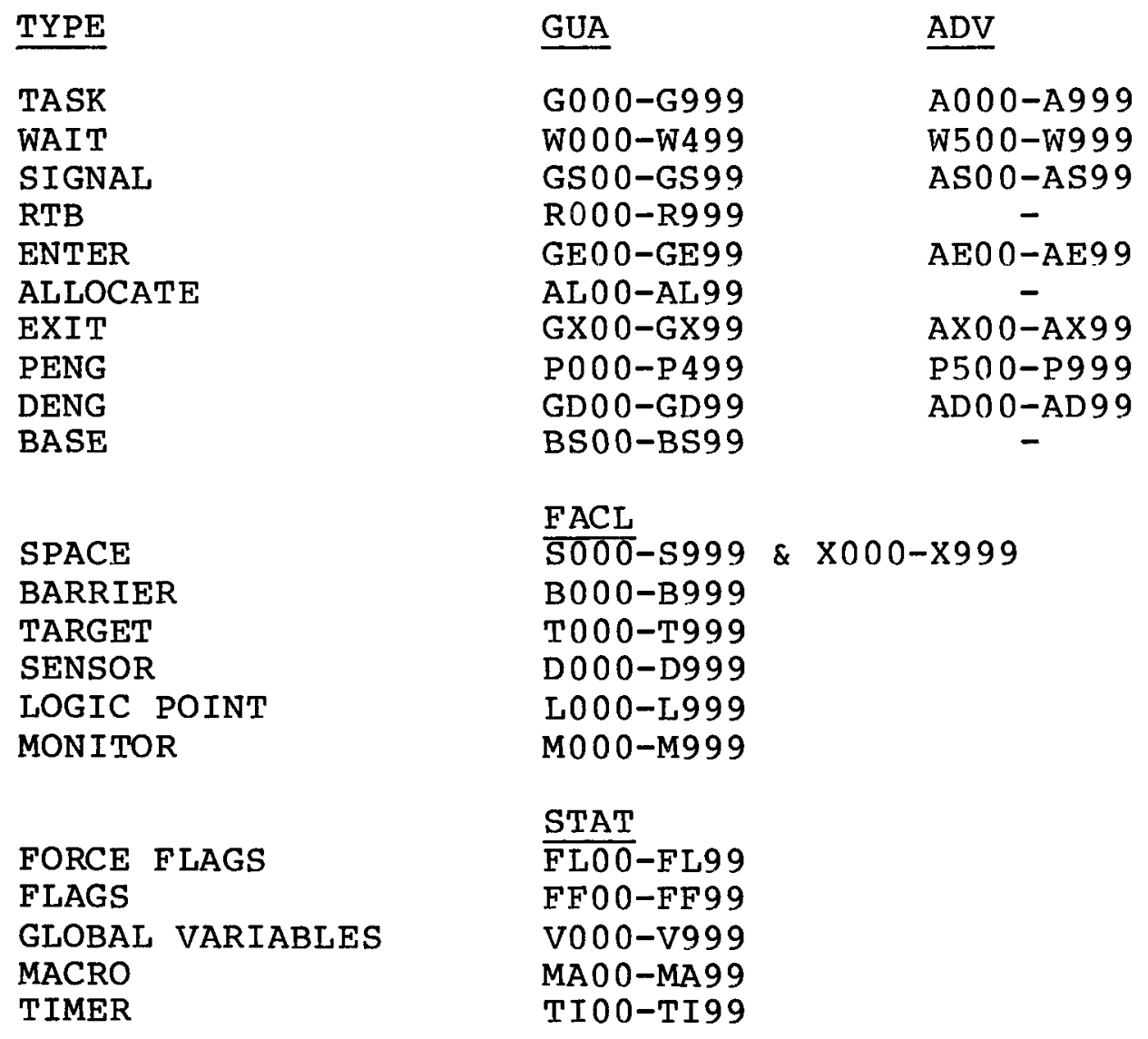


SECTION III

SOS EXECUTIVE

The SNAP Operating System (SOS) is functionally divided into an EXECUTIVE processor and five primary components as shown in Figure 3.1 .

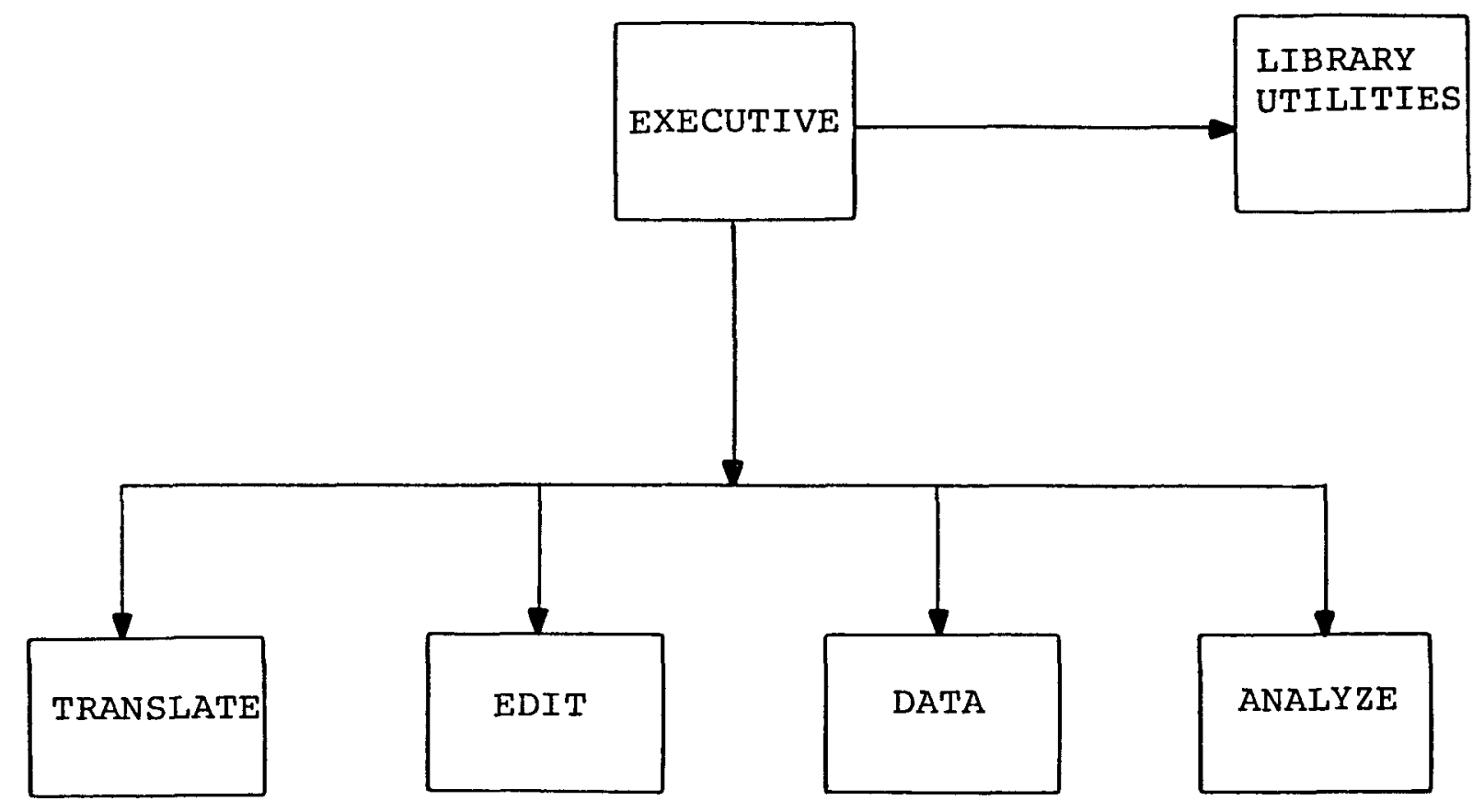

Figure 3.1. SoS Functional Schematic.

The sos is entered through the EXECUTIVE processor, which is the highest level within sos. From this EXECUTIVE processor, the user may invoke the LIBRARY MANIPULATION commands and any of the four primary components directly. 
That is, the LIBRARY MANIPULATION commands may be invoked directly from the EXECUTIVE, whereas the four primary components must be first entered before the commands within them are available to the user. These components, or subsystems within sos, may be entered simply by typing the desired component's name in response to the EXECUTIVE user input prompt:

ENTER COMMAND

The TRANSLATE, EDIT, and ANALYZE components are exited via the QUIT command which returns control to the sos EXECUTIVE. The DATA component will automatically return control to the SOS EXECUTIVE after performing its function. For example, if the user desires to use the EDIT component of sos, he types:

ENTER COMMAND edit

and control would be passed from the sos EXECUTIVE to the sos editor (EDIT). At this point, only EDIT commands may be used to edit a SNAP model. After finishing with EDIT, the user returns to the sos EXECUTIVE by typing: 
The sos itself is also exited using the command QUIT.

Further discussion of the command syntax necessary to invoke the sos primary components is included within the discussion of the respective components. 
EXECUTIVE Command Descriptions

EXECUTIVE/EDIT

COMMAND:

PROCESSOR:

PROMPTS:

DESCRIPTION :

DEFAULTS:

EXAMPLE:
EDIT , ENTRY $=R I$

EXECUTIVE

ENTRY [RI] (Entry name)

Invoke the sos editor to allow the user to graphically create/edit networks and to edit non-graphical data.

None

ENTER COMMAND

edit

ENTRY $=$ gua -1 
COMMAND :

PROCESSOR :

PROMPTS :

DESCRIPTION :

DEFAULTS :

EXAMPLE:
TRANSLATE

EXECUTIVE

None

TRANSLATE a SAFE model into a basic SNAP model. Several subcommands are available and are described in their respective section.

None

ENTER COMMAND

translate 
COMMAND:

PROCESSOR :

PROMPTS:

DESCRIPTION :

DEF AULTS :

EXAMPLE:
$\mathrm{DATA}, \mathrm{SCNR}=\mathrm{R} 1, \mathrm{FILE}=\mathrm{R} 2, \mathrm{REWIND}=\mathrm{R} 3$

\section{EXECUTIVE}

$\begin{array}{lll}\text { P1 - SCNR } & \text { [R1] } & \text { (Scenario name) } \\ \text { P2 - FILE } & \text { [R2] } & \text { (File name) } \\ \text { P3 - REWIND } & \text { [R3] } & \text { (Yes or No) }\end{array}$

Generate a data file of SNAP input records based on a particular scenario stored in the sos library. SNAP data is created for scenario $R 1$ and is written to file R2. If R3 $=Y$, the file is rewound prior to writing on it.
$R I-N / A$
$\mathrm{R} 2-\mathrm{N} / \mathrm{A}$
R3 - "Y"

ENTER COMMAND

data

SCNR 1

FILE myfile

REWIND $n$ 
COMMAND :

PROCESSOR :

PROMPTS :

DESCRIPTION :

EXAMPLE:
ANALYZE ,FENTRY=R 1, TENTRY=R 2, RUN=R3

EXECUTIVE

$\begin{array}{lll}\text { FENTRY } & {[R 1]} & \text { (FACL entry name) } \\ \text { TENTRY } & {[R 2]} & \text { (TRAC entry name) } \\ \text { RUN } & {[R 3]} & \text { (Run number) }\end{array}$

Invoke the SNAP output analysis processor. It provides the means to interactively and graphically review and analyze the SNAP output trace associated with a specified facility R1, trace R2, and run number R3. It will draw the user specified facility level and illustrate guard and adversary movement through the facility. The user controls the display through various commands like RESTART, DRAW, GO, POST, and TIME. The FACL and TRAC entries must be in the WORKING library.

ENTER COMMAND

analyze

FENTRY facl-1

TENTRY trac-2

RUN 3 
SECTION IV

SOS LIBRARY MANIPULATION

The sos library manipulation commands assist the user in creating and maintaining sos libraries. Physically, the library is maintained as a linked set of records on a direct access (or random access) file. Logically, models are organized into sites. More than one site may be present in the library, but information between sites is not logically co-mingled. In other words, each component in the library has a site identifier associated with it and information may not be directly transferred from one site to another. sites, therefore represent the largest organizational unit in the libraries, and are independent. Figure 4.1 illustrates the library structure and how sites, scenarios, and components are related.

There are 17 commands within sos for the creation and manipulation of the sos library. These commands are executed from the EXECUTIVE processor. A detailed discussion of these commands is presented after a discussion on the sos library terminology which follows next. 


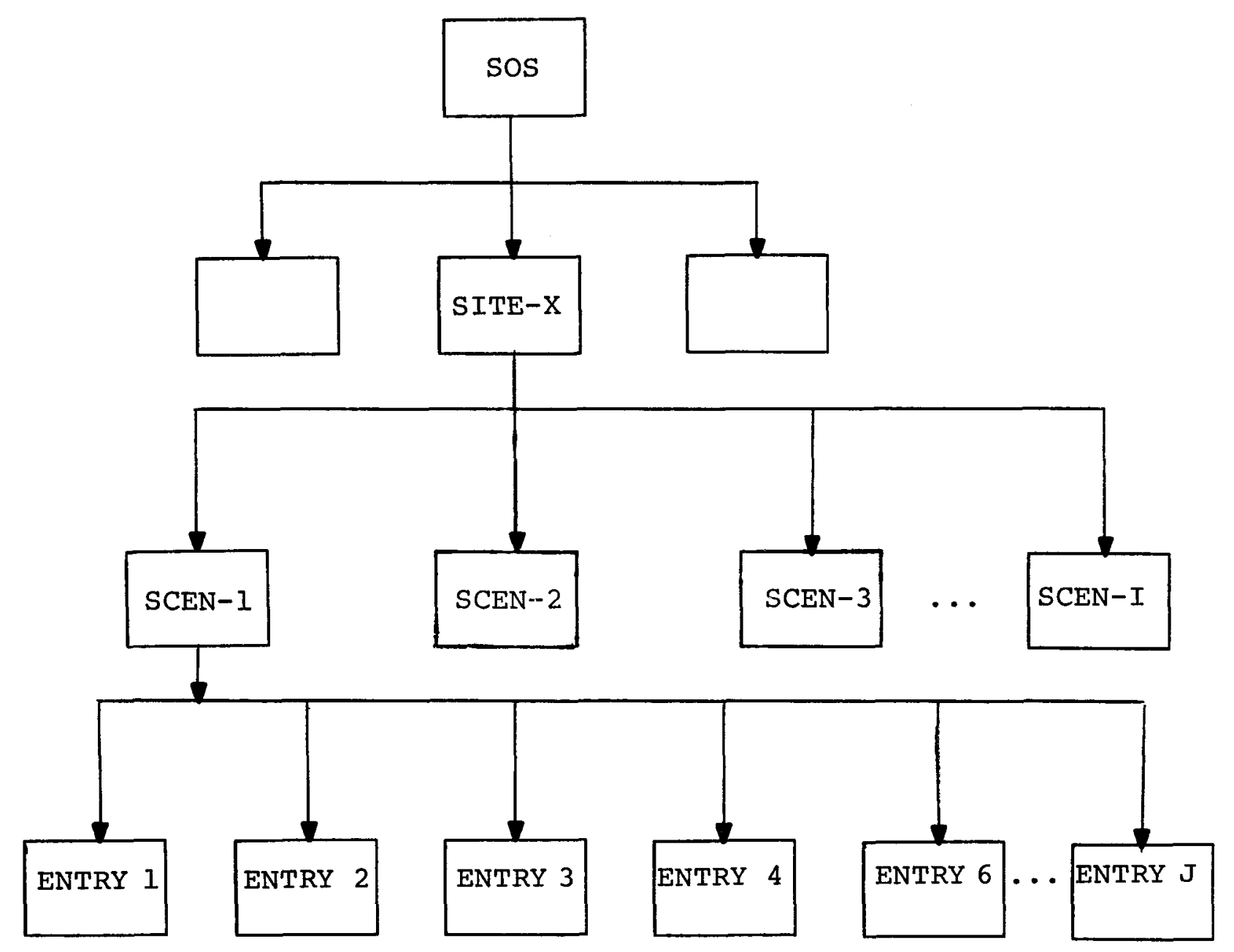

Figure 4.1. Sos Library Structure. 
Sos Terminology

Scenario

A complete scenario consists of the subparts necessary to construct a complete SNAP model including data input and user functions. For example, it will contain a guard submodel, an adversary submodel, possibly a status section, user function, etc. It may also contain additional information which will be discussed later. A scenario is incomplete if it does not contain a complete SNAP model. It may also be overdetermined if it contains, say, two guard models. Incomplete and overdetermined scenarios may not be used to create SNAP data input. Scenarios are numbered by the user. The numbers are positive integers that need not be consecutive.

Entry

An entry is a specific submodel or subcategory of information (e.g., guard, adversary, or facilitỵ network). Entries have two part identifiers. The first part is one of the following:

$$
\begin{aligned}
& \text { GUA - guard subnetwork } \\
& \text { ADV - adversary subnetwork } \\
& \text { FACL - facility subnetwork }
\end{aligned}
$$




$$
\begin{aligned}
& \text { USER - user functions } \\
& \text { TRAC - SNAP trace output file } \\
& \text { STAT - status section } \\
& \text { OTHR - user defined information }
\end{aligned}
$$

The second part of the identifier is a user assigned positive integer. For example, GUA-3 is a guard subnetwork identified by the number 3. The numbers need not be consecutive, however, they must be unique within a site.

\section{$\underline{\text { Site }}$}

A site owns scenarios and entries. It is the largest organizational unit in a SNAP library. A site name is an alphanumeric label with up to 8 characters. Complete references to scenarios and entries include the site name. For example:

$$
\begin{array}{ll}
\text { SITEX-1 - } & \text { scenario } 1 \text { of SITEX (alterna- } \\
& \text { tively, SITEX-SCEN-1) } \\
\text { SITEX-ADV-3 - } & \text { adversary submodel "3" in SITEX }
\end{array}
$$

Clearly, there can be only one ADV-3 in SITEX. A different site may have an ADV-3 submodel, however. Similarly, scenario numbers must be unique within a site. 
Component

A library component is a site, scenario, or entry. In other words, a component is an organizational unit of information.

Site Password

Each site may be assigned a write password of eight or less characters. No read protection is provided.

\section{Master Password}

At the time the library is created, it may be assigned a password of eight characters or less. The user who knows this password can access all site passwords subsequently entered into the library. Also, the library cannot be destroyed by sos without this password. Note that a library is a file and it can be destroyed by the user with his job control language.

WORKING and MASTER Libraries

The user may work with two libraries. Information is copied from a library designated "MASTER" into another library designated "WORKING." Data manipulation can be 
performed only on the WORKING 1ibrary. Data may then be saved on the MASTER library.

\section{Current site}

On the MASTER and WORKING libraries a site can be current. In other words, certain subprograms will operate on it without specifying the site name.

\section{Library Data Structure}

Data in an sos library is stored in records. The last three words in each record hold record linking information. The linking information is: record number of this record, successor record number, and predecessor record number. Thus, chains of records can be created which contain logically connected information, and there is no logical limit to the length of such a chain.

Pointing information to the various components is contained in indexes that are organized according to Figure 4.2. The master index holds the site names and passwords and the record number of the first record of the site indexes. So, for a particular site, the record number of the site index can be determined.

The site index contains a list of all scenario numbers and the record numbers of the scenario indexes. A scenario 


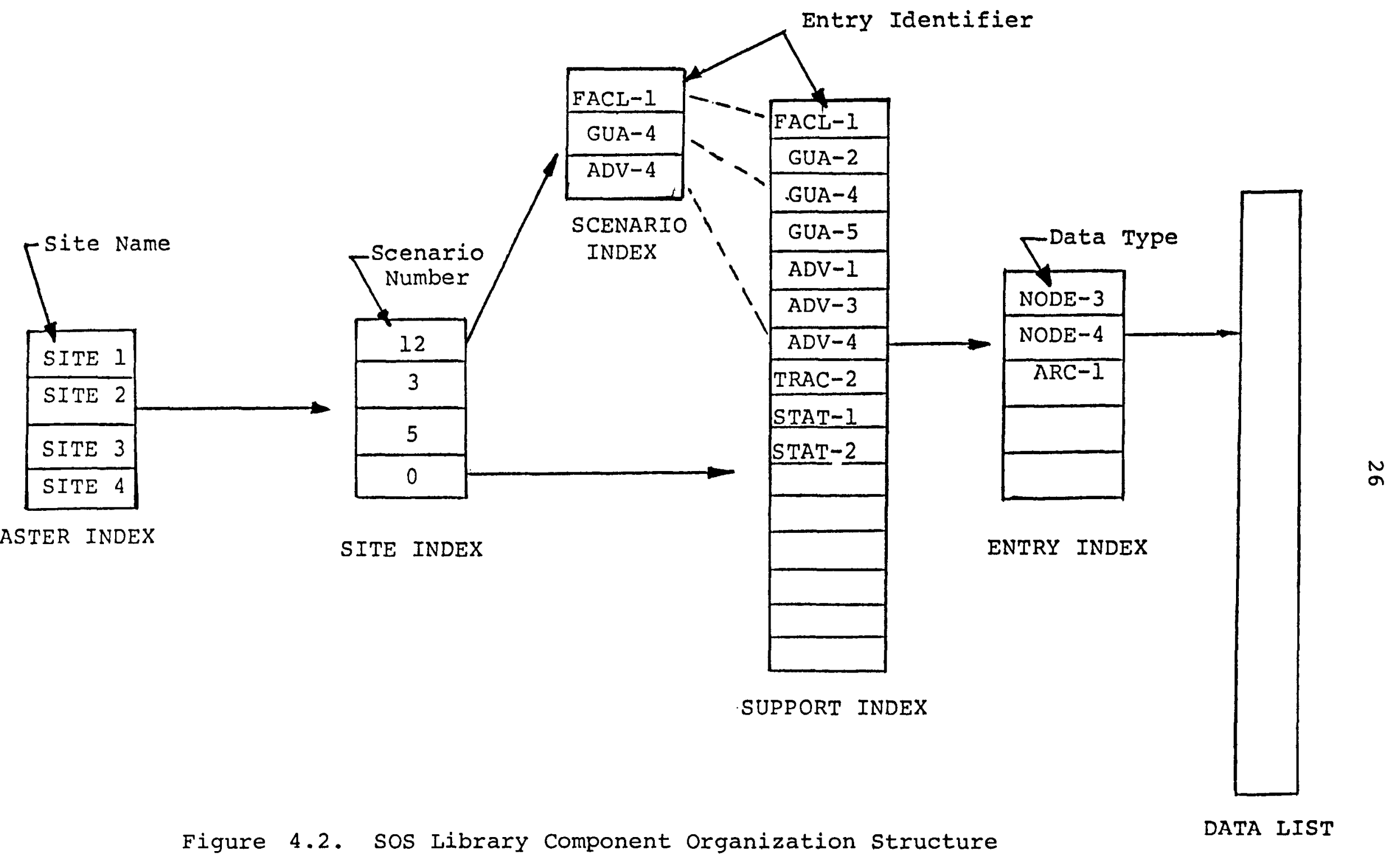


index contains a list of all of the entry identifiers that are "linked" to that scenario and record numbers of the entry indexes. A special "scenario" numbered zero is called the "support scenario" or simply "support." Every entry in the site is Iinked to the support (including the ones linked to scenarios). This provides a cross linking of entries and permits entries to exist that are not linked to any scenario.

An entry index contains a list of data types for the data lists that make up the entry and the associated record numbers of the data lists. Note that the record number of the entry index can be found in both the support index and in any scenario index to which the entry is linked.

Library Command Syntax and Conventions

1. A library "entry" is a collection of information of type ADV, GUA, FACL, STAT, USER, TRAC, or OTHR. Notation is, for example:

site name-ADV-number

2. A "scenario" is any collection of entries. Entries are said to be "linked" to the scenario and may be linked to more than one scenario. Notation for scenarios is:

site name-SCEN-number, or

site name-number 
3. A site is a collection of entries and scenarios. Sites are the largest unit of organization in the library. Sites are independent (they share no information) and more than one site can exist on a library. Notation is:

\section{site name}

4. A component on a library is a site, scenario, or entry.

5. Current site--most operations on a library require a current site. The SELECT command makes a site current. Some commands will automatically make a specified site current. If a site is current then one can use the notation:

$$
\text { ENTRY }=\text { F ACL }-1
$$

When no site name is specified, the current site is used. In a list of entries such as the following:

$$
\text { ENTRY }=\text { F ACL }-1, \text { ADV-2, SHIP-GUA-3, USER-4 }
$$

the first two entries refer to the current site and the last two refer to SHIP. Explicit specification of a site name applies to all subsequent components. If the command receiving the above needed a current site, then sHIP would become current when SHIP-GUA-3 was processed.

6. If an entry name is specified that does not exist (e.g., FACL-1), commands that require that the entry be empty will create it. Sites will never automaticaliy be created, however.

7. Specification of an explicit site name will usually make that site current. 


\section{LIBRARY Command Descriptions}

\section{LIBRARY/ADENTRY}

COMMAND :

PROCESSOR :

PROMPTS :

DESCRIPTION :

DEF AULTS:

NOTES :

EXAMPLE:

$$
\text { ADENTRY , LIBRARY =R1, ENTRY=R2 }
$$

LIBRARY

$\begin{array}{ll}\text { P1 - LIBRARY [R1] } & \text { (MASTER or WORKING) } \\ \text { P2 - ENTRY [R2] } & \text { (Entry name) }\end{array}$

Adds the specified entry $R 2$ to the MASTER Or WORKING LIBRARY as specified in Rl.

\section{RI - "W" (WORKING LIBRARY)}

$\mathrm{R} 2-\mathrm{N} / \mathrm{A}$

The entry to be added must be unique to the current site.

1. adentry, entry $=a d v-2$

2. adentry, $l$ ibr $=m$, en try $=g u a-2$

3. adentry, libr $=m$, en try $=$ ship-gua- 2 
COMMAND :

PROCESSOR :

PROMPTS :

DESCRIPTION :

DEFAULTS :

NOTES:

EXAMPLE:
ADSITE , LIBRARY=RI, SITN=R 2,PASS=R 3

LIBRARY

Pl - LIBRARY [RI] (MASTER or WORKING)

P2 - SITN [R2] (Site name)

P3 - PASS [R3] (Site password)

Adds the specified site R2 to the master index on either the MASTER or WORKING LIBRARY as specified in Rl using the eight character password specified in R3. If a null password is desired, it should be specified as at least one blank character enclosed in double quotes or PASS should be defaulted.

\section{RI - "W" (WORKING LIBRARY) \\ $\mathrm{R} 2-\mathrm{N} / \mathrm{A}$ \\ R3 - blanks (null)}

The site to be added must be new to the master index or an sos query error will be displayed.

1. adsite LIBRARY SITNAME sitea PASS abcd

2. adsite, library=m, sitn=sitea, pass $=a b c d$ 


\section{LIBRARY/ADSCEN}

COMMAND :

PROCESSOR :

PROMPTS :

DESCRIPTION :

DEF AULTS :

NOTES :

EXAMPLE:
ADSCEN , LIBRARY=R I , SCNR=R2

LIBRARY

P1 - LIBRARY [RI] (MASTER or WORKING)

P2 - SCNRIO [R2] (S̄cenario näme)

Adds the specified scenario name R2 to the current site to either the MASTER or WORKING LIBRARY as specified in $\mathrm{Rl}$.

RI - "W" (WORKING LIBRARY)

$R 2-N / A$

The scenario number must be new to the site or an error message will be displayed.
1. adscen LIBRARY m SCNRIO scen-3

2. adscen, 1 ibrary $=m, s c n r=s c e n-3$

3. adscen, 1 ibra $r y=m, s c n r=s h i p-s c e n-4$ 
COMMAND :

PROCESSOR :

PROMPTS :

DESCRIPTION :

DEFAULTS :

EXAMPLES :
ASSIGN , FI LE=R I, LIBRARY=R 2, PASSWORD $=R 3$, MAXRECRD $=R 4$

LIBRARY

P1 - FILE

[RI] (File name for library)

P2 - LIBRARY

[R2] (MASTER or W̄ORKING library)

P3 - PASSWORD [R3] (M̄MSTER password for library)

P4 - MAXRECRD [R4] (Maximum records allowed)

ASSIGN directs the use of file RI as the MASTER or WORKING library. Only one file may be assigned to each of these libraries at any given time. If the specified file does not exist or does not contain an sos library, ASSIGN will open the file and/or create the sos library. The master password R3 and MAXRECRD R4 are used only in this case. If when the ASSIGN command is invoked, the specified library $R 2$ already has a file assigned to it, the file will be closed before the new file is opened. MAXRCRD is the largest record number permitted in the library file. Zero implies no limit.

$\mathrm{R} 1-\mathrm{N} / \mathrm{A}$

R2 - "W" (WORKING library)

R3 - blank

R4 - 0

1. assign, $f i l e=1 \mathrm{ibl}, 1 \mathrm{ibr}=\mathrm{w}$, pass=passl, $\max r=0$ 
LIBRARY/CLOSE

\begin{tabular}{|c|c|}
\hline COMMAND : & CLOSE , FILE=R1, RETAIN=R2 \\
\hline PROCESSOR : & EXECUTIVE \\
\hline PROMPTS : & $\begin{array}{ll}P 1-\text { FILE } & {[R I]} \\
P 2-\operatorname{RETAIN} & {[\mathrm{R} 2]}\end{array}$ \\
\hline DESCRIPTION: & $\begin{array}{l}\text { CLOSE will close a file. R2 should } \\
\text { be } Y \text { or } N \text {. If } Y \text {, the file is not } \\
\text { deleted but becomes inaccessible. RI } \\
\text { is a file name. }\end{array}$ \\
\hline DFF AULT : & $\begin{array}{l}R 1-N / A \\
R 2-" Y "\end{array}$ \\
\hline EXAMPLE: & $\begin{array}{l}\text { 1. close, file=libl, retain=y } \\
\text { 2. close } \\
\text { FILE libl } \\
\text { RETAIN y }\end{array}$ \\
\hline
\end{tabular}


COMMAND :

PROCESSOR :

PROMPTS :

DESCRIPTION :

DEF AULT :

EXAMPLES:
CURRENT , LIBRARY $=$ R 1

\section{LIBRARY}

P1 - LIBRARY [RI] (MASTER or WOORKING)

Prints the current site on the specified library. If only the command is typed, without the prompt, then the default library $(W)$ is used and no interactive prompts are given.

RI - "W" (WORKING LIBRARY)

1. current

2. current, library=m 
COMMAND :

PROCESSOR :

PROMPTS :

DFSCRIPTION :

DEF AULTS :

NOTES :

EXAMPLE:
DELETE , LIBRARY $=R 1$, COMPONNT $=R 2$, RETAIN $=$ R 3

\section{LIBRARY}

$$
\begin{aligned}
& \text { Pl - LIBRARY [RI] (MASTER or } \\
& \text { WORKING } \\
& \text { P2 - COMPONNT [R2] (sīte, scenario } \\
& \text { P3 - RETAIN [R3] (Yes or №) }
\end{aligned}
$$

Delete the specified component. R2 is a site, scenario, or entry. A prompt for the site password will automatically be given if the site has not been previously password verified. If $R 2$ is a scenario, $R 3$ is required to determine the fate of entries linked to the scenario. R3 is $Y$ or $N$. If $R 3=Y$, the entries are retained. If $\mathrm{R} 3=\mathrm{N}$, the entries are deleted.

$$
\begin{aligned}
& \text { R1 - "W" (WORKING LIBRARY) } \\
& \text { R2 - N/A } \\
& \text { R3 - "Y" }
\end{aligned}
$$

Caution should be exercised in using this command, since deleted components may not be retrieved.

1. delete LIBRARY $m$ COMPONNT scen-3 RETAIN $y$ 
COMMAND :

PROCESSOR :

PROMPTS :

DESCRIPTION :

DEF AULTS :

EXAMPLES :
$\mathrm{GET}, \mathrm{COMPONNT}=\mathrm{R} I, \mathrm{R} 1, \mathrm{R} I \ldots$

LIBRARY

COMPONNT $[R], R], \ldots]$ (Site, scenario, or entry)

This command copies entities from the MASTER LIBRARY in to the WORKING LIRBARY. RI is "*", or a component identifier. Rl may be a site, scenario, or entry. The sequence $R I, R I, R 1 \ldots$ is repeated. The command may not be continued to another line. If $R 1=" * "$, the entire library is copied.

$\mathrm{R} I-\mathrm{N} / \mathrm{A}$

1. get, componnt=ship-scen-2,gua-3

2. get COMPONNTS scen-4, ship-scen-3 


$\begin{array}{ll}\text { COMMAND: } & \text { HELP, CMND=Rl } \\ \text { PROCESSOR: } & \text { LIBRARY } \\ \text { PROMPTS: } & \text { NONE } \\ \text { DESCRIPTION: } & \text { HELP is used to either get a list of } \\ & \text { all of the commands available from } \\ & \text { the current level or to get specific } \\ & \text { information on a certain command. If } \\ & \text { no prompts are entered on the command } \\ & \text { line then a list of the available } \\ & \text { commands is printed. If Rl is } \\ & \text { specified then just the description } \\ & \text { of that command is displayed. } \\ & \text { List of available commands at this } \\ & \text { level of sos. } \\ \text { DEFAULTS: } & \text { l. help, cmnd=adsi } \\ \text { EXAMPLE: } & 2 \text { help }\end{array}$


COMMAND :

PROCESSOR :

PROMPTS:

DESCRIPTION :

DEFAULTS :

EXAMPLES :
LINK , LIBRARY =R 1, SCNR=R2, ENTRIES=R3， R3...

\section{LIBRARY}

$\begin{array}{lll}\text { P1 - LIBRARY } & {[R 1]} & \begin{array}{l}\text { (MASTER or } \\ \bar{W} O R K I N G)\end{array} \\ \text { P2 - SCNR } & {[R 2]} & \text { (Scenario name) } \\ \text { P3 - ENTRIES } & {[R 3]} & \text { (Entry name) }\end{array}$

Links the specified entries R3 to the specified scenario R2. The LINK command may be used on either the MASTER or WORKING LIBRARY depending on the response $\mathrm{Rl}$. Linking is done to the specified site. A prompt for the site password will be given if the site has not been password verified previously in the current session.

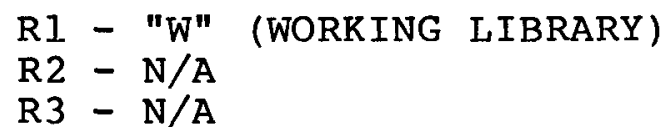

1. link LIBRARY w SCNRIO scen-3 ENTRIES gua-2, ADV-3

2. Iink, libr=w, scnr=ship-scen-4, entries $=g u a-2, a d v-3$ 
COMMAND :

PROCESSOR :

PROMPTS :

DESCRIPTION

DEF AULTS :
LIST, COMPONNT=R I, LIBRARY=R 2, FSTATS $=$ R3, PASS $=$ R 4

LIBRARY

P1 - COMPONNT [RI] (Site or

P2 - LIBRARY

[R2] (MASTER or WORK ING)

P3 - FSTATS

[R3] (Yess or No)

P4 - PASS

[R4] (Master $\bar{p}$ assword)

Prints the contents of the specified component and marks the current site (if it exists) with asterisks (*). If RI is "*", the whole library is listed. $R 3$ is either $y$ or $n$. If $y$, file statistics are printed out for the library. If $n$, no file statistics are printed. If it is desired that site passwords are listed, the library master password must be entered as R4. If defaulted to blank, no passwords will be listed. If only the command LIST is typed, and no prompts are entered, then all four default responses are used and no interactive prompts are given.

RI -N/A (if no prompts are entered, then RI has a default and it is *)

R2 - "W" (WORKING LIBRARY)

R3 - "N" (no file statistics)

R4 - blanks (site passwords not listed) 
EXAMPLES :

1. list, 1 ibrary $=m$ componnt=ship-scen -3

2. list, componnt $=$ *

3. list, library $=w$, componnt $=$ *, 4. list fstats $=y$, pass $=x m a s t$ 
COMMAND :

PROCESSOR :

PROMPTS :

DESCRIPTION :

NOTES :

\section{QUIT}

LIBRARY

NONE

Exits the current processor. The QUIT command is a general command that may be used to exit any level of the SNAP Operating system including the sos itself.

QUIT is the only exit command in the SNAP Operating System. It is used in all the subprocessors. 


\section{LIBRARY/READ}

COMMAND :

PROCESSOR :

PROMPTS :

DESCRIPTION :
READ , FILE=R 1, ENTRY=R 2, REWIND=R3 ， PURGE $=$ R4

\section{LIBRARY}

$\begin{array}{lll}\text { P1 - FILE } & \text { [R1] } & \text { (File name) } \\ \text { P2 - ENTRY } & \text { [R2] } & \text { (Entry name) } \\ \text { P3 - REWIND } & \text { [R3] } & \text { (Yes or No) } \\ \text { P4 - PURGE } & \text { [R4] } & \text { ( } \text { Yes or Nes) }\end{array}$

R2 must be type USER, OTHR, or TRAC. There are two cases:

1. R2 is not a TRAC entry. R1 must be a formatted file of 132

characters/record or less. File RI is read into entry $R 2$ to the end of file. If $R 3=y, R I$ is rewound prior to being read. If $R 3=n$, it is not. If $R 4=y$, the contents of entry $R 2$ are purged before $R I$ is read. If $R 4=n$, the contents of $\mathrm{Rl}$ are added to the end of any information already in entry R2. File R2 is not repositioned after the READ is completed.

If Rl is "DISPLAY", SOS will accept lines of data from the user's terminal until an end of file is encountered or a line is encountered with a dollar sign (\$) in column one. The DISPLAY option is not permitted if $R 2$ is TRAC. 2. R2 is a TRAC entry. The user will be asked whether Rl is a SNAP graphics trace file (for use with ANALYZE) or an alphanumeric trace file (a SNAP output file containing a trace). Only one file of each type is permitted in each TRAC entry. If a file of the same type already exists in the TRAC entry, the command will be aborted, i.e., the PURGE option is ignored. In all other respects the command operates as in Case 1 above. 
DEF AULTS :

EXAMPLES:
RI - N/A

R2 - N/A (USER, TRAC, OTHR)

R3 - "Y"

R4 - "Y"

1. read,file=userf, entry=user -2 , rewi=n, purge $=y$

2. read, file=gtrace, entry $=$ trac-2 
COMMAND :

PROCESSOR:

PROMPTS :

DESCRIPTION :

DEF AULTS:

NOTES:

EXAMPLES :
RENAME , LIBRARY $=R 1, \mathrm{OLD}=\mathrm{R} 2, \mathrm{NEW}=\mathrm{R} 3$

\section{LIBRARY}

$$
\begin{array}{lll}
P 1-\text { LIBRARY } & \text { [RI] } & \text { (MASTER or } \\
\text { WORKING } \\
\text { P2 - OLD } & \text { [R2] } & \text { (OId name) } \\
\text { P3 - NEW } & \text { [R3] } & \text { (New name) }
\end{array}
$$

Changes the old component name R2 to the new component name R3. Works on either the MASTER or WORKING LIBRARY as specified in $\mathrm{Rl}$. This command can be used to rename sites, scenarios, and entries. If the site has not been password verified, a prompt will be given for the site password.

$$
\begin{aligned}
& R 1-" W " \text { (WORKING LIBRARY) } \\
& \text { R2 - N/A } \\
& \text { R3 - N/A }
\end{aligned}
$$

If an entry or scenario is being RENAMED, the rename takes place on the current site. The new name R3 must be of the same type as the old name R3.

1. rename, $l i b r=m, o l d=$ ship, new $=$ ship 2

2. rename, old=ship-gua-3, new=gua-5 
LIBRARY/SAVE

\begin{tabular}{|c|c|}
\hline COMMAND : & $\begin{array}{l}\text { SAVE }, \text { COMPONNT=RI, R1, R1, } . ., \\
\text { CONNECT=R2, RETAIN }=R 3\end{array}$ \\
\hline PROCESSOR : & LIBRARY \\
\hline PROMPTS: & 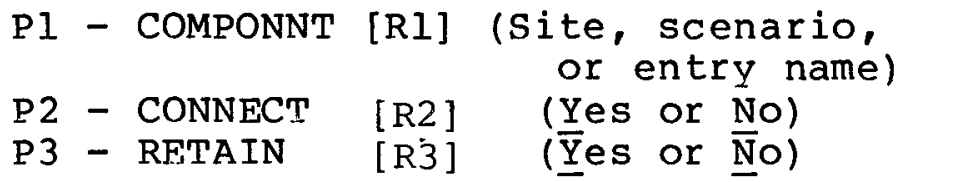 \\
\hline DESCRIPTION: & $\begin{array}{l}\text { This command is used to save a } \\
\text { component in the MASTER LIBRARY. } \\
\text { This command should be used with } \\
\text { caution since it will destroy an old } \\
\text { copy of a component by the same name } \\
\text { in the MASTER LIBRARY. If Rl=*, the } \\
\text { MASTER LIBRARY must be empty and the } \\
\text { entire library will be saved. } \\
\text { CONNECT = Or N (always Y for RI = } \\
\text { *) Previous versions of SAVED } \\
\text { entries may exist on the MASTER } \\
\text { LIBRARY. If CONNECT = Y, the new } \\
\text { SAVED version will be linked to all } \\
\text { sCenarios on the MASTER IIBRARY that } \\
\text { the old version was linked to. If } \\
\text { CONNECT = n, all prior links will be } \\
\text { broken. RETAIN = y or n. If n, the } \\
\text { SAVED Component will be deleted from } \\
\text { the WORKING LIBRARY after the copy. If } \\
\text { RETAIN = Y it will not. }\end{array}$ \\
\hline DEF AULTS : & $\begin{array}{l}R 1=N / A \\
R 2-" Y " \\
R 3-" Y "\end{array}$ \\
\hline EXAMPLES: & $\begin{array}{c}\text { 1. save, componnt=ship-scen-3, } \\
\text { connect=y, retain=n }\end{array}$ \\
\hline
\end{tabular}


COMMAND :

PROCESSOR :

PROMPTS:

DESCRIPTION :

DEF AULT 5 :

EXAMPLES :
SELECT , LIBRARY =R1, $S$ I $T$ NAME $=R 2$, PASS $=$ R3

LIBRARY

$$
\begin{array}{lll}
\text { P1 - LIBRARY } & \text { [R1] } & \text { (MASTER or } \\
\text { P2 - SITNAME } & \text { [R2] } & \begin{array}{l}
\text { (site nKING) } \\
\text { Pite name) }
\end{array} \\
\text { P3 - PASS } & \text { [R3] } & \text { (site password) }
\end{array}
$$

Set the current site to be R2. If the user specifies a site that does not exist, the system will respond with a error message. This command is used to set the current site. It may be used to reset the current site at any time. The password R3 opens a site for write permission.

RI - "W" (WORKING LIBRARY)

R2 - N/A

R3 - N/A

1. select, sitname=ship

2. select, libr=m, sitn=reactor 
COMMAND :

PROCESSOR :

PROMPTS :

DESCRIPTION:

DEF AULT S :

NOTES:

EXAMPLES :
UNLINK , LIBRARY =R I , SCNR=R2, ENTRY $=R 3, \ldots$

LIBRARY
P1 - LIBRARY
[RI] (MASTER or
P2 - SCNR
P3 - ENTRY
[R2] (S̄cenario name)
[R3] (Entry names)

Unlinks the specified entry R3 from the specified scenario R2. The UNLINK command may be used on either the MASTER or WORKING LIBRARY as specified in RI. R3 may be repeated. If R2 specifies a site that is not current or verified, a prompt will be given for the password.

RI - "W" (WORKING LIBRARY)

$R 2-N / A$

R3 - N/A

If the user wishes to remove an entry or scenario the DELETE command should be used.

1. unlink, scnr $=\operatorname{ship}-\operatorname{scen}-3$, entr $=$ gua -3 
LIBRARY/WRITE

PROCESSOR :

PROMPTS :

DESCRIPTION :
COMMAND :

WRITE, FILE=R1, ENTRY=R2, REWIND=R3, RECORDS $=R 4, R 5$

LIBRARY

$\begin{array}{lll}\text { P1 - FILE } & \text { [R1] } & \text { (File name) } \\ \text { P2 - ENTRY } & \text { [R2] } & \text { (Entry name) } \\ \text { P3 - REWIND } & \text { [R3] } & \text { (Yes or No) } \\ \text { P4 - RECORDS } & {[R 4]} & \text { [R5] (Start } \\ & & \text { record, End } \\ & & \end{array}$

WRITE will write the contents of an entry onto a file. The contents must have been previously read into the library by a READ command. RI is the name of the file to be written to. If $R I=$ "DISPLAY", the contents of the entry R2 will be written to the terminal. $R 2$ is the entry identifier (either USER, OTHR or TRAC) with the identifying number (e.g., USER-5). $R 3$ is $y$ or $n$. If $R 3=y$, file $R I$ will be rewound prior to writing on it. R4 and R5 are the start and end records, respectively, to be written. If $R 4=0$ and $R 5=0$, all records in the entry will be written. If $\mathrm{R} 5=$ 0 , then all records from $\mathrm{R} 4$ to the end of the entry will be written. An end of file mark is written to file RI after the entry is written. If R2 is a TRAC entry, the user will be asked if an alphanumeric or a graphics trace file is to be written. R4 and R5 are ignored if a graphics trace file is requested. (The entire graphics trace entry is written to RI.)

DEF AULTS : 
EXAMPLES :

I. write, file=unspace, entry=ship-

2. write othr-5

FILE xfile

ENTRY user-3

REWIND $n$

RFCORDS 0,30 


\section{SECTION V \\ SAFE-TO-SNAP TRANSLATOR (TRANSLATE)}

The SAFE approach to the analysis of nuclear facilities provides a global evaluation of the site's safeguards capabilities. This analysis also yields specific information concerning the probable attack path of adversaries as well as guard defense procedures. Furthermore, SAFE requires a digitization of the facility which provides detail concerning the structure of the facility. The TRANSLATE command makes use of this information in constructing a skeletal SNAP model which represents the SAFE model. It provides the analyst with a starting point for a detailed tactical evaluation of the site. Since the generation of this skeletal model is automated, it can greatly expedite the SNAP model development process.

The TRANSLATE command hierarchy is shown in Figure 5.1. As shown, there are several subcommands which should be executed. These commands are also order dependent. They should be executed in the following order:

1. GENFACILITY

2. PRTARGETS and PRPATHS

3. GENGUARD and GENADVERSARY 


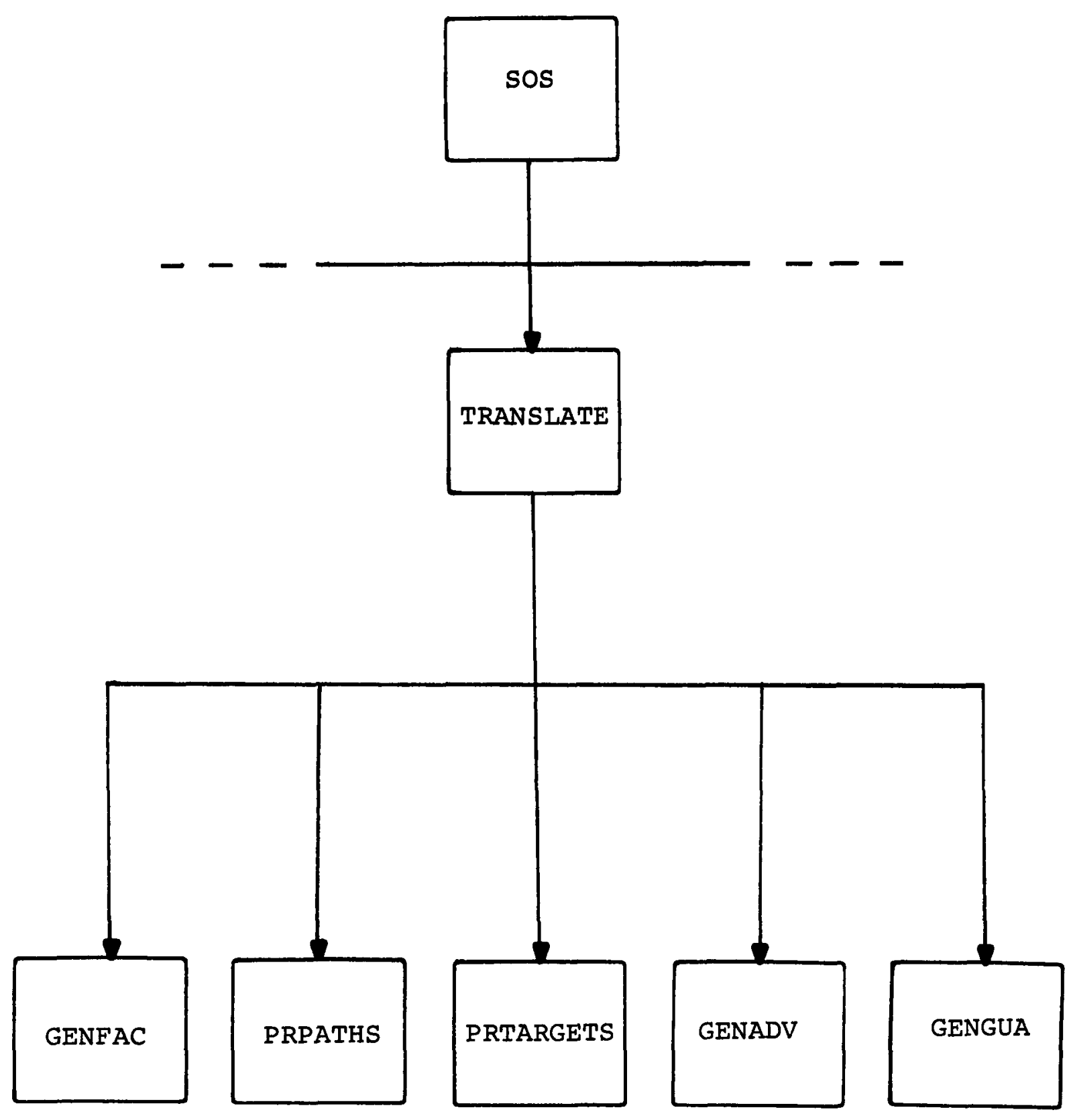

Figure 5.1. TRANSLATE Command Hierarchy. 
The GENFACILITY command will create a SNAP facility model from the SAFE facility digitization. It assumes that the following SAFE files for the site are available to the processor, prior to its execution:

1. LEVELS

2. REGION

3. REGDAT

4. TAPEIN

5. TAPEOUT

The command syntax and parameter definition for subcommand GENFACILITY are provided later in this section.

After the GENFACILITY command has been executed, the user next executes the PRTARGETS and the PRPATHS commands. The PRTARGETS command will print a listing of all targets for which SAFE has generated paths. PRTARGETS requires that SAFE files TAPEIN and TAPEOUT for the site to be locally available. The PRPATHS command will print all paths that were generated by SAFE to a target specified by the user. Information provided by these two commands is used in the generation of the guard and adversary models.

Once the user has paths and targets of interest defined, he may use the GENADVERSARY and GENGUARD commands to create the SNAP models of the adversary attack scenario and the guard defense. These commands reference the facility target and path information previously created via 
the commands GENFACILITY, PRPATHS, and PRTARGETS. The command syntax and parameter definition for the GENADVERSARY and GENGUARD commands are included next. 
TRANSLATE Command Descriptions

TRANSLATE/GENFACILITY

$\begin{array}{ll}\text { COMMAND: } & \text { GENFACILITY, ENTRY=RI } \\ \text { PROCESSOR: } & \text { TRANSLATE } \\ \text { PROMPTS: } & \text { PI - ENTRY [RI] (FACL entry name) } \\ \text { DESCRIPTION: } & \text { GENF builds a facility submodel on } \\ & \text { entry RI from SAFE data files LEVEL, } \\ & \text { REGION, and REGDT. No SAFE path data } \\ & \text { is required to build the facility } \\ & \text { entry, Rl must be type FACI and must } \\ & \text { be empty if it exists prior to issuing } \\ & \text { the GENF command. } \\ & \text { RI - N/A (must be type FACL) } \\ \text { DEFAULTS: } & \text { 1. genf, entry=ship-facl-2 } \\ \text { EXAMPLE: } & 2 . \text { genf, entry=faci-2 }\end{array}$


TRANSLATE/HELP

COMMAND :

PROCESSOR :

PROMPTS:

DESCRIPTION :

DEFAULTS :

EXAMPLE:
HEL $P, C M N D=R 1$

TRANSLATE

PI - CMND [R1] (SOS command name)

HELP is used to either get a list of all of the commands available from the current level of sos or to get specific information on a certain command. If no prompts are entered on the command line then a list of the available commands is printed. If $R I$ is specified then just the description of that command is displayed.

List all available commands at this level of sos.

1. help, cmnd=prpaths

2. help 
TRANSLATE/PRPATHS

COMMAND :

PROCESSOR :

PROMPTS :

DESCRIPTION :

DEFAULTS :

EXAMPLE:
PRPATHS , TARGET $=\mathrm{R} 1$, FACILI TY $=\mathrm{R} 2$

TRANSLATE

P1 - TARRET

[RI] (SNAP TARGFT node label)

P2 - FACILITY [R2] (FACL entry name)

PRPATHS will print all SAFE generated paths to target $R 1$ in facility R2. R2 must have been created earlier with the GENFACILITY and PRTARGETS commands. Both SAFE and SNAP node labels for the paths are printed. SNAP space nodes that have no corresponding SAFE node are listed with the SAFE node label equal to zero. Rl is the SNAP node label for the target desired.

RI - N/A (a SNAP nodel label)

R2 - N/A (must be type FACL)

1. prpa, $\operatorname{targ}=\mathrm{T} 620$, faci=ship-facl -3 
COMMAND :

PROCESSOR :

PROMPTS:

DESCRIPTION :

DEF AULTS :

EXAMPLES :
PRTARGETS , F ACI LITY=R $1, \mathrm{NEW}=\mathrm{R} 2, \mathrm{TYPE}=\mathrm{R} 3$

TRANSLATE

$\begin{array}{lll}\text { P1 - FACILITY } & {[R 1]} & \text { (FACL entry name) } \\ \text { P2 - NEW } & {[R 2]} & \text { (Yes or No) } \\ \text { P3 - TYPE } & {[R 3]} & \text { (STOC or DET) }\end{array}$

PRTARGETS uses SAFE data files TAPEIN and TAPEOUT to include descriptions of SAFE generated paths into facility entry RI. It also prints the SAFE and SNAP labels of all targets for which SAFE has generated paths. If R2=Y, PRTA will purge all path descriptions contained in $\mathrm{Rl}$ and generate new ones from TAPEIN and TAPEOUT. If R2=N, TAPEIN and TAPEOUT are not used, and targets existing in RI from a previous issue of the PRTA command are printed. R3 is "STOC" for stochastic or "DET" for deterministic paths (R3 is needed because the format of the SAFE files is dependent upon which pathfinder was used).

Rl - N/A (must be type FACL)

$R 2$ - N/A (either "Y" or "N"

R3 - N/A (either "STOC" or "DET")

1. prta,faci=facl-l, new=y, type=s toc

2. $\operatorname{pr} t a, f a c i=f a c l-4$, new $=n$, type $=$ det 
TRANSLATE/GENADVERSARY

COMMAND :

PROCESSOR :

PROMPTS :

DESCRIPTION :

DEF AULTS :

EXAMPLE:
GENADVERSARY, PATH=R1, ENTRY=R2, F ACI LITY $=$ R3

TRANSLATE

$$
\begin{array}{lll}
\text { P1 - PATH } & \text { [R1] } & \begin{array}{l}
\text { (Path number from } \\
\text { PRPATHS) }
\end{array} \\
\text { P2 - ENTRY } & \text { [R2] } & \text { (ADV entry name) } \\
\text { P3 - FACILITY } & \text { [R3] } & \text { (FACL entry name) }
\end{array}
$$

GENA builds an adversary entry that represents the SAFE generated path, Rl. RI is obtained from the PRPATHS command. The adversary entry is written to entry R2 which must be type ADV. The facility entry, R3, must have been created earlier with the GENFACILITY and PRTARGETS command.

$\mathrm{Rl}-\mathrm{N} / \mathrm{A}$ (RI is an integer number)

R2 - N/A (must be type ADV)

R3 - N/A (must be type FACL)

1. gena, faci=site $y-f a c l-2$,path=3, en $\operatorname{tr} y=a d v-1$ 
TRANSLATE/GENGUARD

COMMAND :

PROCESSOR :

PROMPTS :

DESCRIPTION :

DEF AULTS :

EXAMPLE:
GENGUARD , PATH=R1, ENTRY=R $2, F A C I L I T Y=R 3$

TRANSLATE

PI - PATH

P2 - ENTRY

P3 - FACILITY

[RI] (Path number from PRPATHS)

[R2] (GUA entry name)

[R3] (FACL entry name)

GENG builds a guard entry that represents the SAFE guard response model for SAFE generated path Rl. Rl is obtained from the PRPATHS command. The guard entry is written to entry R2 which must be type GUA. The facility entry, R3 must have been created earlier with the GENFACILITY and PRTARGETS command.

$\mathrm{Rl}-\mathrm{N} / \mathrm{A}$ ( $\mathrm{Rl}$ is an integer number)

R2 - N/A (must be type GUA)

R3 - N/A (must be type FACL)

1. geng, path=1, en try=gua-3, faci $=f a c l-1$

2. geng, path=3, en try $=$ react $4-$ gua- 1 , faci $=\mathrm{facl}-3$ 
SECTION VI

SNAP MODEL EDITOR (EDIT)

The sos editor, EDIT, is used to create and modify SNAP model entries stored in an sos library. It may be used to edit entries of type ADV, FACL, GUA, or STAT, but not OTHR, TRAC, or USER. The EDIT processor is entered from the SOS EXECUTIVE via the command:

EDIT

The user specifies the entry to be edited in response to the prompt:

\section{ENTRY}

If the entry specified does not exist, it will be created at this time. EDIT then displays the sOs version number followed by the primary level EDIT prompt which is:

EDT *

At this point the user may enter any valid EDIT command. The editing session may be terminated from this level of EDIT, by entering the command QUIT which returns control to 
the sos EXECUTIVE. The user may switch to editing a different entry by entering the command SEIECT.

EDIT consists of 35 commands which allow the user to control the editing environment and to edit the various entry types. These command are functionally grouped into four categories as follows:

* A set of UTILITY commands;

* A command for editing non-graphic SNAP input cards;

* A set of FACL entry editing commands; and

* A set of ADV and GUA entry editing commands.

Furthermore, the ADV and GUA editing commands may be subdivided into ELEMENTAL and MODULAR classes; the former used to create and edit single SNAP elements like nodes or branches; the latter used to create and edit entire subnetworks in one step.

Figure 6.1 illustrates all of the EDIT commands categorized in this fashion.

\section{UTILITY Commands}

There are 12 EDIT/UTILITY commands available to perform functions that are generally independent of the type of entry being edited. These commands are used to control the EDIT environment, perform graphic functions, add and delete textual information, and more. The possible EDIT 


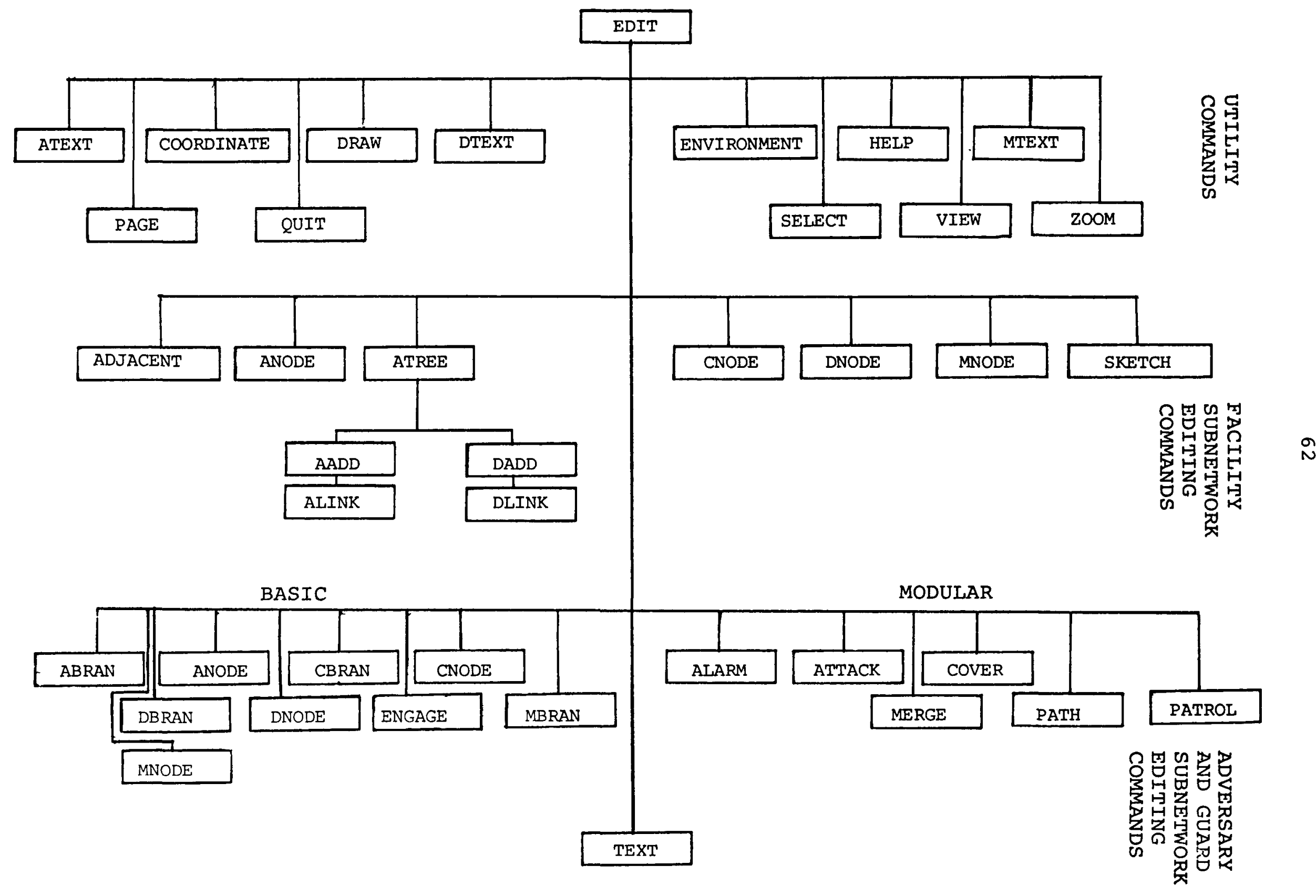

Figure 6.1. EDIT Command Hierarchy 
screen configurations are shown in Figure 6.2. The configuration is user controlled via the UTILITY commands. A brief description of each of the 12 UTILITY commands is presented next.

Command

ATEXT

COORD INATE

DRAW

DTEXT

ENVIRONMENT

HELP

MTEXT

PAGE

QUIT

SELECT

VIEW

ZOOM
Function

Add textual information to a display

Display coordinates of user specified locations on the screen

REDRAW the current graphical display

Delete textual information from a display

Set user controllable EDIT flags and indicators

Provide on line documentation of al1 sos commands and their syntax

Move textual information on a display

Change the current page being displayed

Exit the current EDIT processor

Select the entry to be edited

Redefine the portion of the subnetwork being displayed by performing a "zOOM-OUT" function

Redefine the portion of the subnetwork being displayed by performing a "ZOOM-IN" function.

EDIT is designed for use on a non-refresh (storage) type graphics terminal. The inherent drawback to this type of terminal is that the screen cannot be selectively erased. 


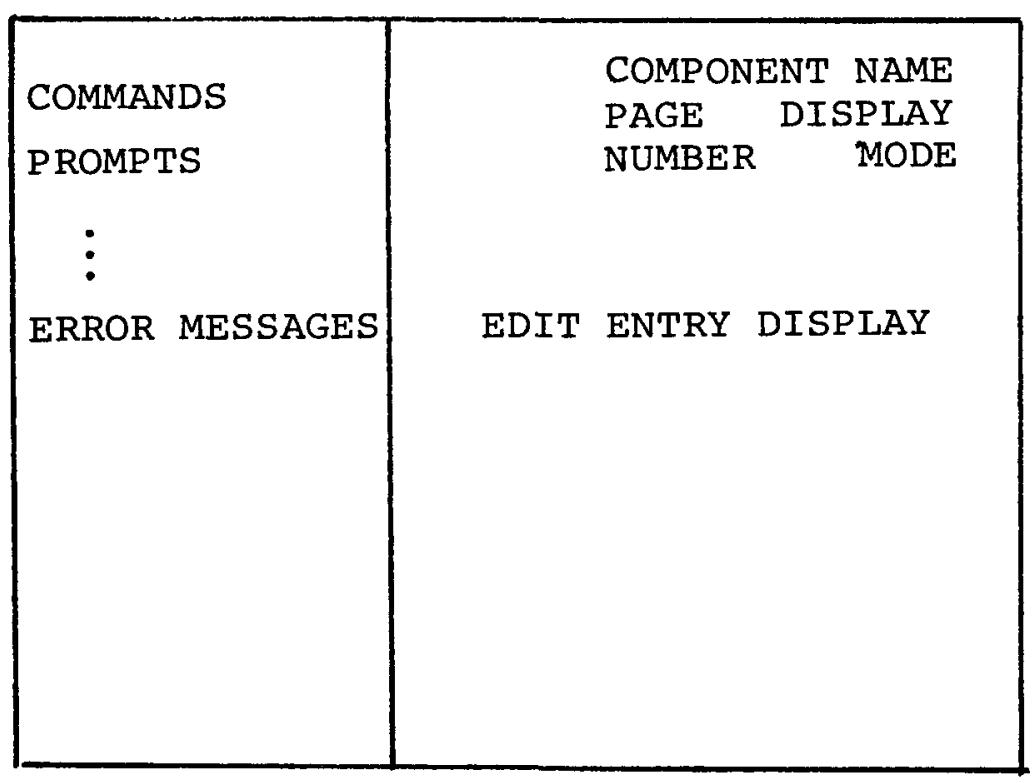

(A)

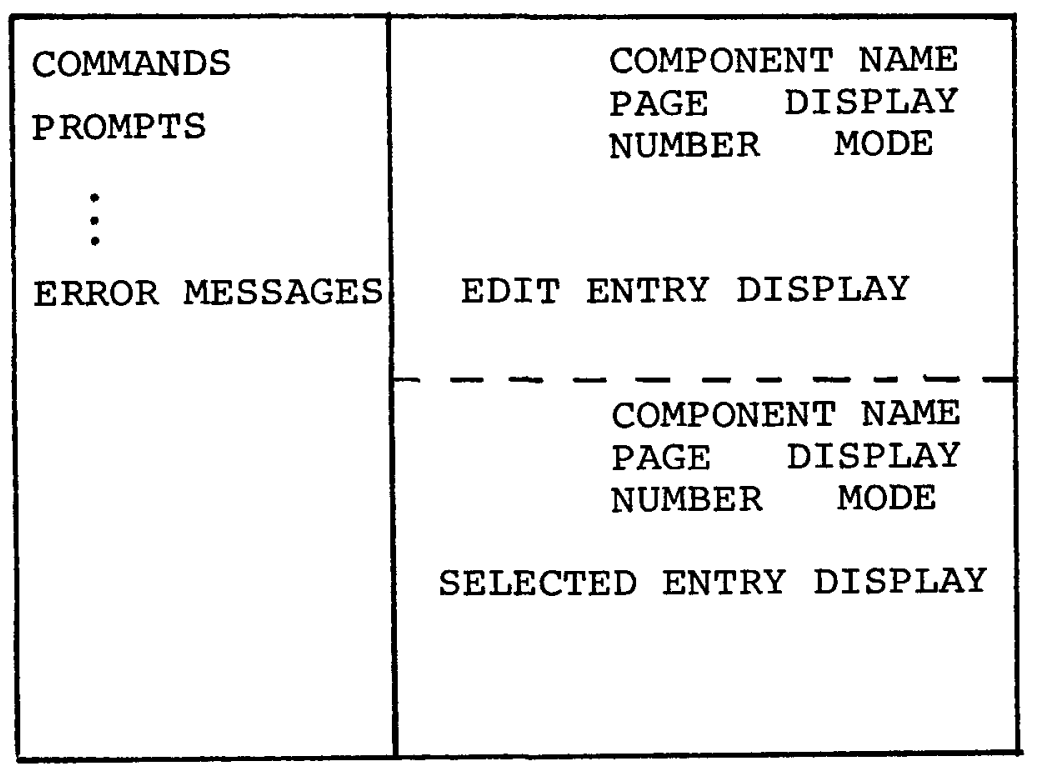

(B)

Figure 6.2. EDIT Screen Configuration. 
Because of this restriction, the current display must be completely redrawn, via the DRAW command, whenever an up-to-date display is desired. The EDIT commands do not automatically redraw the screen after each command for two reasons: (1) it is time consuming and unnecessary to redraw until the screen becomes cluttered, (2) the user may wish to use several UTILITY commands to setup the desired screen configuration parameters before redrawing.

\section{Non-Graphical Input Card Editing}

Some types of SNAP data input records have no graphical representation. These are PARAMETER, ENGAGEMENT, PENG, DENG, OBJECTIVE, BASE, MACRO, TIMER, FLAG, FORCE FLAG, and GLOBAL VARIABLE cards. These eleven card types are edited using the TEXT command.

The TEXT command has no prompts which can be entered on the command line. The user simply types TEXT, followed by a carriage return. He is then given various options and is.interactively led through the editing. For each of the eleven card types handled by the TEXT command, the user can ADD, REPLACE (or MODIFY), DELETE, or DISPLAY the cards. The TEXT command operates on the current entry in the WORKING Library.

For adding or replacing many of the card types, column headers are printed out for the various fields. The user then enters the parameter under their respective 
headings, entering an * to default any field which has a default. Responses are separated by at least one blank or a comma.

Parameter set numbers, values on the ENGAGEMENT card, and DENG parameters must be integers, while parameter values (on the PARAMETER card) and values on PENG cards can be reals or integers. PEBL's and DLBL's are four character alphanumerics.

When entering DENG parameters, the user may simply enter as few or as many of the parameters as desired, and the rest will be defaulted for that DENG card.

Figure 6.3 provides an editing session showing examples of use of the TEXT command. 
LHAT TYPE OF SNAP CARD DO YOU LANT TO EDIT?

ENTER THE CORRESPONDING NUMBER

$$
\begin{aligned}
& 1 \text { - PARAMETER } \\
& 2 \text { - ENGAGEMENT } \\
& 3 \text { - PENG } \\
& 4 \text { - DENG } \\
& 5 \text { - STATUS UARIABLE } \\
& 6 \text { - BASE } \\
& 7 \text { - OBJECTIUE } \\
& 8 \text { - MACRO } \\
& 9 \text { - TIMER } \\
& 10 \text { - EXIT TEXT MODE }
\end{aligned}
$$

CHOOSE A PARAMETER CARD EDITING OPTION

$$
\begin{aligned}
& 1 \text { - ADD PARAMETER CARDS } \\
& 2 \text { - REPLACE A PARAMETER CARD } \\
& 3 \text { - DELETE PARAMETER CARDS } \\
& 4 \text { - DISPLAY PARAMETER CARDS } \\
& 5 \text { - RETURN TO TEXT MODE }
\end{aligned}
$$

1

HOW MANY PARAMETER SETS DO YOU UAANT TO ADD? 2. 
FOR EACH SET TO BE ADDED, ENTER THE SET MUMBER AND 4 PARAMETERS UNDER THEIR

RESPECTIUE HEADINGS.

\begin{tabular}{ccccc} 
PARAMETER SET & 1 & 2 & 3 & 4 \\
\hline 1 & -1 & 1.1 & 5 & .01 \\
58 & 2 & 3.6 & 1.8 & 1.3
\end{tabular}

CHOOSE A PARAMETER CARD EDITING OPTION

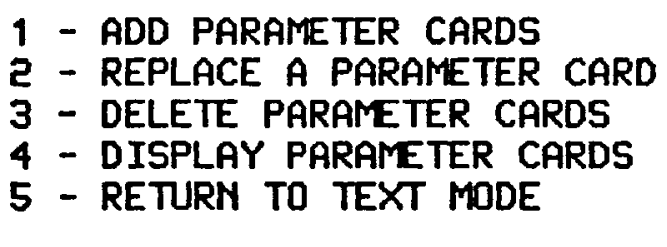

2

PLEASE ENTER THE SET NUMBER TO BE REPLACED

50

FOR PARAMETER SET * 5B,

ENTER THE 4 PARAMETERS UNDER THEIR RESPECTIUE HEADINGS.

\begin{tabular}{cccc}
1 & 2 & 3 & 4 \\
\hdashline 1.5 & 2.5 & 0.7 & .09
\end{tabular}

Figure 6.3. Continued. 
CHOOSE A PARAMETER CARD EDITIMG OPTION

1 - ADD PARAMETER CARDS

2 - REPLACE A PARAMETER CARD

3 - DELETE PARAMETER CARDS

4 - DISPLAY PARAMETER CARDS

3

5 - RETURN TO TEXT MODE

ENTER THE PARAMETER SET MUMBERS TO BE DELETED

1

PARAMETER SET * 1 LAS DELETED FROM ENTRY ADU - 1

CHOOSE A PARAMETER CARD EDITING OPTION

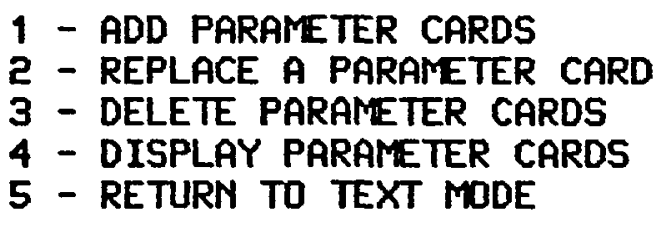

4

ENTER THE DISPLAY OPTION

1 - DISPLAY ALL PARAMETER SETS

2 - DISPLAY PARAMETER SETS FOR SPECIFIED SET NUMBERS

1

\begin{tabular}{ccccc} 
PARAMETER SET & 1 & 2 & 3 & 4 \\
\hline 50 & -2.0000 & 3.6800 & 1.8080 & 1.3000
\end{tabular}

Figure 6.3. Continued. 
CHOOSE A PARAMETER CARD EDITING OPTION

1 - ADD PARAMETER CARDS

2 - REPLACE A PARAMETER CARD

3 - DELETE PARAMETER CARDS

4 - DISPLAY PARAMETER CARDS

5

5 - RETURN TO TEXT MODE

Figure 6.3. Continued. 
WHAT TYPE OF SHAP CARD DO YOU LANT TO EDIT?

ENTER THE CORRESPONDING NUMBER

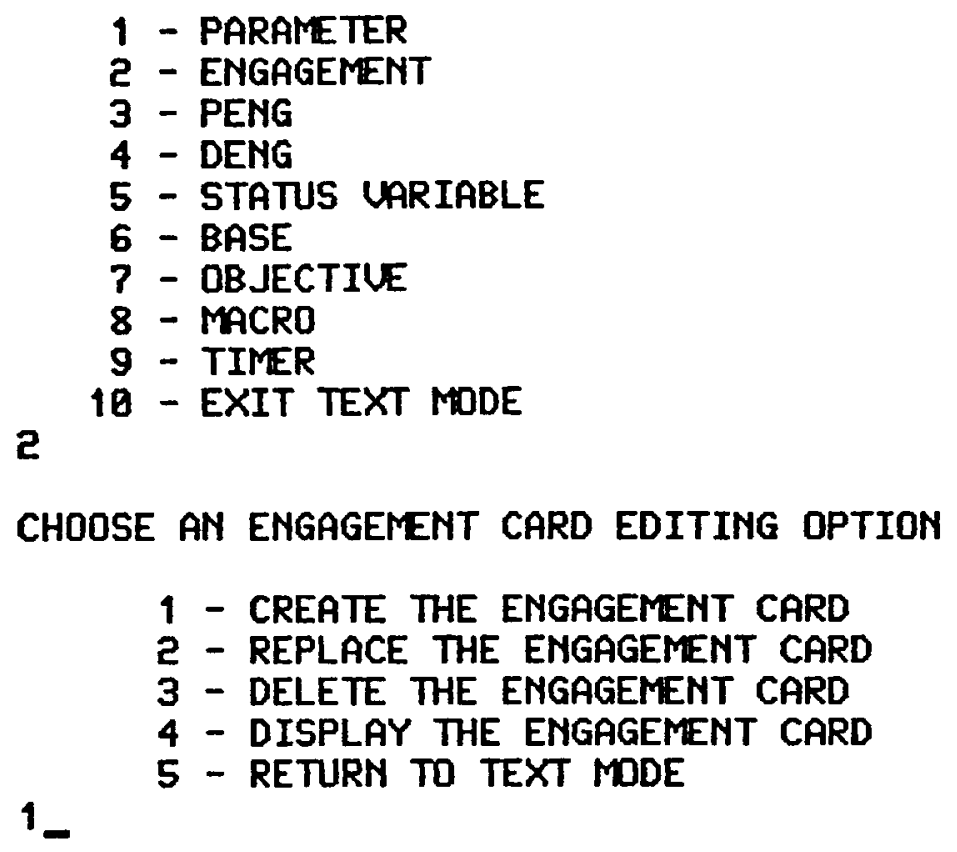

Figure 6.3. Continued. 
THE ENGAGEMENT CARD IS IN THE FOLLOWING FORM: ENGAGEMENT, (SIZE.RC. UALUE), PEBL; ENTER THE RELATIONAL CONDITION (LT,LE,EQ): LE ENTER THE UALUE(MUST BE GLOBAL OR INTEGER): 2 ENTER THE DEFAULT PENG LABEL(PEBL): PBO1

CHOOSE AN ENGAGEMENT CARD EDITING OPTION

1 - CREATE THE ENGAGEMENT CARD

2 - REPLACE THE ENGAGEMENT CARD

3 - DELETE THE ENGAGEMENT CARD

4 - DISPLAY THE ENGAGEMENT CARD

2

5 - RETURN TO TEXT MODE

THE ENGAGEMENT CARD IS IN THE FOLLOWIMG FORM:

ENGAGEMENT, (SIZE.RC.UALUE), PEBL;

ENTER THE RELATIOMAL CONDITION (LT,LE, EQ):

LT

ENTER THE UALUE (MUST BE GLOBAL OR INTEGER):

3

ENTER THE DEFAULT PENG LABEL (PEBL):

POO1_

Figure 6.3. Continued. 
CHOOSE AN ENGAGEMENT CARD EDITING OPTION

1 - CREATE THE EMGAGEMENT CARD

2 - REPLACE THE ENGAGEMENT CARD

3 - DELETE THE ENGAGEMENT CARD

4 - DISPLAY THE ENGAGEMENT CARD

5 - RETURN TO TEXT MODE

4

ENGAGEMENT, (SIZE.LT.3 ),PGB1;

CHOOSE AN ENGAGEMENT CARD EDITING OPTION

1 - CREATE THE ENGAGEMENT CARD

2 - REPLACE THE ENGAGEMENT CARD

3 - DELETE THE ENGAGEMENT CARD

4 - DISPLAY THE ENGAGEMENT CARD

5 - RETURN TO TEXT MODE

3

THE CURRENT ENTRY NOW HAS NO ENGAGEMENT CARD.

CHOOSE AN ENGAGEMENT CARD EDITIMG OPTIDN

1 - CREATE THE EMGAGEMENT CARD

2 - REPLACE THE ENGAGEMENT CARD

3 - DELETE THE ENGAGEMENT CARD

4 - DISPLAY THE ENGAGEMENT CARD

5

5 - RETURN TO TEXT MODE

Figure 6.3. Continued. 
LHAT TYPE OF SNAP CARD DO YOU LANT TO EDIT? ENTER THE CORRESPONDIMG NUMBER

1 - PARAMETER

2 - ENGAGEMENT

3 - PENG

4 - DENG

5 - STATUS UARIABLE

6 - BASE

? - OBJECTIUE

8 - MACRO

9 - TIMER

3

10 - EXIT TEXT MDDE

CHOOSE A PEMG CARD EDITING OPTION

$$
\begin{aligned}
& 1 \text { - ADD PENG CARDS } \\
& 2 \text { - MODIFY A PENG CARD } \\
& 3 \text { - DELETE PENG CARDS } \\
& 4 \text { - DISPLAY PENG CARDS } \\
& 5 \text { - RETURN TO TEXT MODE }
\end{aligned}
$$

1

ENTER THE MUMBER OF PENG CARDS TO BE ADDED 3

Figure 6.3. Continued. 
LHERE DO YOU WANT TO PUT THE PENG CARD(S)?

1 - INSERT AT THE BEgINNIMg OF THE PENG SECTION

2 - INSERT AT THE END OF THE PENG SECTION

3 - INSERT AFTER A GIUEN PEBL

1

4 - DOESN'T MATTER

ENTER THE PENG PARAMETERS UNDER THEIR RESPECTIUE HEADINGS

ENTER A * FOR PEBL IF SYSTEM PROUIDED NDDE LABELS ARE LANTED

ENTER A * FOR TINC TO DEFAULT

PEBL DLBL TINC UALUE (MINUTES)

* ADE1 $\quad$ ALE

PEBL PROUIDED BY THE SYSTEM IS: P580

* ADB2 0.42

PEBL PROUIDED BY THE SYSTEM IS: P501

$\begin{array}{lll}\text { PERS } & \text { DERS } & 999\end{array}$

CHOOSE A PENG CARD EDITING OPTION

1 - ADD PENG CARDS

2 - MODIFY A PENG CARD

3 - DELETE PENG CARDS

4 - DISPLAY PENG CARDS

2

5 - RETURN TO TEXT MODE

Figure 6.3. Continued. 
GIUE THE PEBL FOR THE PENG CARD TO BE MODIFIED

P580

DO YOU LANT TO CHANGE DLBL OR TINC UALUE OR BOTH?

1 - CHANGE DLBL ONLY

2 - CHANGE TINC UALUE ONLY

3 - CHANGE BOTH

2

ENTER THE NEW TINC UALUE (UNITS ARE MIN.)

0.56

CHOOSE A PENG CARD EDITING OPTION

1 - ADD PENG CARDS

2 - MODIFY A PENG CARD.

3 - DELETE PENG CARDS

4 - DISPLAY PENG CARDS

3

5 - RETURN TO TEXT MODE

HOW MANY PENG CARDS DO YOU LANT TO DELETE?

1

ENTER THE (FIRST) PENG CARD TO BE DELETED P501

Figure 6.3. Continued. 
CHOOSE A PENG CARD EDITING OPTION

4

$$
\begin{aligned}
& 1 \text { - ADD PENG CARDS } \\
& 2 \text { - MODIFY A PENG CARD } \\
& 3 \text { - DELETE PENG CARDS } \\
& 4 \text { - DISPLAY PENG CARDS } \\
& 5 \text { - RETURN TO TEXT MODE }
\end{aligned}
$$

ENTER THE DISPLAY OPTION

$$
\begin{aligned}
& 1 \text { - DISPLAY ALL PENG CARDS } \\
& 2 \text { - DISPLAY A STRING OF PENG CARDS } \\
& 3 \text { - DISPLAY ONE PENG CARD }
\end{aligned}
$$

3

ENTER THE PEBL FOR THE PENG CARD TO BE DISPLAYED P500

P500 PENG, ADQ1, (TINC.GT. B.560日);

CHODSE A PENG CARD EDITING OPTION

$$
\begin{aligned}
& 1 \text { - ADD PENG CAROS } \\
& 2 \text { - MODIFY A PENG CARD } \\
& 3 \text { - DELETE PENG CARDS } \\
& 4 \text { - DISPLAY PENG CARDS } \\
& 5 \text { - RETURN TO TEXT MODE }
\end{aligned}
$$$$
5
$$

Figure 6.3. Continued. 
LHAT TYPE OF SMAP CARD DO YOU LANT TO EDIT? ENTER THE CORRESPONDING NUMBER

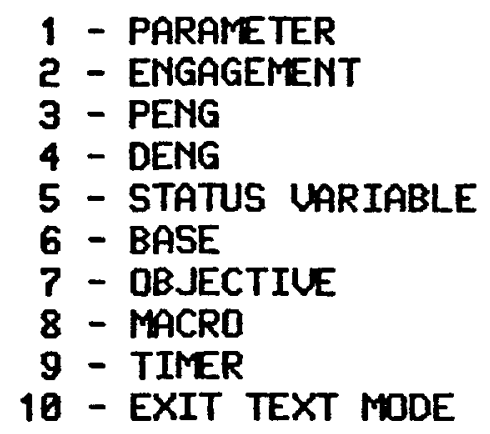

CHOOSE A DENG CARD EDITING OPTION

$$
\begin{aligned}
& 1 \text { - ADD DENG CARDS } \\
& 2 \text { - REPLACE A DENG CARD } \\
& 3 \text { - DELETE DENG CARDS } \\
& 4 \text { - DISPLAY DENG CARDS } \\
& 5 \text { - RETURH TO TEXT MODE }
\end{aligned}
$$

1

ENTER THE MUMBER OF DENG CARDS TD BE ADDED 3_ 
DO YOU LANT TO SEE THE INSTRUCTIONS FOR ENTERING DENG PARAMETERS? TYPE Y OR $\mathrm{N}$

$Y$

ENTER THE DLBL AND THE DENG PARAMETERS UNDER THEIR

RESPECTIUE HEADINGS. TO DEFAULT A UALUE ENTER A * UNDER THE CORRESPONDING

HEADING. LEAUE AT LEAST DNE BLANK BETLEEN RESPONSES.

USE A * FOR DLBL IF A SYSTEM PROUIDED LABEL IS DESIRED.

THE MUMERIC RESPONSES MUST BE INTEGERS.

\begin{tabular}{|c|c|c|c|c|c|c|c|c|c|}
\hline DEFAULT: & $M / A$ & STAN & 100 & 100 & 0 & D & 0 & NO & ASS \\
\hline - - - & --- & $-\cdots-$ & $-\cdots$ & ---- & ---- & ---- & ---- & -- & \\
\hline PARAMETER: & DLBL & POS & ElF & Eld & PTD & SP & ILL & SUP & \\
\hline $\begin{array}{l}\text { DLBL } \\
\text { DLBL }\end{array}$ & $\begin{array}{c}* \\
\text { JUIDED } \\
* \\
\text { JUIDED } \\
\text { DERS }\end{array}$ & $\begin{array}{c}\text { BY THE } \\
\text { BY THE } \\
\text { CROU }\end{array}$ & $\begin{array}{r}98 \\
\text { SYSTEM IS: } \\
* \\
\text { SYSTEM IS: } \\
90\end{array}$ & $\begin{array}{c}87 \\
A D B 9 \\
50 \\
\text { ADO1 } \\
30\end{array}$ & * & * & $*$ & YES & DEFE \\
\hline
\end{tabular}

CHOOSE A DENG CARD EOITING OPTION

1 - ADD DEMG CARDS

2 - REPLACE A DENG CARD

3 - DELETE DENG CARDS

4 - DISPLAY DENG CARDS

2

5 - RETURN TO TEXT MODE

Figure 6.3. Continued. 
ENTER THE DLBL FOR THE DENG CARD TO BE REPLACED, ALONG WITH THE MEW SET OF DENG PARAMETERS.

\begin{tabular}{|c|c|c|c|c|c|c|c|c|c|}
\hline $\begin{array}{l}\text { DEFAULT: } \\
A\end{array}$ & $M / A$ & STAN & 180 & 100 & 8 & $B$ & $\theta$ & No & ASS \\
\hline--------- & ---- & --- & ---- & ---- & ---- & --- & ---- & $-\cdots$ & --- \\
\hline PARAMETER: & DLBL & POS & ELF & Ebl & PTD & SP & ILL & SUP & TAC \\
\hline & ADQ1 & CROU & 91 & & & & & & \\
\hline
\end{tabular}

CHOOSE A DENG CARD EDITING OPTION

$$
\begin{aligned}
& 1 \text { - ADD DENG CARDS } \\
& 2 \text { - REPLACE A DENG CARD } \\
& 3 \text { - DELETE DENG CARDS } \\
& 4 \text { - DISPLAY DENG CARDS } \\
& 5 \text { - RETURN TO TEXT MODE }
\end{aligned}
$$

3

ENTER THE DLBL'S FOR THE DENG CARDS TO BE DELETED ADBB

CHOOSE A DENG CARD EDITING OPTION

$$
\begin{aligned}
& 1 \text { - ADD DENG CARDS } \\
& 2 \text { - REPLACE A DENG CARD } \\
& 3 \text { - DELETE DENG CARDS } \\
& 4 \text { - DISPLAY DENG CARDS } \\
& 5 \text { - RETURN TO TEXT MODE }
\end{aligned}
$$

Figure 6.3. Continued. 
CHOOSE A DISPLAY OPTION

\begin{tabular}{|c|c|c|c|c|c|c|c|c|c|}
\hline PARAMETER: & DLBL & POS & ElFF & ElL & PTD & $\begin{array}{l}S P \\
-\end{array}$ & ILL & SUP & . TAC \\
\hline UALUE: & A081 & CROU & 91 & 100 & $B$ & 8 & D & NO & ASS \\
\hline UALUE: & DERS & CROU & 90 & 30 & $\theta$ & 8 & $\theta$ & NO & ASS \\
\hline
\end{tabular}

CHOOSE A DENG CARD EDITING OPTION

1 - ADD DENG CARDS

2 - REPLACE A DENG CARD

3 - DELETE DENG CARDS

4 - DISPLAY DENG CARDS

5

5 - RETURN TO TEXT MODE

Figure 6.3. Continued. 
LHAT TYPE OF SNAP CARD DO YOU LANT TO EDIT?

ENTER THE CORRESPONDING MUMBER

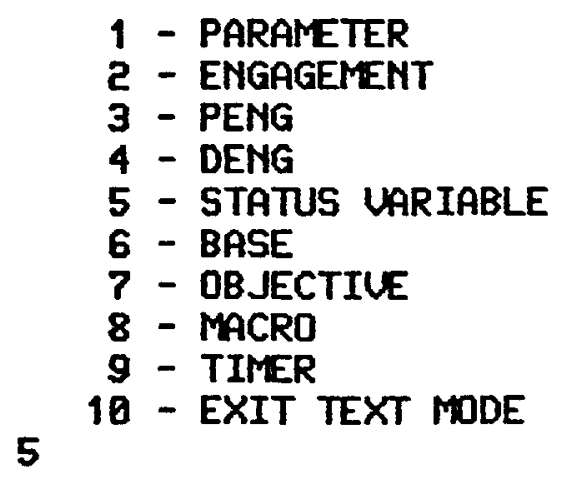

CHOOSE A STATUS UARIABLE EDITING OPTION ENTER THE CORRESPOMDING NUMBER

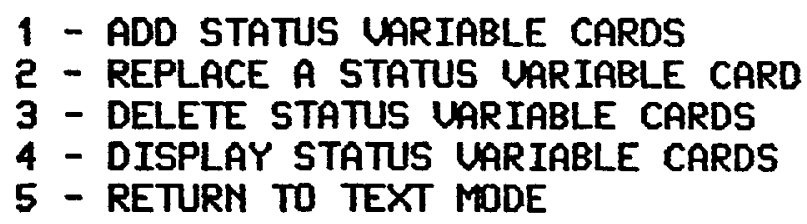

WHICH TYPE OF STATUS UARIABLE DO YOU LANT TO ADD? ENTER THE CORRESPONDING NUMBER

1 - FLAG

2 - FORCE FLAG

1

3 - GLOBAL UARIABLE

Figure 6.3. Continued. 
HOW MANY FLAGS (FORCE FLAGS) DO YOU LAANT TO ADD? 2

FOR EACH FLAG (FORCE FLAG) TO BE ADDED, ENTER

THE LABEL AND THE INITIAL STATUS

( $A=A C T I V E, D=D I S A B L E D)$ UNDER THEIR

RESPECTIUE HEADINGS

LABEL INITIAL STATUS

$\bar{F} \overline{L G} \overline{1}$

FLG2

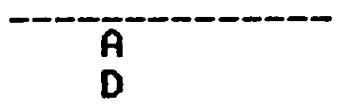

CHOOSE A STATUS UARIABLE EDITING OPTION

ENTER THE CORRESPONDING NUMBER

$$
\begin{aligned}
& 1 \text { - ADD STATUS UARIABLE CARDS } \\
& 2 \text { - REPLACE A STATUS UARIABLE CARD } \\
& 3 \text { - DELETE STATUS UARIABLE CARDS } \\
& 4 \text { - DISPLAY STATUS UARIABLE CARDS } \\
& 5 \text { - RETURN TO TEXT MODE }
\end{aligned}
$$

2

PLEASE ENTER THE LABEL OF THE STATUS UARIABLE TO BE REPLACED FLG1 - 
ENTER THE NEW IMITIAL STATUS FOR THIS FLAG (FORCE FLAG)

( $A=A C T I U E, D=D I S A B L E D)$

A

CHOOSE A STATUS UARIABLE EDITING OPTION

ENTER THE CORRESPONDING NUMBER

3

$$
\begin{aligned}
& 1 \text { - ADD STATUS UARIABLE CARDS } \\
& 2 \text { - REPLACE A STATUS UARIABLE CARD } \\
& 3 \text { - DELETE STATUS UARIABLE CARDS } \\
& 4 \text { - DISPLAY STATUS UARIABLE CARDS } \\
& 5 \text { - RETURN TO TEXT MODE }
\end{aligned}
$$

ENTER THE LABEL(S) OF THE STATUS UARIABLES YOU LANT TO DELETE FLG2

CHOOSE A STATUS UARIABLE EDITING OPTION ENTER THE CORRESPONDING NUMBER

$$
\begin{aligned}
& 1 \text { - ADD STATUS UARIABLE CARDS } \\
& 2 \text { - REPLACE A STATUS UARIABLE CARD } \\
& 3 \text { - DELETE STATUS UAR IABLE CARDS } \\
& 4 \text { - DISPLAY STATUS UARIABLE CARDS } \\
& 5 \text { - RETURN TO TEXT MODE }
\end{aligned}
$$

4_

Figure 6.3. Continued. 
CHOOSE A DISPLAY OPTION

1 - DISPLAY ALL STATUS UARIABLES

2 - DISPLAY STATUS UARIABLES FOR SPECIF IED LABELS

1

UARIABLE UARIABLE INITIAL-UALUE LABEL TYPE OR STATUS

$\overline{F L G} \overline{1}-\bar{F} \bar{A} \bar{G}-\overline{A C T}$

CHOOSE A STATUS UARIABLE EDITING OPTION ENTER THE CORRESPONDING NUMBER

1 - ADD STATUS UARIABLE CARDS

2 - REPLACE A STATUS UARIABLE CARD

3 - DELETE STATUS UARIABLE CARDS

4 - DISPLAY STATUS UARIABLE CARDS

5

5 - RETURN TO TEXT MODE

Figure 6.3. Continued. 
LHAT TYPE OF SNAP CARD DO YOU LANT TO EDIT? ENTER THE CORRESPONDING NUMBER

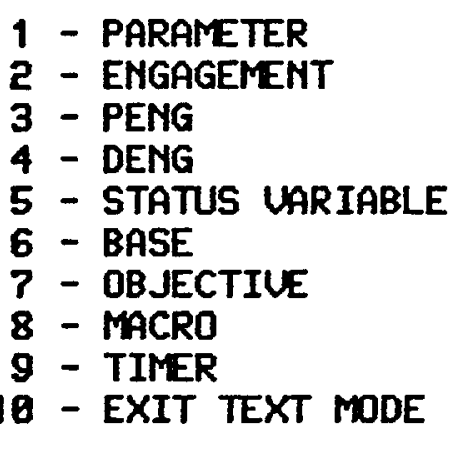

CHOOSE A BASE CARD EDITING OPTION

1 - ADD A BASE CARD

2 - REPLACE A BASE CARD

3 - DELETE BASE CARDS

4 - DISPLAY BASE CARDS

5 - RETURN TO TEXT MODE

1

HOW MANY BASE CARDS DO YOU UANT TO ADO? 3.

Figure 6.3. Continued. 
FOR EACH BASE CARD TO BE ADDED, ENTER THE LABEL, SIZE, WEAPON, AND PROF ICIENCY UNDER THEIR RESPECTIUE HEADINGS

LABEL SIZE WEAPON PROFICIENCY

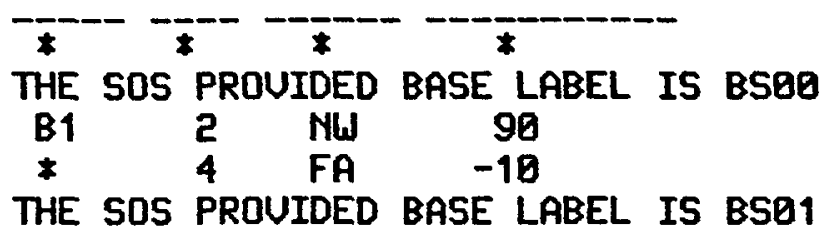

CHOOSE A BASE CARD EDITING OPTION

$$
\begin{aligned}
& 1 \text { - ADD A BASE CARD } \\
& 2 \text { - REPLACE A BASE CARD } \\
& 3 \text { - DELETE BASE CARDS } \\
& 4 \text { - DISPLAY BASE CARDS } \\
& 5 \text { - RETURN TO TEXT MODE }
\end{aligned}
$$

2

ENTER THE LABEL OF THE BASE CARD TO BE REPLACED BSEB

Figure 6.3. Continued. 
ENTER THE NEW SIZI, WEAPON, AND PROFICIENCY FOR THIS BASE UNDER THEIR RESPECTIUE HEADINGS

SIZE LEAPON PROFICIENCY

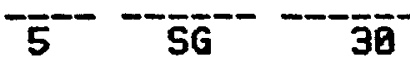

CHOOSE A BASE CARD EDITING OPTION

$$
\begin{aligned}
& 1 \text { - ADD A BASE CARD } \\
& 2 \text { - REPLACE A BASE CARD } \\
& 3 \text { - DELETE BASE CARDS } \\
& 4 \text { - DISPLAY BASE CARDS } \\
& 5 \text { - RETURN TO TEXT MODE }
\end{aligned}
$$

3

ENTER THE LABEL(S) OF THE BASE CARDS YOU WANT TO DELETE BSB1

CHOOSE A BASE CARD EDITING DPTION

$$
\begin{aligned}
& 1 \text { - ADD A BASE CARD } \\
& 2 \text { - REPLACE A BASE CARD } \\
& 3 \text { - DELETE BASE CARDS } \\
& 4 \text { - DISPLAY BASE CARDS } \\
& 5 \text { - RETURN TO TEXT MODE }
\end{aligned}
$$

4_

Figure 6.3. Continued. 
CHOOSE A DISPLAY OPTION

1 - DISPLAY ALL BASE CARDS

2 - DISPLAY BASE CARDS FOR SPECIFIED LABELS

1

LABEL SIZE LEAPON PROFICIENCY

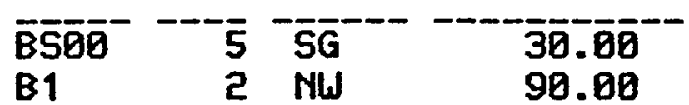

CHOOSE A BASE CARD EOITING OPTION

1 - ADD A BASE CARD

2 - REPLACE A BASE CARD

3 - DELETE BASE CARDS

4 - DISPLAY BASE CARDS

5 - RETURN TO TEXT MDDE

5

Figure 6.3. Continued. 
LHAT TYPE OF SNAP CARD DO YOU LANT TO EDIT? ENTER THE CORRESPONDING MUMBER

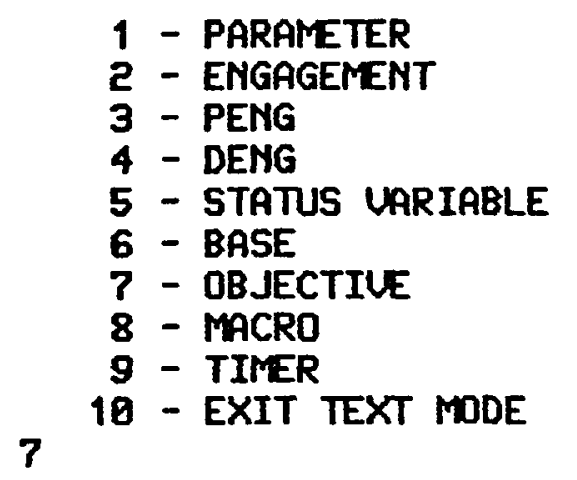

CHOOSE AN OBJECTIUE CARD EDITING OPTION

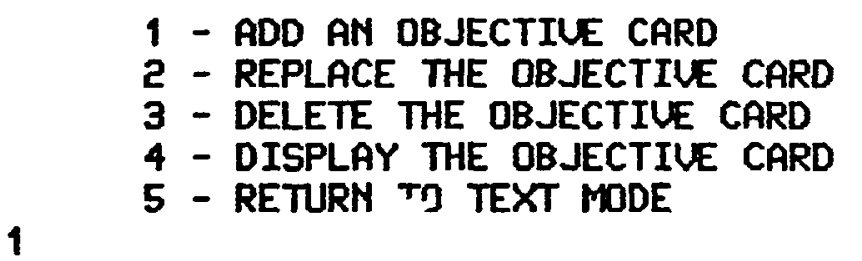

CHOOSE THE MISSION OBJECTIUE

1 - SABOTAGE

1

2 - THEFT

Figure 6.3. Continued. 
ENTER THE FACILITY NODES TO REACH FOR SUCCESSFUL INTRUSION SP01 SPO2 SPO3 SPO4

CHOOSE AN OBJECTIUE CARD EDITING DPTION

5

1 - ADD AN OBJECTIUE CARD

2 - REPLACE THE OBJECTIUE CARD

3 - DELETE THE OBJECTIUE CARD

4 - DISPLAY THE DBJECTIUE CARD

5 - RETURN TO TEXT MDDE

CHOOSE THE MISSION OBJECTIUE

1 - SABOTAGE

2

2 - THEFT

ENTER THE FACILITY NODES TO REACH FOR SUCCESSFUL INTRUSION SPQ5 SP06

CHOOSE AN OBJECTIUE CARD EDITING OPTION

1 - ADD AN OBJECTIUE CARD

2 - REPLACE THE OBJECTIUE CARD

3 - DELETE THE DBJECTIUE CARD

4 - DISPLAY THE OBJECTIUE CARD

3.

5 - RETURN TO TEXT MODE

Figure 6.3. Continued. 
OBJECTIUE CARD DELETED

THIS ENTRY HAS NO OBJECTIUE CARD

CHOOSE AN OBJECTIUE CARD EDITING OPTION

1 - ADD AN OBJECTIUE CARD

2 - REPLACE THE OBJECTIUE CARD

3 - DELETE THE DBJECTIUE CARD

4 - DISPLAY THE OBJECTIUE CARD

1

5 - RETURN TO TEXT MODE

CHOOSE THE MISSION OBJECTIUE

1 - SABOTAGE

2

2 - THEFT

ENTER THE FACILITY NODES TO REACH FOR SUCCESSFUL INTRUSTON SPB1 SPB2

CHOOSE AN OBJECTIUE CARD EDITING OPTION

1 - ADD AN OBJECTIUE CARD

2 - REPLACE THE OBJECTIUE CARD

3 - DELETE THE OBJECTIUE CARD

4 - DISPLAY THE OBJECTIVE CARD

5 - RETURN TO TEXT MODE

4

Figure 6.3. Continued. 
THE CURRENT MISSION OB.JECTIUE IS THEFT

THE FACILITY NODES TO REACH FOR SUCCESSFUL INTRUSION ARE:

SPB1 SPB2

CHOOSE AN OBJECTIUE CARD EDITING OPTION

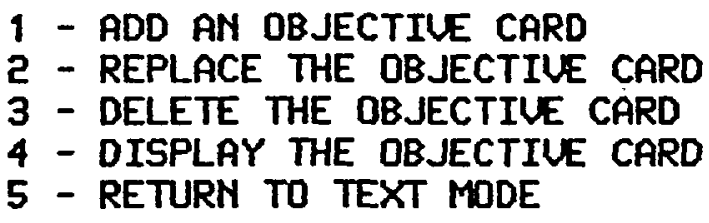

5

WHAT TYPE OF SNAP CARD DO YOU UANT TO EDIT? ENTER THE CORRESPONDING NUMBER

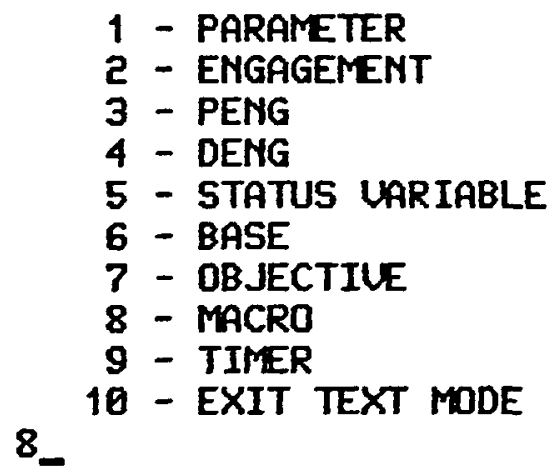

Figure 6.3. Continued. 
CHOOSE A MACRO CARD EDITING OPTION

1 - ADD MACRO CARDS

2 - REPLACE A MACRO CARD

3 - DELETE MACRO CARDS

4 - DISPLAY MACRO CARDS

1

5 - RETURN TO TF.XT MODE

HOW MANY MACRO CARDS DD YOU LANT TO ADD?

3

FOR EACH MACRO CARD ENTER THE LABEL AND THE DOB DESIGMATIONS UNDER THEIR RESPECTIUE HEADINGS

LABEL DOB DESIGNATIONS

$\bar{M} \overline{1}-\overline{A C} \bar{T}(\bar{F} \overline{L G} \overline{1})$

Me DIS(BAR1), MARK(TIM1), RECORD (TIME), SET(GU1, 2.3)

MB SET(GU1, 1)

CHOOSE A MACRO CARD EDITING DPTION

1 - ADD MACRO CARDS

2 - REPLACE A MACRO CARD

3 - DELETE MACRO CARDS

4 - DISPLAY MACRO CARDS

2

5 - RETURN TO TEXT MODE

Figure 6.3. Continued. 
ENTER THE LABEL OF THE MACRO CARD TO BE REPLACED MI

ENTER THE NEW DOB DESIGNATIONS FOR THIS MACRO ACT(FLG1), ACT(FLG2), ACT(FFL1), DIS (FFL2)

CHOOSE A MACRO CARD EDITING OPTION

$$
\begin{aligned}
& 1 \text { - ADD MACRO CARDS } \\
& 2 \text { - REPLACE A MACRO CARD } \\
& 3 \text { - DELETE MACRO CARDS } \\
& 4 \text { - DISPLAY MACRO CARDS } \\
& 5 \text { - RETURN TO TEXT MODE }
\end{aligned}
$$

3

ENTER THE LABEL(S) OF THE MACRO CARDS YOU LAATT TO DELETE $\mathrm{MP}$

CHOOSE A MACRO CARD EDITING OPTION

$$
\begin{aligned}
& 1 \text { - ADD MACRO CARDS } \\
& 2 \text { - REPLACE A MACRO CARD } \\
& 3 \text { - DELETE MACRO CARDS } \\
& 4 \text { - DISPLAY MACRO CARDS } \\
& 5 \text { - RETURN TO TEXT MODE }
\end{aligned}
$$

4 
CHOOSE A DISPLAY OPTION

1 - DISPLAY ALL MACRO CARDS

1

2 - DISPLAY MACRO CARDS FOR SPECIFIED LABELS

LABEL DOB DESIGNATIONS

$\bar{M} \overline{1}-\bar{A} \bar{C} \bar{T}(\bar{F} \overline{L G} \bar{i})$

ACT (FLG2)

ACT (FFL1)

DIS (FFL2)

MB SET CGU1, 1

CHOOSE A MACRO CARD EDITIMG OPTION

1 - ADD MACRO CARDS

2 - REPLACE A MACRO CARD

3 - DELETE MACRO CARDS

4 - DISPLAY MACRO CARDS

5

5 - RETURN TO TEXT MODE

Figure 6.3. Continued. 
WHAT TYPE OF SNAP CARD DO YOU WANT TO EDIT? ENTER THE CORRESPONDIMG MUMBER

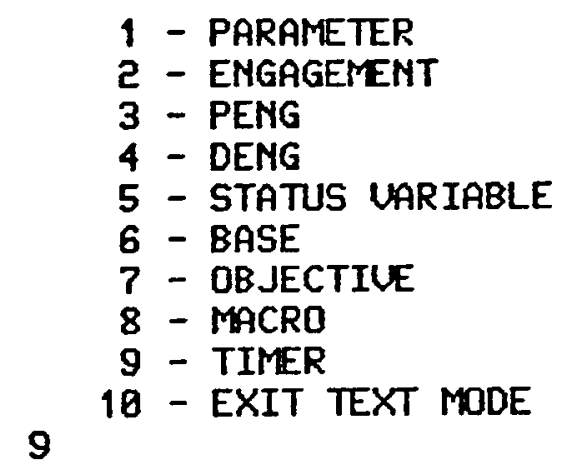

CHOOSE A TIMER NODE EDITIMG OPTION

1 - ADD TIMER NODES

2 - REPLACE A TIMER NODE

3 - DELETE TIMER NODES

4 - DISPLAY TIMER NODES

5 - RETURN TO TEXT MODE

1

HOW MANY TIMER MODES DO YOU WANT TO ADD? 2_ 
FOR EACH TIMER TO BE ADDED, ENTER THE LABEL

THE STATISTICS TYPE (TBR/TSMTTFR), AND THE

IDENTIFICATION LABEL UNDER THEIR RESPECTILE HEADINGS

LABEL TYPE IDENTIF ICATION

- - - IDFŌRTITIERT

THE SOS GEMERATED LABEL IS TIOO

T1 TSM IDFORTIMER2

CHODSE A TIMER MODE EDITING OPTION

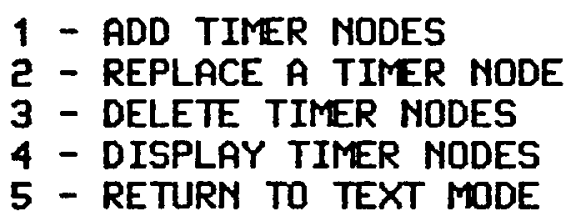

4

CHOOSE A DISPLAY OPTION

1 - DISPLAY ALL TIMER NODES

2 - DISPLAY TIMER NODES FOR SPECIF IED LABELS

1

Figure 6.3. Continued. 


\section{LABEL TYPE IDENTIF ICATION}

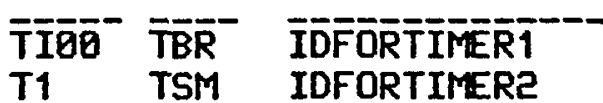

CHOOSE A TIMER MODE EDITING OPTION

1 - ADD TIMER NODES

2 - REPLACE A TIMER NODE

3 - DELETE TIMER NODES

4 - DISPLAY TIMER NODES

2

5 - RETURN TO TEXT MDDE

PLEASE ENTER THE LABEL OF THE TIMER NODE TO BE REPLACED T1

ENTER THE NEW STATISTICS TYPE FOR THIS TIMER NODE (TBR /TSM TFR)

TFR

ENTER THE NEW IDENTIF ICATION LABEL FOR THIS

TIMER MODE

*_ 
CHOOSE A TIMER NODE EDITIMG OPTION

1 - ADD TIMER NODES

2 - REPLACE A TIMER NODE

3 - DELETE TIMER MODES

4 - DISPLAY TIMER NODES

3

5 - RETURN TO TEXT MODE

ENTER THE LABEL(S) OF THE TIMER NODES YOU LANT DELETED TIBO

CHOOSE A TIMER NODE EDITING OPTION

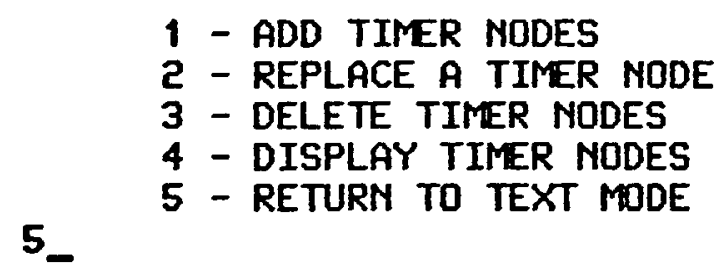

Figure 6.3. Continued. 
FACL Editing Commands

There are six EDIT commands for editing SNAP facility models and five for editing adversary detection device (ADD) diagrams as shown in Figure 6.1. Four of the facility editing commands are used to $\underline{A} d d, \underline{C}$ hange, Delete, and Move SNAP nodes: $\underline{A} O D E, \underline{C N O D E}, \underline{D N O D E}$, and $\underline{M} O D E$, respectively. The SKETCH command is used to edit the lines of the facility diagram. This command allows facility lines to be added and removed by simply "pointing" with the graphics cursor. The FACL editing commands apply only to the level of the SNAP facility currently being edited. The current level, as well as several other facility display parameters, are selected using the EDIT/UTILITY command ENVIRONMENT. The ADJACENT command is used to specify adjacencies between SNAP facility nodes.

SNAP SENSOR, LOGIC POINT, and MONITOR elements are edited using the EDIT Adversary Detection Devices (ADD) diagram editor. This editor is actually a subeditor of EDIT and is entered via the command ATREE. Within this subeditor SENSOR, LOGIC POINTS, MONITORS, and pseudo wait nodes* may be Added (AADD) and Linked (ALINK) or Deleted (DADD) and unlinked (DLINK). This subeditor is exited by using the command QUIT which returns control to the EDIT/FACL editor.

* Pseudo WAIT nodes are nodes which represent real WAIT nodes that exist in the guard or adversary submodel. 
ADV and GUA Editing Commands

There are 15 EDIT commands for editing ADV and GUA entries. This set of commands is divided into two categories: ELEMENTAL commands and MODULAR commands. ELEMENTAL commands are those that perform a function on a single SNAP element and also possibly SNAP elements directly attached to that SNAP element. The ELEMENTAL category includes commands like ANODE (ㅁdd a NODE), and MBRANCH (MOVE a BRANCH) - MODULAR commands are those that perform a function on a group of SNAP elements. The MODULAR commands are high level commands that allow the user to construct entire network segments in a single step. Several user callable network segments are included in the EDIT/MODULAR set of commands. The MODULAR category includes commands like PATH (Add a path segment) and COVER (create an instance of a subnetwork representing forces providing cover). The nine ELEMENTAL ADV and GUA editing commands and their functions are as follows:

\section{COMMAND}

ABRAN

ANODE

CBRAN

CNODE

DBRAN

DNODE

ENGAGE

MBRAN

MNODE

\section{FUNCTION}

Add a BRANCH

$\bar{A} d d$ a NODE

Change a BRANCH

Change a NODE

Delete a $\overline{\text { BRAN }} C H$

Delete a NODE

Change TASK Or WAIT node engagement related data

Move a BRANCH

Move a $\underline{\text { NODE }}$ 
The six MODULAR ADV and GUA editing commands and their functions are as follows:

COMMAND

ALARM

ATTACK

COVER

MERGE

PATH

PATROL

\section{FUNCTION}

Create an instance of the supplied guard subnetwork that represents guards responding to an ALARM.

Create an instance of the supplied adversary subnetwork that represents a skeleton adversary attack scenario.

Create an instance of the supplied adversary or guard subnetwork that represents one force providing cover for another.

Create an instance of the supplied adversary or guard subnetwork that represents a user specified number of forces merging into a single force.

Create a linked series of TASK nodes (a PATH segment) which represents a force traversing a specified list of facility locations.

Create on instance of the supplied guard subnetwork that represents a guard force patrolling a facility.

EDIT Paths and Path Segments

A major goal of the SOS/EDIT processor is to make SNAP model construction faster and easier than the traditional modeling process. The MODULAR commands of EDIT are included as one method of achieving this goal. There are four supplied EDIT/MODULAR commands that facilitate the construction of submodels of forces traversing paths. This is because the path is a common element in almost all SNAP models. All forces must eventually traverse a series of 
facility locations to carry out their mission whether it is the adversaries seeking to accomplish sabotage or theft or the guards trying to thwart the adversary. EDIT facilitates the modeling of paths in a very flexible and easy-to-use manner. The process of using these commands structures scenario construction such that a complete skeleton model is created first which may be embellished later if necessary. The primary EDIT command that deals with the path is the command PATH. The PATH command automatically constructs a linked sequence of TASK nodes that represent a path segment. The information that must be provided by the user in order to construct a single path segment is:

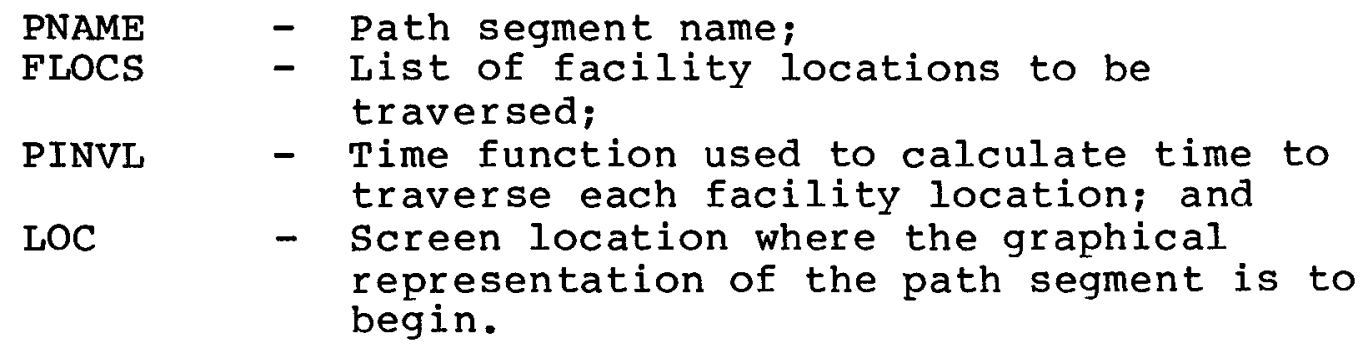

PNAME

PNAME is a user supplied path segment name that is used for two purposes: (1) PNAME is required to reference the path segment on commands that link path segments together (ALARM, ATTACK, and PATROL), (2) path segments are bi-directional and the path segment name is used as a FORCE FLAG to control the direction a force traverses the path segment. The PATH command automatically creates a Force 
Flag with the supplied path segment name after the user supplies the name of the STAT entry to be used.

FLOCS

FLOCS is a list of SNAP facility locations (locations that the path is to traverse) in the order they are to be traversed. Path segments may be traversed starting at either the first or last facility location on a path segment.

$\underline{\text { PINVL }}$

PINVL is the TASK node statistical distribution describing the amount of time it takes to traverse a single facility location. The same PINVL distribution is used at each TASK node.

$\underline{L O C}$

EDIT automatically constructs a linked set of TASK nodes that represent the desired path segment. The TASK nodes are placed on the screen starting at coordinate LOC and downward on the screen. EDIT puts five TASK nodes in each column and then moves one column to the right and begins at the top. An example path segment named GP1 which 
traverses five facility locations is shown below in Figure 6.4. Note that this path segment contains seven TASK nodes, two more than the number of facility locations traversed. The two extra TASK nodes are used as path segment exits to control inter-path segment branching. These two exit TASK nodes have only a single input branch and no emanating branches whereas the other five TASK nodes have one terminating and one emanating branch. The direction of travel along a path segment is controlled by the current status of the path segment Force Flag PNAME.

\section{Path Segment Use}

If a force is to traverse the path segment in the "ACTIVE" direction, the path segment Force Flag should be activated and the force should, referring to Figure 6.4, enter the path segment at TASK node G001. The force will then proceed through TASK nodes G001, G002, G003, G004, G005, and G006. The force will exit the path segment at G006, the path segment exit in the "ACTIVE" direction. If the force is to traverse the path in the "DISABLED" direction, it should enter at node G005 and exit at G000. EDIT automatically stores some additional information. about each path segment created in the entry being edited. This information is used by the ALARM, ATTACK, and PATROL 


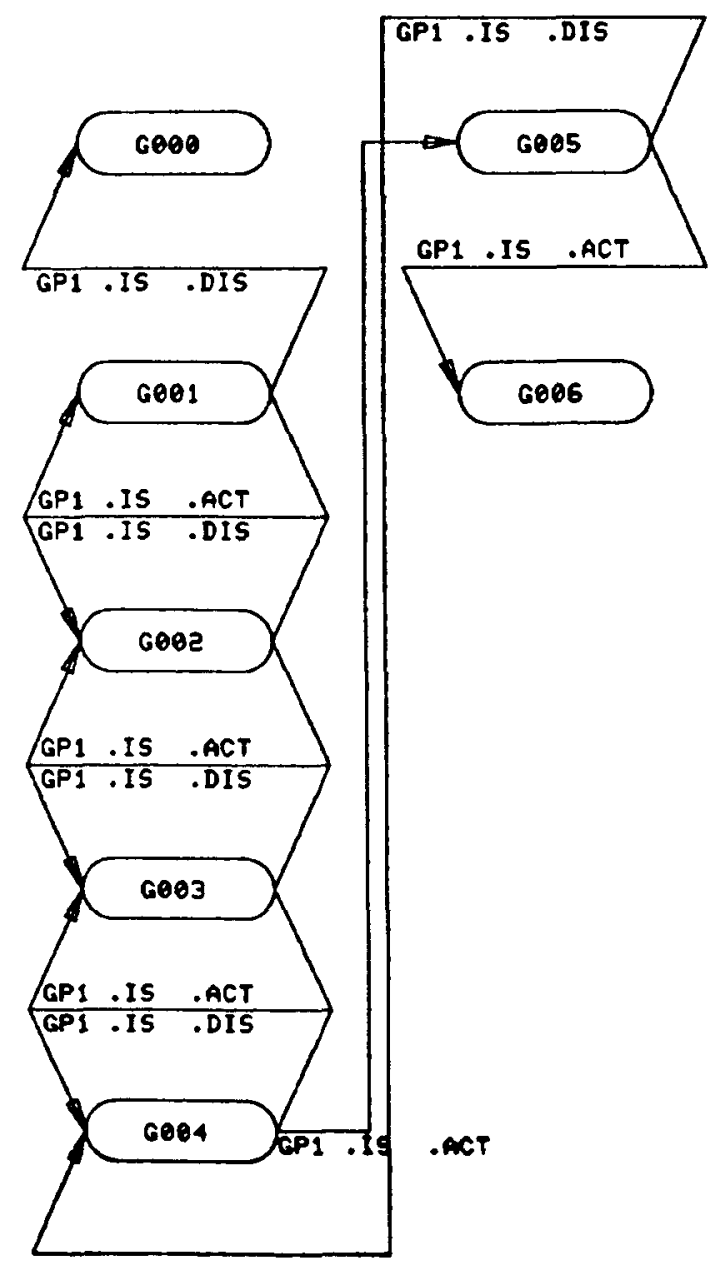

Figure 6.4. Example EDIT Path Segment. 
commands to link path segments together. In this mode, the use of path segments is completely automated in that the user is not required to write USER FUNCTIONS to use linked path segments. SNAP is automatically provided with complete information about linked path segments via the SOS DATA command.

\section{Linking Path Segments into PATHS}

The three EDIT/MODULAR commands that use path segments are ALARM, ATTACK, and PATROL. These commands allow the user to construct entire skeleton networks that effectively model guards responding to alarms, adversaries attacking a site, and guards patrolling a facility. The common trait of these three commands is that they automatically link specified path segments into a path. Each of these commands creates a model of the following type.

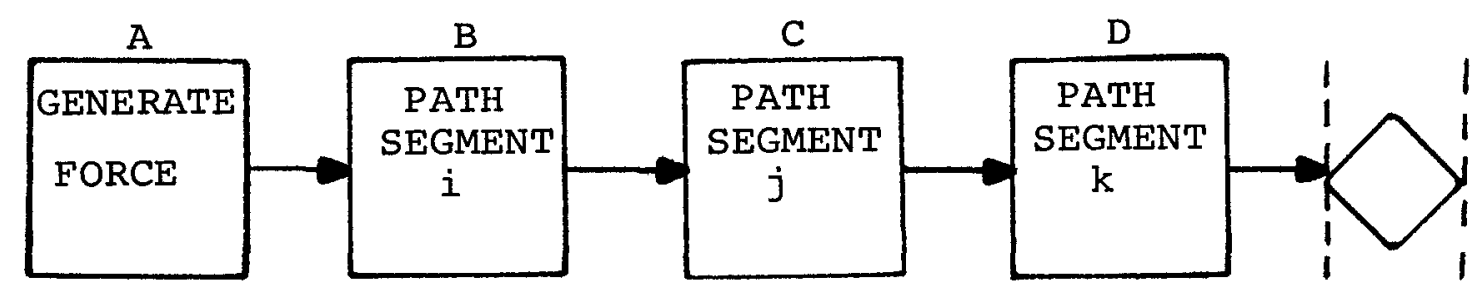


Component $A$ of this generic model is created by the EDIT command ATTACK, ALARM, or PATROL. Each of these commands creates an appropriate network segment representing the generation of a number of forces which eventually enter into a path segment. Each of these commands contains the prompt:

$$
\text { PSEGS }=
$$

The response to this prompt is the user's means of linking path segments into PATHS. The syntax of the response is:

$$
\mathrm{PLBL}_{1}\left(\mathrm{M}_{1}\right), \mathrm{PLBL}_{2}\left(\mathrm{M}_{2}\right), \ldots, \mathrm{EXIT}
$$

where

$\mathrm{PLBL}_{1} \quad$ is the name (Force Flag label) of the first path segment on the path;

$\mathrm{PLBL}_{2}$ is the name (Force Flag label) of the second path segment on this path;

(M) is the direction code for this path segment and is either (A) if the segment is to be traversed in the "ACTIVE" direction or is (D) if the segment is to be traversed in the "DISABLED" direction; and

EXIT is an optional parameter used to indicate whether the force is to EXIT at the end of the PATH. This option is permitted only with the ALARM and ATTACK commands and is ignored on the PATROL command.

With this format, the user can link any number of path segments together, each segment may be traversed in either direction, and an EXIT node may be tacked on to the end of 
the path if desired. The key features of this capability include:

1. All linking between path segments is automatic;

2. Branching code at path segment exit TASK nodes (in UF) is automatic;

3. The same path segment may be used as often as desired, thus reducing the number of nodes required to route forces throughout the facility.

The key to the flexibility provided by this capability

is due to two factors: They are:

1. Each path (series of path segments) will have a unique number associated with it, henceforth called a path number. A path number is automatically generated each time a command which eventually uses the prompt PSEGS $=$ is invoked.

2. Branching between path segments is automated by using the SNAP capability to branch based on the value of a GLOBAL VARIABLE. The GLOBAL VARIABLE used here is named "PATH". The branching between path segments is of the form:

$$
\text { DEC. , (PATH.EQ.N) }
$$

where

$$
\mathrm{N} \text { is a PATH NUMBER }
$$

The sequence of events for constructing and using a path in a SNAP simulation is as follows:

1. Generate path segments using the command PATH; and

2. When the PSEGS = prompt is encountered while using ALARM, ATTACK Or PATROL:

* Enter the desired path segments to be traversed. The overall picture looks like: 


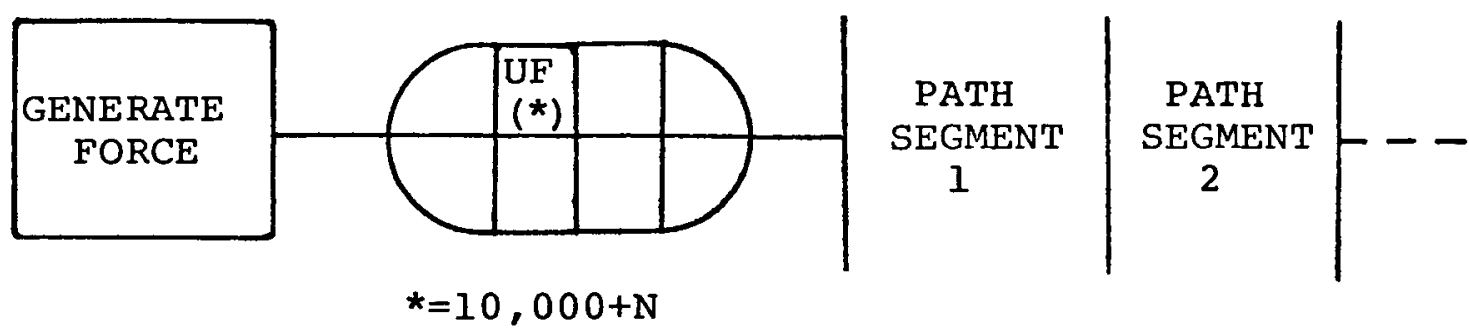

The "SETUP" Task node is used to initiate the appropriate SNAP variables which control a forces movement along path $\mathrm{N}$.

\section{EDIT Error Processing}

The EDIT error processor is designed to provide user friendly information whenever illegal or illogical user input is encountered. The form of the EDIT error message is: 
A

B

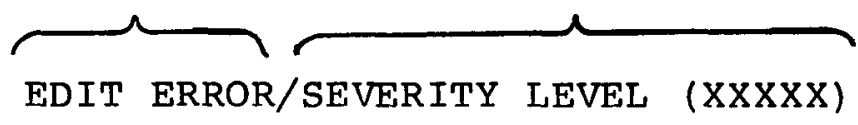

INFORMATIVE ERROR MESSAGE

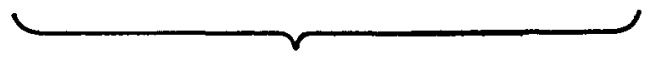

$\mathrm{C}$

Component $A$ of the error message tells the user that the error that has occurred is definitely from within EDIT and not from any other sos component or from the host computer.

Component B of the error message tells the user the severity of the error that has occurred and thus the appropriate general steps to take to correct the error. The severity codes are based on a scale of one to five with five being the most severe error that can occur. These codes are defined as follows:

CODE

COMMENT:

CAUTION :

WARNING :

SEVERE :

\section{MEAN ING}

INFORMATION ONLY, REENTER DATA.

ILLOGICAL DATA ENTERED BUT NOT ACCEPTED BY EDIT. REENTER DATA.

ILLOGICAL DATA ENTERED, REVIEW INPUT DATA AND MAKE NECESSARY CORRECTIONS.

INTERNAL EDIT ERROR, LIBRARY NOT DAMAGED, MAKE COPY OF CURRENT DISPLAY, PROCEED WITH CAUTION, INFORM PRITSKER \& ASSOCIATES. 
FATAL: INTERNAL EDIT ERROR, LIBRARY MAY BE DAMAGED, MAKE COPY OF CURRENT DISPLAY, SEEK ASSISTANCE FROM PRITSKER \& ASSOCIATES BEFORE PROCEEDING.

Examples of the use of these error codes are:

CODE

COMMENT

CAUTION

WARNING

SEVERE

FATAL

\section{EXAMPLE SITUATION}

Illegal command.

Alpha response encountered when numeric required.

Two nodes encountered with same label.

Tried to use array subscript greater than array dimension.

Library routine error--cannot add entry.

Component $\mathrm{C}$ of the error message provides user-friendly information regarding the specific error that has occurred. Examples of typical informative message are shown below. 
ILLEGAL COMMAND ENTERED:

COMMAND

CANNOT BE USED WHILE EDITING ENTRIES

ILLEGAL PROMPT FOR COMMAND ENTERED : ILLEGAL RESPONSE FOR PROMPT ENTERED : NON-EXIST ENT SPECIFIED FOR PROMPT: TOO MANY RESPONSES ENTERED FOR PROMPT: ARRAY OVERFLOW, DIMENSION $=$
REQUESTED $=$
LIBRARY MANIPULATION ERROR USING ROUTINE , ERROR NUMBER $=$

EDIT Command Syntax and Conventions

The syntax of the EDIT command is in general identical to the general sos command syntax discussed earlier. Exceptions and EDIT specific conventions are discussed below.

1. When the EDIT is ready for another command it prints "EDT*" in normal mode; "ATR*" in ATREE mode.

2. Commas, "(",")", and "-" can be used for separators, although "-" can be used only as a separator in specifying entry names (e.g., FACL-1). The blank is not a separator within EDIT.

3. Relational indicators such as AND, OR, AT, IS, $\mathrm{EQ}, \mathrm{NE}, \mathrm{GE}$, and GT must be separated by commas and not by periods as is done on SNAP WAIT triggers, decision branches, engagement pointers, etc. (e.g., GUA(1), AT, SPI, AND, ID, NE, l). 
4. EDIT uses the sos naming convention scheme for all symbol labels it creates automatically. A record of the next available label is kept within the entry being edited. The naming convention scheme is included in section II.

5. On some EDIT commands the prompts entered on the command line are order dependent. This is because on these commands the first few prompts determine the remaining necessary prompts (e.g., ANODE,TYPE=...). If default responses are desired for these commands, the first few prompt = response sequences must be specified on the command line, and they must be ordered as shown in the documentation. This order dependency is best learned by typing the command name only and allowing EDIT to print all of the command prompts.

6. The asterisk (*) is the interactive default character in EDIT. The user may type "*" in response to any EDIT prompt when the default value for that response is desired. If the prompt does not have a default, an error message will be printed followed by the prompt again. For EDIT commands that add symbols, the default value is normally the SNAP default value. For EDIT commands that change symbols, the default value is normally the existing value. The command description section gives detailed information on default definitions. The default value for the label of SNAP symbols being added is automatically generated by EDIT.

Use of EDIT's Graphics Cursor

Several EDIT commands require the user to "point" at the graphics screen using the graphics cursor. The user knows when a "pointing" action is required because the graphics cross-hairs appear on the screen. The user's response is to position the cursor at the desired location and to depress either a "P" or "C", a " $P$ " indicating "point" and " $C$ " indicating "cancel". In the cases where multiple 
points may be entered (e.g., describing a BRANCH) a space bar should be depressed to inform EDIT when the "pointing" process is finished. Only a single key may be depressed whenever the graphics cursor is showing. All responses that do not require the graphics cursor require a Carriage Return $(C / R)$ to end the response. If no characters are entered, the response is interpreted as either a blank or zero depending on the type of response expected.

Prompts that require a "pointing" response may also be entered on the command line. In this case, no response can be specified and should be left blank. For example, if the prompt for specifying the location of a new node is LOC=, then this prompt would be included on the command line as:

$$
\text { ANODE }, \text { TYPE }=A L L O C A T E, L A B E L=A L, L O C=, \ldots
$$

The graphics cross-hairs will appear, as always, when the user is to respond via pointing.

EDIT Command Descriptions

This section presents a detailed description of each of the 35 sOS/EDIT commands. Each description contains the following information: 


$\begin{array}{ll}\text { COMMAND LINE - } & \begin{array}{l}\text { The complete command line including } \\ \text { all associated prompts. prompts } \\ \text { enclosed in brackets are dependent on } \\ \text { the response to a preceding prompt. }\end{array} \\ \text { PROCESSOR } & \text { The EDIT processor which the command } \\ \text { belongs to. The only sublevel } \\ \text { processor in EDIT is ATREE. }\end{array}$

The 35 SOS/EDIT commands are listed in Table 6.1. 
Table 6.1. The SOS/EDIT Commands

\begin{tabular}{|c|c|}
\hline $\begin{array}{l}\text { COMMAND } \\
\text { NUMBER }\end{array}$ & $\begin{array}{l}\text { COMMAND } \\
\text { NAME }\end{array}$ \\
\hline 1 & AADD \\
\hline 2 & ABRANCH \\
\hline 3 & ADJACENT \\
\hline 4 & ALARM \\
\hline 5 & ALINK \\
\hline 6 & ANODE \\
\hline 7 & ATEXT \\
\hline 8 & ATREE \\
\hline 9 & ATTACK \\
\hline 10 & CBRANCH \\
\hline 11 & CNODE \\
\hline 12 & COORD INATE \\
\hline 13 & COVER \\
\hline 14 & DADD \\
\hline 15 & DBRANCH \\
\hline 16 & DLINK \\
\hline 17 & DNODE \\
\hline 18 & DRAW \\
\hline 19 & DTEXT \\
\hline 20 & ENGAGE \\
\hline 21 & ENVIRONMENT \\
\hline 22 & HELP \\
\hline 23 & MBRANCH \\
\hline 24 & MERGE \\
\hline 25 & MNODE \\
\hline 26 & MTEXT \\
\hline 27 & PAGE \\
\hline 28 & PATH \\
\hline 29 & PATROL \\
\hline 30 & QUIT \\
\hline 31 & SELECT \\
\hline 32 & SKETCH \\
\hline 33 & TEXT \\
\hline 34 & VIEW \\
\hline 35 & ZOOM \\
\hline
\end{tabular}

PAGE

NUMBER

129

119

121

122

130

124

127

128

133

135

136

137

139

131

141

132

142

143

144

145

146

148

149

150

151

152

153

155

157

159

160

161

162

163

164 
EDIT/ABRANCH

COMMAND :

PROCESSORS :

PROMPTS/UNIVERSE:
$A B R A N C H, S N O D E=R 1, B N U M=R 2, E N O D E=R 3, B T Y P E=R 4$, $S P L I T=R 5, P O I N T S=R 6[, P R O B=R 7]$ OR $[, C O N D=R 7]$

EDIT

\begin{tabular}{|c|c|c|c|c|}
\hline ROMPTS & & UNIVERSE & DEFAULT & NOTES \\
\hline SNODE $=$ & [RI] & $\begin{array}{l}\text { any existing } \\
\text { node label }\end{array}$ & $\mathrm{N} / \mathrm{A}$ & $\mathbf{E}$ \\
\hline BNUM= & [R2] & numeric & 9999 & $\mathrm{E}$ \\
\hline ENODE = & [R3] & $\begin{array}{l}\text { existing node } \\
\text { label or } \\
\text { "RETURN" }\end{array}$ & $N / A$ & $\mathbf{E}$ \\
\hline BTYPE= & [R4] & $\begin{array}{l}\text { REG , REGU, } \mathrm{PRO}, \\
\text { PROB , DEC , DECI }\end{array}$ & REGU & $\mathrm{E}$ \\
\hline SPLIT $=$ & [R5] & numeric & 0.0 & $\mathrm{E}$ \\
\hline POINTS $=$ & [R6] & $N / A$ & none & $\mathrm{P}$ \\
\hline $\begin{array}{r}\mathrm{PROB}= \\
\text { or }\end{array}$ & [R7] & numeric, GV & 0.5 & $E$ \\
\hline COND $=$ & [R7] & $\mathrm{N} / \mathrm{A}$ & SIZE.GE.I & $\mathrm{E}$ \\
\hline
\end{tabular}

DESCRIPTION :

ABRANCH permits the user to add a single branch between two nodes. The user first defines the start node RI, the branch number $\mathrm{R} 2$, and the end node R3. R2 is specified as the number of the existing branch before which the new branch is to be inserted. Therefore, if $\mathrm{R} 2=1$, the new branch will become the first branch; R2=2, the new branch will become the second branch. If R2 is greater than the number of existing branches emanating from Rl, the new branch will become the last branch. This branch ordering is used by SNAP as the sequence in which the branches are examined when leaving the start node. The user then specifies the branch type R4 as REG, PRO, or DEC followed by the value of SPLIT [R5]. Next the intermediate branch end points, if any, are specified via pointing [R6]. The branch will be drawn as these points are entered. And finally, the PROBability of taking this branch or the CONDITION for taking this 
branch are requested if $R 4$ is PRO or DEC, respectively. If $R 4$ is COND, the specified branching conditions will be displayed near the end of the first line segment in the branch.

NOTES :

The end node label "RETU" is a reserved label which designates the branch is a

"RETURN" branch. 
COMMAND :

PROCESSOR :

PROMPTS/UNIVERSE:

PROMPT

$F L B L=[R I]$

$A L O C S=[R 2]$
ADJ ACENT $, F L B L=R 1, A L O C S=R 2, R 2, \ldots$

EDIT
UNIVERSE

any existing facility node

anv existing facility node(s)
DEFAULT

$\mathrm{N} / \mathrm{A}$

no adjacent locations

DESCRIPTION :

ADJACENT is used to specify which facility locations $\mathrm{R} 2$ are adjacent to facility location R1. Multiple adjacent locations may be specified. 
COMMAND :

PROCESSOR :

PROMPTS/UNIVERSE :

PROMPT

FLBL $=$

[RI]

\section{UN IVERSE}

any facility node label

$\mathrm{BLBL}=[\mathrm{R} 2]$

TRIG =

[R3]

any guard base label

PSEGS $=[R 5]$

$\mathrm{LOC}=[\mathrm{R} 6]$

$$
\text { trigger }
$$

[R4] numeric value

$\mathrm{N} / \mathrm{A}$
$A L A R M, F L B L=R 1, B L B L=R 2, T R I G=R 3, S I Z E=R 4$, PSEGS $=\mathrm{R} 5, \mathrm{LOC}=\mathrm{R} 6$

EDIT
DEFAULT

$\mathrm{N} / \mathrm{A}$

$\mathrm{N} / \mathrm{A}$

SIGNAL

E

1

E

see path segments N/A

$\mathrm{N} / \mathrm{A}$

$\mathbf{E}$

ALARM is used to model guards responding to an alarm. The origin of the guards and the base they allocated from are specified in RI and R2, respectively. The WAIT node TRIGGER(S) for releasing the guards and the number of these guards are specified in R3 and R4, respectively. The path segments to be traversed by the guard forces are specified in R5. And finally, the screen location of the ENTER node of this network module is specified via pointing [R6]. The network module generated by the ALARM command is: 

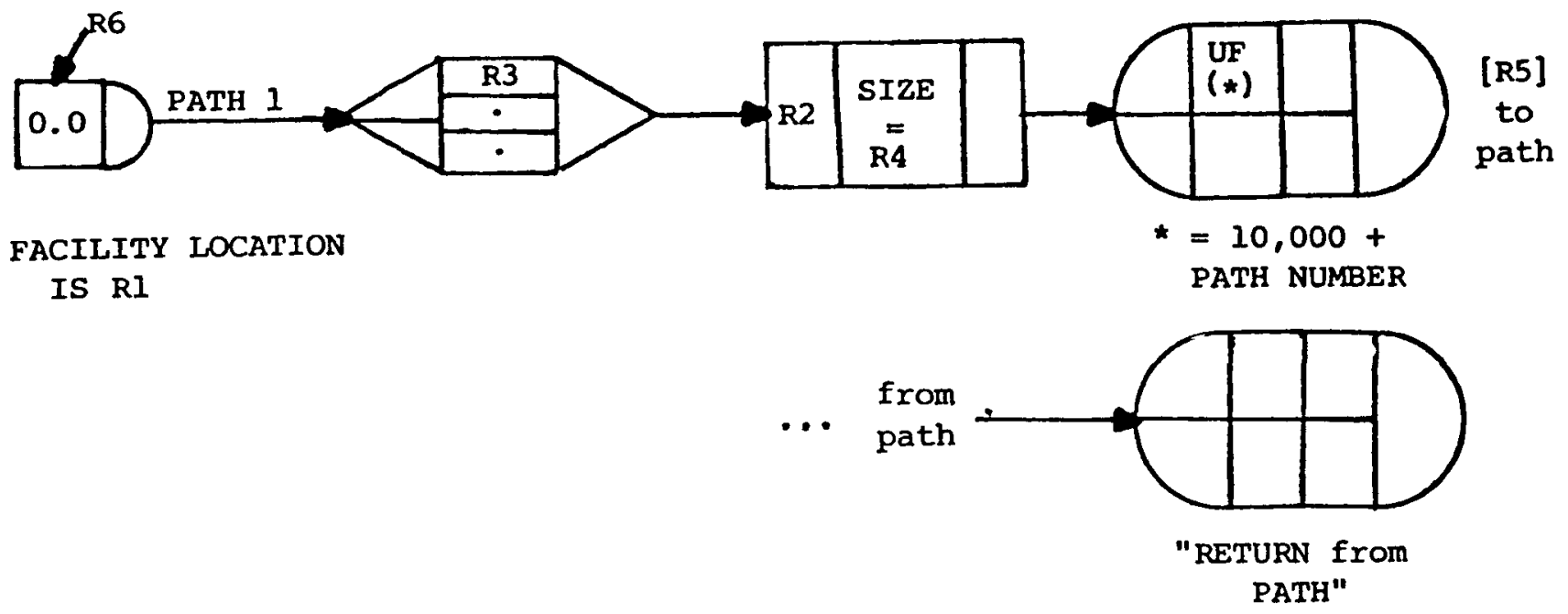

Figure 6.5. The EDIT/ALARM Modular Subnetwork.

This network module begins by generating a zero ID force which proceeds directly to a WAIT node. The WAIT node may be triggered by user specified triggers. When the WAIT node is triggered, the transaction is routed to the ALLOCATE node where the specified number of guards are allocated if available. The force then proceeds through a "path entry" TASK node after which it traverses the specified path segments in the specified direction(s). When the guard force is finished traversing all of the specified path segments it is routed to the "return" TASK node. It is the user's responsibility to route the guard transaction from this TASK node. 
COMMAND :

PROCESSOR :

PROMPTS/UNIVERSE :

$\begin{array}{lll}\text { PROMPTS } & \text { UNIVERSE } & \text { DEFAULT } \\ \text { TYPE }= & \text { [RI] } & \text { ALLO,BARR,ENTE, N/A } \\ & \text { EXIT,RTB,SIGN, } \\ & \text { SPAC,TARG,TASK, } \\ & \text { WAIT }\end{array}$
PARAMETER $_{\mathrm{I}}=\mathrm{R} 4, \ldots$

EDIT

Remainder of prompts depend on response RI

DESCRIPTION :

NOTES :

ALLO
ANODE , $T Y P E=R 1, L A B E L=R 2, L O C=R 3$,

ANODE allows the user to add a node with label R2 of type R1 at the graphics location R3. The system will prompt the user for the appropriate node parameters based on the node type.

There are 10 SNAP node types, but some apply only to certain entries (e.g., ALLO nodes in GUA entries). If the user tries to add an illegal node type to the edit entry an EDIT error will result. The 10 SNAP node types, their corresponding parameters, prompts, and default values are shown on the next several pages. If facility nodes are added to a level other than the current level they will not be displayed since only the current level of the facility model is ever displayed. Nor will facility nodes be displayed if the facility display parameters so specify. See the ENVIRONMENT command description for complete information on the user controllable facility display parameters.

\section{RI $\underline{\text { PROMPTS }} \underline{\text { UNIVERSE }} \underline{\text { DEFAULT }}$ NOTES}

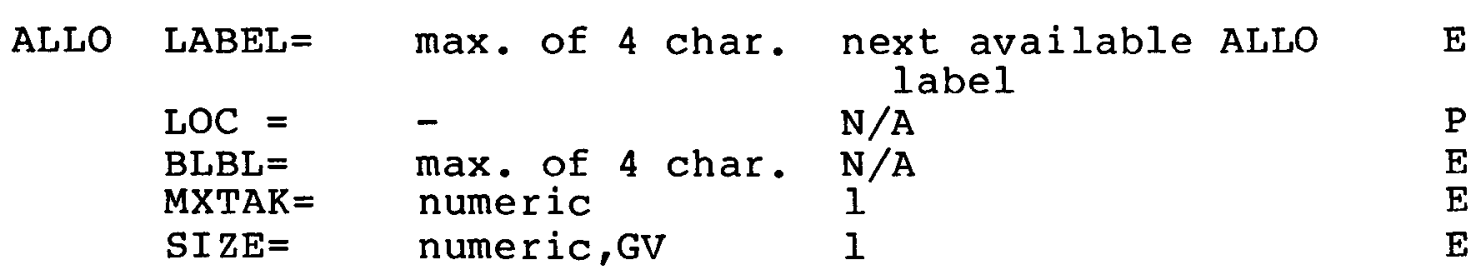




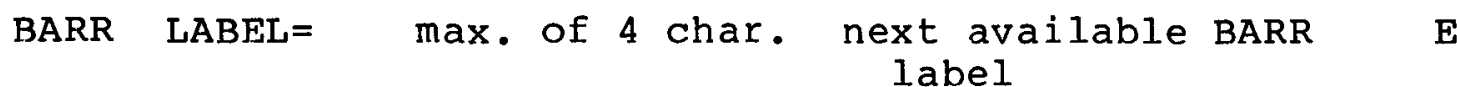

\begin{tabular}{|c|c|c|}
\hline $\begin{array}{l}\text { LOC }= \\
\text { LEVEL }=\end{array}$ & $\begin{array}{l}\text { numeric, max. } \\
\text { of } 4 \text { char. } \\
\text { separated by } \\
\text { commas }\end{array}$ & $\begin{array}{l}N / A \\
\text { current level }\end{array}$ \\
\hline BSTATUS= & $\mathrm{ACT} / \mathrm{DIS}$ & $\mathrm{ACT}$ \\
\hline $\mathrm{FSTAT}=$ & S/blank & blank \\
\hline $\mathrm{JLBL}=$ & $\begin{array}{l}\text { max. of } 4 \text { char. } \\
\text { separated by } \\
\text { commas }\end{array}$ & $\begin{array}{l}\text { no adjacent facility } \\
\text { locations }\end{array}$ \\
\hline$A D D=$ & max. of 4 char. & no associated ADDS \\
\hline
\end{tabular}

ENTE LABEL= max. of 4 char. next available ENTE $E$

LOC $=-\quad$ label $\quad$ N/A P

TOA $=$ numeric $\quad 0.0 \quad \mathrm{E}$

FLBL $=$ max. of 4 char. N/A E

$\operatorname{MXTAK}=$ numeric $\quad 1 \quad \mathrm{E}$

SIZE= numeric $\quad 1.0 \quad \mathrm{E}$

WEAPON $=\mathrm{NW} / \mathrm{HG} / \mathrm{SG} / \mathrm{SA} / \mathrm{HG} \quad \mathrm{E}$

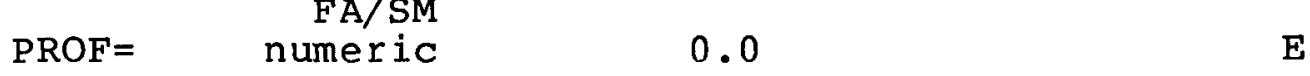

EXIT LABEL $=$ max. of 4 char. next available EXIT E

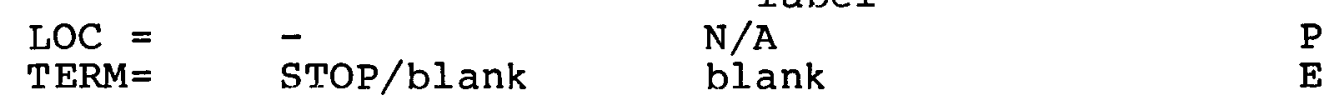

RTB LABEL= max. of 4 char. next available RTB E

LOC $=\quad-\quad$ label $\quad \mathrm{N} / \mathrm{A}$

BLBL max. of 4 char. N/A E

MXTAK $=$ numeric $\quad 1 \quad E$

SIGN LABEL $=\max$. of 4 char. next available SIGN E

LOC $=\quad-\quad$ label $P$

RSIG $=$ see SNAP User N/A

MXTAK= numeric $\quad 1 \quad$ E

SPAC LABEL $=$ max. of 4 char. next available SPAC E

LOC $=\quad-\quad$ label $\quad P$

LEVEL $=$ numeric current level E

FSTAT $=$ S/blank blank E

JLBL $=\quad \max$. of 4 char. no adjacent facility E

ADD = $\quad \max$. of 4 char. no associated ADDS E 
TARG LABEL $=\max$. of 4 char. next available TARG E

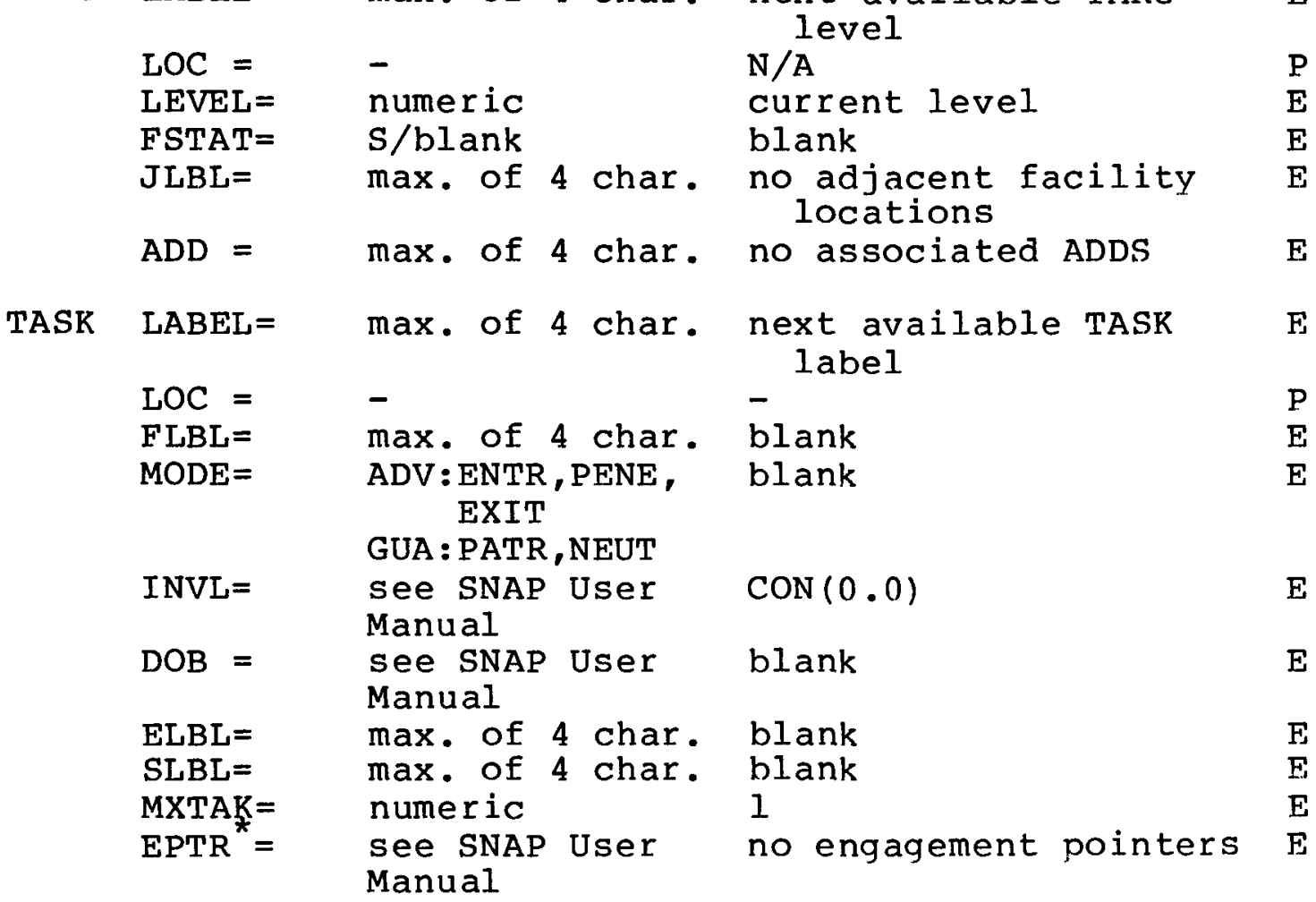

WAIT LABEL $=$ max. of 4 char. next available WAIT $E$

LOC $=\max$. of 4 char. $\mathrm{N} / \mathrm{A} \quad \mathrm{P}$

MTRAN $=$ MERG/TRAN/blank blank E

MXTAK $=$ numeric $\quad 1 \quad E$

ELBL $=\quad \max$. of 4 char. blank E

SLBL max. of 4 char. blank E

EPTR $=$ see SNAP User no engagements E

TRGR= $\quad$ see SNAP User N/A E

* The prompt for Engagement Pointers. The response should be one or more set $\bar{s}$ of FBLBL, RANGE, PENG label (e.g., SPI, 20 Penl, SP2, 50, Pen2). 
EDTT/ATEXT

COMMAND :

PROCESSOR:

PROMPTS/UNIVERSE :

DESCRIPTION :

PROMPTS

OTYPE

OWNER $=[R 2]$
TEXT $=$

[R4]

\section{UNIVERSE}

NODE, BRAN, or blank

any existing node

or branch if

$\mathrm{Rl}$ is not blank

$\begin{array}{ll}\text { TLOC } & {[\mathrm{R} 3]} \\ \mathrm{TEXT} & =[\mathrm{R} 4]\end{array}$

$\mathrm{N} / \mathrm{A}$

$\mathrm{N} / \mathrm{A}$

blank

blank

$\mathrm{N} / \mathrm{A}$

$\mathrm{N} / \mathrm{A}$
DEFAULT

ATEXT is used to add textual information to an EDIT display beginning at a location R3 with owner R1, R2. The Owner TYPE R1 and the OWNER R2 are specified as follows:

$\begin{aligned} & \text { Rl:Owner } \\ & \text { Type }\end{aligned} \begin{aligned} & \text { R2:Owner } \\ & \text { "BRAN" }\end{aligned} \begin{gathered}\text { Owner is specified } \\ \text { branch }\end{gathered}$
"NODE"
point to
node
node


COMMAND :

PROCESSOR :

PROMPTS/UNIVERSE :

DESCRIPTION :

DEFAULTS :

NOTES :
ATREE

EDIT

$\mathrm{N} / \mathrm{A}$

ATREE is used to enter the detection device diagram associated with the facility subnetwork currently being edited. ATREE causes EDIT to enter a sublevel editor associated with the facility subnetwork editor. This sublevel may be exited using the QUIT command. Four editing commands are available to the user to add and delete ADDS and links of the detection device diagram and these are:

1. AADD - Add ADD

2. ALINK - Add LINK

3. DADD - Délete ADD

4. DLINK - Delete $\underline{\text { LINK }}$

5. QUIT

The procedure to use these commands is described in their corresponding command description.

$\mathrm{N} / \mathrm{A}$

The EDIT/ATREE command prompt is "ATR*". 
COMMAND :

PROCESSOR :

PROMPTS/UNIVERSE :

PROMPTS

TYPE $=\quad[\mathrm{R} I]$

LABEL $=[$ R2 $] \quad \mathrm{N} / \mathrm{A}$

$\mathrm{LOC}=[\mathrm{R} 3] \quad \mathrm{N} / \mathrm{A}$

unless $\mathrm{R} 1=$ SENS, then

DESCRIPTION :

$\begin{array}{lllll}\text { PROB }= & {[\mathrm{R} 3]} & \text { numeric, GV } & 1.0 & \text { E } \\ \text { STYPE }= & {[R 4]} & \text { TEMP or PERM } & \text { PERM } & \text { E } \\ \text { LOC }= & {[R 5]} & \text { N } / A & \text { N } / A & \text { P }\end{array}$

$\mathrm{AADD}, \mathrm{TYPE}=\mathrm{R} 1, \mathrm{LABEL}=\mathrm{R} 2[, \mathrm{LOC}=\mathrm{R} 3] \mathrm{OR}$ [, $\mathrm{P} \mathrm{POB}=\mathrm{R} 3, \mathrm{STYPE}=\mathrm{R} 4, \mathrm{LOC}=\mathrm{R} 5]$

EDIT/ATREE

UNIVERSE

DEFAULT

NOTES

SENS , LOGI, MONI, PWAI N/A

E

next avail- $\mathrm{E}$ able ADD

label

$\mathrm{N} / \mathrm{A}$

$\mathbf{P}$

AADD adds an Adversary Detection Device of type RI and label R2 at location R3 (or R5) on the adversary detection device diagram. The four types of ADDs are SENSOR, LOGIC POINT, MONITOR, AND PWAIT, where type PWAIT is a pseudo WAIT node. A pseudo WAIT node is used to represent the signal receiver from a MONITOR; the label on the PWAIT node must be the label of the real WAIT node in the ADV or GUA entry. All ADD's are represented graphically as solid circles; PWAIT nodes are represented as dashed circles. 
COMMAND :

PROCESSOR :

PROMPTS/UNIVERSE :

PROMPTS

$\mathrm{SADD}=\quad[\mathrm{R} I]$

$\mathrm{EADD}=[\mathrm{R} 2]$

NOTES :

ALINK , $S A D D=R 1, E A D D=R 2$

EDIT/ATREE

UNIVERSE
any existing ADD
NEFAULT

If two SENSOR nodes are linked via the ALINK command, the second will be treated as a TAMPER alarm on the first. 
COMMAND :

PROCESSOR :

PROMPTS/UNIVERSE :

\section{PROMPT}

$\mathrm{ADD}=$

[RI]

$\mathrm{DADD}, \mathrm{ADD}=\mathrm{R} 1$

EDIT/ATREE

\section{UN IVERSE}

any existing $A D D$
DEFAULT

$\mathrm{N} / \mathrm{A}$

NOTES

E

DADD deletes ADD RI from the Adversary Detection Device diagram. The ADD will remain on the graphical display until the DRAW command is used to redraw the screen. All incoming and emanating links are also deleted. Thus ADD RI will be removed from all other ADD adjacency lists. 
COMMAND :

PROCESSOR :

PROMPTS/UNIVERSE :

$\underline{\text { PROMPTS }}$

SADD $=$

[RI]

$\mathrm{EADD}=\quad[\mathrm{R} 2]$

DLINK , SADD=R $1, E A D D=R 2$

EDIT/ATREE

UN IVERSE

any existing $\mathrm{ADD}$

any existing ADD
DEFAULT

$\mathrm{N} / \mathrm{A}$

$\mathrm{N} / \mathrm{A}$
NOTES

E

$\mathrm{E}$

DESCRIPTION:

DLINK deletes the link from ADD R1 to ADD R2. In terms of SNAP input data, ADD R2 is removed from ADD Rl's adjacent ADD list. The graphical link remains on the graphics display until the DRAW command is next used. 
COMMAND :

PROCESSOR :

PROMPTS/UNIVERSE :
$A T T A C K, S I Z E=R 1$, WEA PON=R2, TOA=R 3, PROF=R4, $\mathrm{FLBL}=\mathrm{R} 5, \mathrm{PSEGS}=\mathrm{R} 6, \mathrm{LOC}=\mathrm{R} 7$

EDIT

\begin{tabular}{|c|c|c|c|c|}
\hline PROMPTS & & UNIVERSE & DEF AULT & NOTES \\
\hline $\mathrm{SIZE}=$ & [RI] & numeric & 1 & $\mathbf{E}$ \\
\hline WEAPON= & [R2] & $\mathrm{NW} / \mathrm{HG} / \mathrm{SG} / \mathrm{SA} / \mathrm{FA} / \mathrm{SM}$ & HG & $\mathbf{E}$ \\
\hline $\mathrm{TOA}=$ & [R3] & numeric & 0.0 & $E$ \\
\hline $\mathrm{PROF}=$ & [R4] & numeric & 0.0 & $\mathbf{E}$ \\
\hline FLBL $=$ & [R5] & $\begin{array}{l}\text { any facility node } \\
\text { label }\end{array}$ & $\mathrm{N} / \mathrm{A}$ & $\mathrm{E}$ \\
\hline PSEGS $=$ & [R6 ] & $\begin{array}{l}\text { see path segment } \\
\text { description }\end{array}$ & $N / A$ & $\mathbf{E}$ \\
\hline $\mathrm{LOC}=$ & [R7] & $N / A$ & $N / A$ & $\mathbf{P}$ \\
\hline ION : & & $\begin{array}{l}\text { ATTACK is a high level } \\
\text { the user to construct a } \\
\text { an entire adversary att } \\
\text { the network generated } \\
\text { follows: }\end{array}$ & $\begin{array}{l}\text { command which } \\
\text { skeleton netwo } \\
\text { tack A schemat } \\
\text { via the ATTACK }\end{array}$ & $\begin{array}{l}\text { allows } \\
\text { ork of } \\
\text { tic of } \\
\text { command }\end{array}$ \\
\hline
\end{tabular}
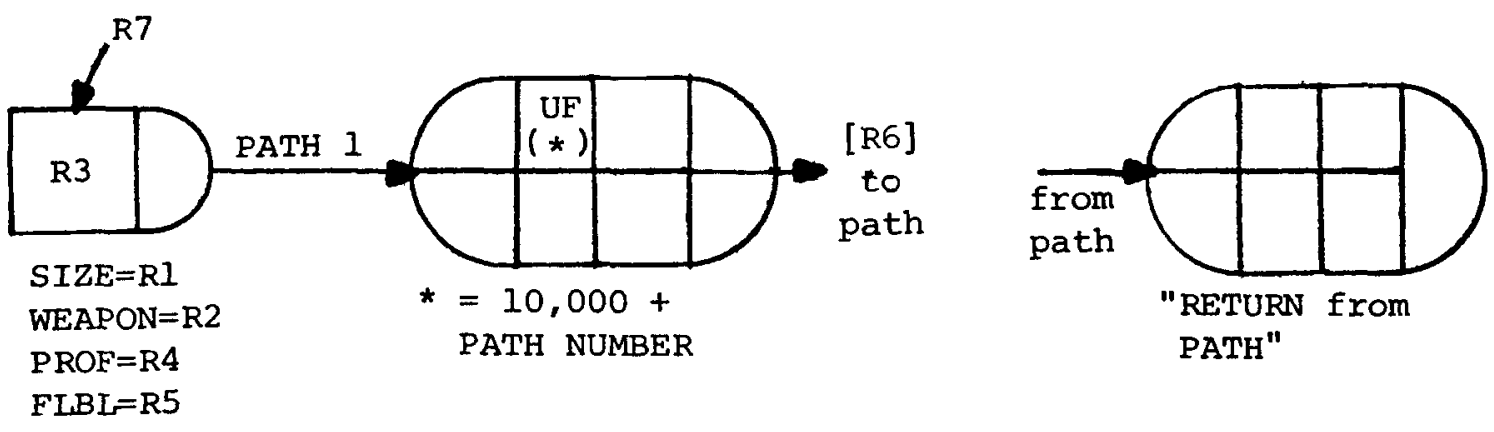

Figure 6.6. The EDIT/ATTACK Modular Subnetwork. 
The user first specifies the adversary force size RI, its weapon type R2, its arrival time R3, its proficency level R4, and the force's initial facility location R5. The user then specifies R6, a list of path segments to be traversed suffixed by "/A" or "/D" depending on whether the segment is to be traversed in the ACTIVE or DISABLED DIRECTION. The network module generated consists of an ENTER node, a "path-entry" TASK node, and a set of branches that link the necessary path segments. The last TASK node of the subnetwork is used as the "return" node. A branch from the last path segment traversed to this node is automatically added to the network by EDIT. It is the user's responsibility to route emanating forces from this TASK node. 
COMMAND :

PROCESSOR :

PROMPTS/UNIVERSE :
$\mathrm{CBRANCH}, \mathrm{BRANCH}=\mathrm{R} 1, \mathrm{ENODE}=\mathrm{R} 2, \mathrm{BTY} P E=\mathrm{R} 3$, $S P L I T=R 4$ [, $P R O B=R 5]$ OR $[, C O N D=R 5]$

EDIT

\begin{tabular}{|c|c|c|}
\hline PROMPTS & & UN IVERSE \\
\hline $\mathrm{BRANCH}=$ & [R1] & any existing branch \\
\hline ENODE $=$ & [R2] & $\begin{array}{l}\text { any existing node } \\
\text { or RETU }\end{array}$ \\
\hline $\mathrm{BTYPE}=$ & [R3] & $\begin{array}{l}\text { REG , REGU , } \mathrm{PRO}, \mathrm{PROB} \text {, } \\
\mathrm{DEC}, \mathrm{DECI}\end{array}$ \\
\hline SPLIT= & [R4] & numeric value \\
\hline $\mathrm{PROB}=$ & {$[\mathrm{R} 5]$} & numeric value \\
\hline Or & & \\
\hline COND $=$ & [R5] & $\mathrm{N} / \mathrm{A}$ \\
\hline
\end{tabular}

DEFAULT $\quad$ NOTES

$\mathrm{N} / \mathrm{A} \quad \mathrm{P}$

existing $\quad E$

value

existing $\quad E$

value

existing $\quad E$

value

existing $E$

value unless

R3 changed

then $\mathrm{N} / \mathrm{A}$

existing $\quad \mathrm{E}$

value unless

R3 changed

then $\mathrm{N} / \mathrm{A}$

DESCRIPTION :

CBRANCH is used to modify the parameters of a specified existing branch RI. The branch end node R2, type R3, SPLIT R4, and the probability of taking the branch or the condition for taking the branch, R5, may be changed with CBRANCH. 
COMMAND :

PROCESSOR :

PROMPTS/UNIVERSE :
CNODE , NODE $=R 1$, PARAMETSER ${ }_{1}=\mathrm{R} 2, \ldots$, PARAMETER $_{\mathrm{N}}=\mathrm{RN}+\mathrm{I}$

EDIT
PROMPTS

NODE $=$ [RI]

The remainder of the prompts depend on the node type of node $\mathrm{RI}$

\section{UNIVERSE}

any existing node
DEFAULT

$\mathrm{N} / \mathrm{A}$

the parameter $\mathrm{E}$ value is not changed
DESCRIPTION :
CNODE permits the user to change the nongraphical parameters associated with node Rl. The parameters that may be changed are the same as the parameters referenced on the ANODE command with the following exceptions:

1. FACILITY node adjacent nodes (JLBL) are not changed with CNODE. This is accomplished via the ADJACENT command.

2. TASK and WAIT node EPTR's are not changed with the CNODE command. This is accomplished with the ENGAGE command.

The default values used in the CNODE command are the node's existing values. 
COMMAND :

PROCESSOR :

PROMPTS/UNIVERSE :

PROMPTS

SCREEN =

$[R I]$
COORDINATE $[, \operatorname{SCREEN}=\mathrm{R} 1]$

EDIT
DESCRIPTION :

$\begin{array}{lll}\text { UNIVERSE } & \text { DEFAULT } & \text { NOTES } \\ \text { point to either the } & \text { N/A } & \text { does } \\ \text { upper or lower } & & \text { not ap- } \\ \text { screen } & \text { ply if } \\ & & \text { in full } \\ & \text { screen } \\ & \text { mode }\end{array}$

The capability to display specified coordinates of the current EDIT virtual window is accomplished by using the command named COORDINATE.

The prompt "SCREEN=" is required only if EDIT is currently in the split screen mode. COORDINATE will begin by displaving the coordinates of the four corners and the center of the current virtual window and then prompting the user for the desired action as shown below:

EDT * COORDINATE

$$
\begin{aligned}
& \left(X_{1}, Y_{1}\right) \quad\left(X_{2}, Y_{2}\right) \\
& \left(X_{3}, Y_{3}\right) \\
& \left(X_{4}, Y_{4}\right) \quad\left(X_{5}, Y_{5}\right) \\
& \text { P - Display current cursor coordinate }
\end{aligned}
$$$$
\text { Q - Quit }
$$

The graphics cursor will then appear and the user may position the cursor and enter " $P$ " to instruct EDIT to display the coordinates of the current cursor location. This action may be repeated as often as desired until a "Q" is entered to exit the COORDINATE command. 
EXAMPLE (ASSUME FULL SCREEN MODE)

EDT * COORDINATE

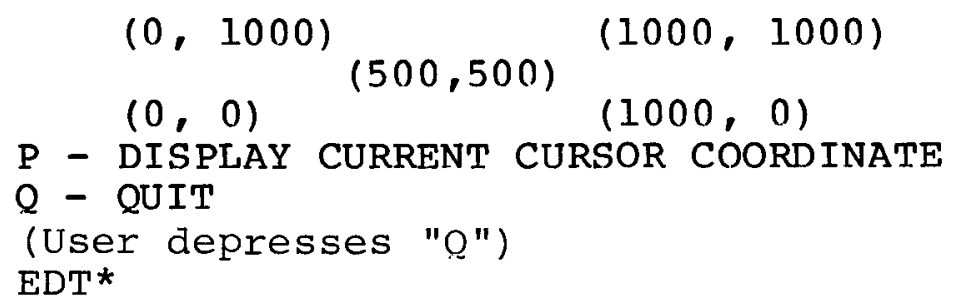




\section{EDIT/COVER}

COMMAND :

PROCESSOR :

PROMPTS/UNIVERSE :

SNODE $=$

[RI]

SPLIT $=[R 2]$

LFLAG $=[R 3]$

$\mathrm{COND}=\quad[\mathrm{R} 4]$
COVER, SNODE=R1, SPLIT=R2, LFLAG=R 3, COND=R4, $S L B L=R 5, E L B L=R 6, E P T R=R 7, T R I G=R 8, E N O D E=R 9$, $L O C=R 10$

EDIT
UN IVERSE

any existing node

numeric

$\mathrm{N} / \mathrm{A}$

"AND" operator only on conditions
DEFAULT

NOTES

$\mathrm{N} / \mathrm{A}$

E

0.0

E

blank

E

R3,IS,DIS E unless $\mathrm{R} 3$ is blank, then default is R4=blank

blank E

blank E no engagement $\mathrm{E}$ pointers

signal

E

TRIG $=[R 8] \quad N / A$

ENODE $=[\mathrm{R} 9] \quad \begin{aligned} & \text { any existing node } \\ & \text { label }\end{aligned}$

$\mathrm{N} / \mathrm{A}$

E

$\mathrm{LOC}=[\mathrm{R} 10] \quad \mathrm{N} / \mathrm{A}$
E

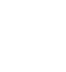




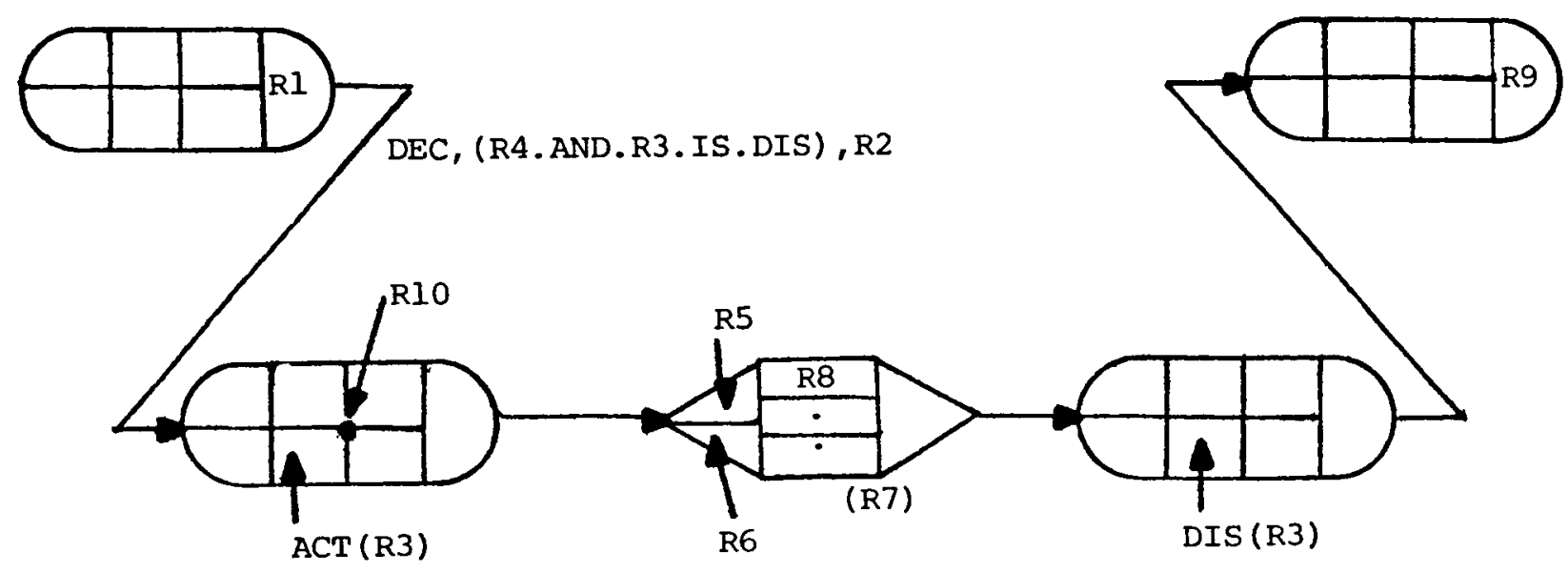

Figure 6.7. The EDIT/COVER Modular Subnetwork.

The user first specifies the existing node Rl where the covering force originates, what portion of the total force is to provide cover, R2, and under that condition(s) cover is to be initiated, $\mathrm{R} 4$. The user may also define a flag which will be automatically activated when cover is being provided and disabled when not,R3. If a non-blank flag is specified, it will be included with the conditions to provide cover $\mathrm{R} 4$ in the form:

$$
\text { R4 .AND.FLAG R3.IS.DISABLED }
$$

The force providing cover waits in a WAIT node until it either becomes involved in an engagement and is removed from the WAIT node via SLBL, or a user specified trigger R8 releases the force from the WAIT node. After being released from the WAIT node, the force proceeds through a zero time TASK node which disables FLAG $R 3$ if necessary and then on to the specified route node $\mathrm{R} 9$. The three node network module is positioned on the screen such that the left TASK node is centered at the location Rl0. 
COMMAND :

PROCESSOR :

PROMPTS/UNIVERSE :

PROMPTS
SNODE $=[\mathrm{R} 1]$
BRANCH $=[\mathrm{R} 2]$

DESCRIPTION:
DBRANCH , $\mathrm{SNODE}=\mathrm{R} 1, \mathrm{BRANCH}=\mathrm{R} 2$

EDIT

\section{UN IVERSE}

any existing node label

DEFAULT

NOTES

$\mathrm{N} / \mathrm{A}$

E

any existing

branch

$\mathrm{N} / \mathrm{A}$

$\mathbf{P}$

This command is used to delete specified branches R1, R2 from the guard or adversary subnetwork being edited. $R 2$ is specified by pointing at the first line segment of the desired branch. Any text owned by the deleted branch is also automatically deleted (see ATEXT). 
COMMAND :

PROCESSOR :

PROMPTS/UNIVERSE :

\section{PROMPTS \\ NODES $=$}

DESCRIPTION :
DNODE , NODES=RI, RI, RI, ...

EDIT

UNIVERSE $\quad$ DEFAULT NOTES

[R1]

any existing nodes $\mathrm{N} / \mathrm{A}$

$E$

DNODE is used to delete the specified node(s) Rl from the entry being edited. All branches terminating at and emanating from the deleted node(s) will also be deleted. This command may be used on GUA and ADV entries to delete network nodes or it may be used on FACL entries to delete facility nodes. Any text owned by the deleted nodes is also automatically deleted (see ATEXT). 
COMMAND :

PROCESSORS :

PROMPTS/UNIVERSE :

DESCRIPTION :

\section{DRAW}

EDIT

None

DRAW clears the graphics screen and redraws the current display(s) using the current display window dimensions. The DRAW command should be used to maintain a display relatively uncluttered of old commands, prompts, and unnecessary graphics that are inherent in using non-refresh graphics devices. 
COMMAND :

PROCESSOR :

PROMPTS/UNIVERSE :

PROMPTS

$\mathrm{TLOC}=[\mathrm{RI}]$
DTEXT , TLOC $=\mathrm{R} 1$

EDIT

\section{UN IVERSE}

the start location

of any textual

information currently on the screen.

DESCRIPTION :

DTEXT is used to delete existing text from the EDIT display. The text to be deleted is specified by pointing at the screen location of the lower left corner of the first character with the graphics cursor. If the text indicated consists of multiple lines, then all lines are deleted. 
COMMAND :

PROCESSOR :

PROMPTS/UNIVERSE :

PROMPTS

NODE $=$

[RI]

$\mathrm{ELBL}=\quad[\mathrm{R} 2]$

$S L B L=[R 3]$

EPTR

[R4]
$E N G A G E, N O D E=R 1, E L B L=R 2, S L B L=R 3, E P T R=R 4$

EDIT
UN IVERSE

any existing TASK

or WAIT node

$\mathrm{N} / \mathrm{A}$

$\mathrm{N} / \mathrm{A}$

N/A-FLBLE, RANGE, PENG
DEFAULT

$\mathrm{N} / \mathrm{A}$

blank

blank

no engagement data
NOTES

E

E

E

F
DESCRIPTION :

ENGAGE is used to add or change TASK or WAIT node engagement information. The desired TASK or WAIT node label is first specified, RI, followed by the new value for ELBL, R2, and SLBL, R3. The response to EPTR is specified as sets of FLBLE, RANGE, and PEBL data where FLBLE is a 4 character facility label; RANGE is the distance in meters between FLBLE and the force, and PEBL is the label of the PENG card to be referenced. Sets of EPTR data are separated by commas (e.g., EPTR=SP01,123,Pen1,SP02,56,Pen2). 
COMMAND :

PROCESSOR:

PROMPTS/UNIVERSE :
ENVIRONMENT , ENTRY=R $1, S C R E E N=R 2, F N O D E=R 3$, FLINE=R4 , FNLABEL=R5, FNSI $7 E=R 6, F L E V E L=R 7$, TXTFLAG $=$ R8, TXTSI $7 E=R 9$

EDIT
UN IVERSE

any existing entry of type ADV, FACL, or GUA

SCREEN $=[R 2]$

$F N O D E=[R 3]$

FLINE $=\quad[R 4]$

FNLABEL $=[R 5]$

FNSIZE $=[R 6]$

FLEVEL $=[$ R7 $]$

TXTFLAG $=[R 8]$

TXTSIZE = [R9] point to upper or lower screen if in split screen mode

"Y" or "N"

"Y" or "N"

"Y" or "N"

numeric value

integer value

"NONE" , "PARTIAL" ,

"SMALL", "MEDIUM" " $\overline{\text { LARGE }} "$, "EXTRA L $\overline{\text { ARGE }} "$

DEFAULT

NOTES

current value $\mathrm{E}$

\section{E}

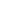

$\mathrm{N} / \mathrm{A} \quad \mathrm{P}$

current value $\mathrm{E}$

current value $E$

current value $\mathrm{E}$

current value $\mathrm{E}$

current value $\mathrm{F}$.

current value $\mathrm{E}$

current value $\mathrm{E}$

P




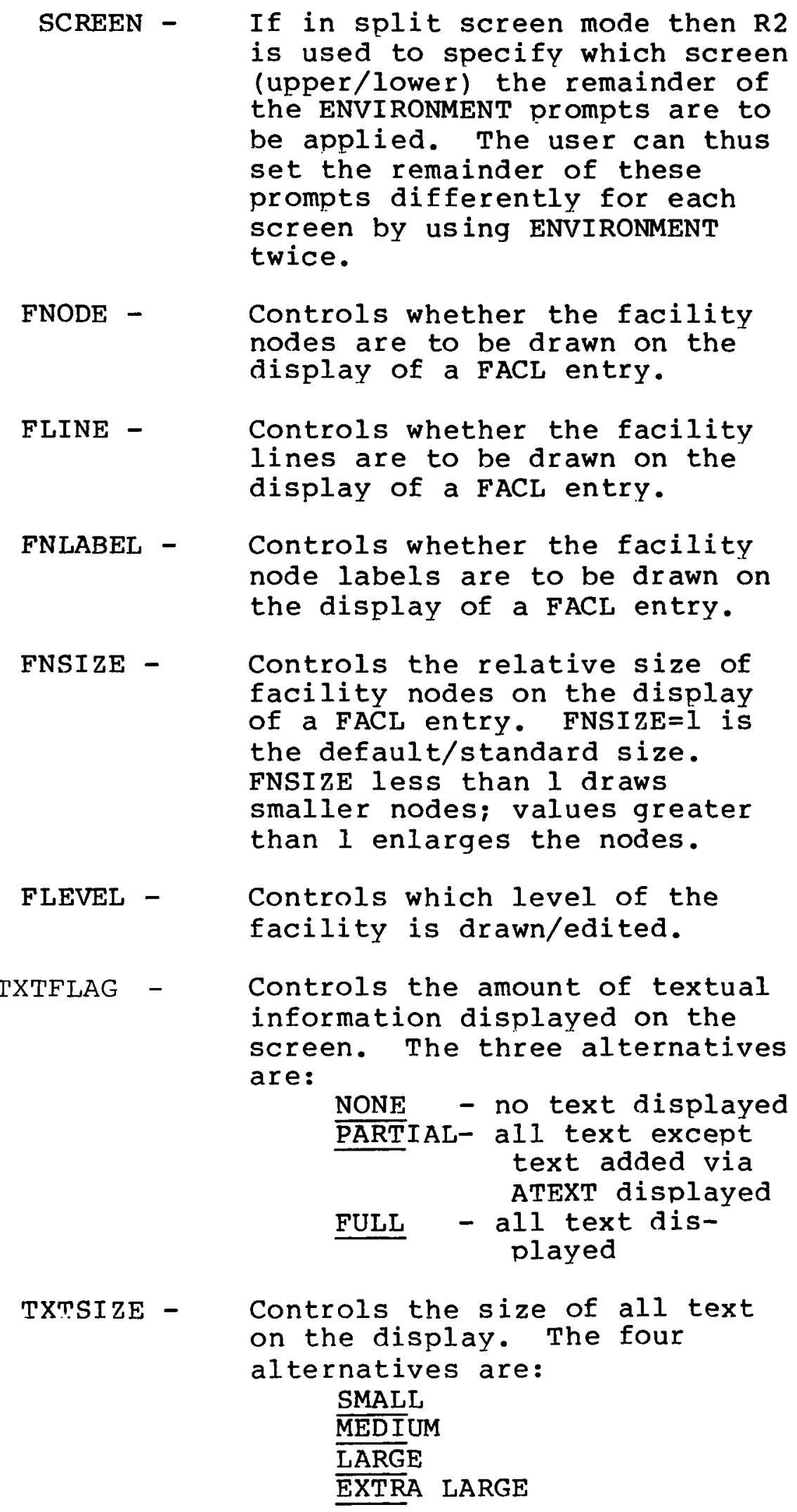


COMMAND :

PROCESSOR :

PROMPTS/UNIVERSE :

PROMPTS

CMND $=$

[RI]
HELP , CMND = R I

EDIT

UN IVERSE

any of the 35 EDIT command names
DFF AULT $\quad$ NOTES

display all $\mathbf{E}$ available commands

DESCRIPTION :

HELP is used to either get a list of all of the commands available from the current level or to get specific information on a certain command. If no prompts are entered on the command line then a list of the available commands is printed. If Rl is specified then just the description of that command is displayed. 
COMMAND :

PROCESSORS :

PROMPTS/UNIVERSE :

PROMPTS

$\mathrm{BRANCH}=[\mathrm{R} I]$

POINTS $=[\mathrm{R} 2]$
MBRANCH , BRANCH $=\mathrm{R} 1, \mathrm{POINTS}=\mathrm{R} 2$

EDIT

UN IVERSE

any existing branch

DEFAULT

NOTES

$\mathrm{N} / \mathrm{A}$

$\mathrm{P}$

$\mathrm{N} / \mathrm{A}$

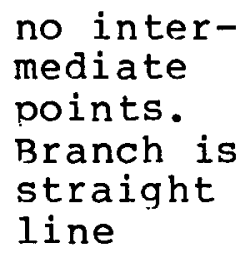

no intermediate points. Branch is straight line

DESCRIPTION :

MBRANCH allows the user to redfine the graphical representation of an existing branch. The user first points to the first line segment of the desired branch. The specified branch's line segments and points may then be redefined by pointing. The SNAP parameters of the branch are not affected by this command. 
$\underline{\text { EDIT/MERGE }}$

COMMAND :

PROCESSORS :

PROMPTS/UNIVERSE :
$\mathrm{MERGE}, \mathrm{FLBL}=\mathrm{R} 1, \mathrm{SIZE}=\mathrm{R} 2, \mathrm{LOC}=\mathrm{R} 3$

EDIT

$\begin{array}{lllll}\text { PROMPTS } & & \text { UNIVERSE } & \text { DEFAULT } & \text { NOTES } \\ \text { FLBL }= & {[R 1]} & \begin{array}{l}\text { any facility node } \\ \text { label }\end{array} & \text { N/A } & \text { E } \\ \text { SIZE }= & {[R 2]} & \text { numeric value } & 2 & \mathrm{E} \\ \text { LOC }= & {[R 3]} & \mathrm{N} / \mathrm{A} & \mathrm{N} / \mathrm{A} & \mathrm{P}\end{array}$

DESCRIPTION :

MERGE is a high level command that creates a 3 node, 2 branch SNAP subnetwork which merges a forces of size R2 or greater at facility location Rl. The network created bv MERGE is:

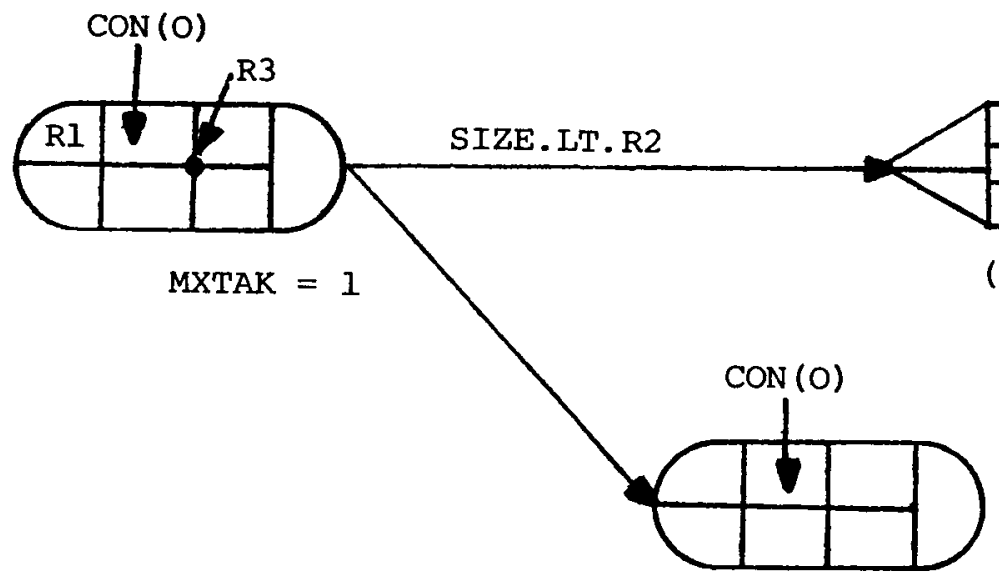

Figure 6.8. The EDIT/MERGE Modular Subnetwork.

Once the MERGE module is created, it is the user's responsibility to add branches, using the ABRANCH command, to the input side (left TASK node) and output side (right TASK node) of the module. Then, during the SNAP simulation, forces which arrive to the module and will be accumulated at the WAIT node until a force of size $R 2$ has been created after which the merged force will proceed through the "exit" TASK node. The network module created by MERGE will be graphically positioned on the screen such that the left TASK node is centered at R3. 
COMMAND :

PROCESSORS :

PROMPTS/UNIVERSE :

PROMPTS

NODE $=\quad[R I]$

$\mathrm{LOC}=[\mathrm{R} 2]$

DESCRIPTION :
MNODE , NODE $=\mathrm{R} 1, \mathrm{LOC}=\mathrm{R} 2$

EDIT

\section{UN IVERSE}

any existing node

$\mathrm{N} / \mathrm{A}$
DEFAULT

$\mathrm{N} / \mathrm{A}$

$\mathrm{N} / \mathrm{A}$
NOTES

E

$\mathbf{P}$
MNODE is used to graphically reposition node RI at a specified location R2 on the screen. Immediately after the new position is specified the node will be drawn at that location. The old copy of the node will remain on the screen until the next use of the DRAW command. The node's parameters are not affected by the MNODE command. Also, when the node is redrawn at position R2, all branches terminating at and emanating from node Rl will have the line segment adjacent to node RI redrawn. Any text owned by the moved node is also automatically moved (see ATEXT). 
COMMAND :

PROCESSOR :

PROMPTS/UNIVERSE :

PROMPTS

$\mathrm{TLOC}=[\mathrm{RI}]$

$\mathrm{NLOC}=$

DESCRIPTION :
MTEXT , $\mathrm{TLOC}=\mathrm{R} I, \mathrm{NLOC}=\mathrm{R} 2$

EDIT

\section{UN IVERSE}

DEF AULT

NOTES

the location of any user textual information currently displayed

$\mathrm{N} / \mathrm{A}$

$P$

$\mathrm{N} / \mathrm{A}$

$\mathrm{N} / \mathrm{A}$

P

MTEXT is used to move existing text on an EDIT display to a new location. As with DTEXT, the text to be moved is specified by pointing at the lower left screen location where it begins, Rl. The new location for the text is also specified via pointing, R2. If the indicated text consists of multiple lines, all are moved. 
COMMAND :

PROCESSOR :

PROMPTS/UNIVERSE :

$\frac{\text { PROMPTS }}{\text { NUMBER }}[R 1]$
SCREEN $=[R 2]$

DESCRIPTION:
PAGE , NUMBER=RI [, SCREEN=R2]

EDIT

\section{UN IVERSE}

integer values other than $0(I, J)$

point to upper or lower screen

\section{DEFAULT $\quad$ NOTES}

current $\quad \mathrm{E}$

values

$\mathrm{N} / \mathrm{A}$

$\mathbf{P}$
The size of a SNAP network created by EDIT is graphically unbounded. That is, SNAP networks created by EDIT are drawn in a virtual space, any portion of which may be displayed on the upper, lower, or full screen.

The EDIT user has full control over the portion of the virtual network display on the screen at any particular time except that EDIT automatically maintains the $X-Y$ scale ratio to the same $X-Y$ scale ratio as that of the screen display area. The PAGE command facilitates "moving around" in the virtual space by structuring virtual space into an addressable grid. This grid structure is shown in Figure 6.9 


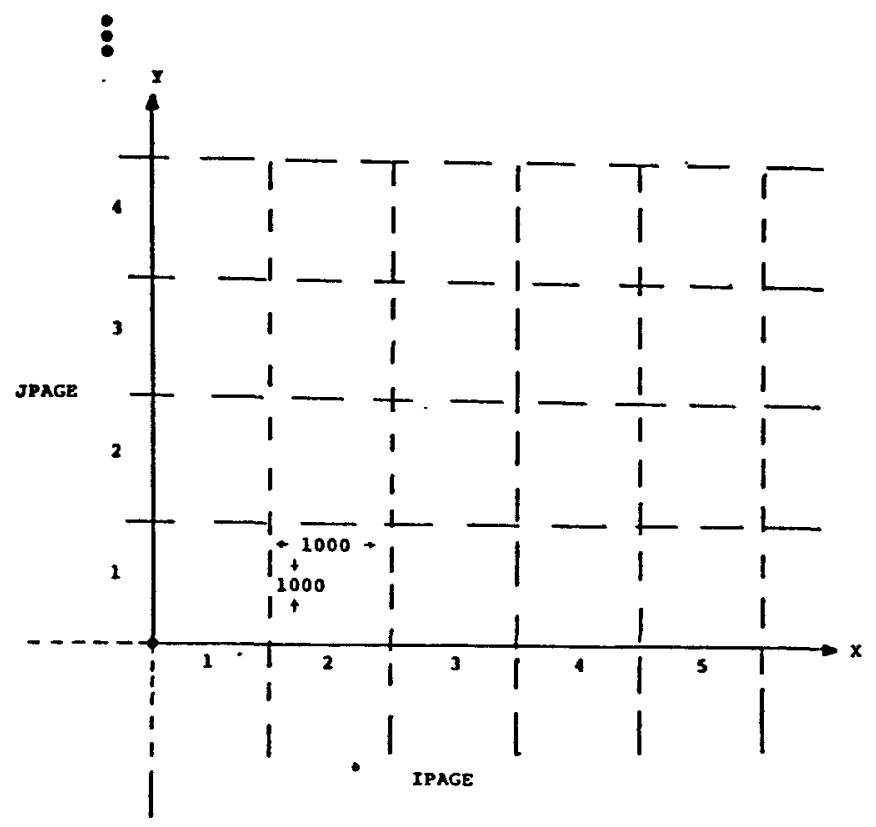

Figure 6.9. The EDIT Graphical Paging System.

Each square of the virtual grid is termed a page and each page is referenced by two integer numbers: the I-page number and the $\mathrm{J}$-page number. The value of $\mathrm{RI}$ of the PAGE command is the I-PAGE and J-PAGE reference numbers desired. EDIT starts in PAGE number 1,1 . Page numbers include all non-zero integer numbers within the range of the host computer. The user may easily move from page to page simply by using the PAGE command followed by the DRAW command. The current page numbers are always displayed in the upper right-hand corner of the relevant screen display. In split screen mode, the user must also specify R3 for which screen display area the new page definition is to apply. For example, if $\mathrm{ADV}-1$ is being edited and GUA-1 is being displayed on the lower screen, and the PAGE command is invoked, the user must specify both the new page reference number and for which entry (upper/lower) this page request is to be applied. In split screen mode, the specified page $R I$ and the page immediately to its right are displayed simultaneously for symmetry purposes.

EXAMPLE:

1. page, numb $=3,4$

2. page NUMBER $=-1,3$ 
COMMAND :

PROCESSORS :

PROMPTS/UNIVERSE :
$\mathrm{PATH}, \mathrm{PNAME}=\mathrm{R} 1, \mathrm{FLOCS}=\mathrm{R} 2, \mathrm{PINVL}=\mathrm{R} 3, \mathrm{SENTRY}=\mathrm{R} 4$, $\mathrm{LOC}=\mathrm{R} 5$

EDIT
PROMPTS

PNAME $=$

[RI]

FLOCS $=[R 2]$

PINVL $=[R 3]$

SENTRY $=[R 4]$

$\mathrm{LOC}=$

$[\mathrm{R} 5]$
UN IVERSE

max. of 4 char. except existing PATH names

list of facility node labels

any valid TASK node $\operatorname{CON}(0.0)$ INVL

entry name (e.g. STAT- 27

$\mathrm{N} / \mathrm{A}$
DEFAULT

$\mathrm{N} / \mathrm{A}$

$\mathrm{N} / \mathrm{A}$

E

E

E

$\mathrm{N} / \mathrm{A}$

$\mathrm{N} / \mathrm{A}$

P

DESCRIPTION :

PATH allows the user to construct a guard or adversary bi-directional path segment that traverses any number of specified facility locations R2. The user must specify a path segment name RI which also becomes a FORCE FLAG for direction control. This FORCE FLAG is automatically added to the STAT entry specified in R4. A path segment consists of one TASK node to traverse each facility location to be traversed plus two additional TASK nodes for controlling inter-path segment branching. The user also specifies a single INVL, R3, to be used as the time to traverse each facility location specified. The user must also specify the screen location for the center of the first TAsK node of the path segment. A path segment named "PTHI" which traverses five locations is shown in Figure 6.10 . 
LDIP PATH

PMATE: PTHI

rLOCS. 1,2.3.4.5

PINYL CONT12

LOC ËEO PATH SECMENT PTHI EC? YIL

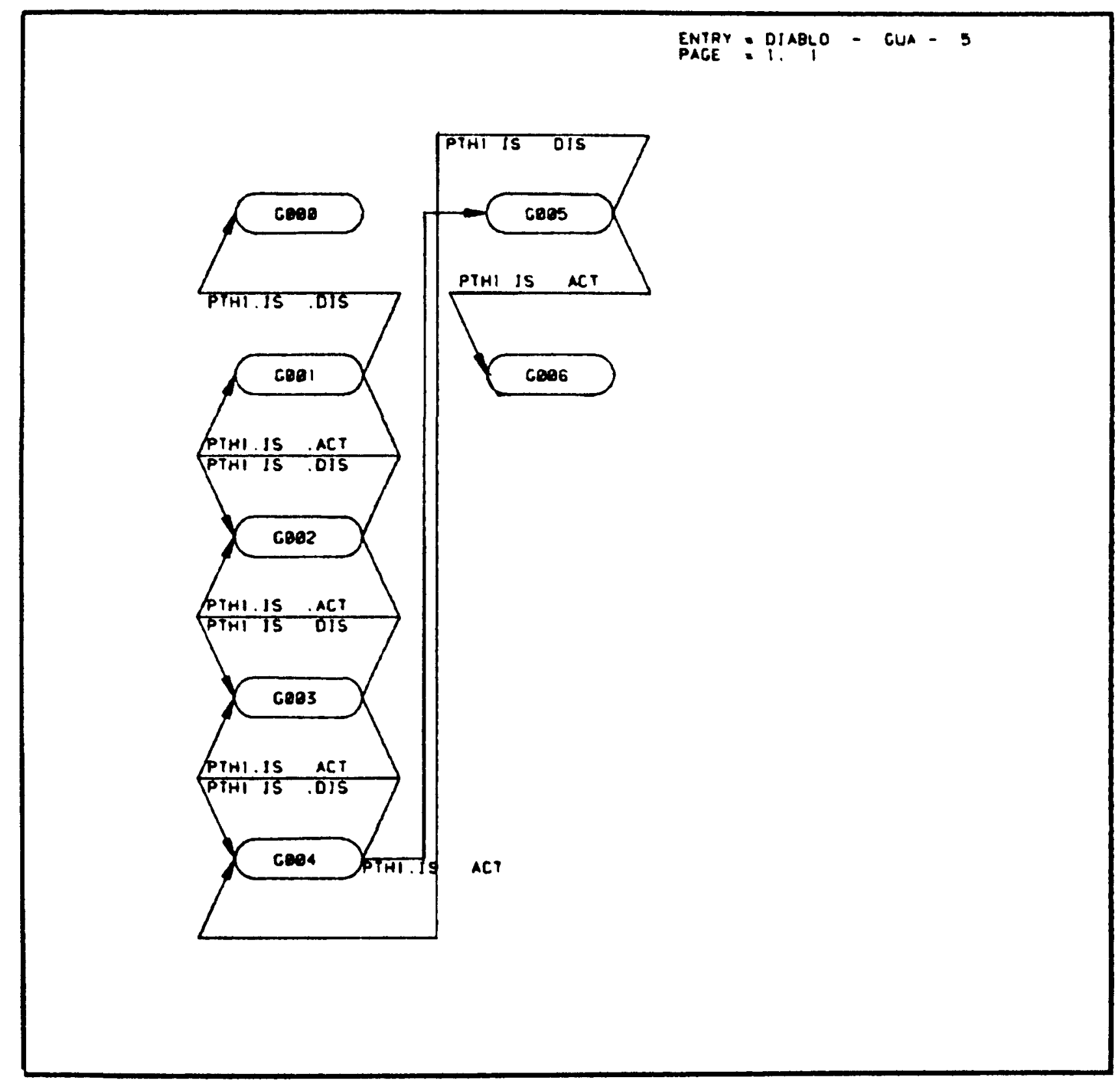

Figure 6.10. Example Edit Path Segment. 
COMMAND :

PROCESSORS :

PROMPTS/UNIVERSE : PROMPTS

TOA $=[R I]$

$F L B L=\quad[R 2]$

$\mathrm{BLBL}=\quad[\mathrm{R} 3]$

SIZE $=$

[R4]

$\mathrm{TRIG}=\quad[\mathrm{R} 5]$

PSEGS $=$

[R6]

$\mathrm{LOC}=$

[R7]

DESCRIPTION :
PATROL, $T O A=R 1, F L B L=R 2, B L B L=R 3, S I 7 E=R 4$, $\mathrm{TRIG}=\mathrm{R} 5, \mathrm{PSEGS}=\mathrm{R} 6, \mathrm{LOC}=\mathrm{R} 7$

EDIT

\section{UNIVERSE}

DEFAULT

NOTES

numeric value

0.0

E

any facility node label

$\mathrm{N} / \mathrm{A}$

E

any BASE element label

$\mathrm{N} / \mathrm{A}$

E

numeric, GV

1

E

any WAIT node trigger

SIGNAL

E

see path segments description

$\mathrm{N} / \mathrm{A}$

$\mathbf{E}$

$\mathrm{N} / \mathrm{A}$

P

PATROL is used to allocate guards from existing guard base, R3, and send them to patrol a specified series of linked path segments, R6, beginning at time Rl. The number of guards to go on the patrol is also specified, R4. The initial facility location of the guards is also specified, R2, as is the screen location of the center of the ENTER node, R7. After the guard force has completed the specified patrol it waits at a SNAP WAIT node until trigger R5 occurs. When released the guard force begins the same patrol again. The quard network segment automatically constructed by the PATROL command is shown in Figure 6.11. 


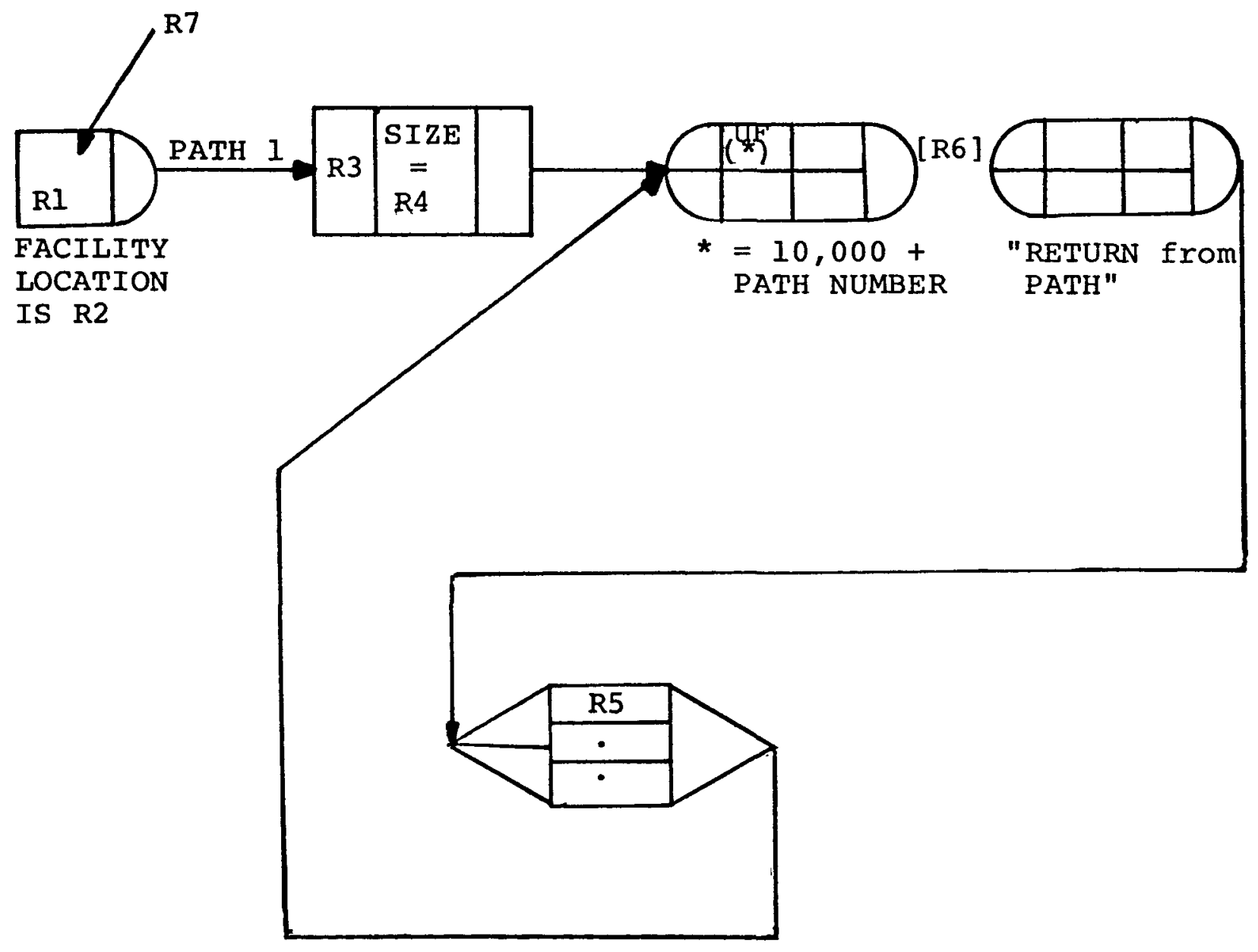

Figure 6.11. The EDIT/PATROL Modular Subnetwork. 
COMMAND :

PROCESSOR :

PROMPTS/UNIVERSE :

DESCRIPTION :
QUIT

EDIT

None

QUIT exits the current level of sos. The QUIT command is a general command that may be used to exit any level of the SNAP Operating system including the sos itself. If the user is currently in the ATREE mode then control is returned to the primary EDIT mode. If the user is currently in the primary EDIT mode, then control is returned to the sos EXECUTIVE level after the screen is erased. 
COMMAND :

PROCESSOR :

PROMPTS/UNIVERSE :

PROMPTS

ENTRY $=[R I]$
SELECT,$E N T R Y=R 1$

EDIT

\section{UNIVERSE}

entry of type ADV FACL, GUA, Or STAT

\section{DEF AULT}

$\mathrm{N} / \mathrm{A}$

NOTES

E

DESCRIPTION :

SELECT is used to change the current entry being edited. The entry specified must be type GUA, ADV, FACL, or STAT. If the entry specified does not exist SELECT will automatically create a new entry of the specified name. The DRAW command should he used to reset the display after using the SELECT command. The name of the entry being edited is displayed in the upper right hand corner of the appropriate screen window. The current site may not be changed using the EDIT/SELECT command. The user must "QUIT" the editor to change the current site. 
COMMAND :

PROCESSOR :

PROMPTS :

DESCRIPTION :

NOTES :

\section{SKETCH}

EDIT

D - DASHED, M - MOVE, Q-QUIT

S - SOLID, R - REMOVE, T - TIC

SKETCH is used when editing a SNAP facility diagram to add and remove lines from the facility diagram. The command begins by displaying the menu of available options. Lines are added by pointing to the desired end point of the line and depressing either "D", "M", " $S$ ", or "T". Lines are removed from the diagram by pointing to the desired Iine and depressing an " $R$ " for remove. The SKETCH command is exited by typing a "Q" for QUIT.

As an example, to add a solid line, move the cursor to the start point and depress "M". This sets the initial point. Then move the cursor to the end point and depress "S". A solid line will be drawn from the initial point to the end point. "D" or "T" could have been depressed to draw a dashed or ticked line, respectively. The end point of the last line becomes the initial point of the next line, so to draw another line from the end point of the last line to a new point, move the cursor to the desired point and depress "S" again. 


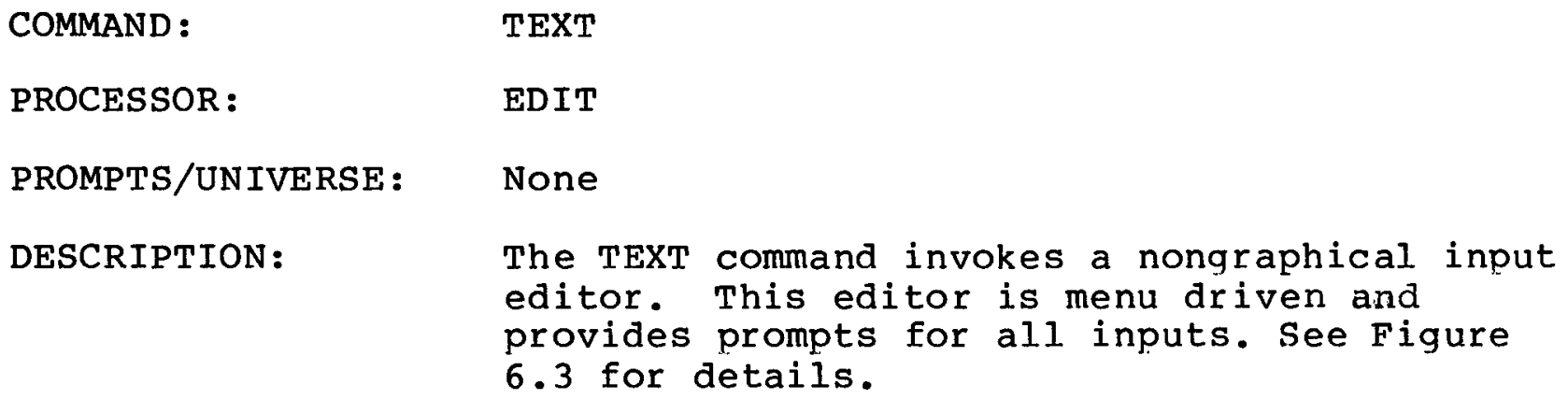


COMMAND :

PROCESSORS :

PROMPTS/UNIVERSE :

\section{UN IVERSE}

Numeric

$\mathrm{LOCl}=$

$[R]$

$\mathrm{LOC} 2=$

SCREEN =

Numeric
$\mathrm{N} / \mathrm{A}$

$\mathrm{N} / \mathrm{A}$

DEF AULT

$\mathrm{N} / \mathrm{A}$

$\mathrm{N} / \mathrm{A}$
DESCRIPTION :

EXAMPLES :
VIEW , LOC $1=\mathrm{R} 1, \mathrm{LOC} 2=\mathrm{R} 2[, \mathrm{SCREEN}=\mathrm{R} 3]$

EDIT
$\mathbf{E}$

$\mathbf{E}$

$p$, only if in split screen mode
VIEW allows the user to define what portion of the virtual space is to be shown on the screen The responses $\mathrm{R} 1$ and $\mathrm{R} 2$ are the coordinates of two diagonal corners of a rectangular area to be shown on the screen. If the screen is split the user must also specify R3 the screen window to be affected. The specified rectangular area will be adjusted so that its $X-Y$ scale ratio is the same as the $X-Y$ scale ratio of the screen window. The VIEW command provides an alternative to the PAGE command and is useful for "zooming out". VIEW must be used when it is desired to display more than one page on the screen. The page specified on the screen is the page in which the lower left corner of the displayed area resides.

VIEW, LOC $1=500,500, \operatorname{LOC} 2=2500,2500$ 
COMMAND :

PROCESSORS :

PROMPTS/UNIVERSE :

PROMPTS

SCREEN $=[R I] \quad N / A$

$\mathrm{LOCl}=[\mathrm{R} 2] \quad \mathrm{N} / \mathrm{A}$

$\mathrm{N} / \mathrm{A}$

LOC $2=$

[R3]

DESCRIPTION :

EDIT
$\mathrm{ZOOM}[, \mathrm{SCREEN}=\mathrm{RI}], \mathrm{LOC} \mathrm{l}=\mathrm{R} 2, \mathrm{LOC} 2=\mathrm{R} 3$

\section{UN IVERSE}

\section{$\underline{\text { DEF AULT }}$}

$\mathrm{N} / \mathrm{A}$
NOTES

$P$, only

if split screen mode

$\mathbf{P}$

$\mathrm{P}$
zoOM allows the user to zoom-in on the current graphical display. That is, it allows the user to redefine what portion of the current display is to be shown on the screen. This is accomplished by first specifying, if in split screen mode, which screen window is to be affected and then pointing to diagonal corners of the rectangular area to be shown on that screen. Thus, if in full screen mode, the user simply points to two diagonal corners of the desired area and if in split screen mode, first specify the desired window, then point to the two desired points. The DRAW command must be used to redraw the display before the affects are noted. The user should not use the zOOM command repeatedly on the same screen window without intervening DRAWS. See also the PAGF and VIEW commands. 


\title{
SECTION VII \\ SNAP DATA INPUT RECORD GENERATOR (DATA)
}

\begin{abstract}
In order to minimize storage and data transfer requirements, the sos library processor stores only graphical information and the associated data for each node. To run the models developed using sos, the user is required to generate SNAP data records using the DATA command. This command will create a file which contains the necessary data to be supplied to the SNAP analysis program. This file is then read by SNAP and executed to provide information about the performance of the system.

As indicated by the command hierarchy shown in Figure 7.1, there are no subcommands in the DATA command. The DATA command syntax and definition of the various command parameters is also provided in this section. Prior to executing the DATA command, the user should have initialized the sos library containing the scenario of interest via the appropriate ASSIGN, SELECT, ADSCEN, and LINK commands.
\end{abstract}




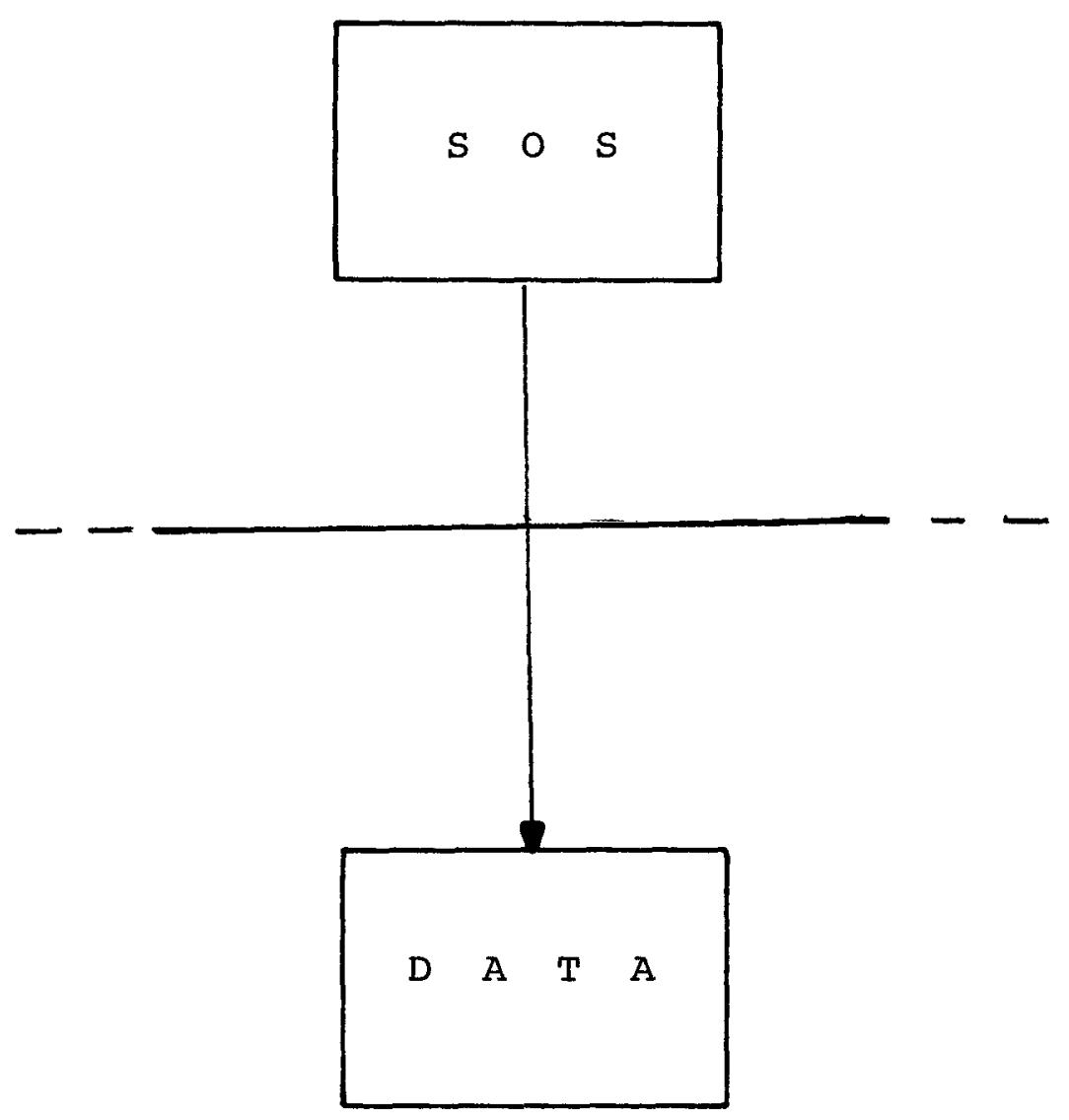

Figure 7.1. DATA Command Hierarchy. 
DATA Command Description

COMMAND :

PROCESSOR :

PROMPTS :

DESCRIPTION :

DEF AULTS :

EXAMPLES :
DATA , SCNR=R1, FILE=R2, REWIND=R3

\section{DATA}

$$
\begin{array}{lll}
\text { P1 - SCNR } & \text { [R1] } & \text { (Scenario name) } \\
\text { P2 - FILE } & \text { [R2] } & \text { (File name for data) } \\
\text { P3 - REWIND [R3] } & \text { (Yes or No) }
\end{array}
$$

DATA will create SNAP data cards from the scenario Rl on file R2. If R3=Y, the file will be rewound prior to writing on it. An end of file mark is written on file R2 after the data cards have been written to the file. Scenario Rl must contain one (and only one) ADV, GUA and FACL entry. It may also contain one STAT entry. The user will be advised if the scenario also contains a USER entry. USER entries must be written to another file (or to file R2) with the WRITE command. Entries of type OTHR and TRAC are ignored by DATA. DATA will prompt the user for parameters on the SNAP card and the TRACE card.

$$
\begin{aligned}
& \text { R1 - N/A (a scenario specification) } \\
& \text { R2 - N/A (a file name) } \\
& \text { R3 - N/A (must be "Y" or "N") } \\
& \text { data, scnr=reac-scen- } 2 \text {,file=snapf, } \\
& \text { rewi=y }
\end{aligned}
$$


SECTION VIII

SNAP OUTPUT ANALYZER (ANALYZE)

The SNAP Output Analyzer of sos is provided to assist the user in the debugging and analysis of SNAP models. The capabiliy provided permits the user to review the SNAP trace output graphically in an interactive mode. ANALYZE is a tool to aid in the understanding and debugging of SNAP simulation models. The package is used in a post-run mode to analyze the simulated guard/adversary movement through the facility. The user observes the various movements and interactions and thereby verifies model accuracies and/or programmed strategies.

The package is used solely as an output analyzer. It is not designed to operate in an interactive run-time mode permitting the modeler to make changes based on current system status. It will however permit post-run interactive decisions pertaining to the options regarding the viewing of the trace output.

The ANALYZE processor is invoked by the command

ANALYZE , FENTRY=RI, TENTRY=R2, RUN=R3

where Rl is the name of the facility entry to be used (e.g., FACL-1), R2 is the name of the trace entry (e.g., TRAC-1) into which the SNAP graphical trace has previously been 
read, and $\mathrm{R} 3$ is the run number to be illustrated during this session. The default run number lised is 1 if $R 1$ and/or $R 2$ are specified on the command line. ANALYZE will prompt the user for $\mathrm{R} 1$ and $\mathrm{R} 2$ if they are not included on the command line.

Upon entering ANALYZE the graphics screen is erased, the ANALYZE version date is displayed, and the prompt signaling ANALYZE is ready for the next command appears. This prompt is:

ANA*

There are nine commands within ANALYZE which permit the user to control the viewing of the SNAP trace output and these commands are shown in Figure 8.1. They include capabilities to draw or redraw a user specified level of the facility (DRAW), to display the current facility locations for force positions (POST), display a predefined increment of the simulation results (GO), exit ANALYZE (QUIT), and a variety of other functions for controlling the display. Each of these commands is discussed in detail in the command description section of this section.

The ANALYZE graphics display is divided into two sections in a manner similar to EDIT. The left side of the screen will request user responses at decision display points, accept user responses, and print informative messages when necessary. The right side of the screen is 


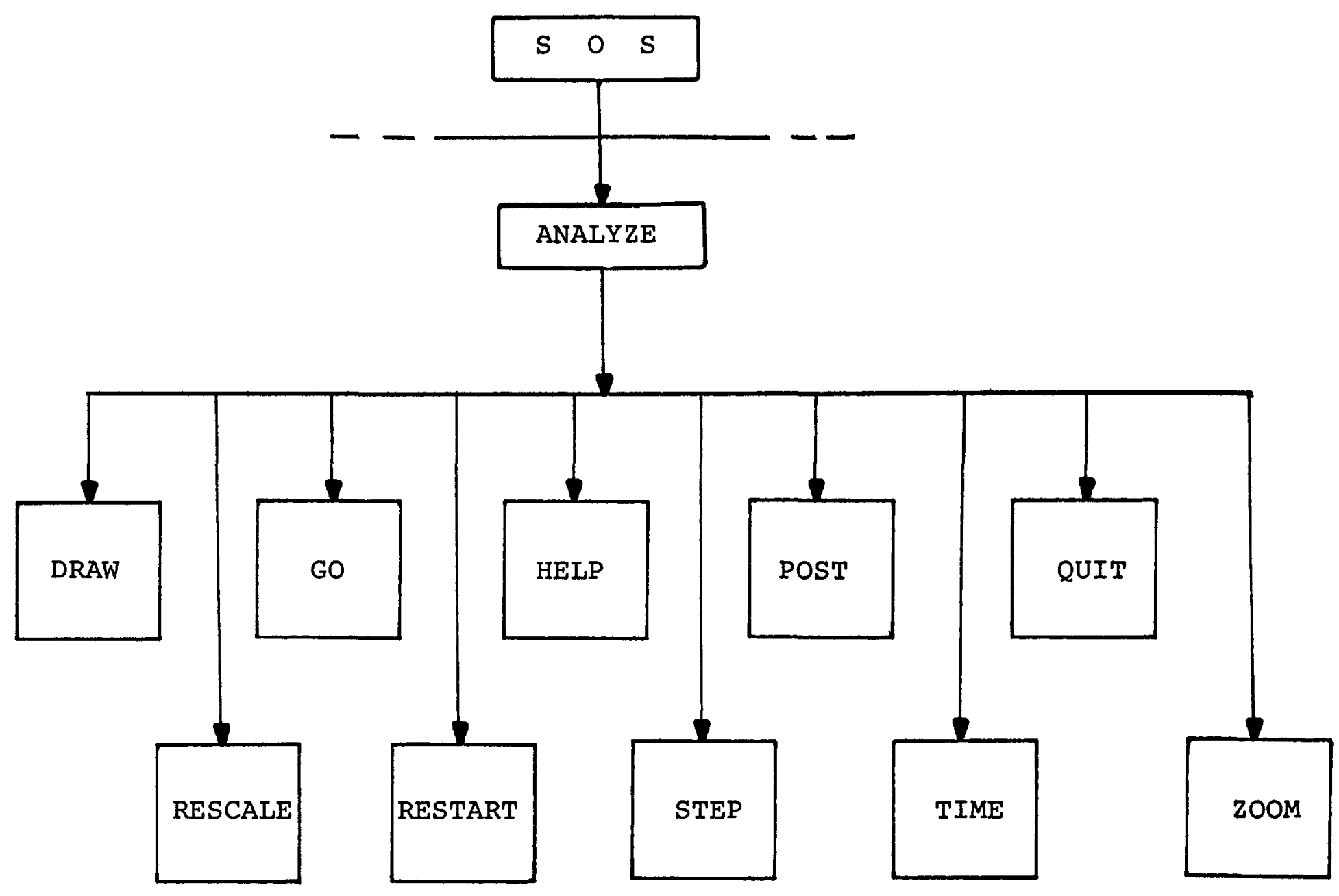

$\stackrel{5}{0}$

Figure 8.1. ANALYZE Command Hierarchy. 
used to display the facility diagram on which guard and adversary movement is illustrated.

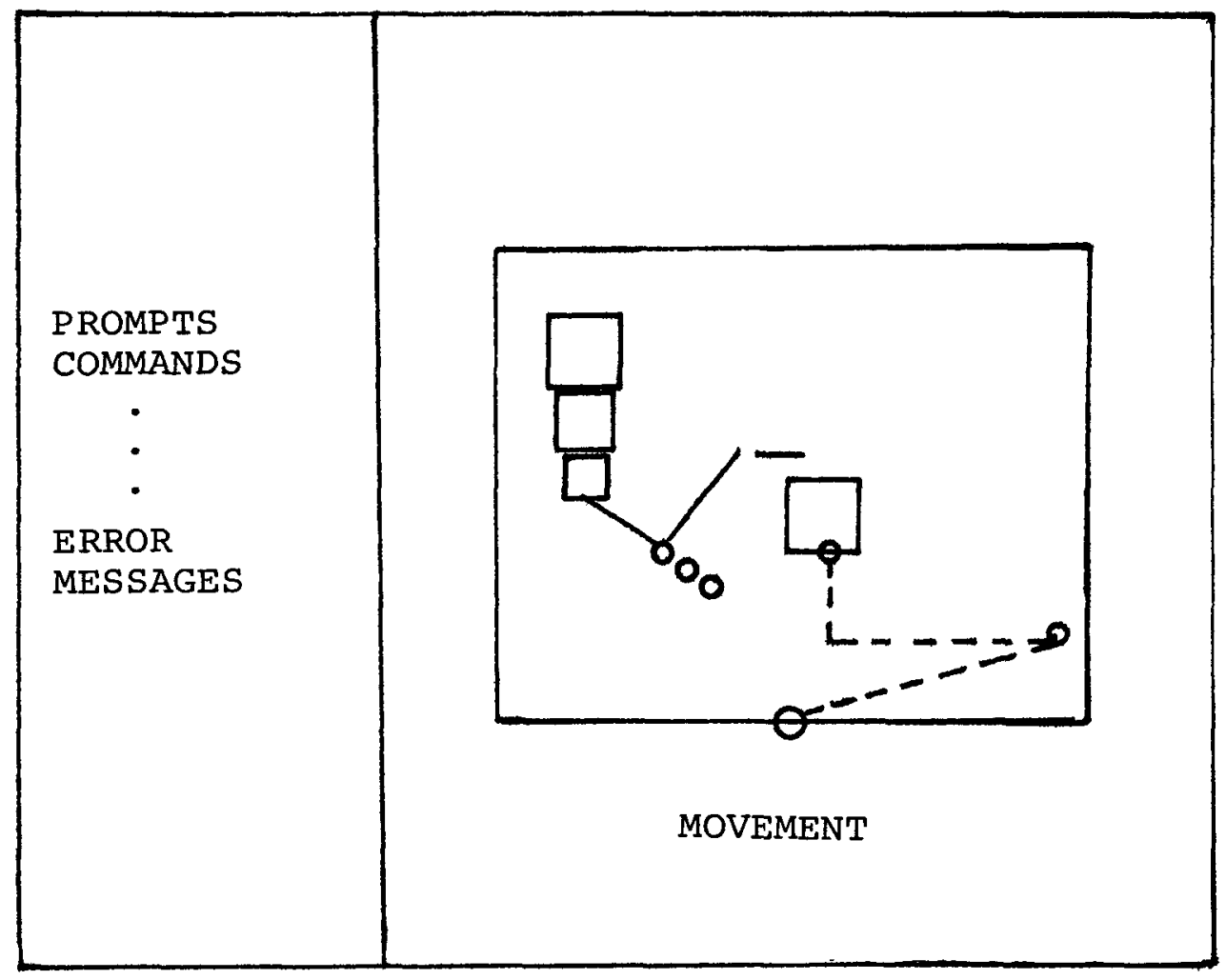

Figure 8.2. ANALYZE Screen Configuration.

Like EDIT, ANALYZE is based on non-refresh or storage tube graphics technology and thus has limited capability to show force movement and to modify display content. It is the user's responsibility to redraw the current display via the DRAW command whenever an up-to-date, uncluttered display is desired. The user may wish to use the POST command after each DRAW to show the current force position(s) and/or detailed facility locations. 
Since ANALYZE is a non-refresh output illustrator, it illustrates the SNAP output trace in steps. A display step is defined as either a number of SNAP events or as a simulation time interval. The user controls the current step definition via the STEP command.

This step size defines the amount of simulation output to be illustrated at the next use of the GO command. The GO command instructs ANALYZE to illustrate the next increment of the simulation beginning at the current simulation time. To review a previously illustrated simulation period the RESTART command must be used to reset the simulation clock back to time zero. Figure 8.3 shows the symbology used to illustrate a SNAP simulation.

\section{ANALYZE Command Syntax and Conventions}

ANALYZE commands are inherently less complex than the SOS library manipulation and EDIT commands. This is because much less information is required from the user to illustrate SNAP results. Because of this feature, the ANALYZE processor àlways prompts for needed information and does not allow this information to be entered directly on the command line as in the rest of SOS. ANALYZE is thus very easy to operate and requires only that the user know the various ANALYZE command names to operate it. Care should be taken however in specifying the FACL and TRAC 
SYMBOL

ID
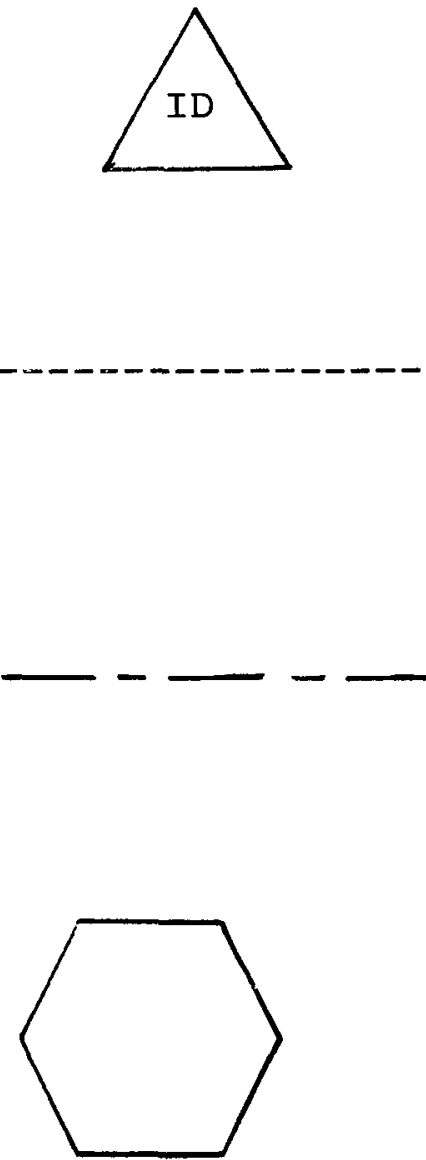

DEFINITION

The guard force symbol specifying the force identifier.

The adversary force symbol specifying the force identifier.

A line indicating guard/adversary movement through the facility.

A line indicating an engagement is underway between a guard and adversary force.

A symbol that is drawn around a guard or adversary symbol when the surrounded force has been neutralized.

Figure 8.3. ANALYZE Symbology. 
entries to be used. It is the user's responsibility to make sure that the specified facility entry was the same facility entry used by SNAP when it created the trace entry currently being used. 
ANALYZE Command Descriptions

ANALYZE/DRAW

COMMAND :

PROCESSOR :

PROMPTS :

DESCRIPTION :

DEF AULTS :
DRAW

ANALYZE

Pl - LEVEL NUMBER [RI] (Facility

level

number)

The DRAW command clears the graphics screen and draws or redraws level RI of the facility diagram using the current graphics window definition. The DRAW command should be used to maintain a display relatively uncluttered of old commands, prompts, and unnecessary graphics that are inherent in using non-refresh graphics systems.

Rl - The current facility level if defined, otherwise level number 1 . 
COMMAND:
PROCESSOR :

PROMPTS :

DESCRIPTION :

DEF AULTS :

NOTE:
GO

ANALYTE

NONE

The Go command initiates the illustration of guard and adversarv movement through the facility diagram. The command will illustrate the predefined number of steps (events or minutes) of the simulation. The current value and definition of the step size is defined by the user through the command STEP.

NONE

A response of $C / R$ is identical to typing the GO command. 


\section{ANALYZE/HELP}

COMMAND :

PROCESSOR :

PROMPTS :

DESCRIPTION :

DEFAULTS :
HELP

ANALYZE

$C M N D=[R 1]$ (ANALYZE command name)

HELP is used to either get a list of all of the commands available from the current level or to get specific information on a certain command. If the response $\mathrm{Rl}$ is blank then a list of the available commands is printed. If $R I$ is specified then just the description of that command is displayed.

List all available commands at this level of sos. 
COMMAND :

PROCESSOR :

PROMPTS :

DESCRIPTION :

DEFAULTS :
POST

ANALYZE

Pl - OPTION (LBL/DRW) [RI] (LBL - facility labels; DRW - force locations)

If Rl is "DRW" the POST command displays the current position of all active guard and adversary forces by drawing their symbol at the appropriate location on the facility diagram. This command will post guard/adversary positions at their last executed position. If RI is "LBL", the POST command draws all space, barrier and target node labels on the facility diagram.

NONE 


\section{ANALYZE/QUIT}

COMMAND :

QUIT

PROCESSOR :

ANALYZE

PROMPTS :

NONE

DESCRIPTION :

QUIT exits the ANALYZE processor after erasing the graphics screen and returns control to the SOS EXECUTIVE.

DEF AULT S :

NONE 
ANALYZE/RESCALE

COMMAND :

PROCESSOR :

PROMPTS :

DESCRIPTION :

DEF AULT S :
RESCALE

ANALYZE

NONE

RESCALE is used to reset the graphics window definition. ANALYZE assumes that this default window definition contains the entire facility diagram and that the ZOOM command will be used if a smaller portion of the facility is to be displayed. The RESCALE command simply permits the user to return to the original size after using the ZOOM command without effecting other ANALYZE parameters. RESCALE erases the current display but does not automatically redraw so that the user may first use other ANALYZE commands to alter the graphics display.

NONE 
COMMAND :

PROCESSOR :

PROMPTS :

DESCRIPTION :

DEF AULT $S:$
RESTART

ANALYZE

NONE

The RESTART command restarts the ANALYZE package as if it were just invoked from the SOS EXECUTIVE. The command rewinds all of the data files including the TRAC and FACL entries associated with the scenario specified to be illustrated. It also resets all system variables to the initial default values. The command can be used to restart ANALYZE without exiting (QUITing) the output package and then reinvoking it. The RESTART command erases the current display, and then prompts the user for his next command.

NONE 
ANALYZE/STEP

COMMAND :

PROCESSOR :

PROMPTS :

DESCR IPTION :

DEF AULTS :
STEP

ANALYZE

$\mathrm{P} 1$ -
STEP TYPE (COU/TIM) [R1]
(COUnt or TIMe)
P2 - TIME/COUNT STEP SIZE [R2]
(desired step size)

The STEP command is used to redefine the amount of simulation output to be illustrated upon the next use of the Go command. After the Go command has illustrated the defined steps, it will pause and allow the user to intervene and use any of the ANALYZE commands. An extremely large value of the step size allows the GO command to illustrate the entire trace before user intervention. A step type of "COU" and step size of 1 allows ANALYZE to illustrate the SNAP output file 1 event at a time. This technique permits extremely detailed output trace analysis to be performed.

$\mathrm{RI}$ - "COU "

$R 2-5$ (5 events) 
COMMAND :

PROCESSOR :

PROMPTS :

DESCRIPTION :

DEF AULTS :
TIME

ANALYZE

NONE

The TIME command will illustrate the current simulated time that is in effect from the trace file at this point in the simulated run. The TIME command responds with the value of time last encountered in the trace file.

NONE 
ANALYZE/ZOOM

COMMAND :

PROCESSOR :

PROMPTS :

DESCRIPTION :
7OOM

ANALYZE

NONE

zoom allows the user to zoom in on a portion of the facility diagram currently displayed. After typing the command name, the user is prompted for two points which define the area of the current display to be mapped into the screen window. These two points are specified by pointing with the graphics cursor. The resulting virtual window definition remains in effect until the next use of either the ZOOM, RESTART, or RESCALE commands. ZOOM automatically erases the graphics screen and redraws the display using the new virtual window definition. 
SECTION IX

SUMMARY

This reference manual has been designed to be a procedures guide on the use of the SNAP Operating system. It provides the user with an easy-to-use reference on sos, its various commands, and their syntax.

A User's Guide to sos has been developed. This will support those just learning to use sos. Both documents assume a working knowledge of SAFE and SNAP. Detailed User's Guides on these documents are available $(2,3)$. 
186

REFERENCES 


\section{REFERENCES}

1. Sabuda, J., Polito, J., Walker, J., and Grant III, F. H., The SNAP Operating System User's Guide, Pritsker \& Associates, Inc., West Lafayette, IN, October 1981, ABQ008.

2. Grant III, F. H., Engi, D. and Chapman, L. D., User's Guide for SNAP, Sandia National Laboratories, Albuquerque, NM, JulY 1981, NUREG/CR-1246, SAND80-0315

3. Graphics Compatibility System (GCS), U. S. Army Engineer Waterways Experiment Station, Automatic Data Processing Center, P. O. Box 631, Vicksburg, Miss., 1975 (Revised 1979)

4. Primer on Computer Graphics Programming, U. S. Army Engineer Waterways Experiment Station, Automatic Data Processing Center, P. O. Box 631, Vicksburg, Miss., 1975 (Revised 1979)

5. Chapman, L. D., Engi, D., Grady, L. M. and Pavlakos, C., SAFE User's Manual, Vol. 1, Executive Summary, Sandia National Laboratories, Albuquerque, NM, October 1980, NUREG/CR-1246, SAND79-2247

6. Chapman, L. D., Engi, D., Grady, L. M. and Pavlakos, C., SAFE User's Manual, Vol. 2, Method Description, Sandia National Laboratories, Albuquerque, NM, August 1981, NUREG/CRI246, SAND79-2247

7. Chapman, L. D., Engi, D., Grady, L. M. and Pavlakos, C., SAFE User's Manual, Vol. 3, Example Application, Sandia National Laboratories, Albuquerque, NM, October 1980 , NUREG/CR-1246, SAND79-2247

8. Polito, Joseph, "FFIN2-FORTRAN 77 FormatFree Input Subprogram," Pritsker \& Associates, Inc., Albuquerque, NM, Report ABQ004, April 1981 (Revised July 1981) 
APPENDIX A 


\section{APPENDIX A \\ SOS COMMAND SYNTAX SUMMARY}

In this appendix the reader will find a summary of the following sos Command syntax summary.

Page

SOS EXECUTIVE Commands ................. 190

LIBRARY MANIPULATION Commands.............. 191

TRANSLATE Commands..................... 192

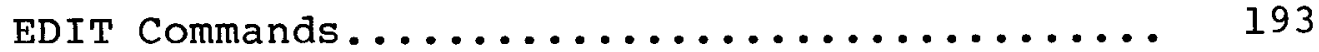

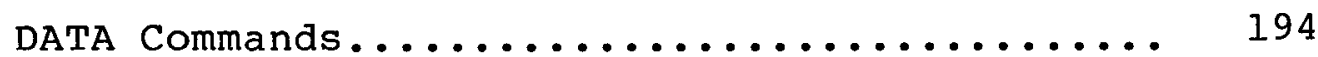

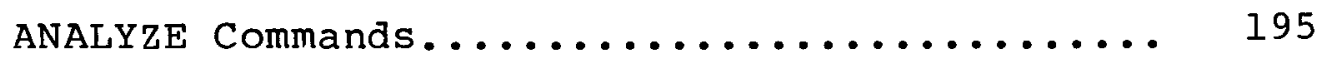




\section{SOS EXECUTIVE Command Lines}

\section{TRANSLATE}

EDIT, ENTRY $=$ RI

DATA , SCNR=RI, FILE=R2, REWI=R3，

ANALYZE , FENTRY=R1 , TENTRY=R2 , RUN=R3

QUIT 


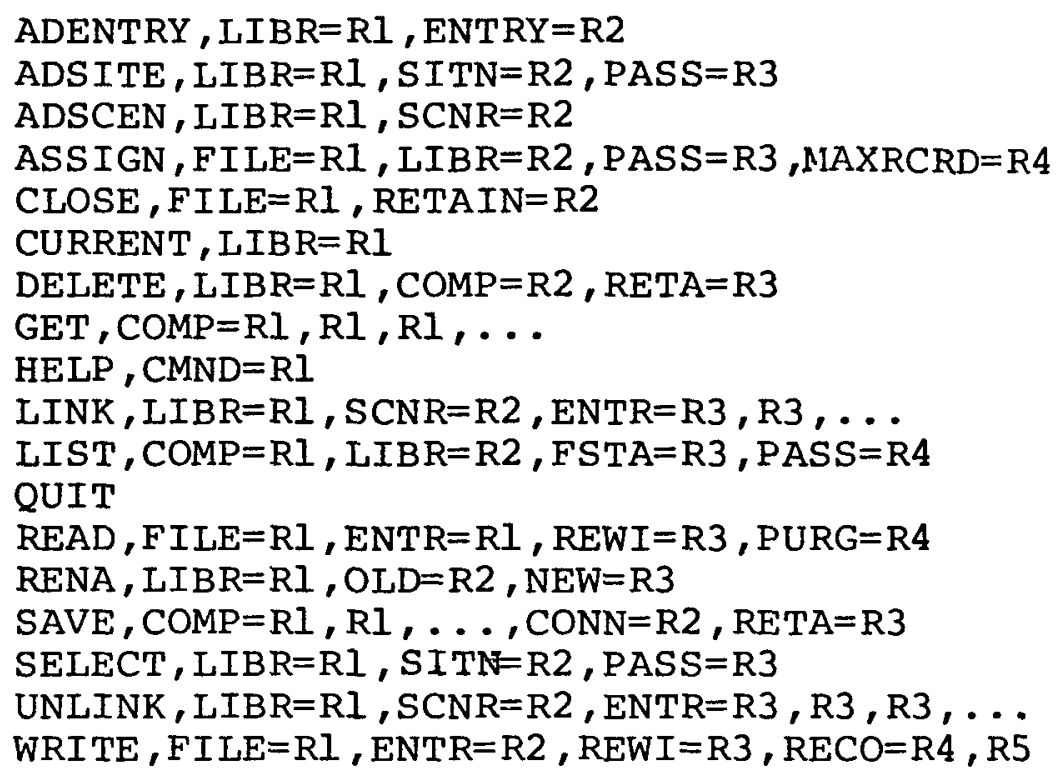


TRANSLATE Command Lines

\author{
GENADVERSARY , PATH=RI, ENTRY=R2, FACILITY=R3 \\ GENFACILITY, ENTRY $=$ RI \\ GENGUARD, PATH=R1, ENTRY=R2, FACILITY=R3 \\ HELP , CMND $=\mathrm{RI}$ \\ PRPATHS , TARGET $=\mathrm{R} 1, \mathrm{FACI} L I T Y=R 2$ \\ PRTARGETS , FACILITY=R1 , NEW=R2 , TYPE=R3 \\ QUIT
}


EDIT Command Lines

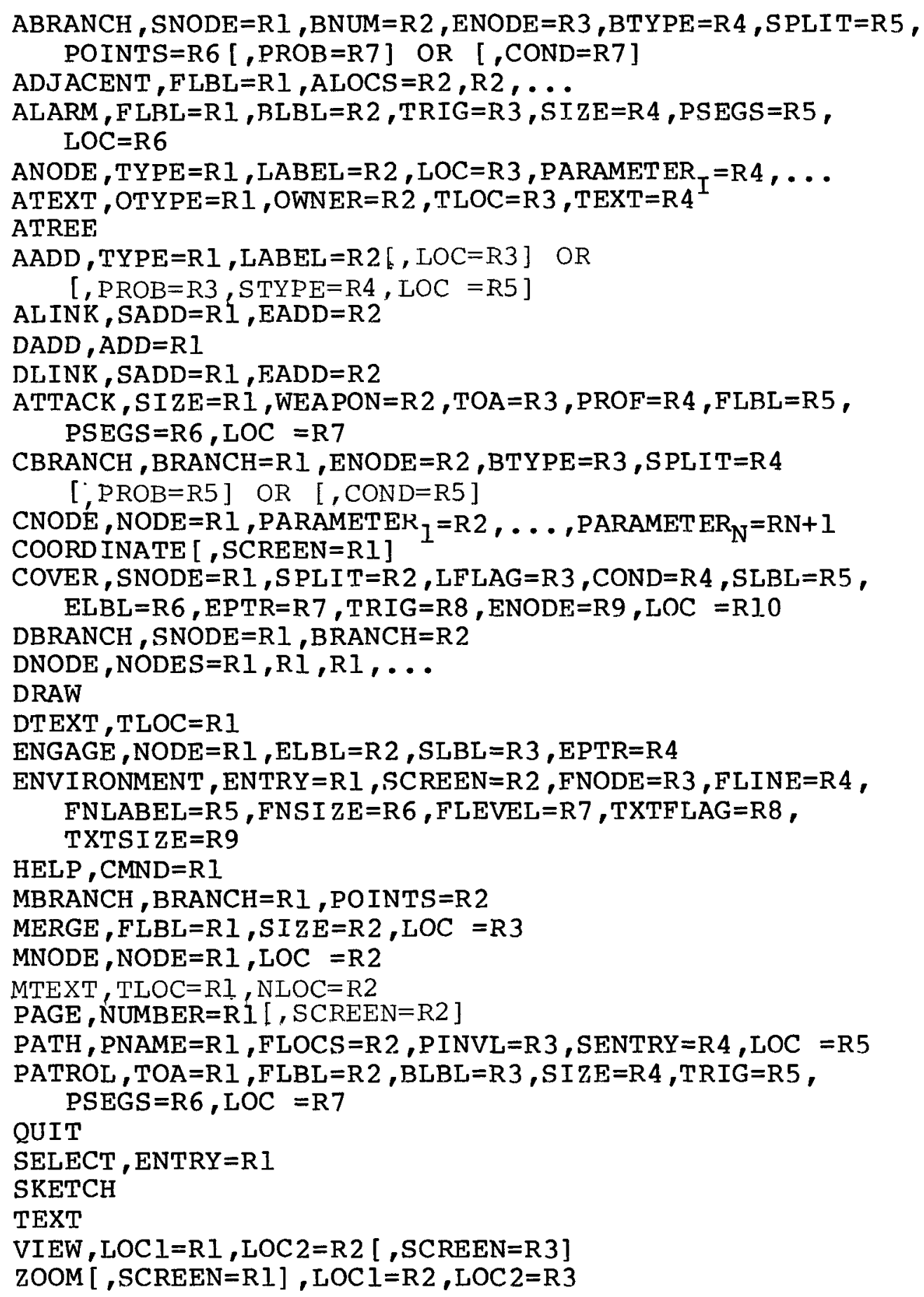


DATA Command Lines

DATA , SCNR=R1 , FILE=R2 , REWIND=R3 
ANALYZE Command Lines

\author{
DRAW \\ GO (ALIAS $C / R$ ) \\ HELP \\ POST \\ QUIT \\ PESCALE \\ RESTART \\ STEP \\ TIME \\ ZOOM
}


196

APPENDIX B 


\section{APPENDIX B \\ SNAP OPERATING SYSTEM DATA LIST DEFINITIONS}

This appendix contains the definitions of each data list used by the sos processor. Each data list is referenced by a two part identifier such as NODE, LABEL where NODE identifies this data list as containing node data and LABEL is the label of the specific node referenced. This appendix is included in this manual for completeness only. It should not be necessary for the average sos user to need this information. However, the data lists and routines for manipulating them are contained and available in sos for the advanced user who wishes to enhance sos. The data lists defined and used in this version of sos are listed on the following page. 
SOS LIBRARY DATA IISTS

IDENTIFIER

HEAD, GUA/ADV
PARA, GUA/ADV
DENG, LABEL
PENG, LABEL
ENGA, BLANK
BASE, LABEL
OBJE, BLANK
BRAN, LNUM
NODE, LABEL

(i) ENTER

(ii) EXIT

(iii) TASK

(iv) SIGNAL

(v) ALLOCATE

(vi) RTB

(vii) WAIT

PTHD, PATH SEG. NAME

PTHP, ADV/GUA

PTHL, ADV/GUA

DUMY, -

FACI, BLANK

PATH, PATH NUMBER

SNAP, SCNR NUMBER

SENS, LABEL

LOGI, LABEL

MONI, LABEL

PWAI, LAABEL

LEVE, N (LEVEL \#)

LINE, N(LEVEL \#).

NODE, LABEL

(i) SPACE

(ii) BARRIER

(iii) TARGET

HEAD, STAT

FLAG， BLANK

FFLA， BLANK

GLOB, BLANK

TIME， BLANK

MACR, LABEL

READ, BLANK

TRAC, ALPHA

TRAC, RUN NUMBER

TEXT, BRAN/NODE/BLANK
ENTRIES

GUA, ADV

GUA, ADV

GUA, ADV

GUA, ADV

GUA, ADV

GUA

ADV

GUA, ADV

GUA, ADV

GUA, ADV

GUA, ADV

GUA, ADV

GUA, ADV

GUA

GUA

GUA

GUA, ADV

GUA, ADV

GUA, ADV

GUA, ADV

FACL

FACL

FACL

FACL

FACL

FACL

FACL

FACL

FACL

FACL

FACL

FACL

FACL

STAT

STAT

STAT

STAT

STAT

STAT

(1)

ADV/GUA/STAT
PAGE

B- 1

B- 3

B- 4

B- 5

B- 6

B- 7

B- 8

B- 9

B-12

B-14

B-15

B-18

B-20

B-21

B-22

B -25

B-2 6

B- 27

B- 28

B- 29

B- 31

B- 32

B- 35

B- 36

B- 37

B- 38

B- 39

B -40

B -41

B- 43

B- 45

B -47

B- 48

B- 49

B- 50

B- 51

B- 52

B -53

B- 54

B -55

B-56 
DATA LIST DESCRIPTION

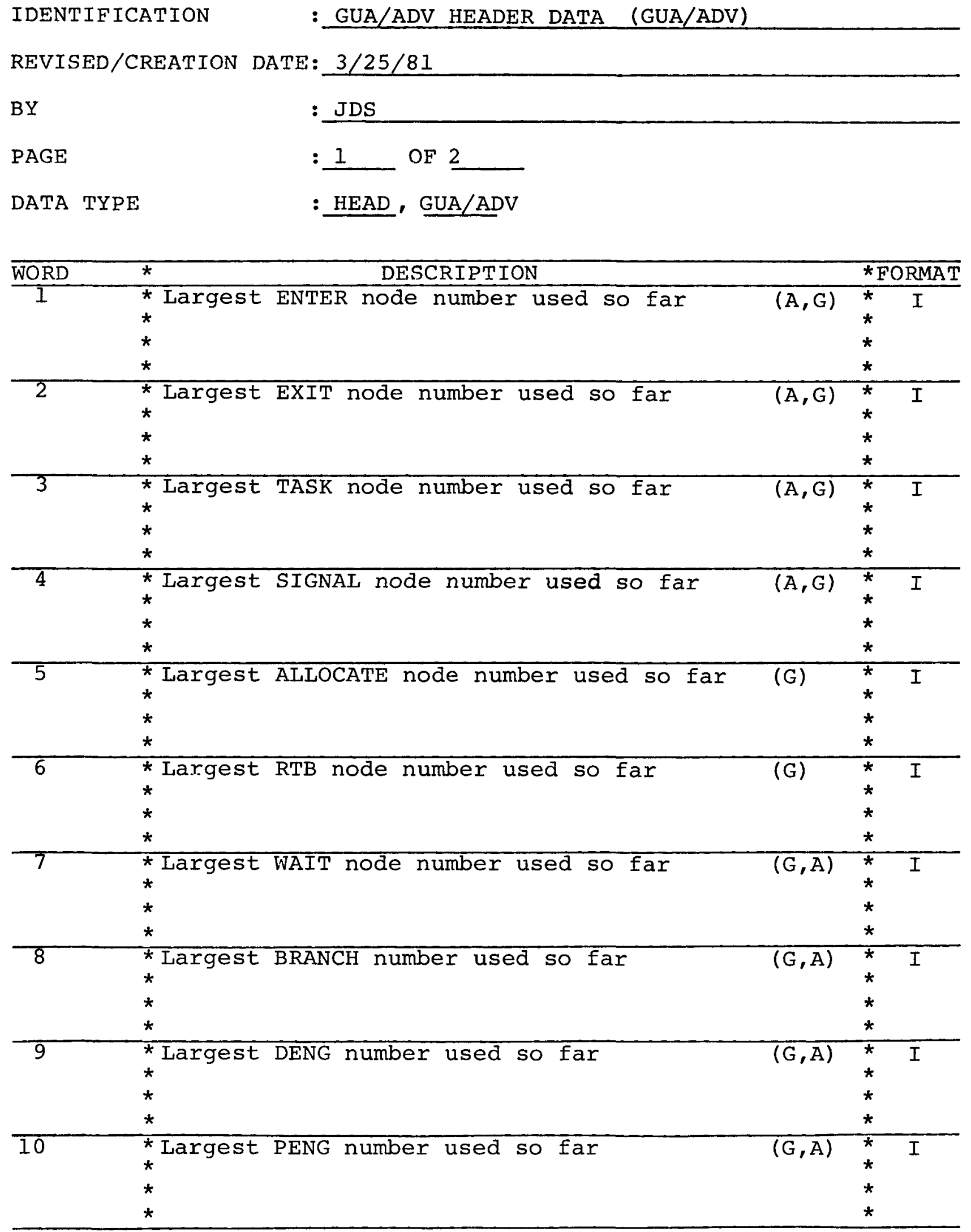




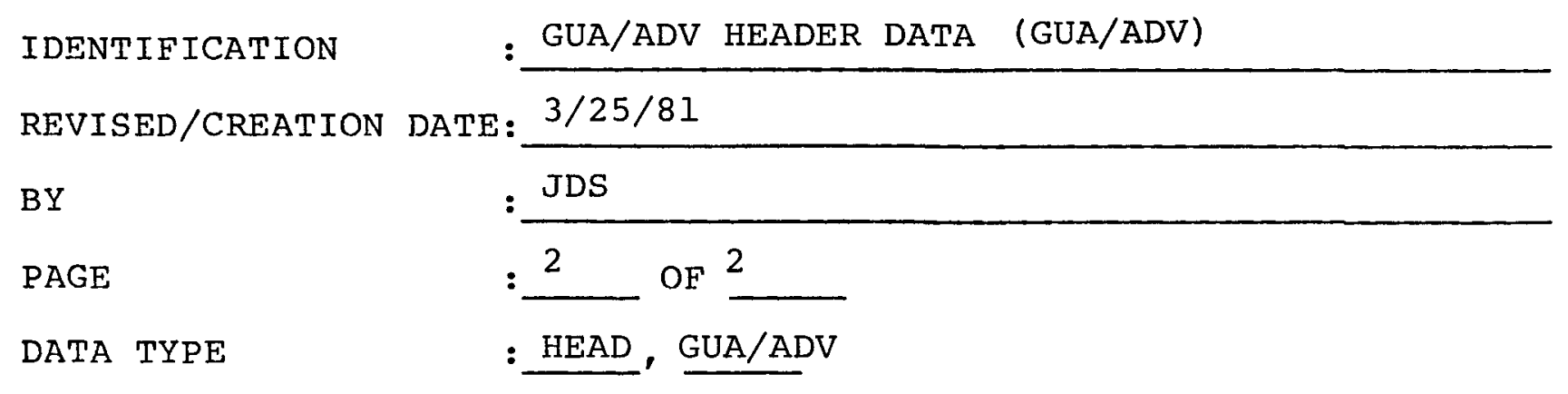

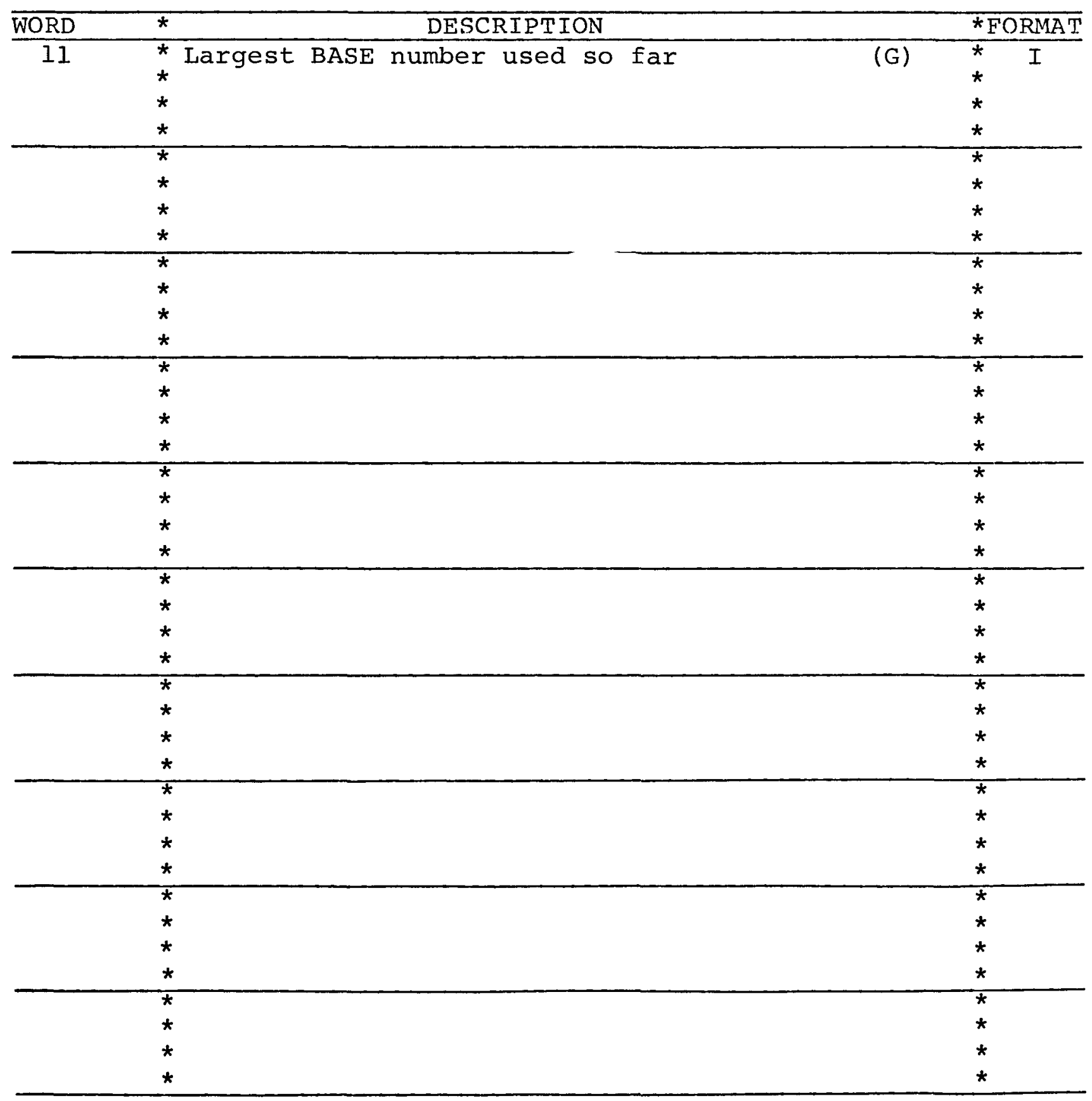




\section{DATA LIST DESCRIPTION}

B-3

PARAMETER SETS-These data lists may appear

IDENTIFICATION : in GUA and ADV entries (GUA/ADV)

REVISED/CREATION DATE: 2/10/81

BY

: JP

PAGE

$: 1$

DATA TYPE

: PARA, GUA Or ADV

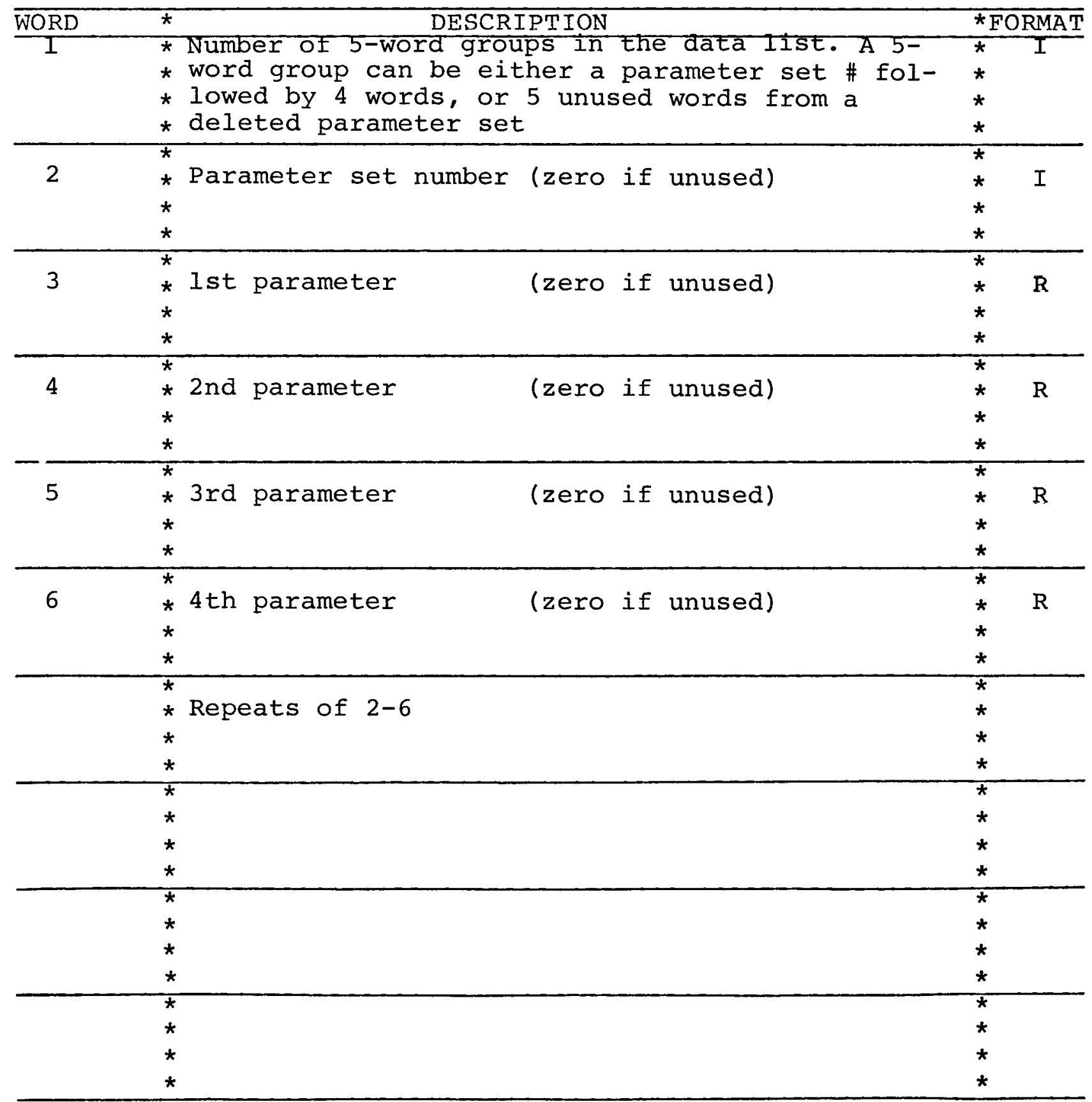




\section{DATA LIST DESCRIPTION B-4}

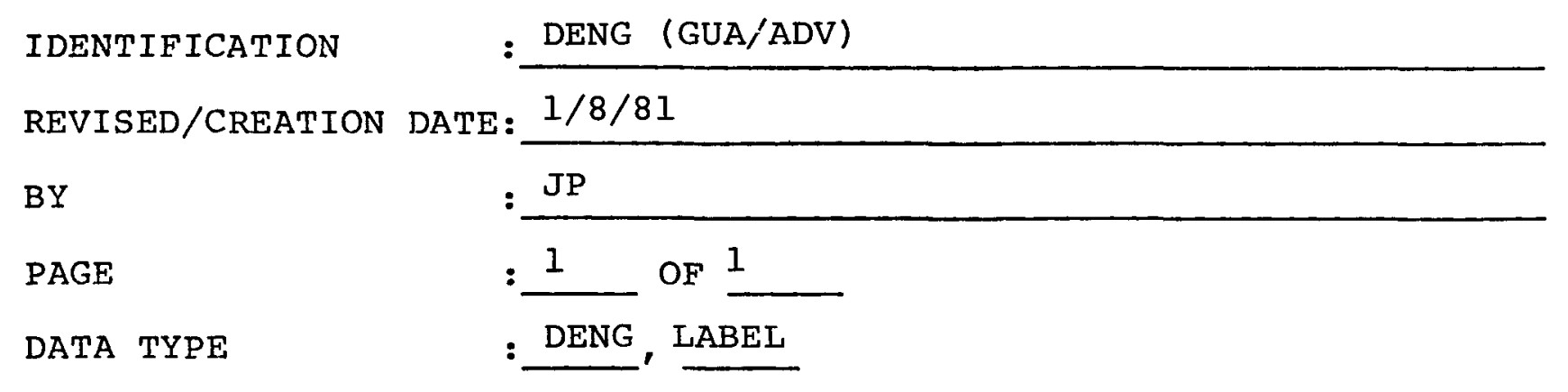

\begin{tabular}{|c|c|c|c|}
\hline WORD & DESCRIPTION & & $\overline{\mathrm{RMAT}}$ \\
\hline 1 & * Label & * & $\overline{A 4}$ \\
\hline & * & * & \\
\hline & * & * & \\
\hline & * & * & \\
\hline 2 & * Type Code-21 & * & I \\
\hline & 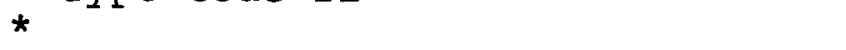 & * & \\
\hline & * & * & \\
\hline & * & * & \\
\hline 3 & * Posture & * & $\mathrm{A4}$ \\
\hline & * & * & \\
\hline & * & * & \\
\hline & * & * & \\
\hline 4 & * Exposure while firing & * & $I$ \\
\hline & * & * & \\
\hline & * & * & \\
\hline & $\star$ & * & \\
\hline 5 & * Exposure while loading & * & I \\
\hline & * & * & \\
\hline & * & * & \\
\hline & * & * & \\
\hline 6 & * Percent time delaying & * & $I$ \\
\hline & & * & \\
\hline & * & * & \\
\hline & * & * & \\
\hline 7 & * Self posture firing degradation & * & $I$ \\
\hline & $\begin{array}{lll}* \\
* \\
*\end{array}$ & * & \\
\hline & * & * & \\
\hline 8 & * Illumination firing degradation & ॠ & I \\
\hline & * & * & \\
\hline & * & * & \\
\hline & * & * & \\
\hline 9 & * Suppression (yes, no) & * & A4 \\
\hline & $\star \star$ & * & \\
\hline & * & * & \\
\hline 10 & * Tactic (ASSA, DEFE) & * & $\overline{\mathrm{A} 4}$ \\
\hline & * & * & \\
\hline & * & * & \\
\hline
\end{tabular}




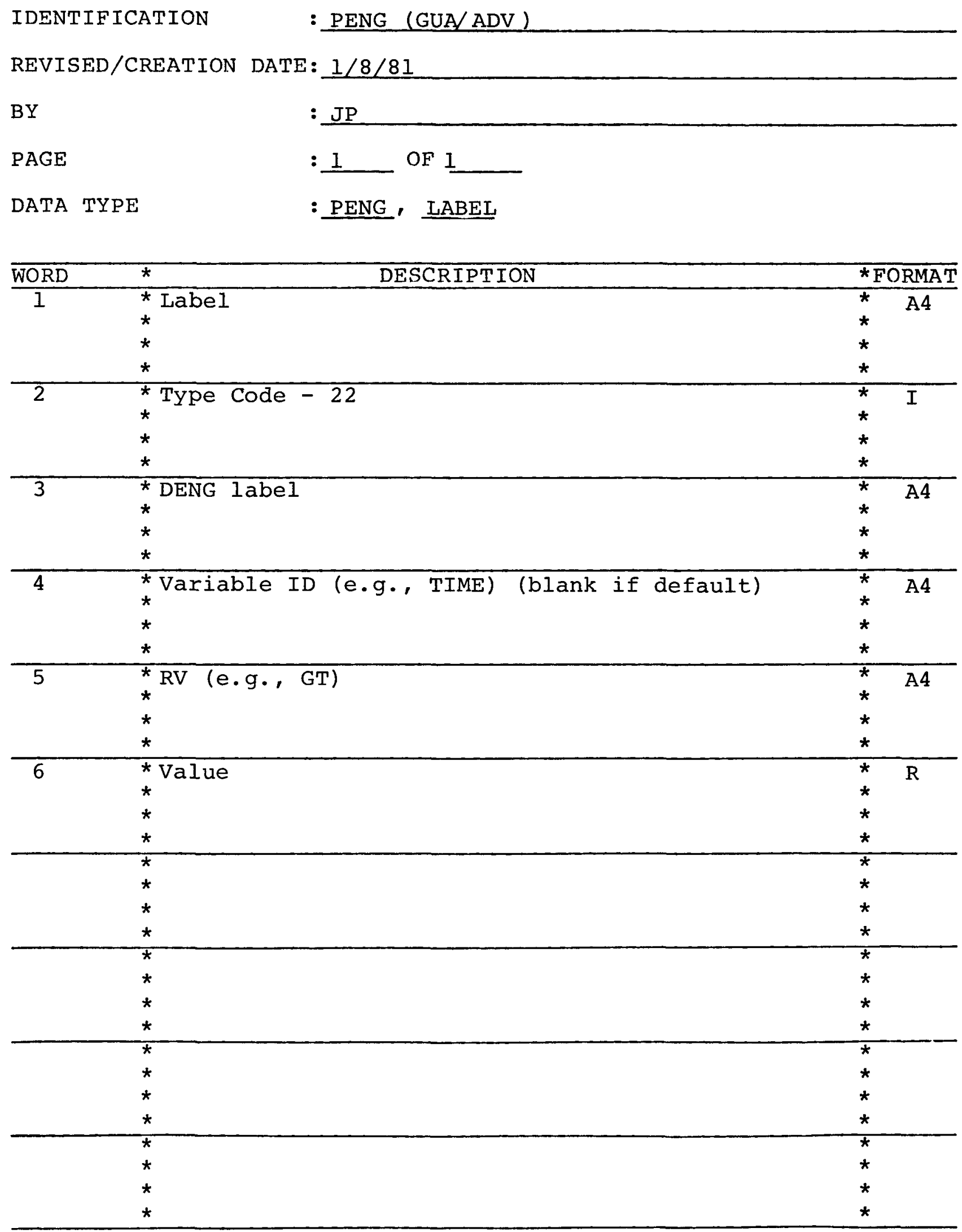


DATA LIST DESCRIPTION B-6

IDENTIFICATION

: ENGAGEMENT (GUA/ADV)

REVISED/CREATION DATE: 1/8/81

BY

: JP

PAGE

$: 1$

DATA TYPE

: ENGA, BLANK

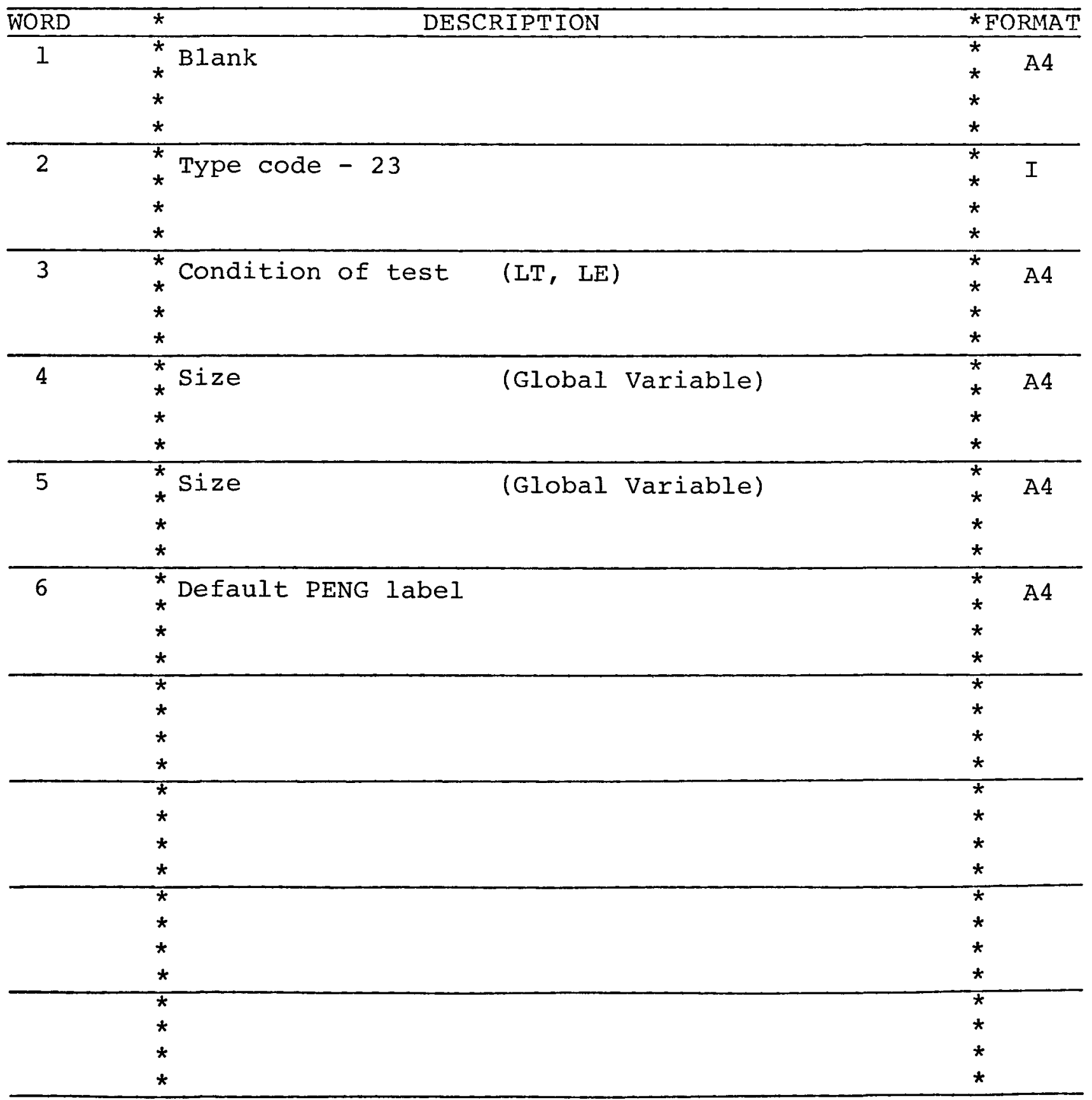




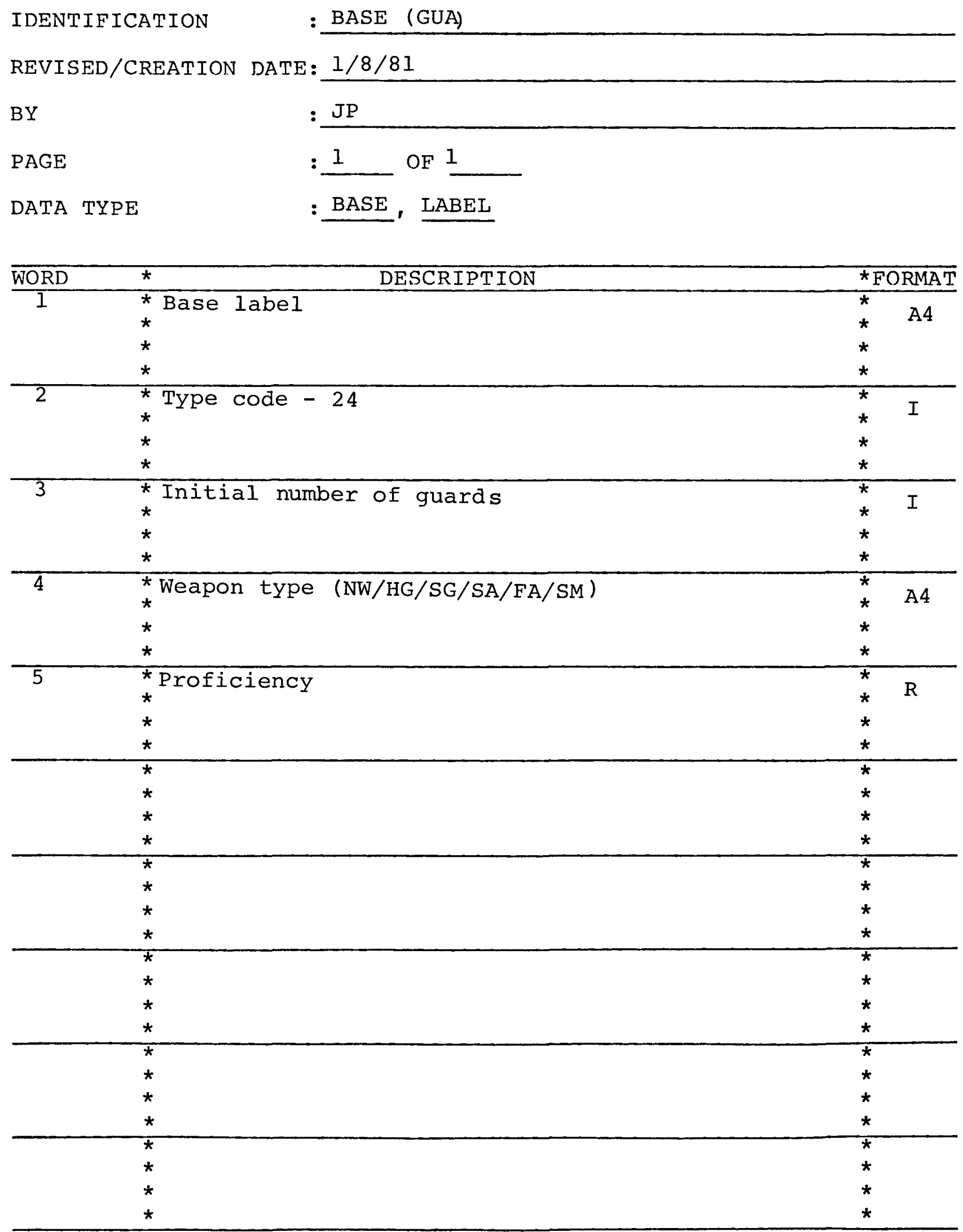


DATA LIST DESCRIPTION

B-8

$\begin{array}{ll}\text { IDENTIFICATION } & : \text { OBJECTIVE (ADV) } \\ \text { REVISED/CREATION DATE } & : \frac{1 / 8 / 81}{\mathrm{JP}} \\ \text { BY } & : \frac{1}{\text { OBJE }}, \text { BLANK } \\ \text { PAGE } & : \text { OF } \\ \text { DATA TYPE } & \end{array}$

\begin{tabular}{|c|c|c|}
\hline WORD & $\star$ & *FORMAT \\
\hline 1 & $\begin{array}{l}* \text { Blank } \\
\star \\
\star \\
\star\end{array}$ & $\begin{array}{ll}* & \mathrm{~A} 4 \\
* & \\
* & \\
\star & \end{array}$ \\
\hline 2 & $\begin{array}{l}\star \\
\star \\
\star \\
\star\end{array}$ & $\begin{array}{l}* \\
\star \\
* \\
*\end{array}$ \\
\hline 3 & $\begin{array}{l}\text { * Objective (SABO, THEF) } \\
\star \\
\star\end{array}$ & $\begin{array}{ll}* & \mathrm{~A} 4 \\
\star & \\
\star & \\
\star & \end{array}$ \\
\hline 4 & $\begin{array}{l}\text { * Last word of facility nodes to visit for } \\
\text { * success } \\
\text { * }\end{array}$ & $\begin{array}{ll}* & 1 \\
* & 1 \\
* & \\
* & \end{array}$ \\
\hline 5 & $\begin{array}{l}\text { * Facility node label } \\
\star \\
\star\end{array}$ & $\begin{array}{ll}* & \mathrm{~A} 4 \\
\star & \\
\star & \\
\star & \end{array}$ \\
\hline & $\begin{array}{l}* \text { Repeats of } 5 \\
* \\
*\end{array}$ & $\begin{array}{l}* \\
\star \\
* \\
\star\end{array}$ \\
\hline & $\begin{array}{l}* \\
\star \\
* \\
\star\end{array}$ & $\begin{array}{l}* \\
\star \\
\star \\
\star\end{array}$ \\
\hline & $\begin{array}{l}\star \\
\star \\
\star \\
*\end{array}$ & $\begin{array}{l}* \\
\star \\
* \\
*\end{array}$ \\
\hline & $\begin{array}{l}* \\
\star \\
\star \\
\star\end{array}$ & $\begin{array}{l}* \\
\star \\
\star \\
\star\end{array}$ \\
\hline & $\begin{array}{l}* \\
\star \\
* \\
\star\end{array}$ & $\begin{array}{l}* \\
* \\
* \\
\star\end{array}$ \\
\hline
\end{tabular}


GUARD AND ADVERSARY NETWORK RECORD DEFINITIONS (Graphic) 
B-9

DATA LIST DESCRIPTION

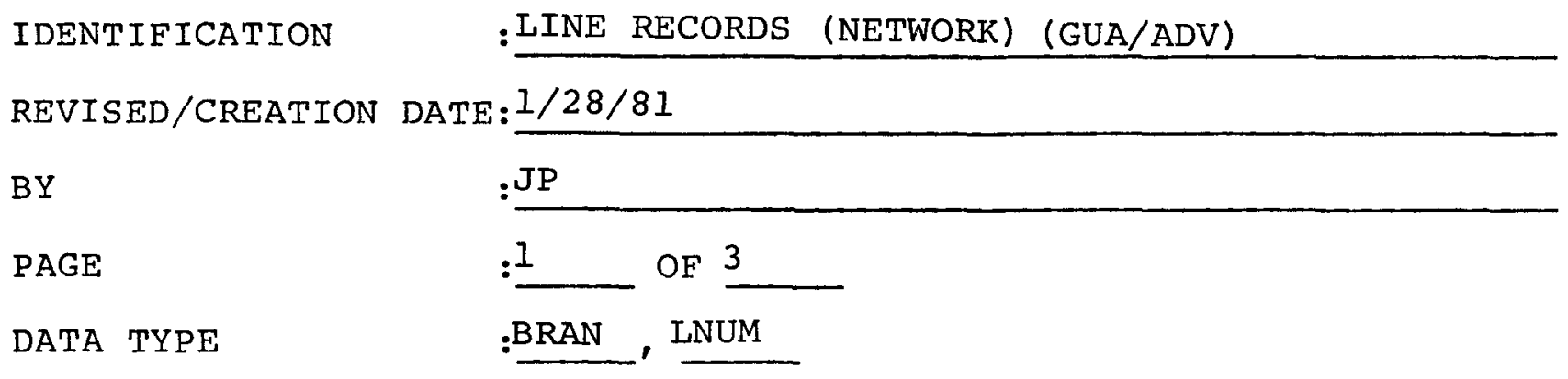

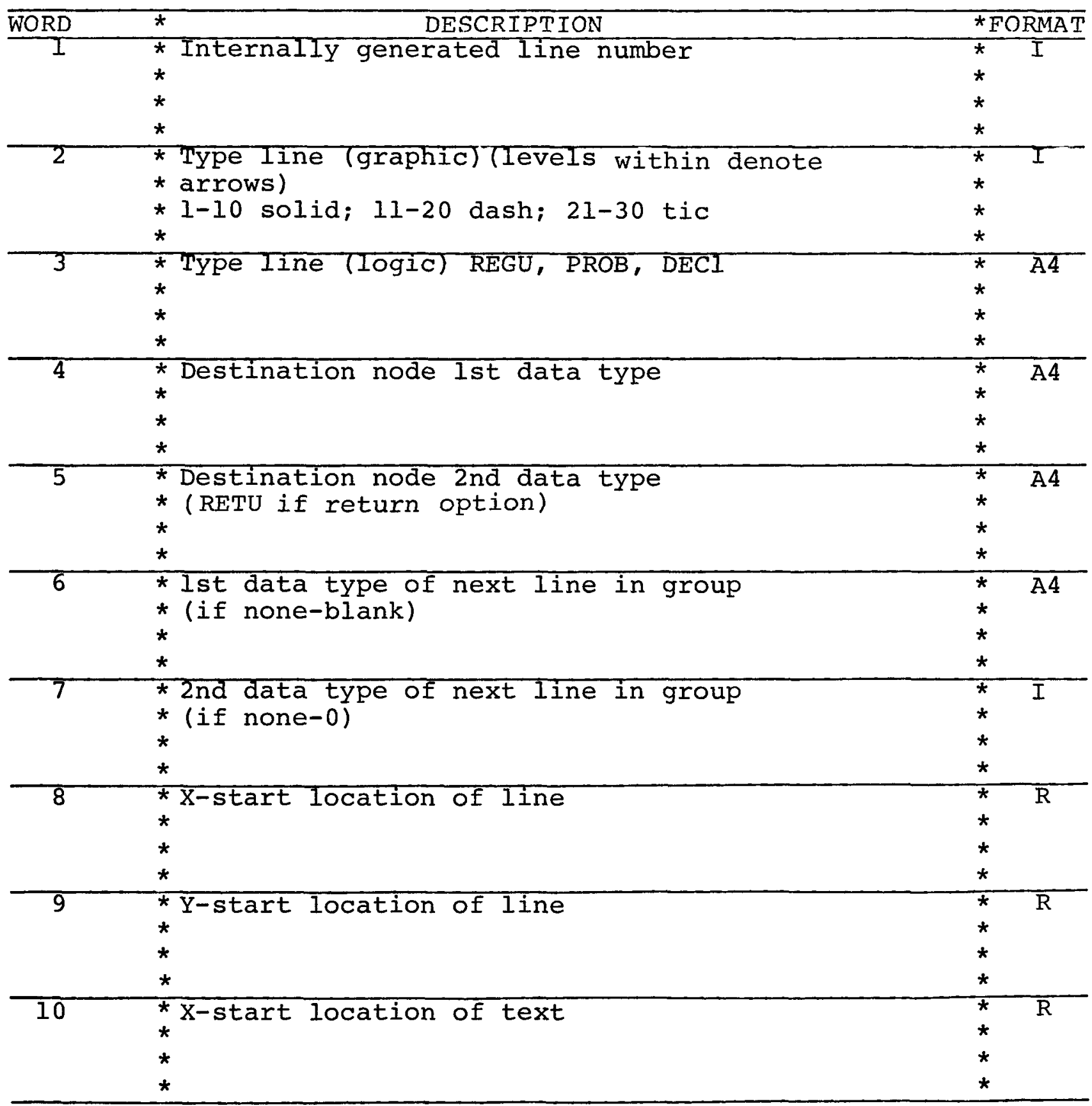


DATA LIST DESCRIPTION B-10

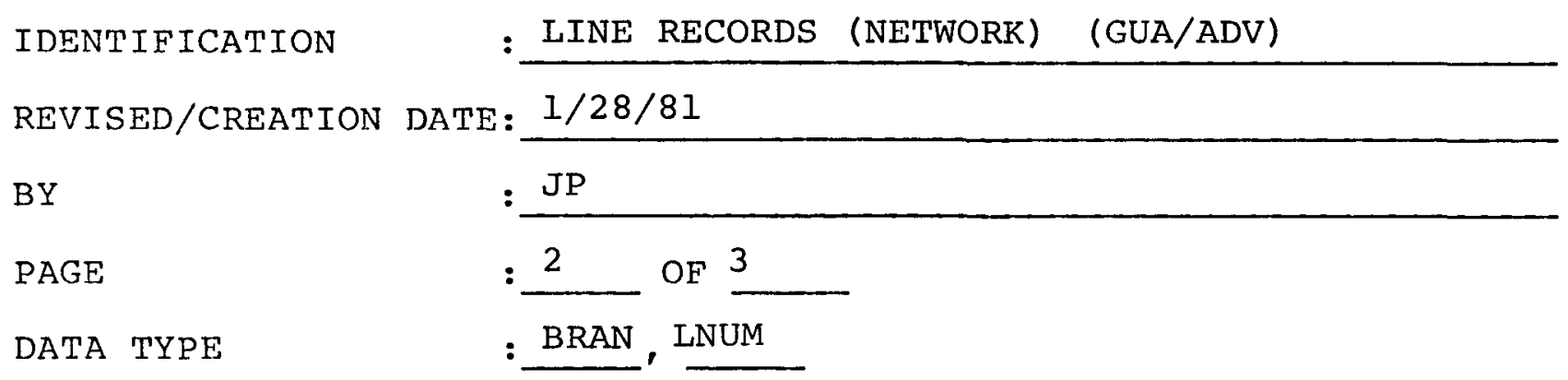

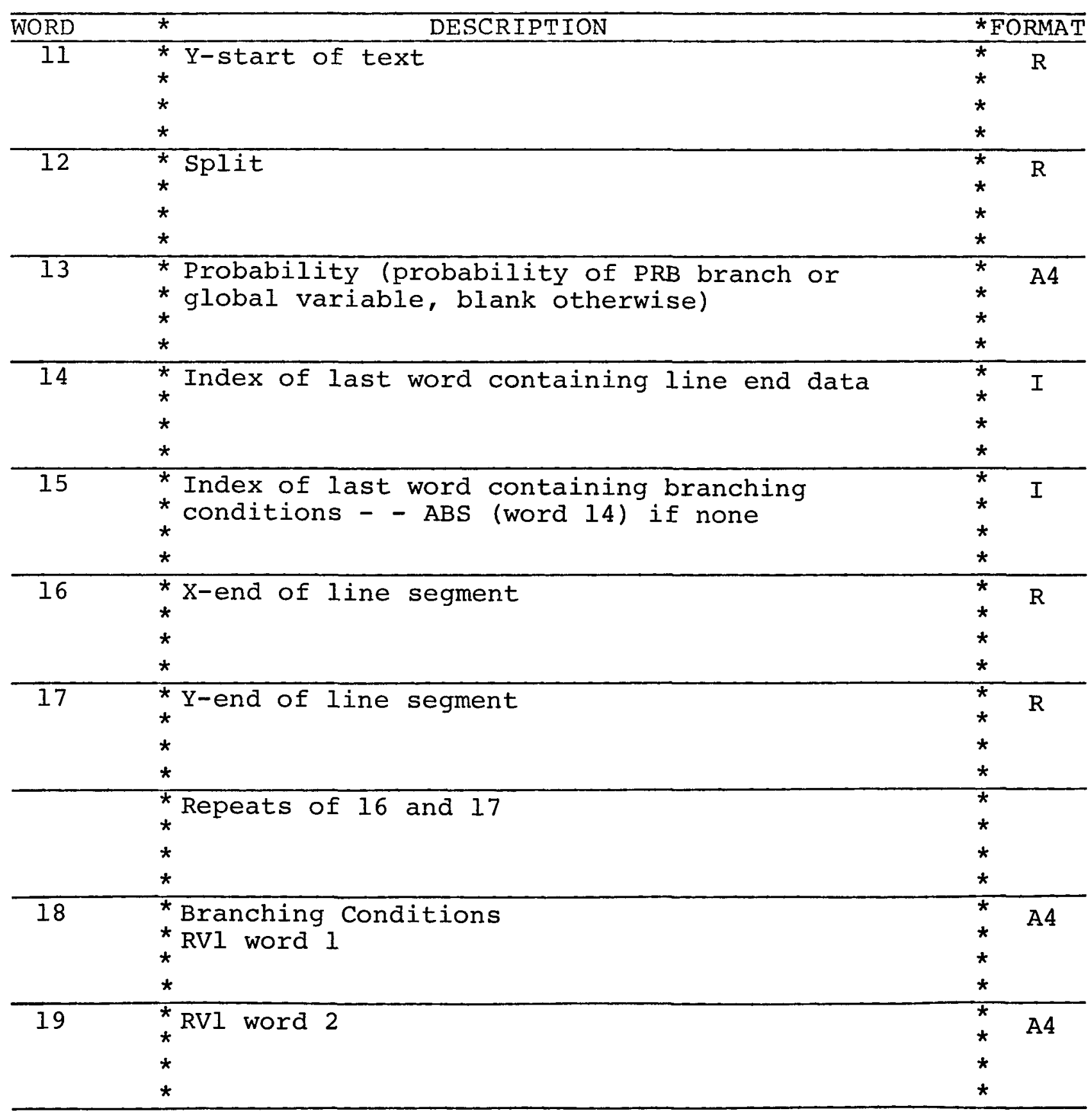


IDENTIF ICATION

: LINE RECORDS (NETWORK) (GUA/ADV)

REVISED/CREATION DATE: 1/28/81

BY

: JP

PAGE

$: 3$ OF 3

DATA TYPE

: BRAN, LNUI

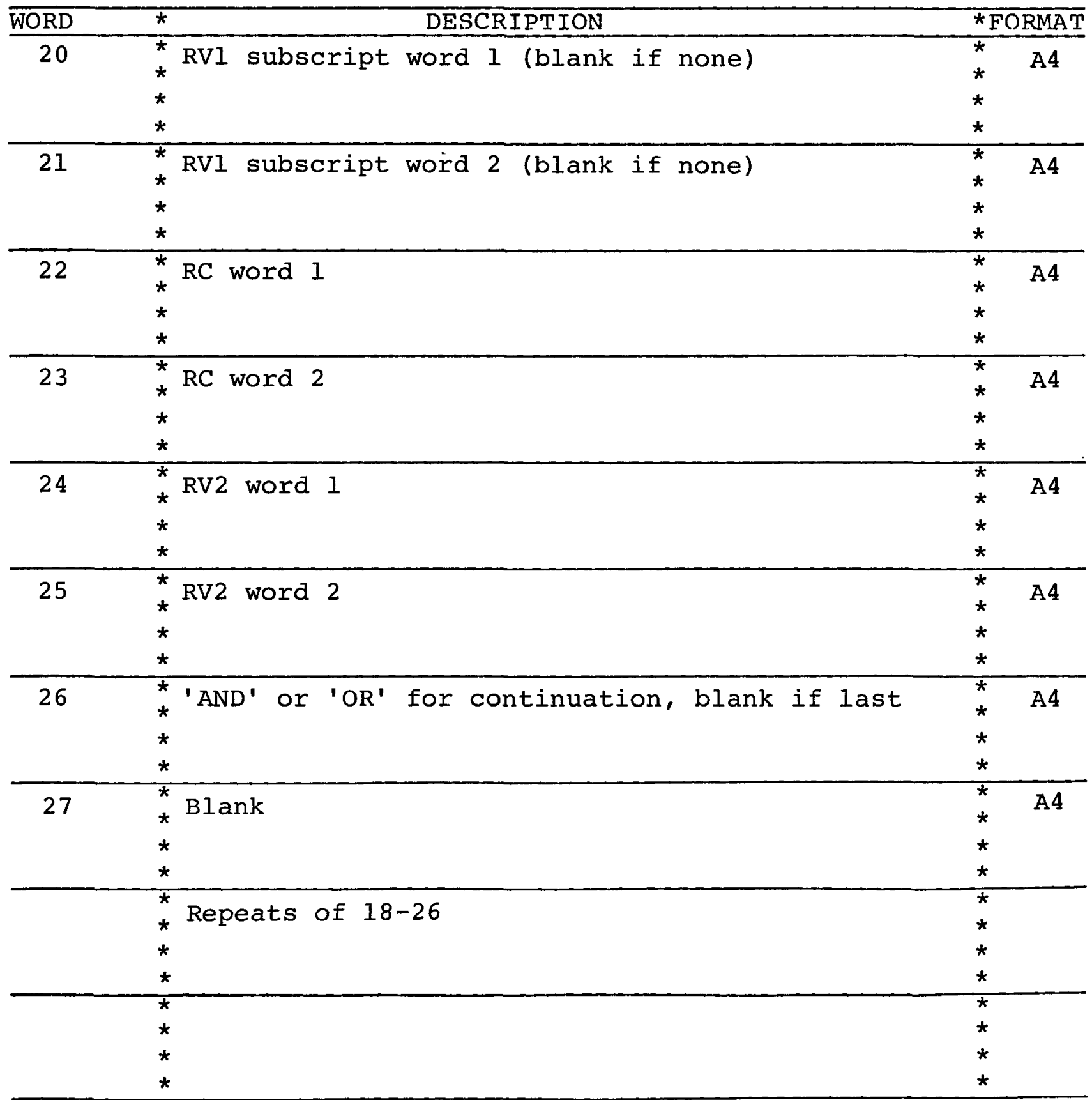




\section{IDENTIFICATION}

: ENTER NODE (GUA/ADV)

REVISED/CREATION DATE: 6/5/80
BY
: JM
PAGE
$: \underline{1}$ OF $\underline{2}$
DATA TYPE
: NODE, LABEL

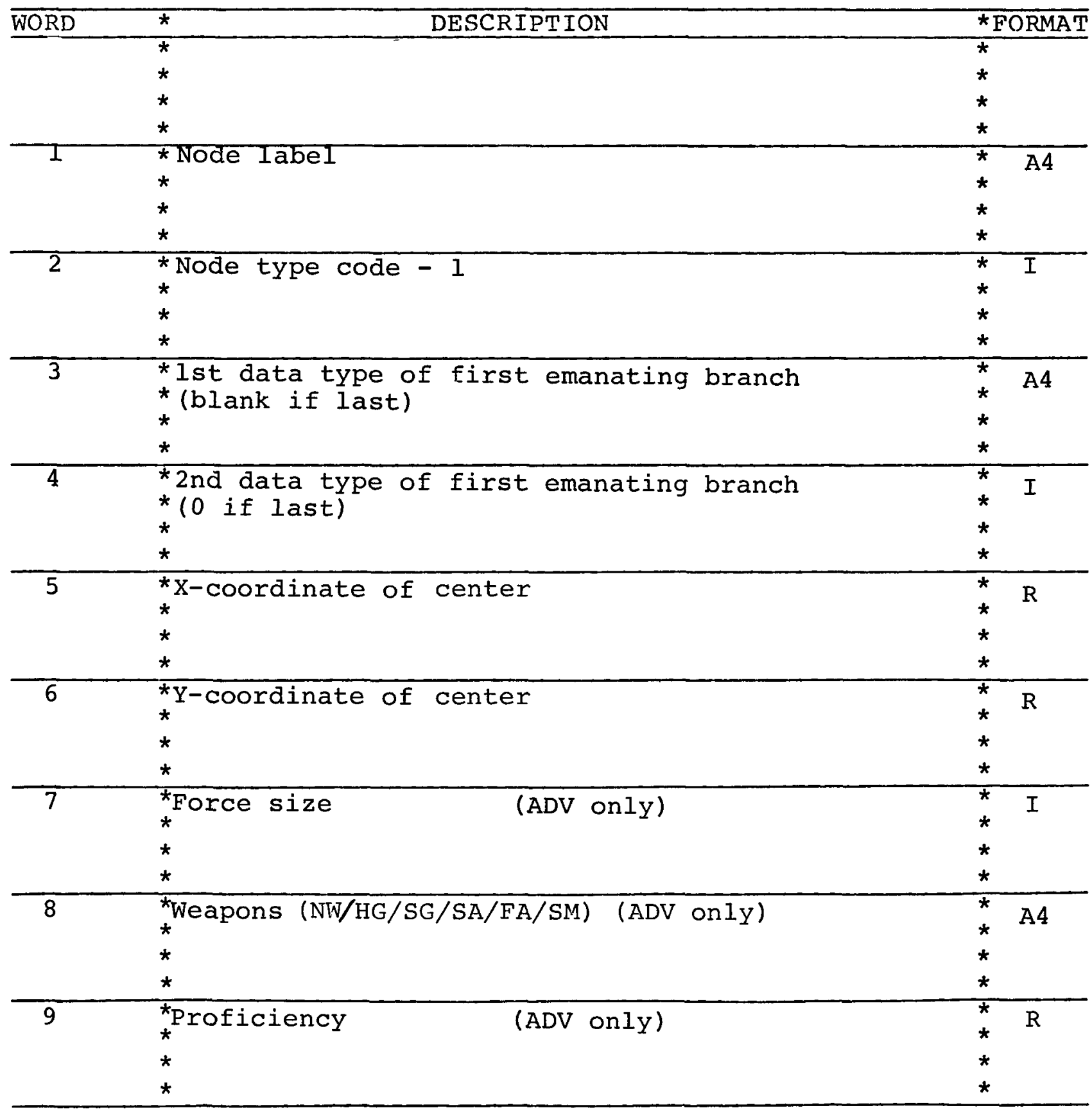




\section{DATA LIST DESCRIPTION \\ $B-13$}

IDENTIFICATION : ENTER NODE (GUA/ADV)

REVISED/CREATION DATE: $6 / 5 / 80$

BY $\quad$ : JM

PAGE

$: 2 \quad$ OF 2

DATA TYPE

: NODE, LABEL

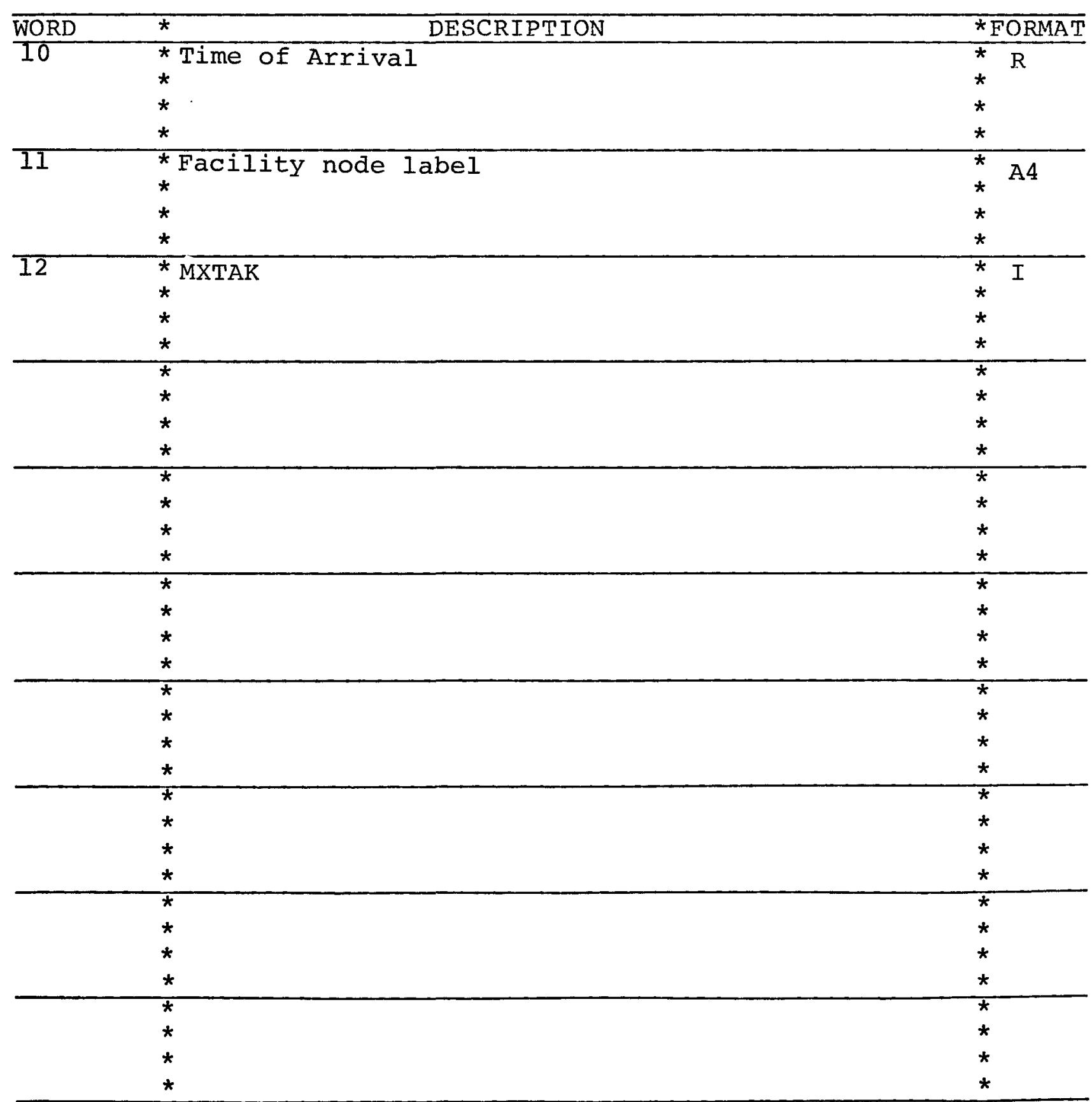




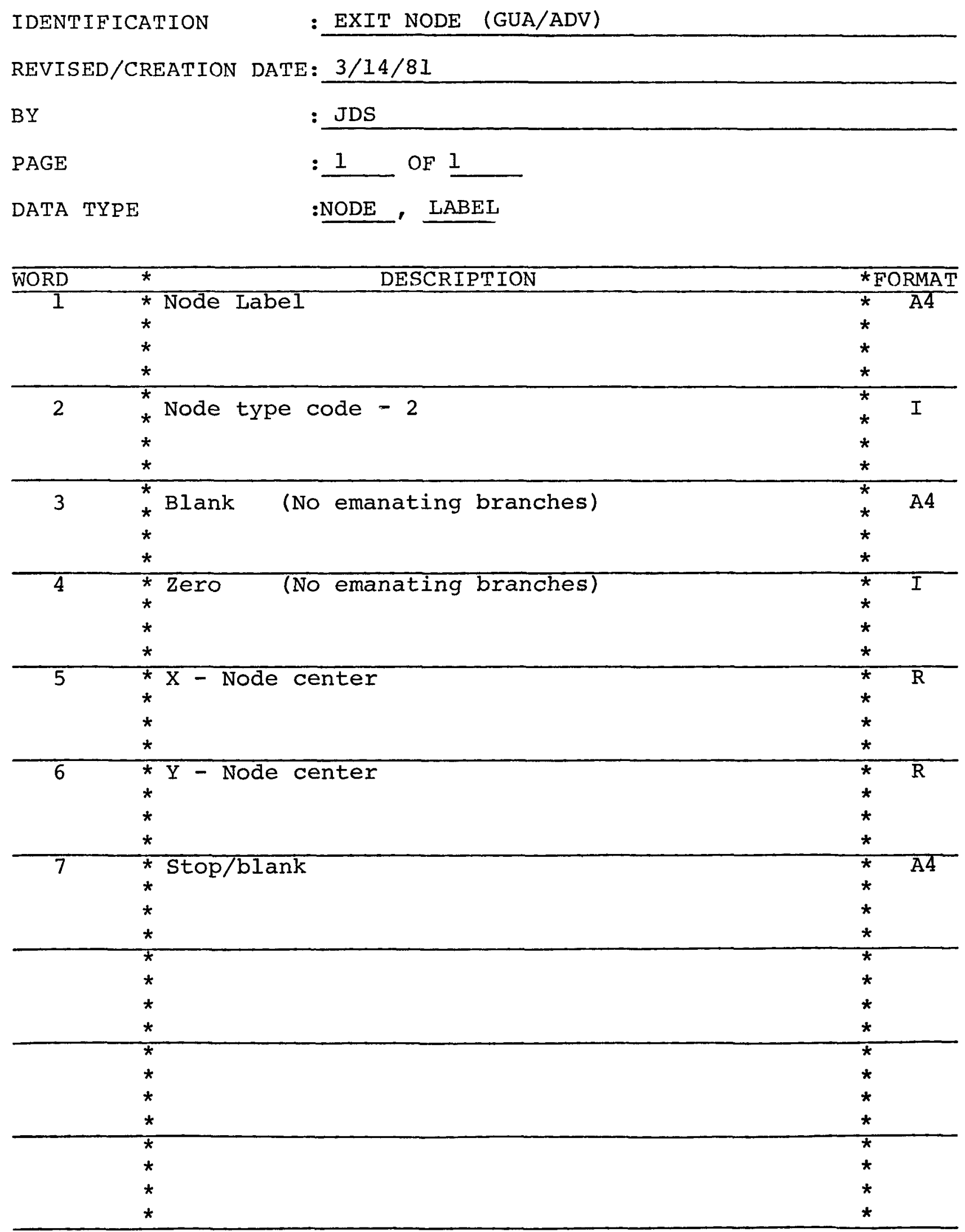


DATA LIST DESCRIPTION

IDENT IF ICATION

: TASK NODE (GUA/ADV)

REVISED/CREATION DATE: $1 / 23 / 81$

BY

: JDS

PAGE

$: 1$

OF 3

DATA TYPE

: NODE, LABEL

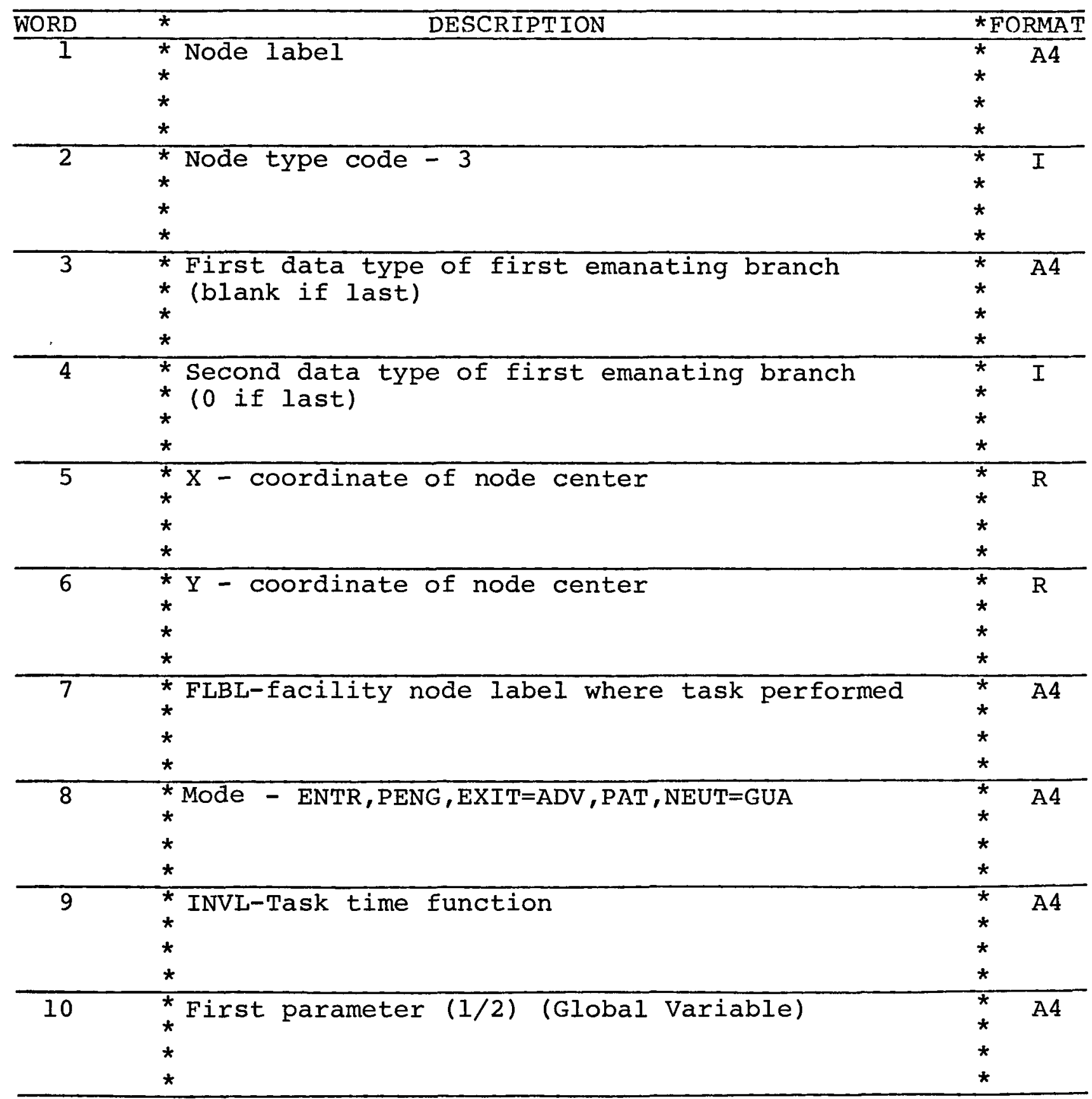


DATA IIST DESCRIPTION

IDENTIEICATION

: TASK NODE (GUA/ADV)

REVISED/CREATION DATE: $8 / 21 / 81$

BY

: JDS

PAGE

$: \underline{2}$ OF 3

DATA TYPE

: NODE, LABEL

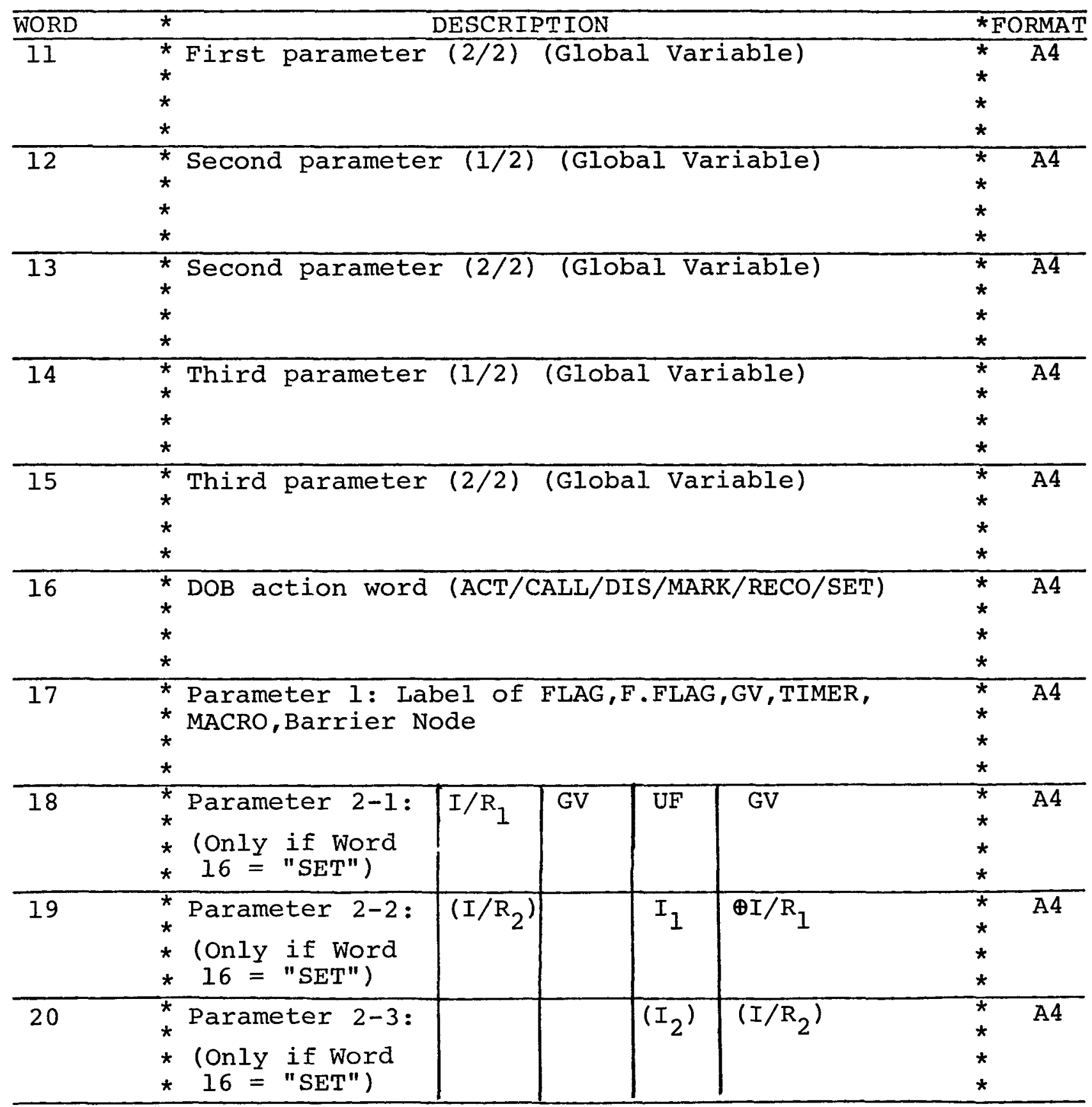


DATA LIST DESCRIPTION

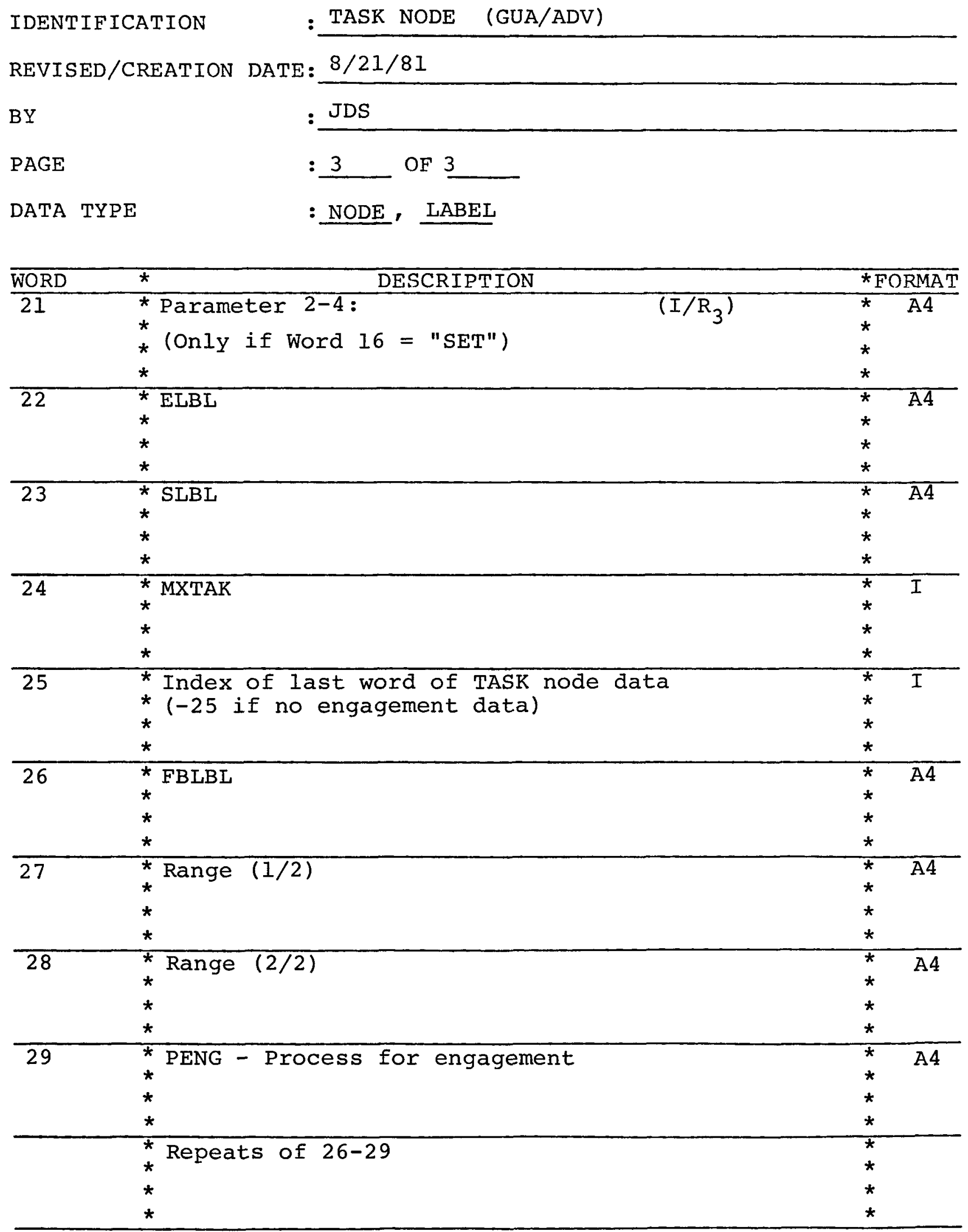


IDENTIFICATION

REVISED/CREATION DATE: $6 / 5 / 80$

BY

: JM

PAGE

$: \underline{1}$ OF 2

DATA TYPE

: NODE, LABEL

\begin{tabular}{|c|c|c|}
\hline WORD & DESCRIPTION & *FORMAT \\
\hline & * & * \\
\hline & $\star$ & * \\
\hline & * & * \\
\hline & * & * \\
\hline 1 & * Node label & $\overline{A 4}$ \\
\hline & * & * \\
\hline & * & * \\
\hline & * & * \\
\hline 2 & * Node type code -4 & * \\
\hline & & * \\
\hline & * & * \\
\hline & * & * \\
\hline 3 & * Ist data type of first emanating branch & A4 \\
\hline & * (blank if last) & * \\
\hline & * & * \\
\hline 4 & * 2nd data type of first emanating branch & * \\
\hline & * (0 if last) & * \\
\hline & & * \\
\hline & 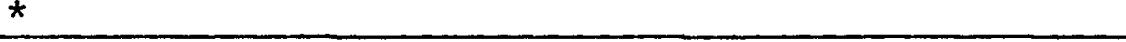 & * \\
\hline 5 & * $x$-coordinte of center & $\mathbf{R}$ \\
\hline & * & * \\
\hline & * & * \\
\hline & * & * \\
\hline 6 & * Y-coordinate of center & $\mathrm{R}$ \\
\hline & * & * \\
\hline & * & * \\
\hline & * & * \\
\hline 7 & * Wait node label (Force code or logic point & * A4 \\
\hline & * label ADV-GUA) & * \\
\hline & $\star$ & * \\
\hline & * 0 & $\frac{\pi}{*}$ \\
\hline 8 & * Permanent or Temp code (FACL LOC or & * $\quad$ A4 \\
\hline & * Force ID) & * \\
\hline & ( & * \\
\hline 9 & * TRAN, TISV, or NNLBL label & $\star \quad$ A4 \\
\hline & * & * \\
\hline & $\star$ & * \\
\hline
\end{tabular}




$\begin{array}{ll}\text { IDENTIFICATION } & : \text { SIGNAL NODE } \quad \text { (GUA/ADV) } \\ \text { REVISED/CREATION DATE: } & \frac{6 / 5 / 80}{\text { JM }} \\ \text { BY } & : \frac{2}{\text { PAGE }} \\ \text { DATA TYPE } & : \text { NODE, LABEL }\end{array}$

\begin{tabular}{|c|c|c|}
\hline WORD & * DESCRIPTION & *FORMAT \\
\hline \multirow{5}{*}{10} & * MXTAK & * I \\
\hline & * & * \\
\hline & * & * \\
\hline & * & * \\
\hline & * & * \\
\hline & * & * \\
\hline & * & * \\
\hline & * & * \\
\hline & * & * \\
\hline & * & * \\
\hline & * & * \\
\hline & * & * \\
\hline & * & * \\
\hline & * & * \\
\hline & * & * \\
\hline & * & * \\
\hline & $\star$ & * \\
\hline & * & * \\
\hline & * & * \\
\hline & $\star$ & * \\
\hline & $\star$ & * \\
\hline & * & * \\
\hline & * & * \\
\hline & * & * \\
\hline & ๘ & * \\
\hline & * & * \\
\hline & * & * \\
\hline & * & * \\
\hline & $\star$ & * \\
\hline & * & * \\
\hline & $\star$ & * \\
\hline & * & * \\
\hline & $\star$ & * \\
\hline & * & * \\
\hline & * & * \\
\hline & * & * \\
\hline & $\star$ & ‡ \\
\hline & $\star$ & * \\
\hline & * & * \\
\hline & * & * \\
\hline
\end{tabular}


DATA LIST DESCRIPTION B-20

$\begin{array}{ll}\text { IDENTIFICATION } & : \text { ALLOCATE NODE (GUA) } \\ \text { REVISED/CREATION DATE }: & 6 / 5 / 80 \\ \text { BY } & : \text { JM } \\ \text { PAGE } & : 1 \quad \text { OF I } \\ \text { DATA TYPE } & : \text { NODE, LABEL }\end{array}$

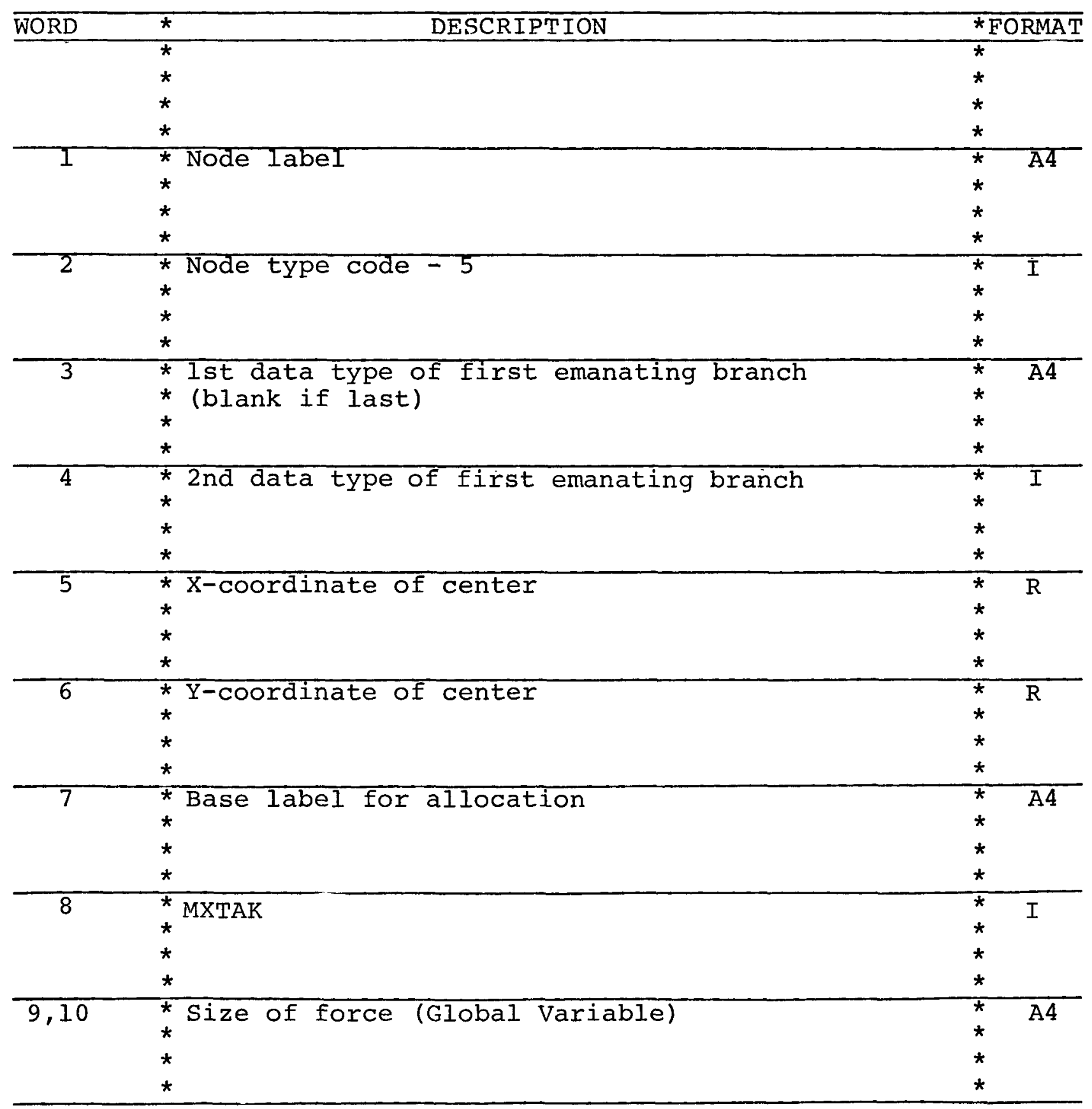


DATA LIST DESCRIPTION

B-21

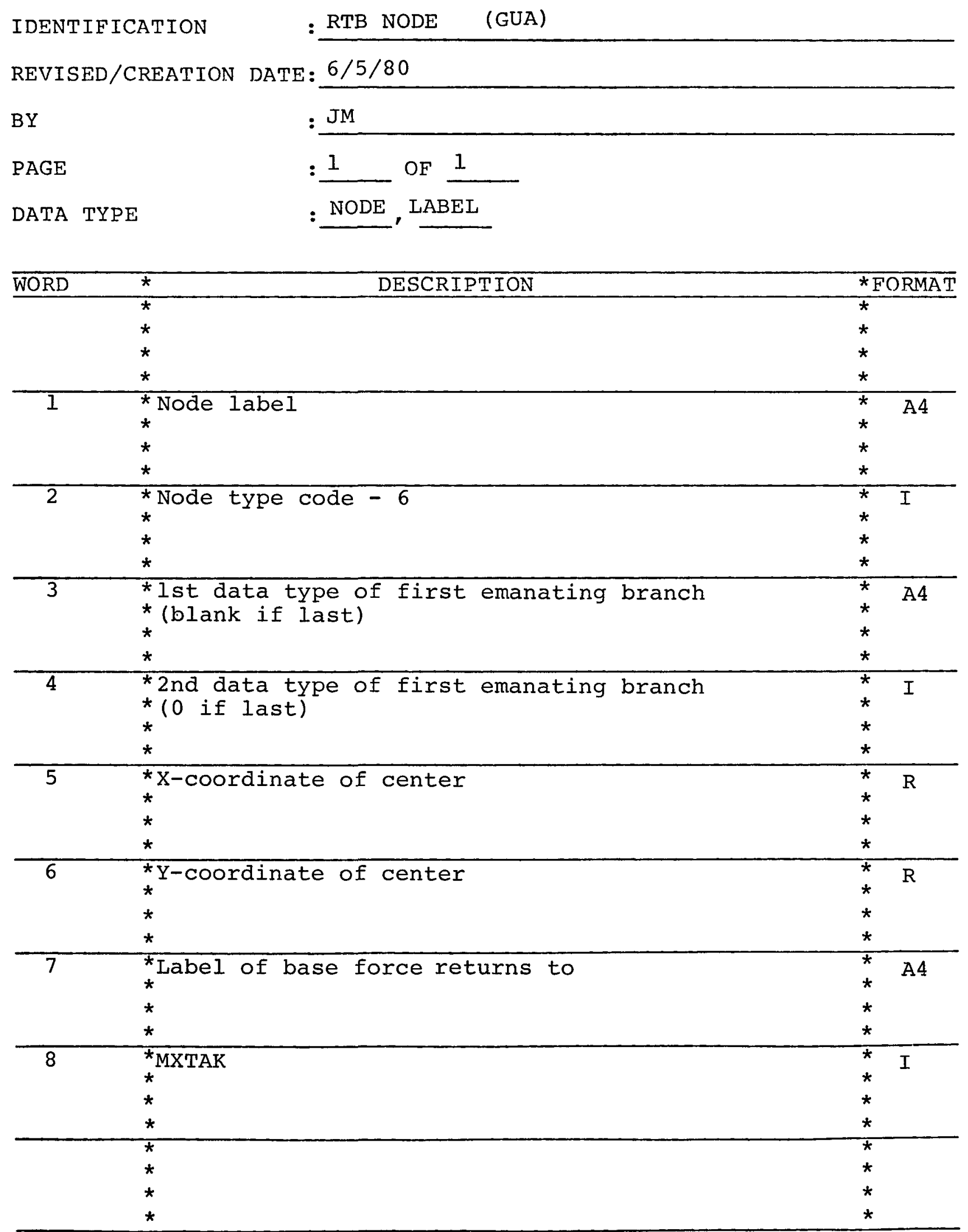




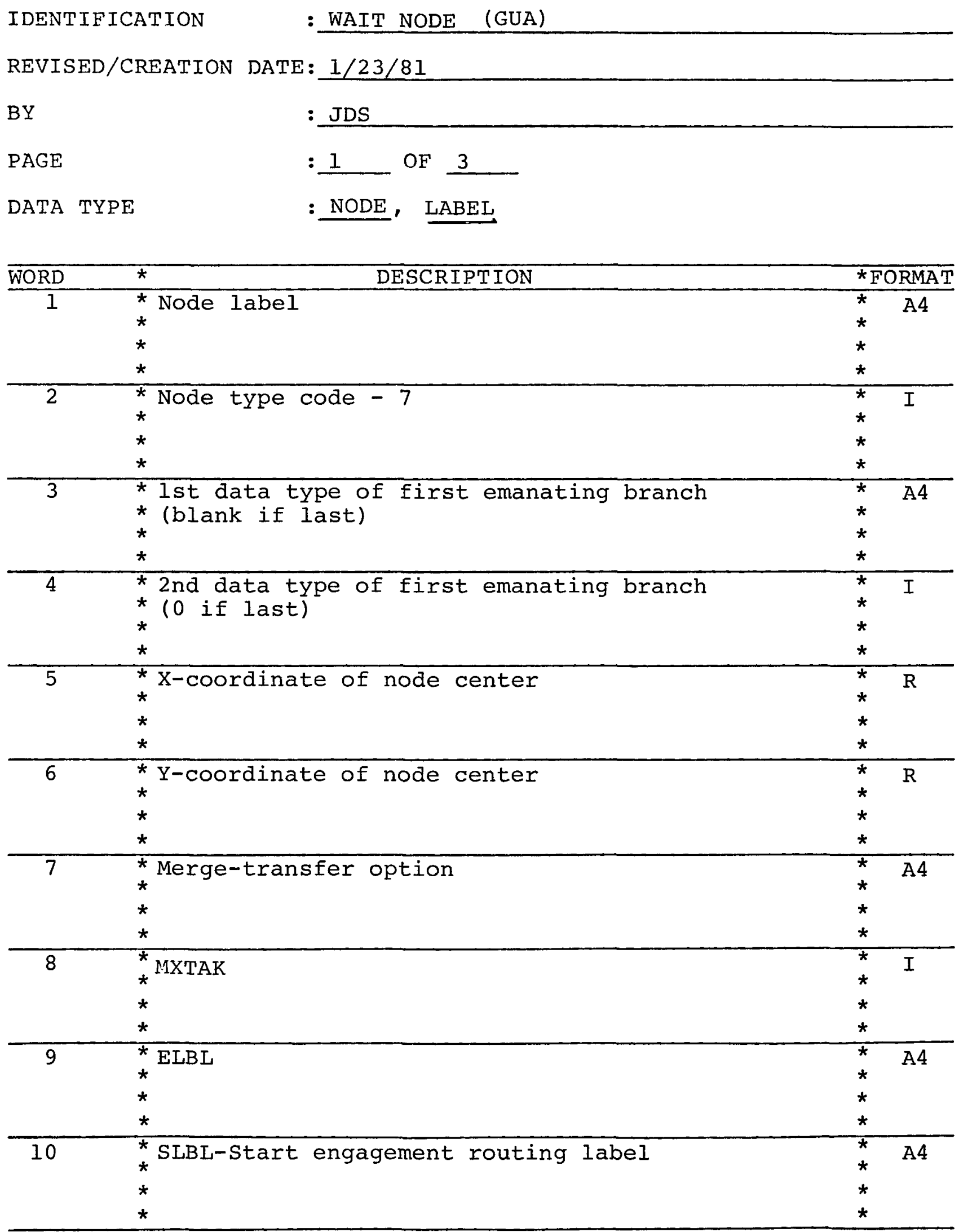


IDENTIFICATION : WAIT NODE (GUA)

REVISED/CREATION DATE: $1 / 23 / 81$

BY

JDS

PAGE

$: 2$ OF 3

DATA TYPE

: NODE, LABEL

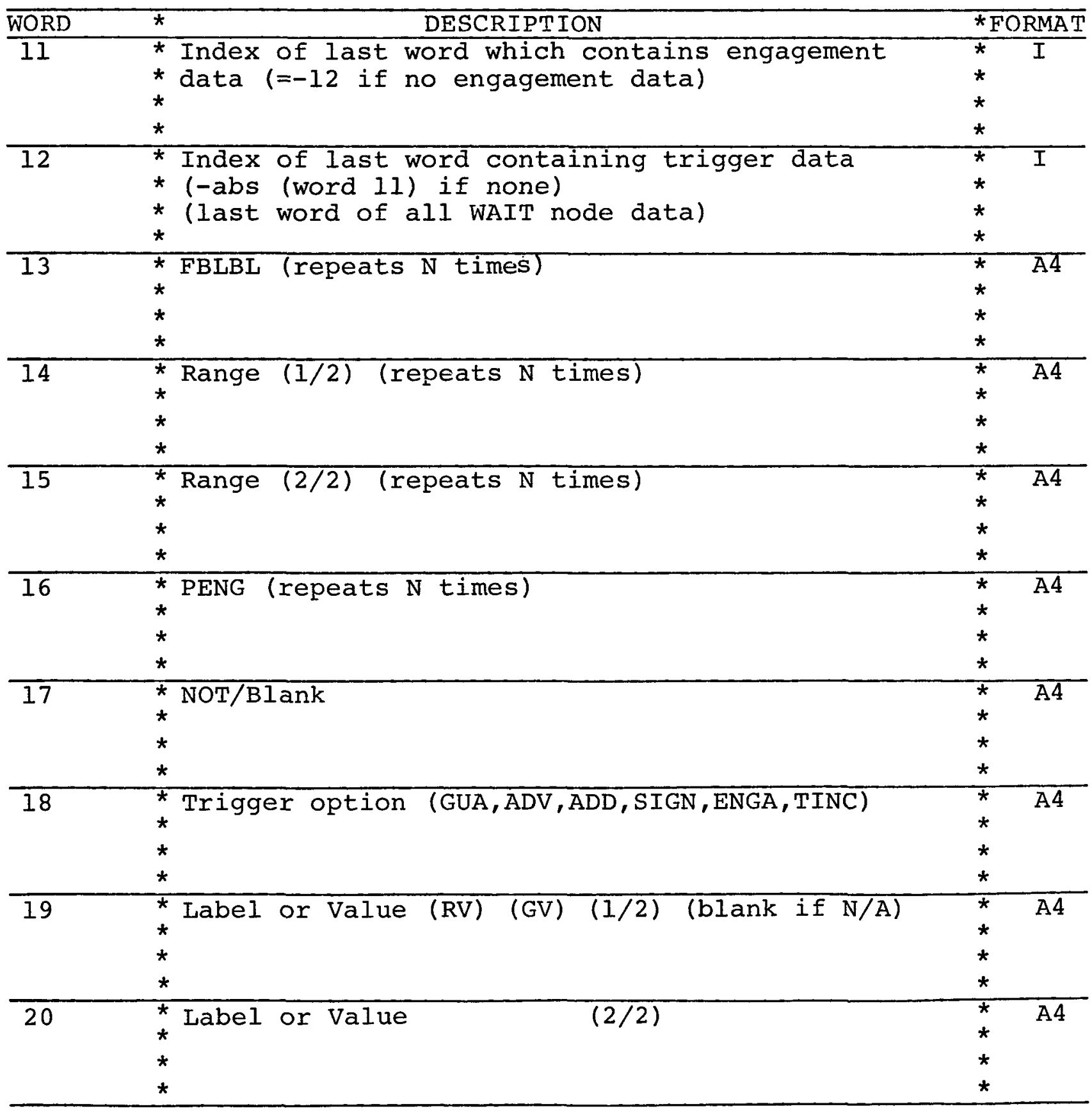


DATA LIST DESCRIPTION B-24

IDENTIFICATION : WAIT NODE (GUA)

REVISED/CREATION DATE: $8 / 21 / 81$

BY

: JDS

PAGE

$: \underline{3}$ OF 3

DATA TYPE

:

\begin{tabular}{|c|c|c|}
\hline \multirow{2}{*}{$\frac{\text { WORD }}{21}$} & * DESCRIPTION & \#FORMAT \\
\hline & $\begin{array}{l}\text { * Continue Condition (AND/OR/BLANK) } \\
\text { * (Blank if last) } \\
\text { * } \\
\text { * }\end{array}$ & $\begin{array}{ll}* & \text { A4 } \\
\star & \\
\star & \\
\star & \end{array}$ \\
\hline & * & \# \\
\hline & $\star$ & * \\
\hline & * & * \\
\hline & * & * \\
\hline & * & $\bar{t}$ \\
\hline & * & * \\
\hline & * & * \\
\hline & * & * \\
\hline & * & * \\
\hline & * & * \\
\hline & * & * \\
\hline & * & * \\
\hline & * & \# \\
\hline & * & * \\
\hline & * & * \\
\hline & * & * \\
\hline & \# & * \\
\hline & *. & * \\
\hline & * & * \\
\hline & * & * \\
\hline & ‡ & * \\
\hline & * & * \\
\hline & * & * \\
\hline & * & * \\
\hline & $\star$ & * \\
\hline & * & * \\
\hline & * & * \\
\hline & * & * \\
\hline & $\star$ & $\star$ \\
\hline & $\star$ & $\star$ \\
\hline & $\star$ & * \\
\hline & $\star$ & $\star$ \\
\hline & $\star$ & $\hbar$ \\
\hline & * & * \\
\hline & * & * \\
\hline & $\star$ & * \\
\hline
\end{tabular}


DATA LIST DESCRIPTION

B-25

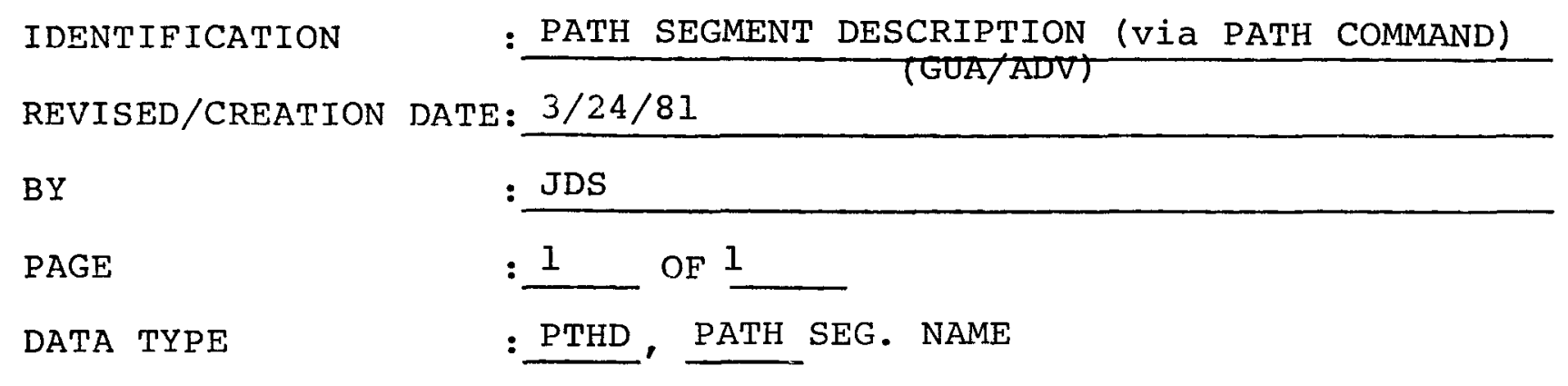

\begin{tabular}{|c|c|c|}
\hline WORD & * DESCRIPTION & *FORMAT \\
\hline \multirow[t]{4}{*}{1} & * Path segment name & * $\overline{\mathrm{A} 4}$ \\
\hline & & * \\
\hline & * & * \\
\hline & * & $\star$ \\
\hline \multirow[t]{4}{*}{2} & * Label of first task node in "ACT" direction & $\overline{\mathrm{A}} 4$ \\
\hline & * & * \\
\hline & * & * \\
\hline & * & * \\
\hline \multirow[t]{4}{*}{3} & * Label of first task node in "DIS" direction & $\overline{\mathrm{A}} 4$ \\
\hline & & * \\
\hline & * & * \\
\hline & * & * \\
\hline \multirow[t]{3}{*}{4} & * Label of "JUNCTION" task node at end of path & $\star A 4$ \\
\hline & * in "DIS" direction & * \\
\hline & $\begin{array}{ll}* \\
\star \\
\star\end{array}$ & * \\
\hline \multirow[t]{24}{*}{5} & * Label of "JUNCTION" task node at end of path & * $\overline{A 4}$ \\
\hline & * in "ACT" direction & * \\
\hline & * & * \\
\hline & 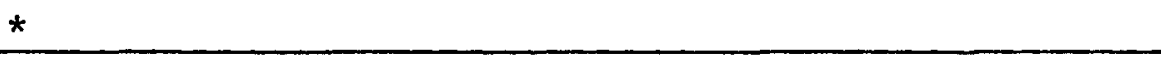 & * \\
\hline & \# & \# \\
\hline & * & * \\
\hline & * & * \\
\hline & * & * \\
\hline & ‡ & * \\
\hline & * & * \\
\hline & * & * \\
\hline & * & * \\
\hline & ॠ & * \\
\hline & * & * \\
\hline & * & * \\
\hline & * & * \\
\hline & * & \# \\
\hline & * & * \\
\hline & $\star$ & * \\
\hline & * & * \\
\hline & $\star$ & $\star$ \\
\hline & * & * \\
\hline & * & * \\
\hline & * & * \\
\hline
\end{tabular}




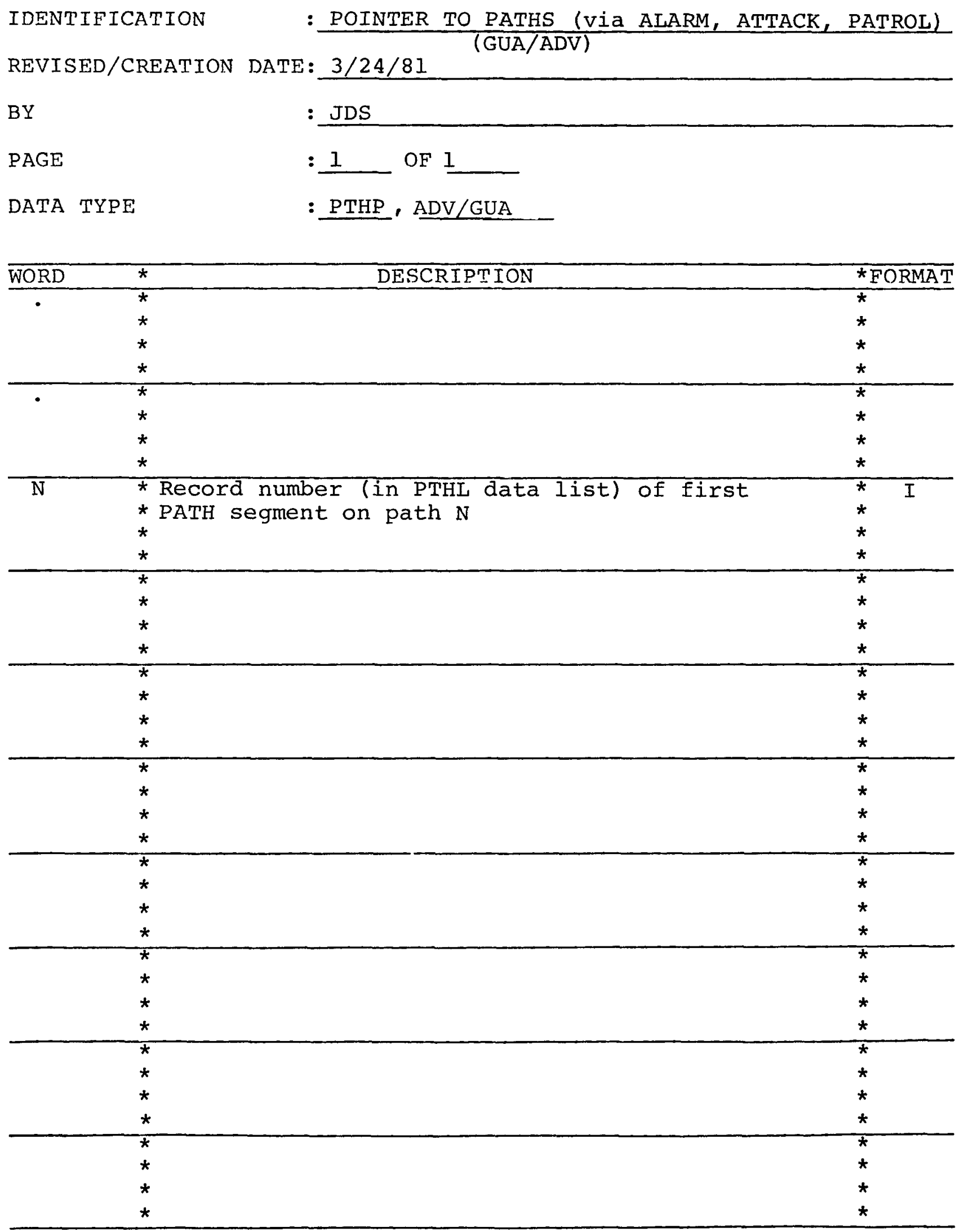


$\begin{array}{ll}\text { DATA LIST DESCRIPTION } & \text { B-27 }\end{array}$

$\begin{array}{ll}\text { IDENTIFICATION } & : \text { PATH/LINKED PATH SEGMENTS (GUA/ADV) } \\ \text { REVISED/CREATION DATE }: & 3 / 24 / 81 \\ \text { BY } & : \text { JDS } \\ \text { PAGE } & : 1 \\ \text { DATA TYPE } & : \text { PTHL }, \text { ADV/GUA }\end{array}$

\begin{tabular}{|c|c|c|}
\hline WORD & $\star \quad$ DESCRIPTION & *FORMAT \\
\hline 1 & $\begin{array}{l}\text { * Largest path number used so far in this entry } \\
\star \\
\star\end{array}$ & $\begin{array}{ll}\star & I \\
\star & \\
\star & \\
\star & \end{array}$ \\
\hline 2 & $\begin{array}{l}\text { * Last word used in this data list } \\
\star \\
\star\end{array}$ & $\begin{array}{l}* \\
\star \\
\star \\
\star\end{array}$ \\
\hline 3 & $\begin{array}{l}\text { * Path segment name of first path segment on } \\
\text { * PATH } 1 \\
\text { * }\end{array}$ & $\begin{array}{l}* \\
\star \\
\star \\
\star\end{array}$ \\
\hline 4 & 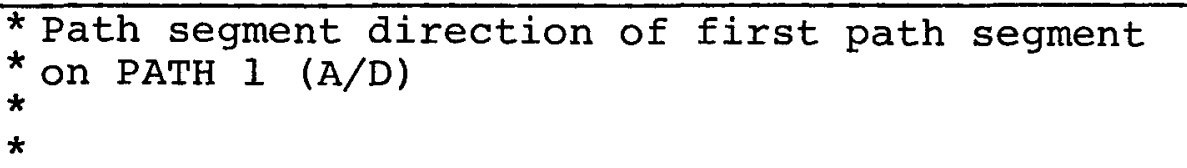 & $\begin{array}{ll}* & \text { A4 } \\
* & \\
* & \\
* & \end{array}$ \\
\hline 5 & $\begin{array}{l}\text { * Path segment name of second path segment on } \\
\text { * PATH } 1 \\
\text { * }\end{array}$ & $\begin{array}{ll}* & \mathrm{~A} 4 \\
* & \\
\star & \\
\star & \end{array}$ \\
\hline 6 & $\begin{array}{l}\text { * Path segment direction of second path segment } \\
\text { * on PATH } 1 \\
\text { * }\end{array}$ & $\begin{array}{ll}* & \mathrm{A4} \\
* & \\
* & \\
* & \end{array}$ \\
\hline & $\begin{array}{l}\text { * Repeats of } 3-4, \text { blank ends list } \\
\star \\
\star\end{array}$ & $\begin{array}{l}* \\
\star \\
\star \\
\star\end{array}$ \\
\hline$\dot{\circ}$ & $\begin{array}{l}\star \\
\star \\
\star \\
\star\end{array}$ & $\begin{array}{l}\star \\
\star \\
\star \\
\star\end{array}$ \\
\hline & $\begin{array}{l}\text { * PATH segment name of first path segment on } \\
\text { * PATH } 2 \\
\star\end{array}$ & $\begin{array}{l}* \\
\star \\
\star \\
*\end{array}$ \\
\hline & $\begin{array}{l}\text { * PATH segment direction of first path segment } \\
\text { * on PATH } 2 \\
\text { * } \\
\text { * }\end{array}$ & $\begin{array}{l}* \\
\star \\
\star \\
\star\end{array}$ \\
\hline
\end{tabular}


DATA LIST DESCRIPTION

$B-28$

IDENTIFICATION

: DUMY DATA LIST (GUA/ADV)

REVISED/CREATION DATE: 4/23/81

BY

: JP

PAGE

$: 1$

OF 1

DATA TYPE

: DUMY, -

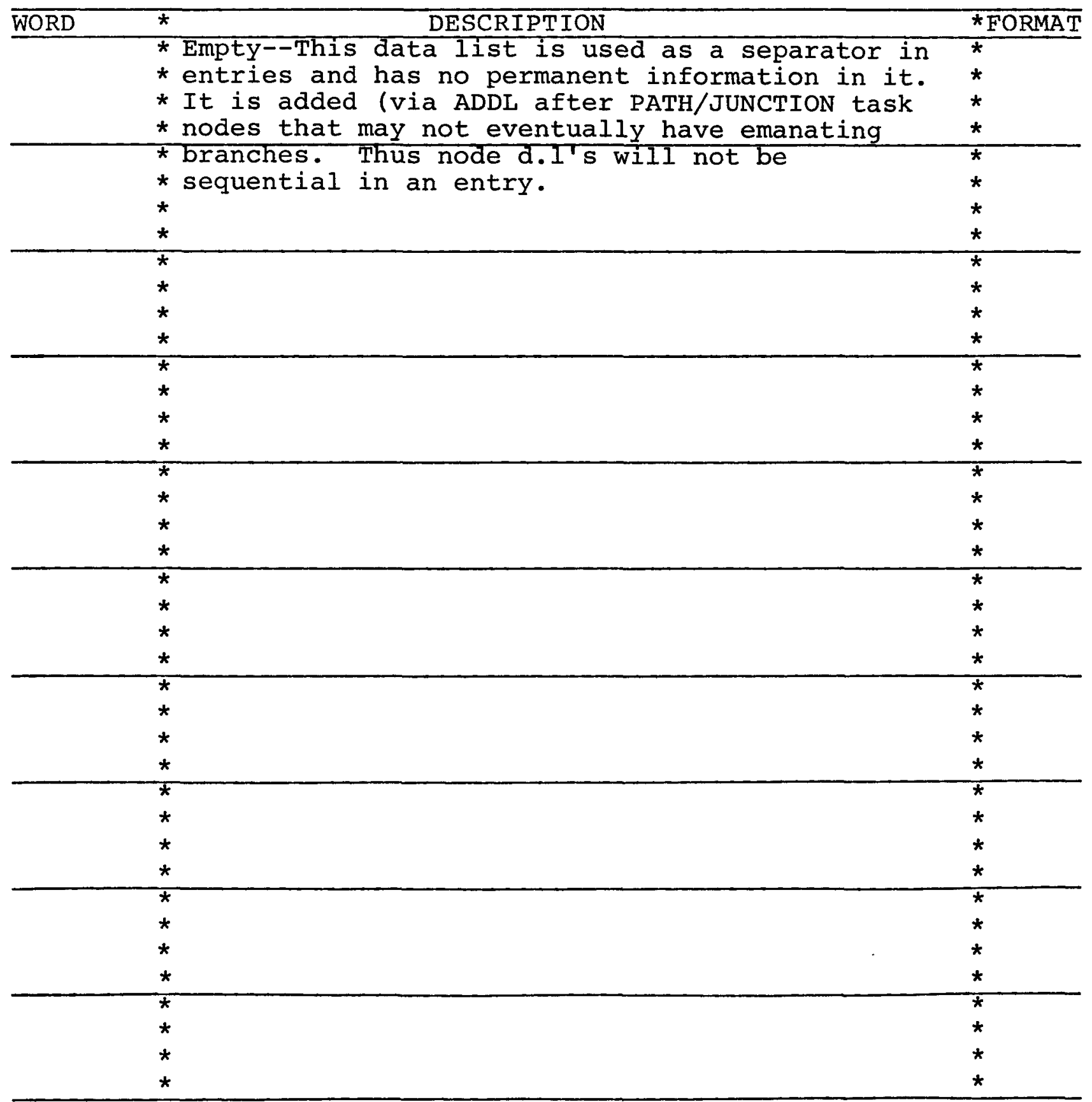


228

FACILITY RECORD DEFINITIONS 
DATA LIST DESCRIPTION

$B-29$

IDENTIFICATION

:FACILITY ENTRY (FIRST DATA LIST)

(FACI)

REVISED/CREATION DATE:12/8/80--Extended 3/21/81

BY

: JP

JDS

PAGE

$: 1$

DATA TYPE

:FACI, BLANK $n$ is part of ID (e.g., FACI-n)

\begin{tabular}{|c|c|c|c|}
\hline WORD & $\star \quad$ DESCRIPTION & & RMAT \\
\hline 1 & $\begin{array}{l}\text { * Maximum number of " } \mathrm{X} \text { " space node labels } \\
\star \\
\star\end{array}$ & $\begin{array}{l}* \\
\star \\
* \\
\star\end{array}$ & $\bar{I}$ \\
\hline 2 & $\begin{array}{l}\text { * Minimum number of "S" space node labels } \\
\star \\
\star\end{array}$ & $\begin{array}{l}* \\
\star \\
* \\
*\end{array}$ & I \\
\hline 3 & $\begin{array}{l}\text { * Level indicator (0-level } 0 \text { not present, } \\
* 1-\text { present) } \\
\star\end{array}$ & $\begin{array}{l}* \\
\star \\
* \\
*\end{array}$ & I \\
\hline 4 & $\begin{array}{l}\text { * Level indicator }(0-\text { level } 1 \text { not present, } \\
\text { * } 1 \text { - present) } \\
\star\end{array}$ & $\begin{array}{l}* \\
\star \\
* \\
\star\end{array}$ & I \\
\hline 5 & $\begin{array}{l}\text { * Level indicator (0-level } 2 \text { not present, } \\
\text { * } 1 \text { - present) } \\
\text { * }\end{array}$ & $\begin{array}{l}* \\
* \\
\star \\
\star\end{array}$ & I \\
\hline 6 & $\begin{array}{l}\text { * Level indicator (0-level } 3 \text { not present, } \\
\text { * } 1 \text { - present) } \\
\text { * }\end{array}$ & $\begin{array}{l}* \\
* \\
* \\
*\end{array}$ & I \\
\hline 7 & $\begin{array}{l}\text { * Level indicator }(0-\text { level } 4 \text { not present, } \\
\text { * } 1 \text { - present) } \\
\text { * }\end{array}$ & $\begin{array}{l}\text { * } \\
\text { * } \\
\text { * } \\
\text { * }\end{array}$ & I \\
\hline 8 & $\begin{array}{l}\text { * Level indicator }(0-\text { level } 5 \text { not present, } \\
* 1-\text { present }) \\
*\end{array}$ & $\begin{array}{l}* \\
\star \\
* \\
*\end{array}$ & I \\
\hline 9 & $\begin{array}{l}\text { * Level indicator }(0-\text { level } 6 \text { not present, } \\
\star 1-\text { present }) \\
\star\end{array}$ & $\begin{array}{l}\text { ॠ } \\
\star \\
\star \\
\star\end{array}$ & I \\
\hline 10 & $\begin{array}{l}\text { * Level indicator }(0-\text { level } 7 \text { not present, } \\
\star 1-\text { present } \\
\star\end{array}$ & $\begin{array}{l}\text { * } \\
\star \\
\star \\
*\end{array}$ & $\mathbf{I}$ \\
\hline
\end{tabular}


DATA LIST DESCRIPTION B-30

IDENTIFICATION

: FACILITY ENTRY (FIRST DATA LIST) (FACL)

REVISED/CREATION DATE: 12/8/80--Extended 3/21/81

BY

: JP JDS

PAGE

$: 2 \quad$ OF 2

DATA TYPE

$:$ FACI, BLANK, $\mathrm{n}$ is part of ID (e.g., FACI-n)

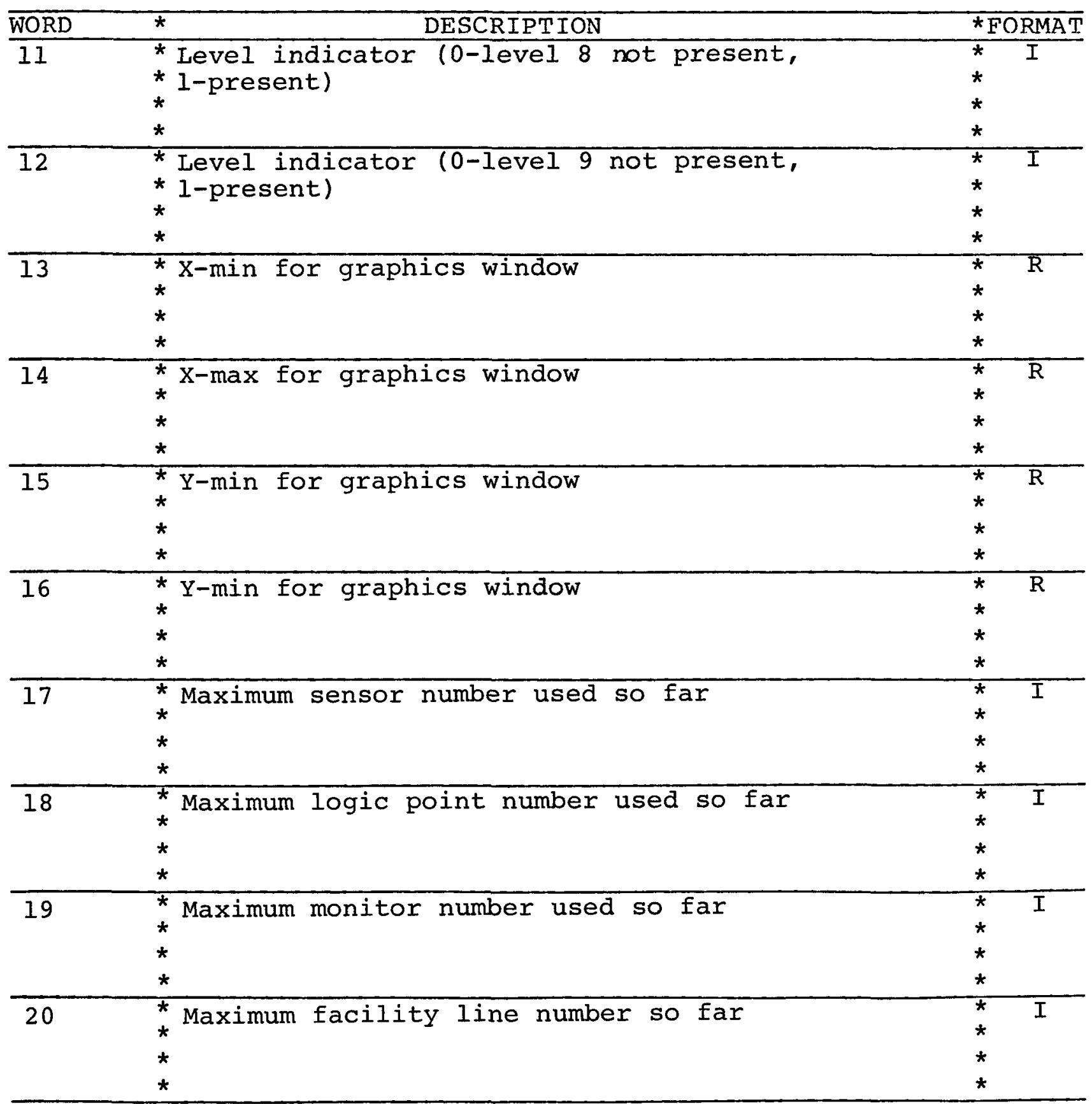


REVISED/CREATION DATE: $12 / 23 / 80$

BY

: JP

PAGE

$: 11$ OF 1

DATA TYPE

: PATH, PATH NUMBER

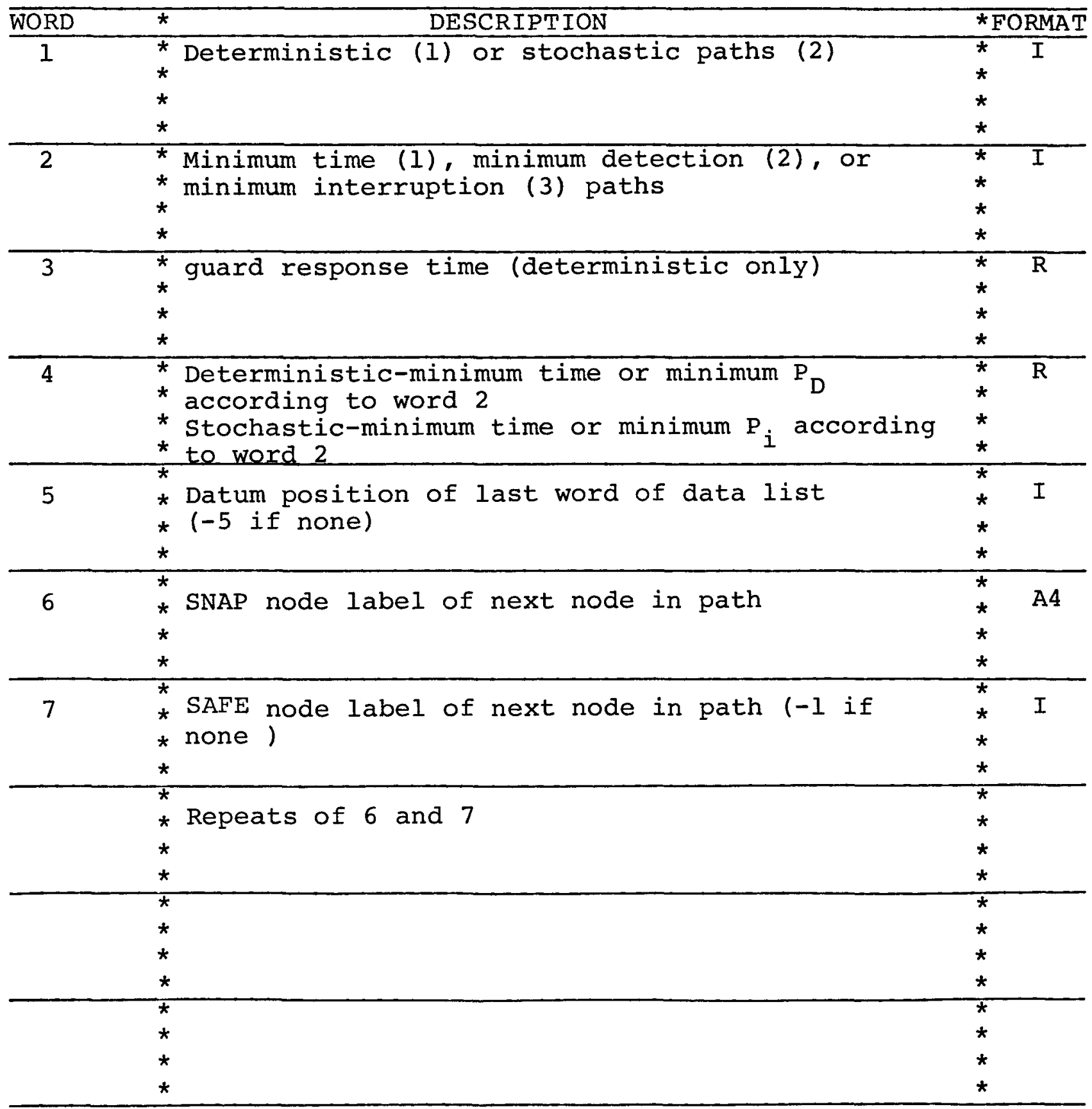


DATA LIST DESCRIPTION

$B-32$

IDENTIFICATION

: SNAP Card in Facility Entry (FACL)

REVISED/CREATION DATE: 3/13/81

BY

: JP

PAGE

$: 1$ OF 3

DATA TYPE

: SNAP, SCNR NUMBER

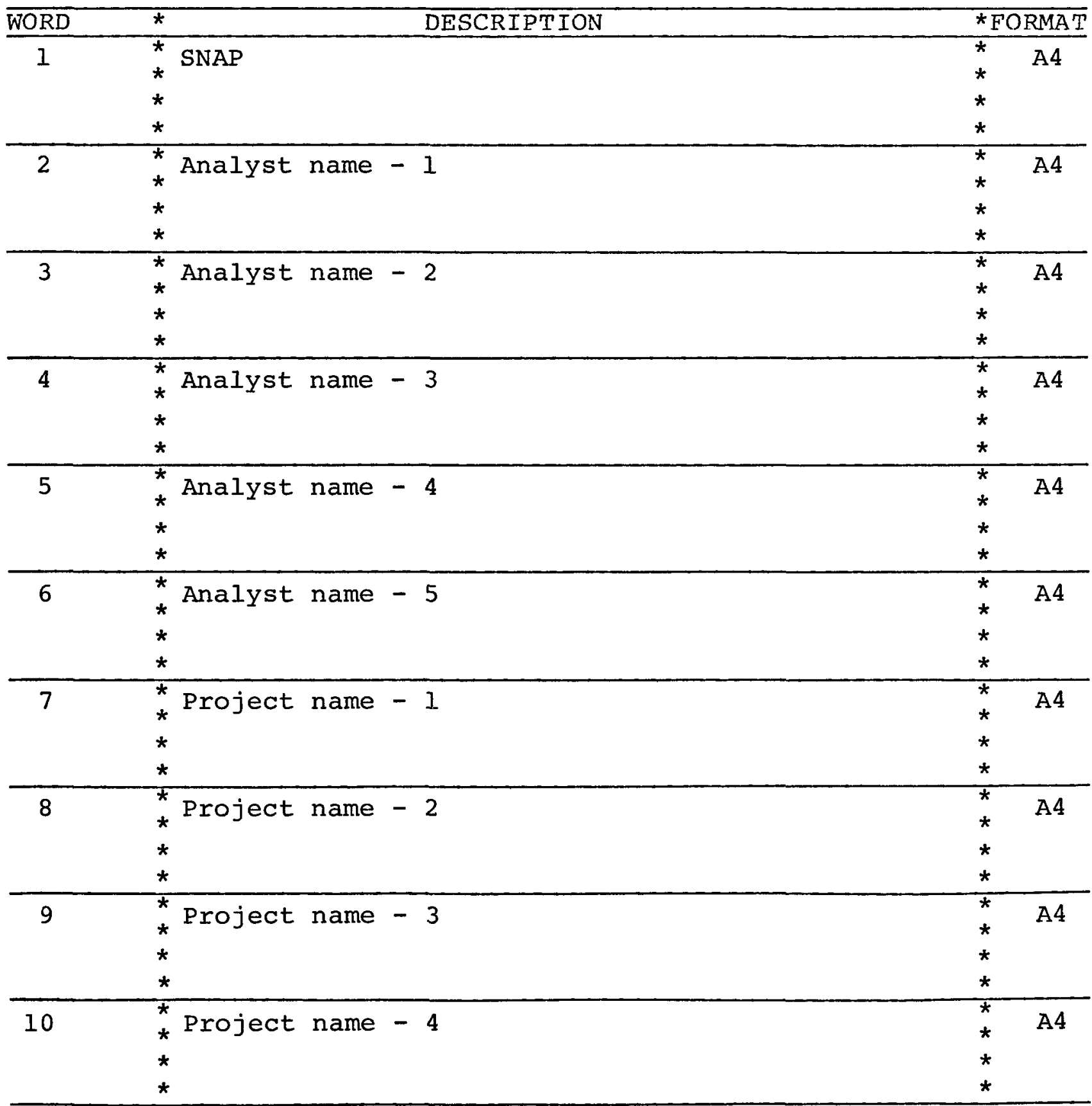


IDENTIFICATION

: SNAP Card in Facility Entry (FACL)

REVISED/CREATION DATE: $3 / 13 / 81$

BY

: JP

PAGE

$: 2$ OF 3

DATA TYPE

: SNAP, SCNR NUMBER

\begin{tabular}{|c|c|c|c|}
\hline \multirow{2}{*}{$\frac{\overline{\text { WORD }}}{11}$} & \multirow{3}{*}{$\begin{array}{l}* \\
* \text { PESCRIPTION } \\
*\end{array}$} & \multicolumn{2}{|c|}{ *FORMAT } \\
\hline & & ћ & $\overline{\mathrm{A} 4}$ \\
\hline & & * & \\
\hline & * & * & \\
\hline & * & * & \\
\hline \multirow[t]{4}{*}{12} & * Month & $\bar{*}$ & $\bar{I}$ \\
\hline & * & * & \\
\hline & $\star$ & * & \\
\hline & * & * & \\
\hline \multirow[t]{4}{*}{13} & * Day & * & $\bar{I}$ \\
\hline & * & * & \\
\hline & * & * & \\
\hline & $\star$ & * & \\
\hline \multirow[t]{4}{*}{14} & * Year & * & $\mathrm{I}$ \\
\hline & & * & \\
\hline & * & * & \\
\hline & * & * & \\
\hline \multirow[t]{3}{*}{15} & ${ }^{*}$ Number of Runs & * & I \\
\hline & $\begin{array}{l}\star \\
\star\end{array}$ & * & \\
\hline & * & * & \\
\hline \multirow[t]{4}{*}{16} & * TTFIN (blank if default) & & $(\mathrm{A} 4)$ \\
\hline & * & * & \\
\hline & $\star$ & * & \\
\hline & $\star$ & * & \\
\hline \multirow[t]{4}{*}{17} & * NNTRY & * & $\bar{I}$ \\
\hline & * & * & \\
\hline & * & * & \\
\hline & * & * & \\
\hline \multirow[t]{4}{*}{18} & ${ }^{\star} \mathrm{ECHO}(\mathrm{C}, \mathrm{P}, \mathrm{N})$ & * & $\overline{A 4}$ \\
\hline & & * & \\
\hline & * & * & \\
\hline & $\star$ & * & \\
\hline \multirow[t]{4}{*}{19} & ${ }^{\star}$ HISTO $(\mathrm{Y}, \mathrm{N})$ & * & A4 \\
\hline & * & * & \\
\hline & * & * & \\
\hline & $\star$ & * & \\
\hline \multirow[t]{3}{*}{20} & ${ }_{\star}^{*} \operatorname{FSTAT}(\mathrm{C}, \mathrm{P}, \mathrm{N})$ & * & A4 \\
\hline & $*$ & * & \\
\hline & $\star$ & * & \\
\hline
\end{tabular}


DATA LIST DESCRIPTION B-34

$\begin{array}{ll}\text { IDENTIFICATION } & : \frac{\text { SNAP Card in Facility Entry (FACL) }}{3 / 13 / 81} \\ \text { REVISED/CREATION DATE: } & : \frac{\mathrm{JP}}{3} \\ \text { BY } & : \frac{3}{\text { SNAP }}, \text { SCNR NUMBER } \\ \text { PAGE } & : \text { SATA TYPE }\end{array}$

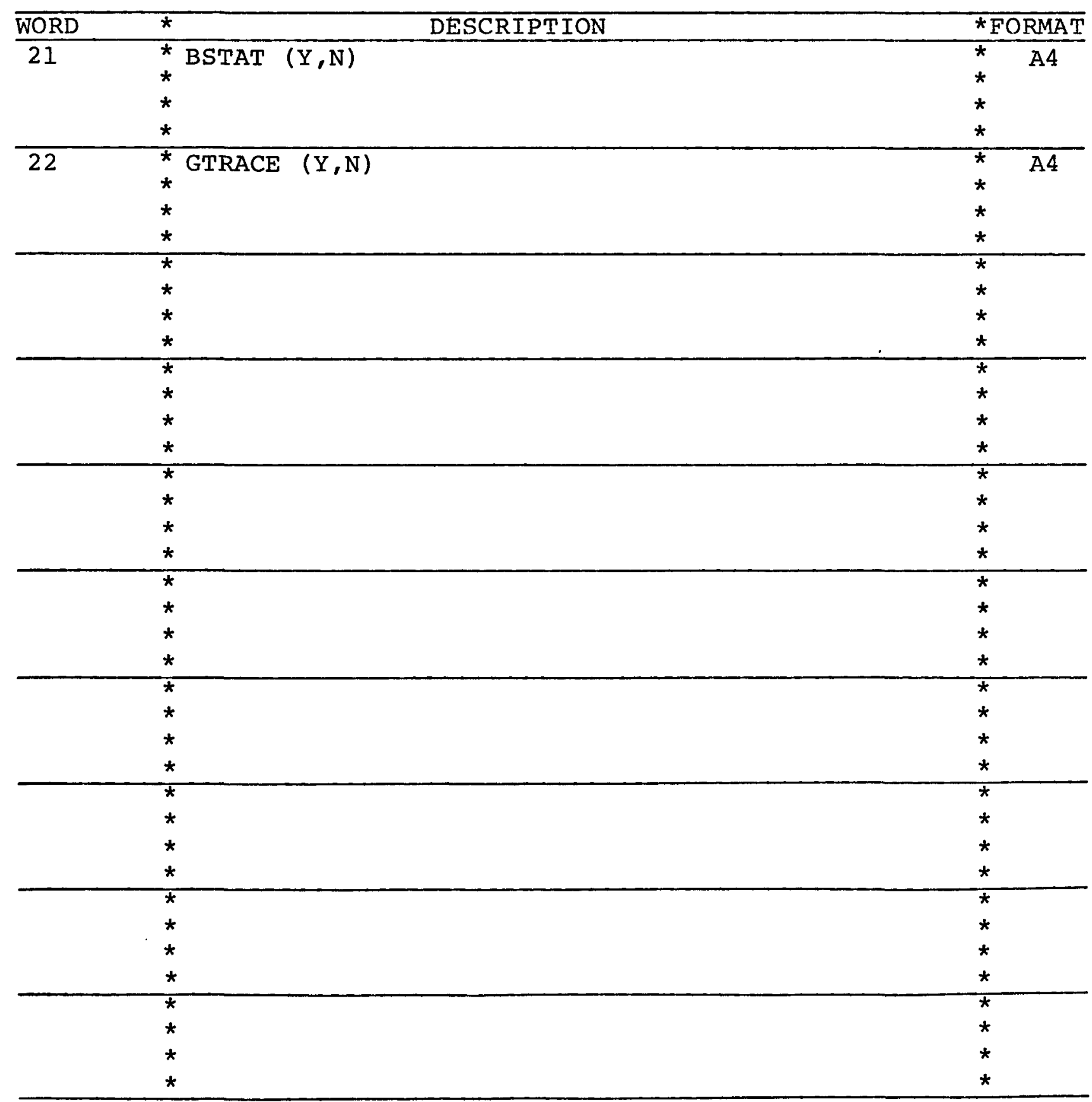


DATA LIST DESCRIPTION B-35

$\begin{array}{ll}\text { IDENTIFICATION } & : \text { SENSOR (FACL) } \\ \text { REVISED/CREATION DATE }: & \frac{1 / 20 / 81}{\text { JP }} \\ \text { BY } & : \frac{1}{\text { PAGE }} \\ \text { DATA TYPE } & : \text { SENS }, \text { LABEL }\end{array}$

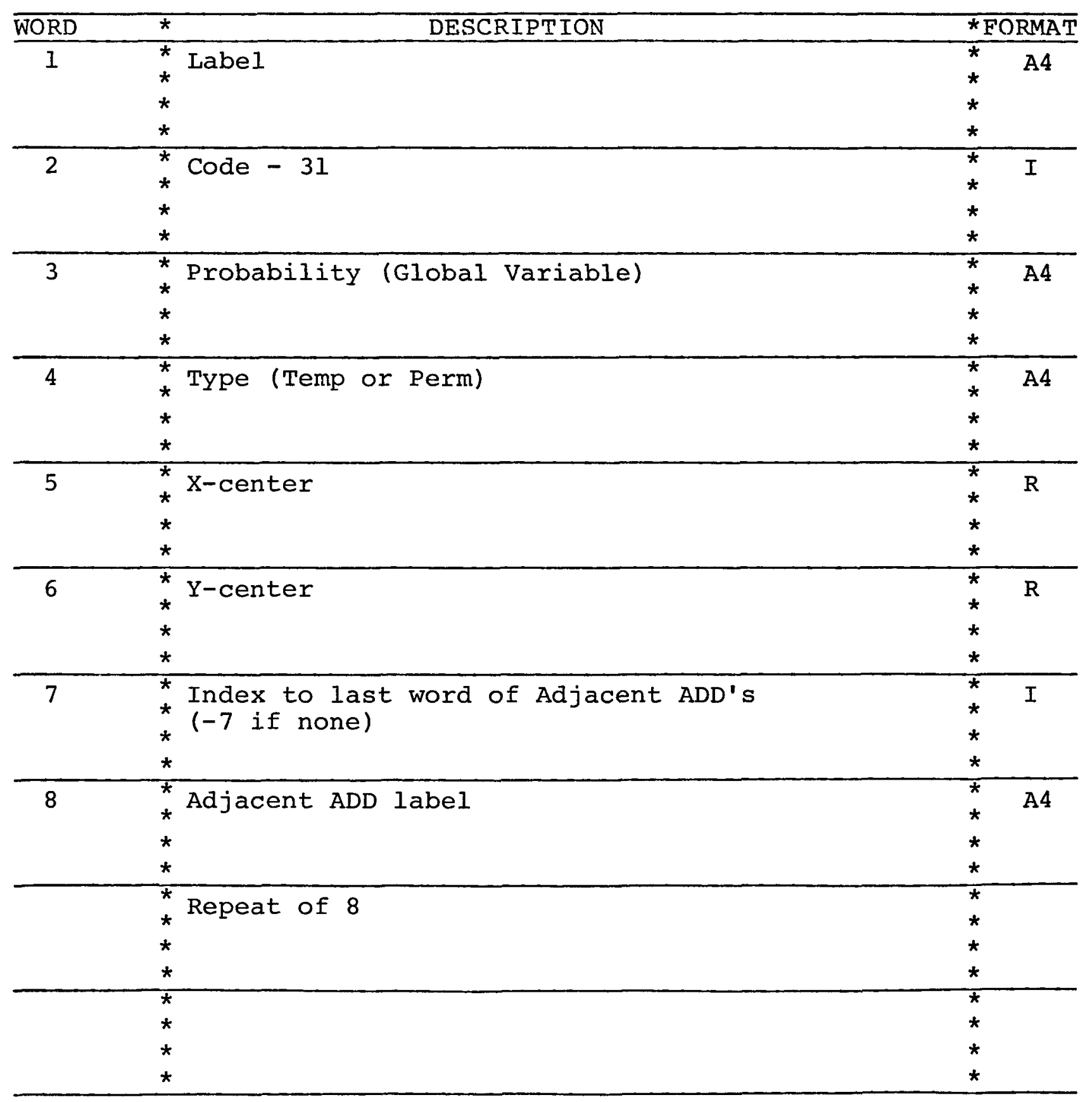


DATA LIST DESCRIPTION

$$
\text { B-36 }
$$

IDENTIFICATION

: LOGIC POINT (FACL)

REVISED/CREATION DATE: $1 / 20 / 81$

BY

: JP

PAGE

$: 1 \quad$ OF 1

DATA TYPE

: LOGI, LABEL

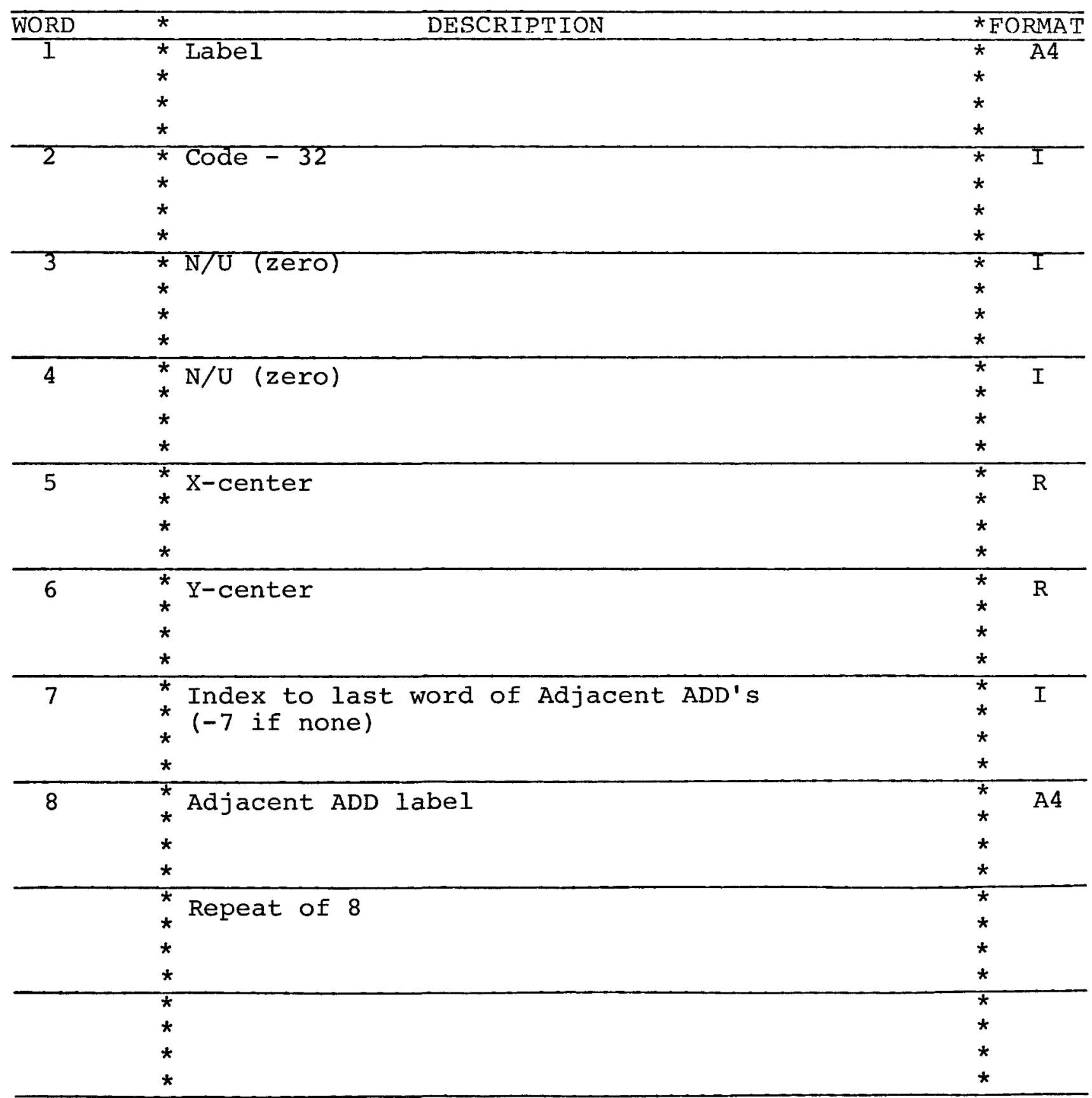


IDENTIFICATION

: MONITOR (FACL)

REVISED/CREATION DATE: 1/20/81

BY

: JP

PAGE

$: 1$

OF 1

DATA TYPE

: MONI, LABEL

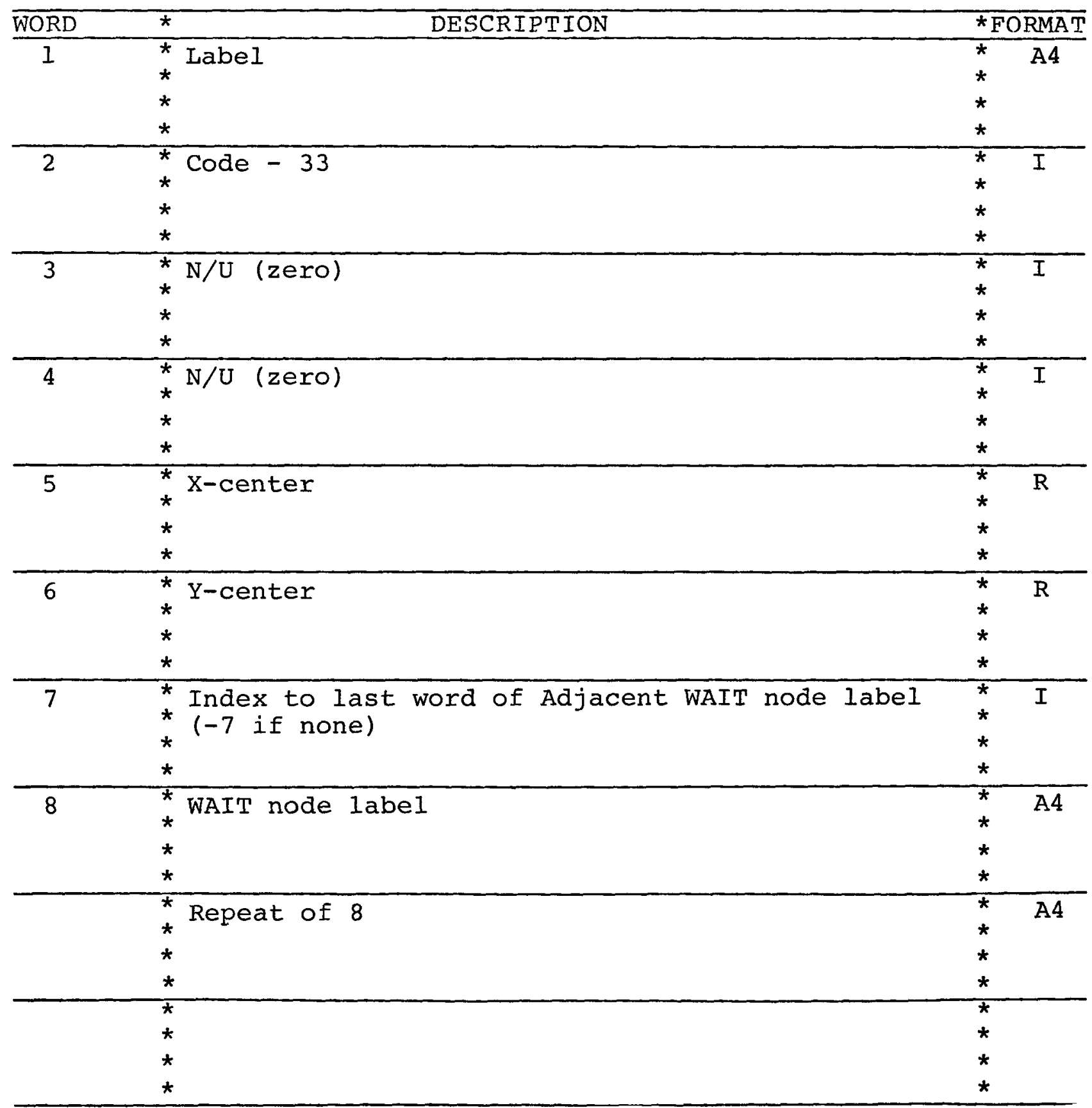


DATA LIST DESCRIPTION B-38

$\begin{array}{ll}\text { IDENTIFICATION } & : \frac{\text { PSEUDO WAIT NODES (FACL) }}{7 / 14 / 81} \\ \text { REVISED/CREATION DATE: } & : \frac{\text { JDS }}{1} \text { BY OF } 1 \\ \text { PAGE } & : \frac{1}{\text { PWAI }, \text { LABEL }} \\ \text { DATA TYPE } & \text { P }\end{array}$

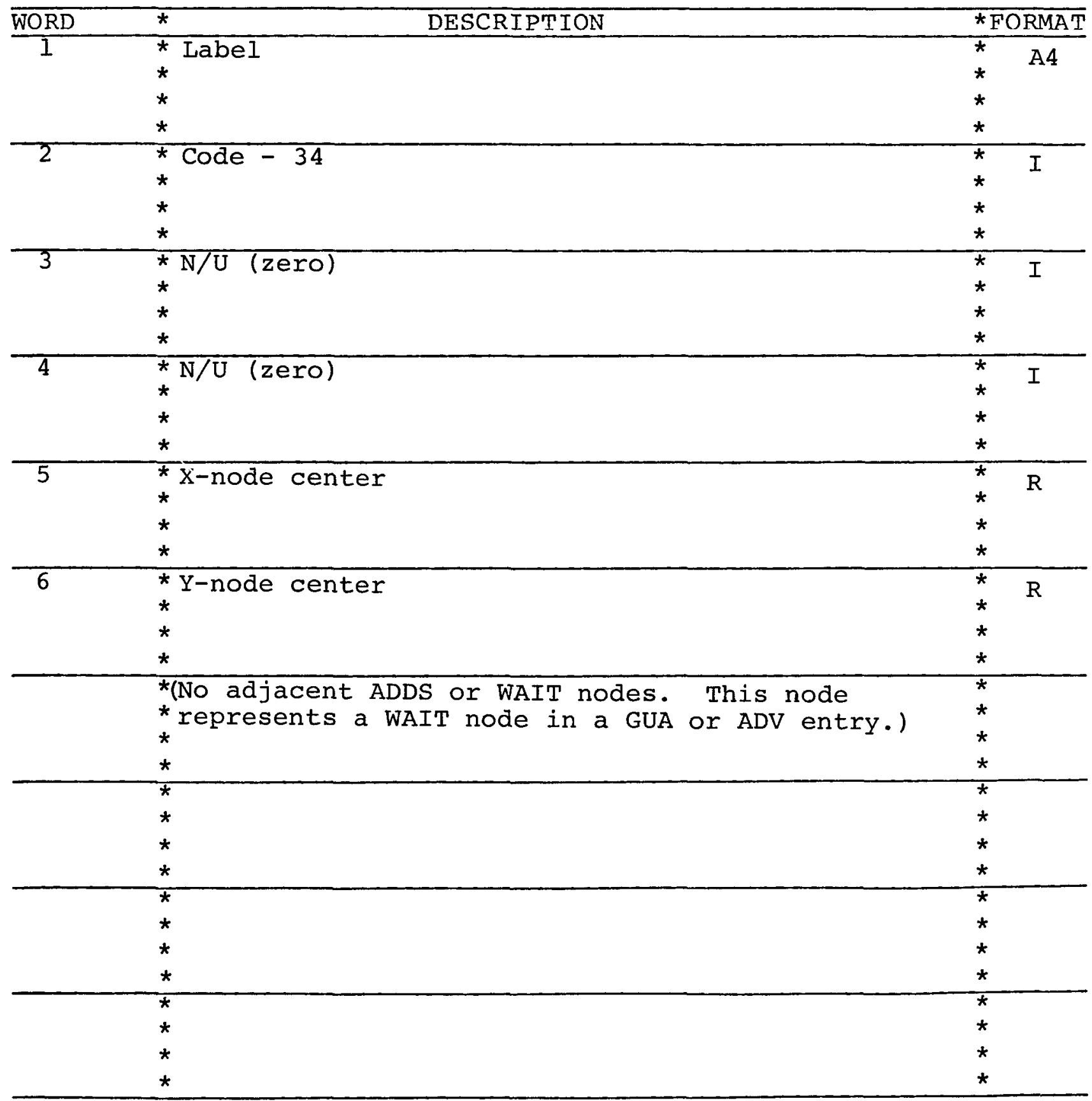




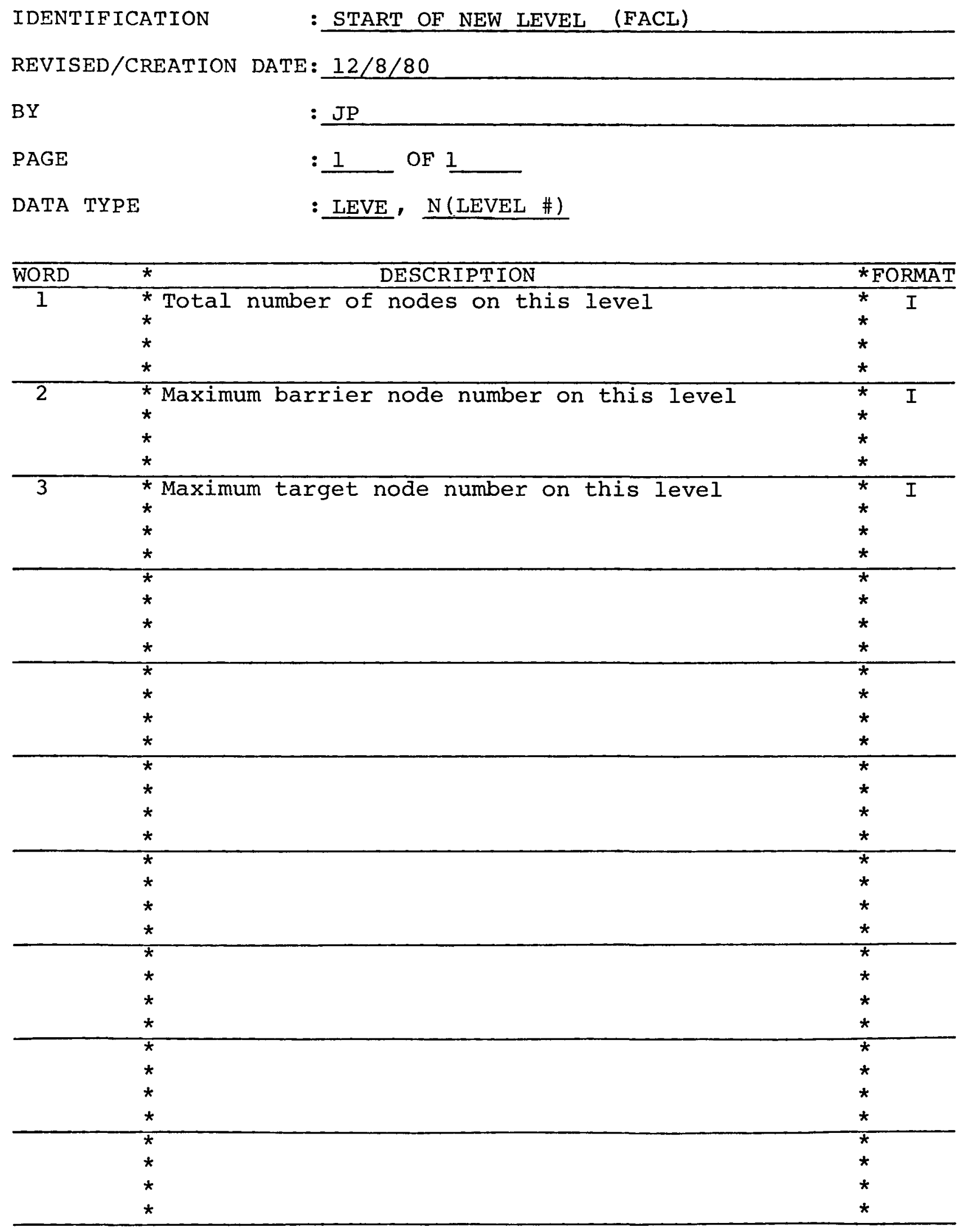


IDENTIFICATION

: FACILITY LINE (FACL)

REVISED/CREATION DATE: $12 / 8 / 80$

BY

: JP

PAGE

$: 1 \quad$ OF 1

DATA TYPE

: LINE, N(LEVEL \#)

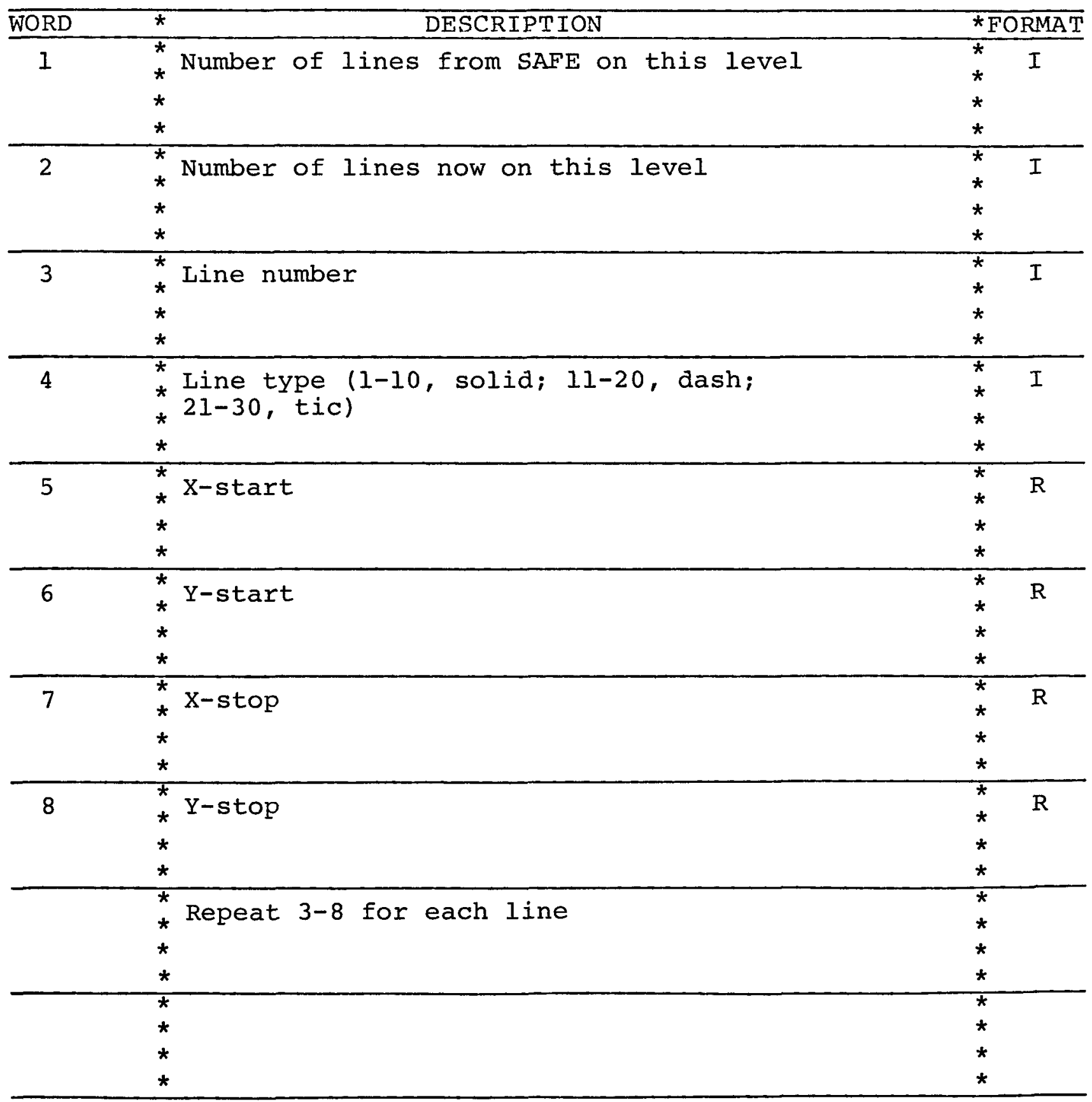




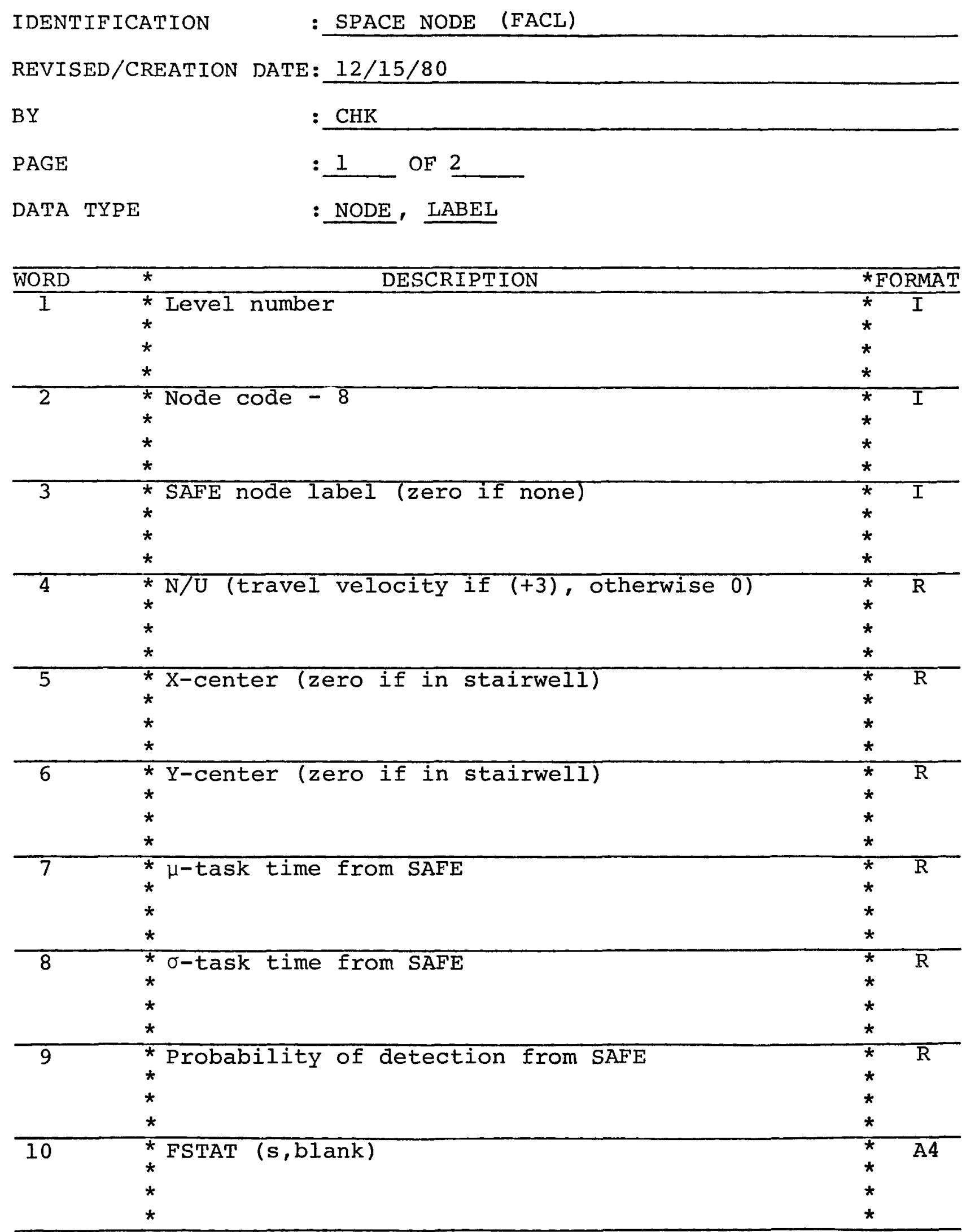


DATA LIST DESCRIPTION

IDENTIFICATION

: SPACE NODE (FACL)

REVISED/CREATION DATE: $12 / 15 / 80$

BY

: $\mathrm{CHK}$

PAGE

$: \underline{2}$ OF 2

DATA TYPE

:NODE, LABEL

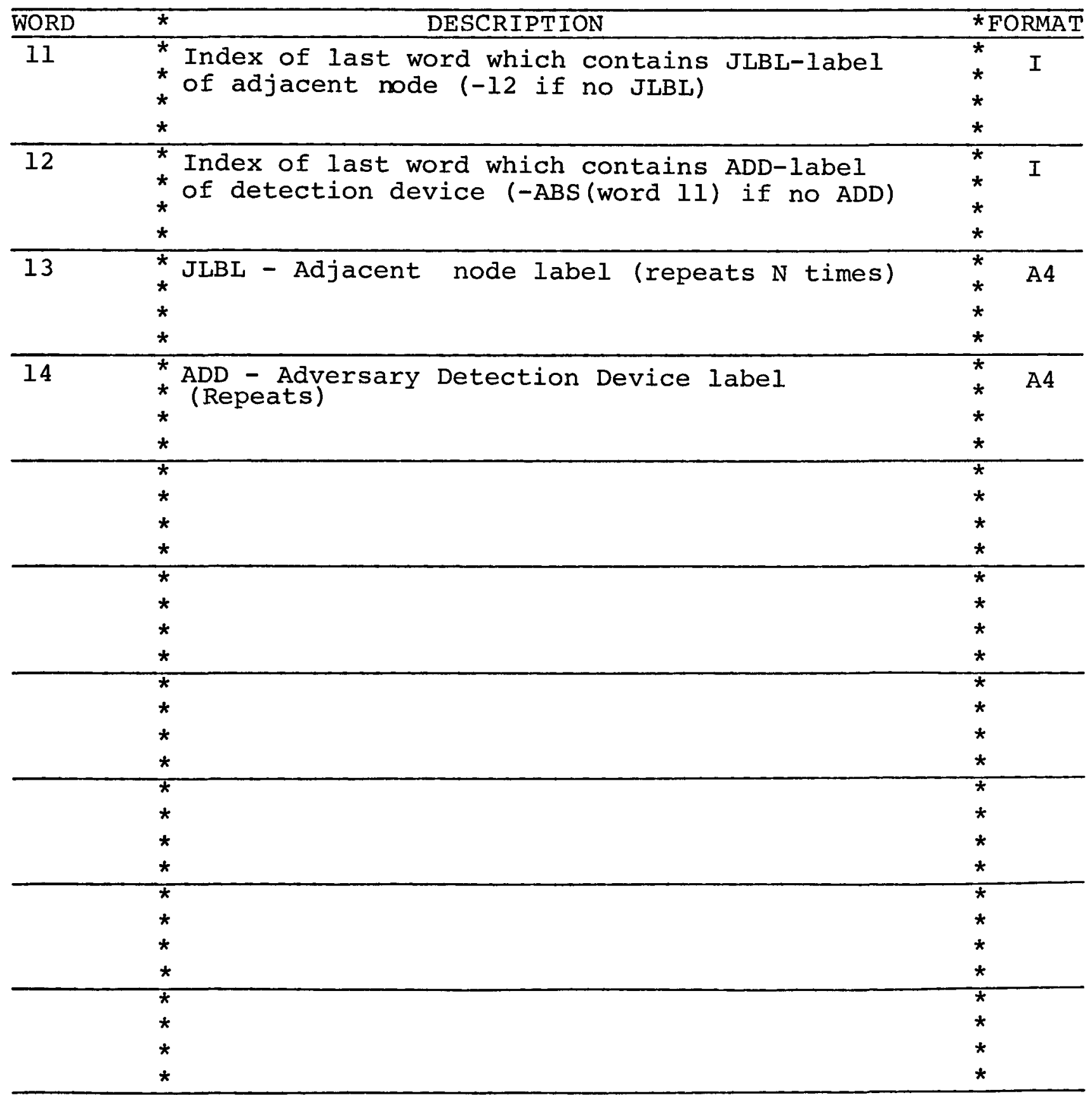




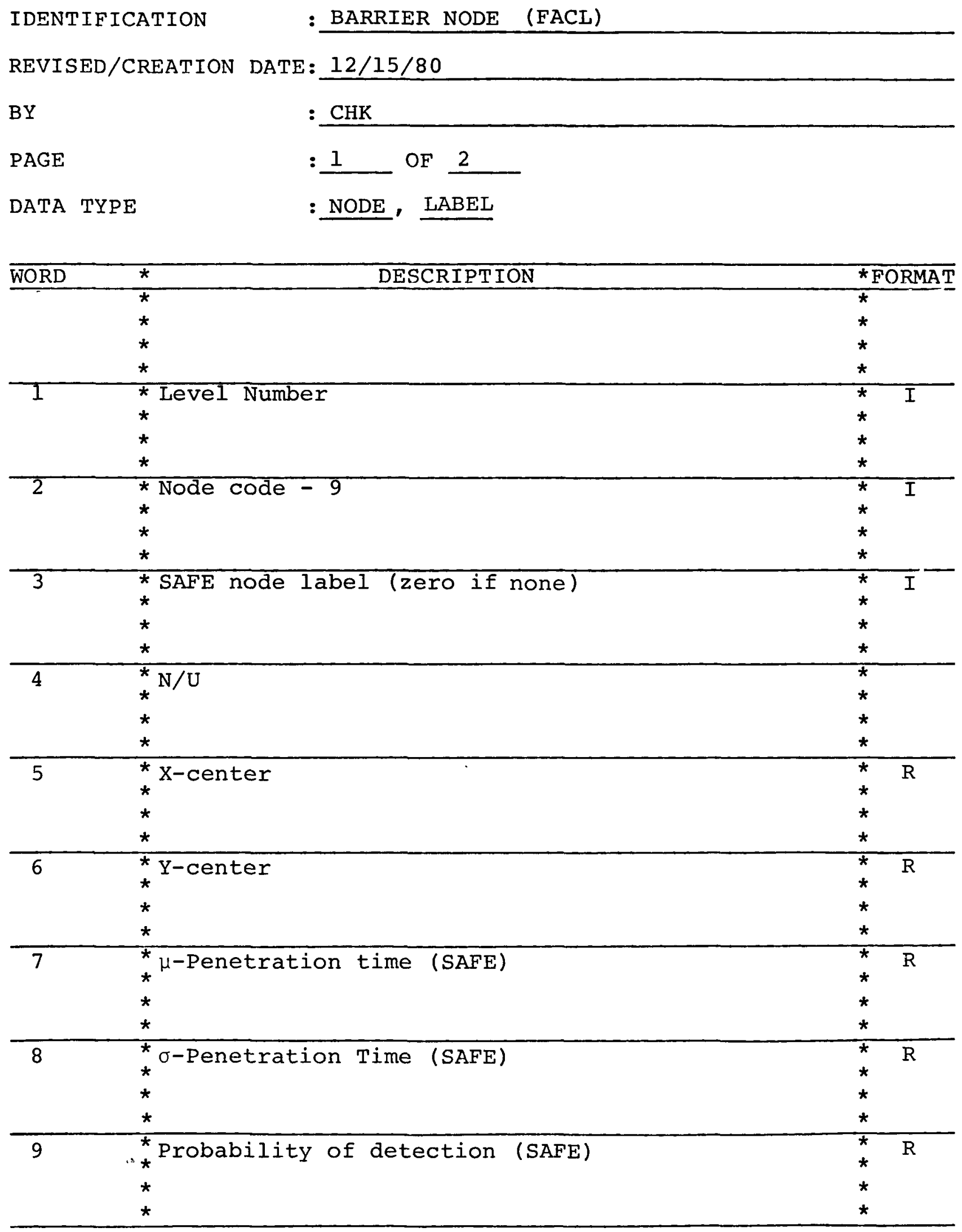




$\begin{array}{ll}\text { IDENTIFICATION } & : \text { BARRIER NODE (FACL) } \\ \text { REVISED/CREATION DATE: } & 12 / 15 / 80 \\ \text { BY } & : \text { CHK } \\ \text { PAGE } & : 2 \quad \text { OF } 2 \\ \text { DATA TYPE } & \text { :NODE }, \text { LABEL }\end{array}$

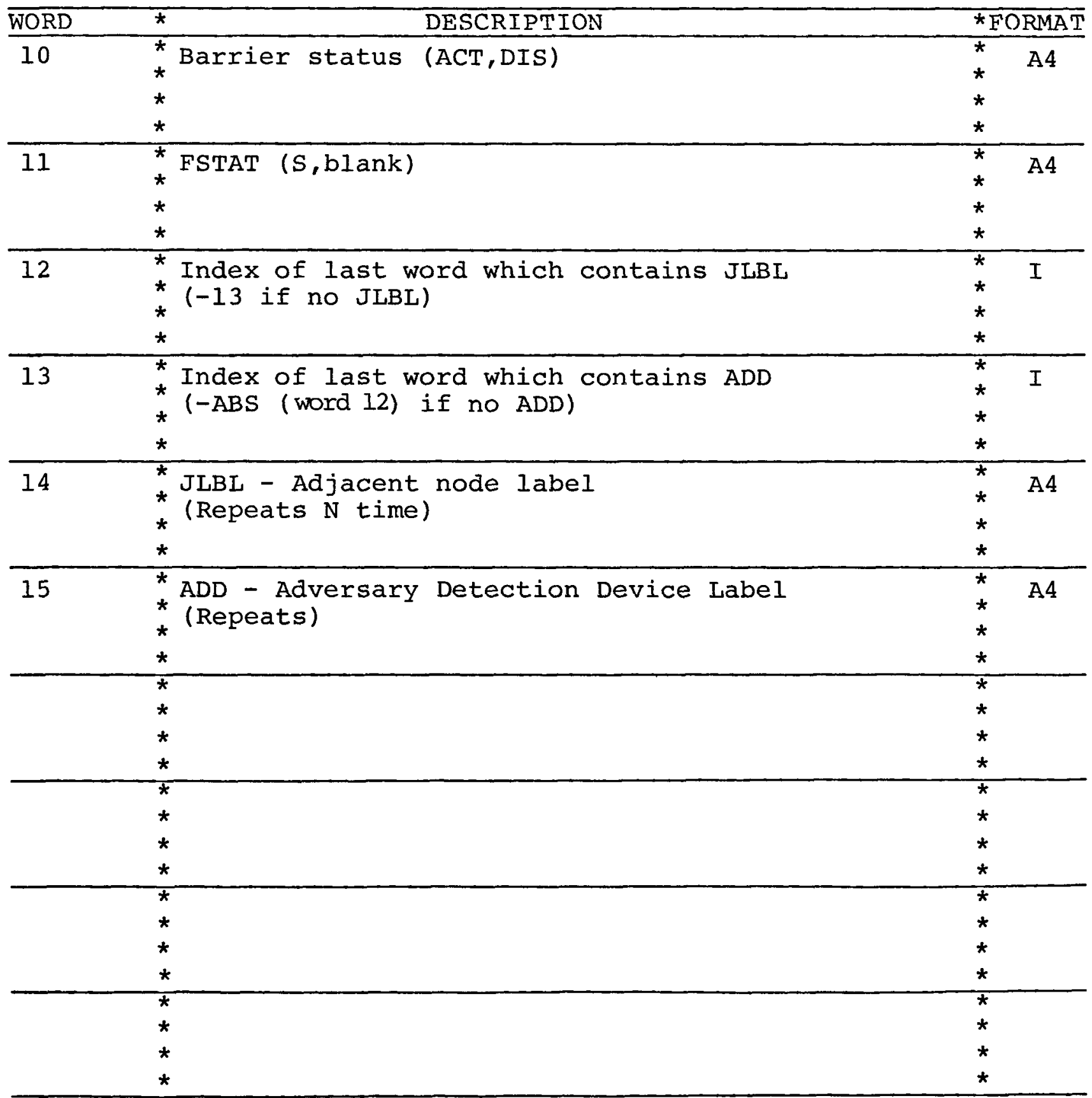




$\begin{array}{ll}\text { IDENTIFICATION } & : \frac{\text { TARGET NODE (FACL) }}{12 / 15 / 80} \\ \text { REVISED/CREATION DATE: } & : \text { CHK } \\ \text { BY } & : 11 \text { OF } 2 \\ \text { PAGE } & : \text { NODE }, \text { LABEL } \\ \text { DATA TYPE } & \end{array}$

\begin{tabular}{|c|c|c|}
\hline \multirow[t]{5}{*}{ WORD } & \multirow[t]{2}{*}{ DESCRIPTION } & ÆFORMAT \\
\hline & & $\star$ \\
\hline & * & * \\
\hline & * & * \\
\hline & * & * \\
\hline \multirow[t]{4}{*}{1} & * Level number & * \\
\hline & * & * \\
\hline & * & * \\
\hline & * & * \\
\hline \multirow[t]{4}{*}{2} & * Node code -10 & * \\
\hline & & * \\
\hline & * & * \\
\hline & $\star$ & * \\
\hline \multirow[t]{4}{*}{3} & * SAFE node label & $\overline{\mathrm{A} 4}$ \\
\hline & * & * \\
\hline & 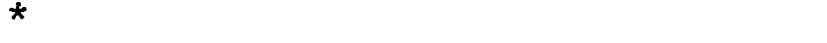 & * \\
\hline & $\star$ & * \\
\hline \multirow[t]{4}{*}{4} & $\star \mathrm{N} / \mathrm{U}$ & * \\
\hline & * & * \\
\hline & * & * \\
\hline & * & * \\
\hline \multirow[t]{4}{*}{5} & * X-center & $\mathrm{R}$ \\
\hline & * & * \\
\hline & * & * \\
\hline & * & * \\
\hline \multirow[t]{3}{*}{6} & * Y-center & $\begin{array}{ll}* \\
*\end{array}$ \\
\hline & * & * \\
\hline & $\star$ & * \\
\hline \multirow[t]{4}{*}{7} & ${ }^{\star} \mu$-Penetration time (SAFE) & $\bar{R}$ \\
\hline & * & * \\
\hline & * & * \\
\hline & * & * \\
\hline \multirow[t]{4}{*}{8} & * $\sigma$-Penetration Time (SAFE) & $\overline{\mathrm{R}}$ \\
\hline & $\star$ & * \\
\hline & * & * \\
\hline & * & * \\
\hline \multirow[t]{3}{*}{9} & ${ }_{\star}^{\star}$ Probability of detection (SAFE) & * $\mathrm{R}$ \\
\hline & * & * \\
\hline & * & $\star$ \\
\hline
\end{tabular}


DATA LIST DESCRIPTION B $\quad \mathrm{B}-46$

$\begin{array}{ll}\text { IDENTIFICATION } & : \text { TARGET NODE (FACL) } \\ \text { REVISED/CREATION DATE: } & 12 / 15 / 80 \\ \text { BY } & : \text { CHK } \\ \text { PAGE } & : 2 \\ \text { DATA TYPE } & : \text { NODE }, \text { LABEL }\end{array}$

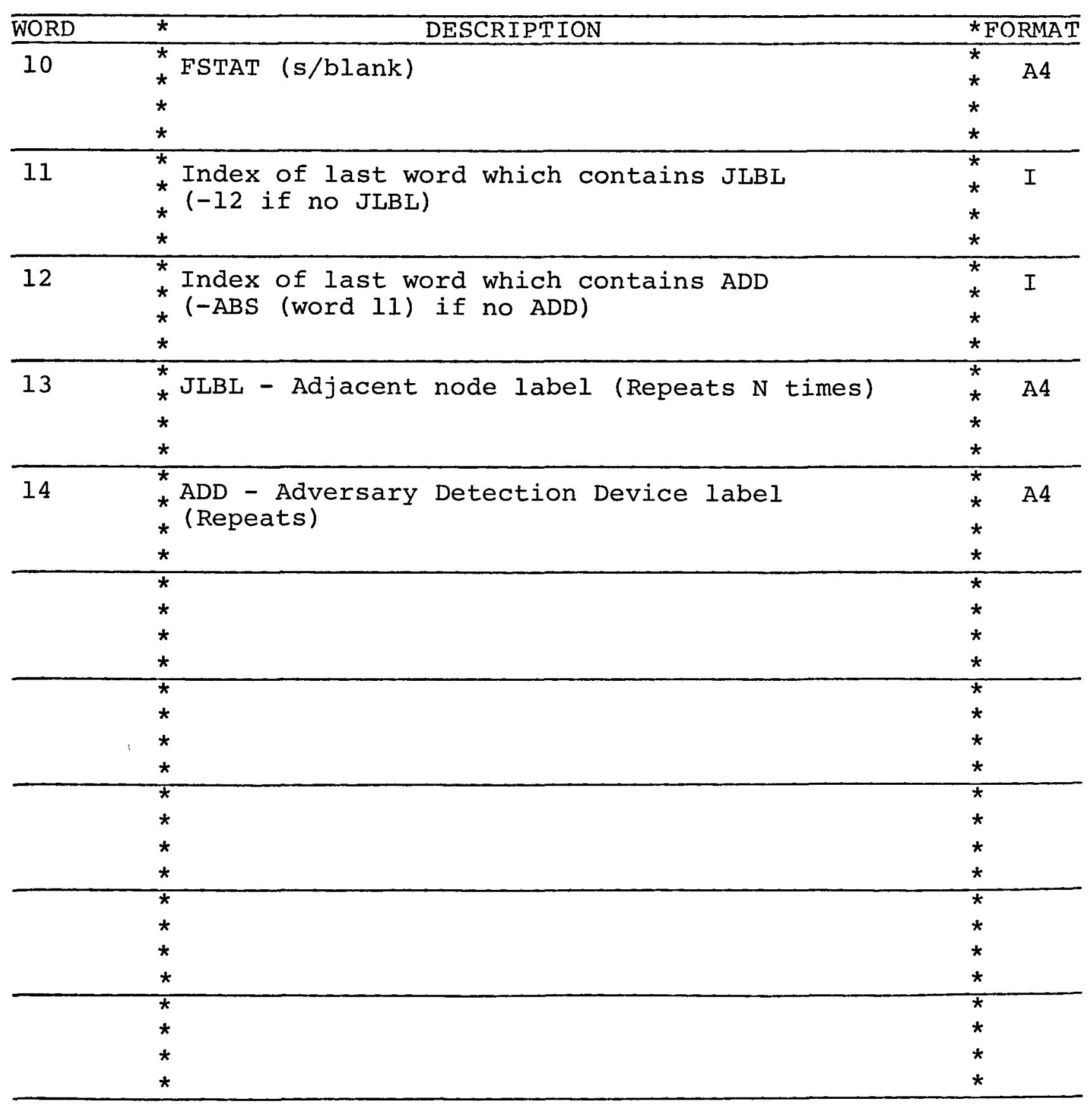


STATUS VARIABLE FILE RECORD DEFINITIONS 
DATA LIST DESCRIPTION

B-47

$\begin{array}{ll}\text { IDENTIFICATION } & : \text { STAT HEADER (STAT) } \\ \text { REVISED/CREATION } & : \frac{1 / 21 / 81}{\text { JDS }} \\ \text { BY } & : \frac{1}{\text { PAGE }} \\ \text { DATA TYPE } & : \text { HEAD }, \text { STAT }\end{array}$

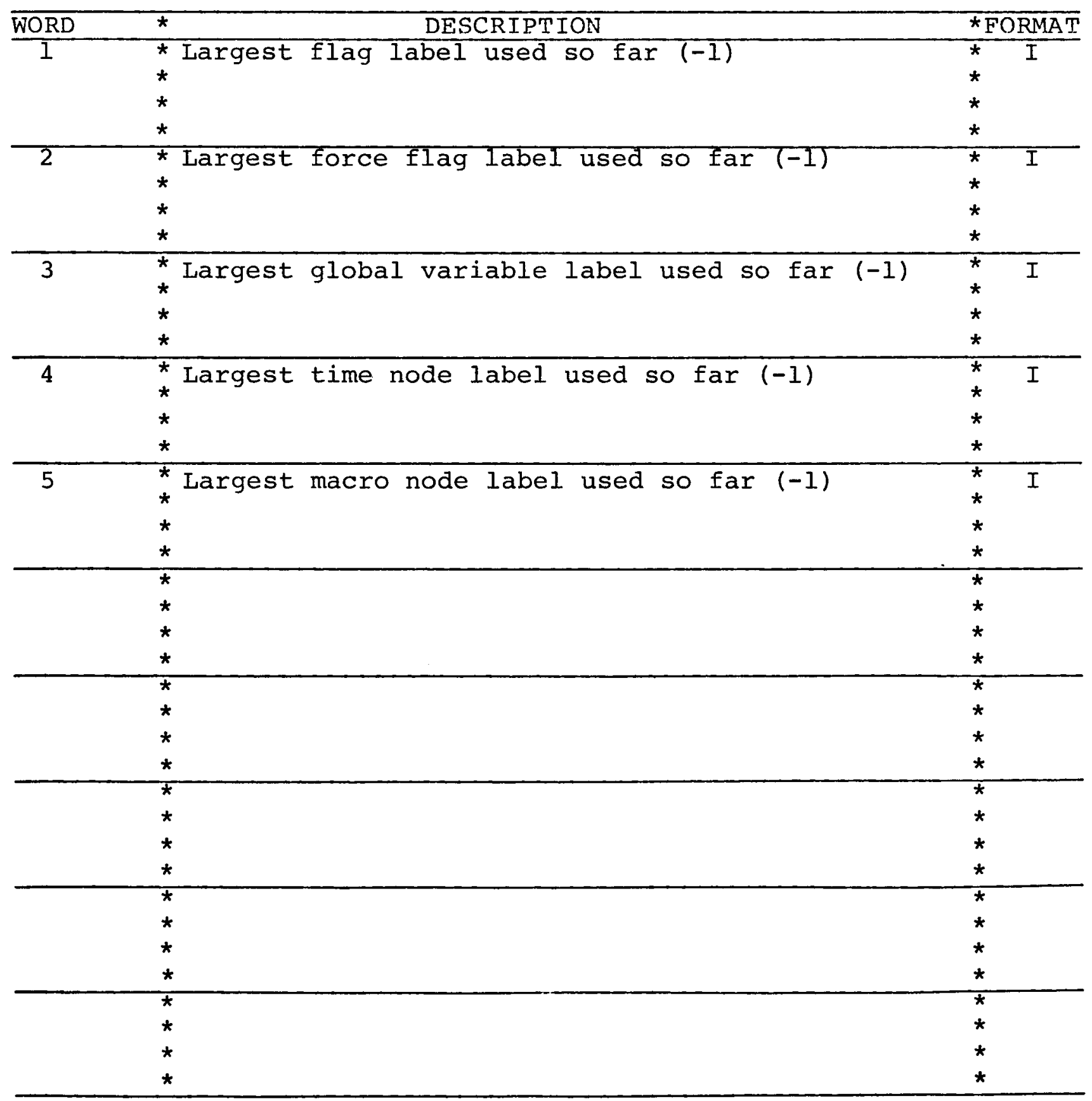




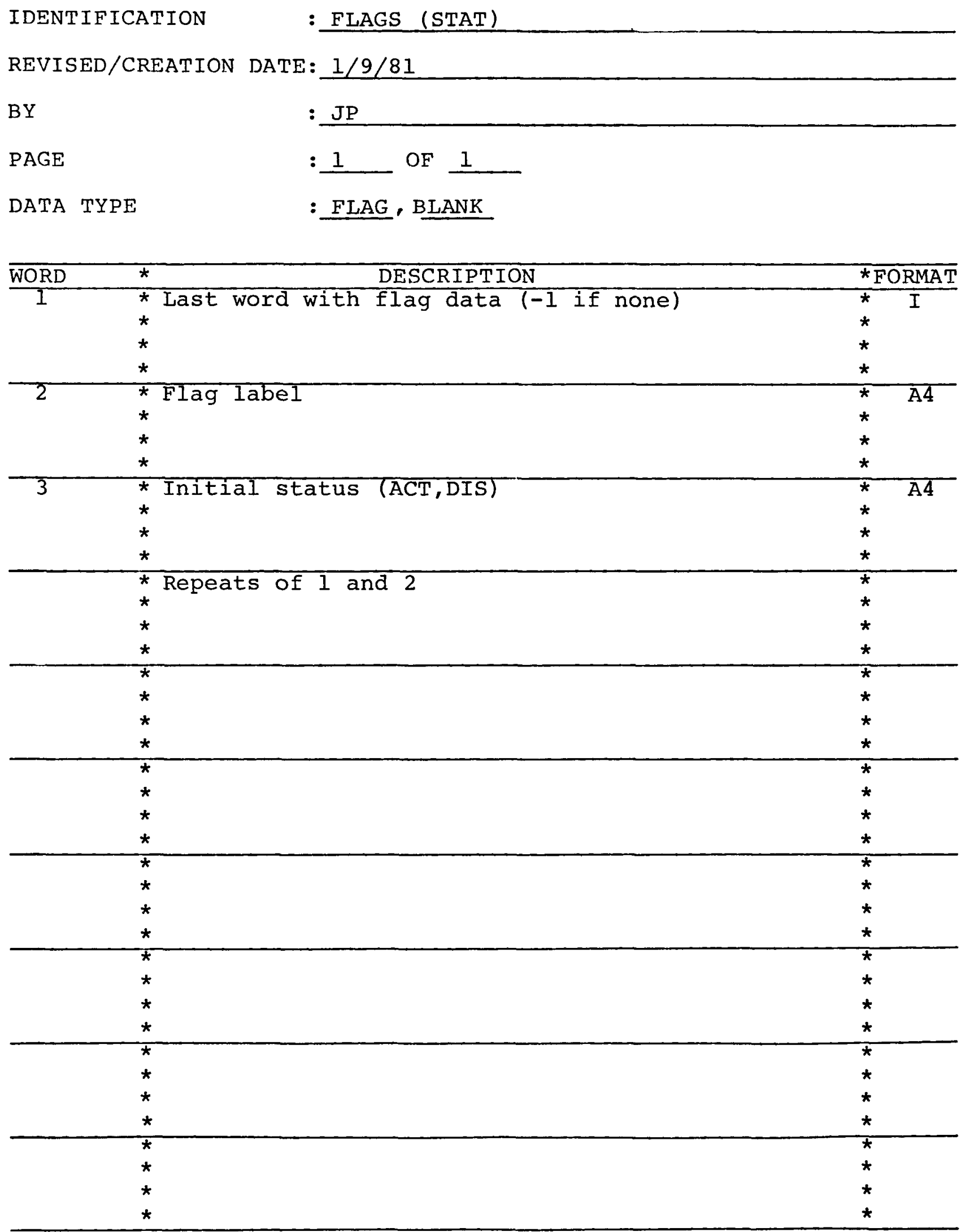


DATA LIST DESCRIPTION

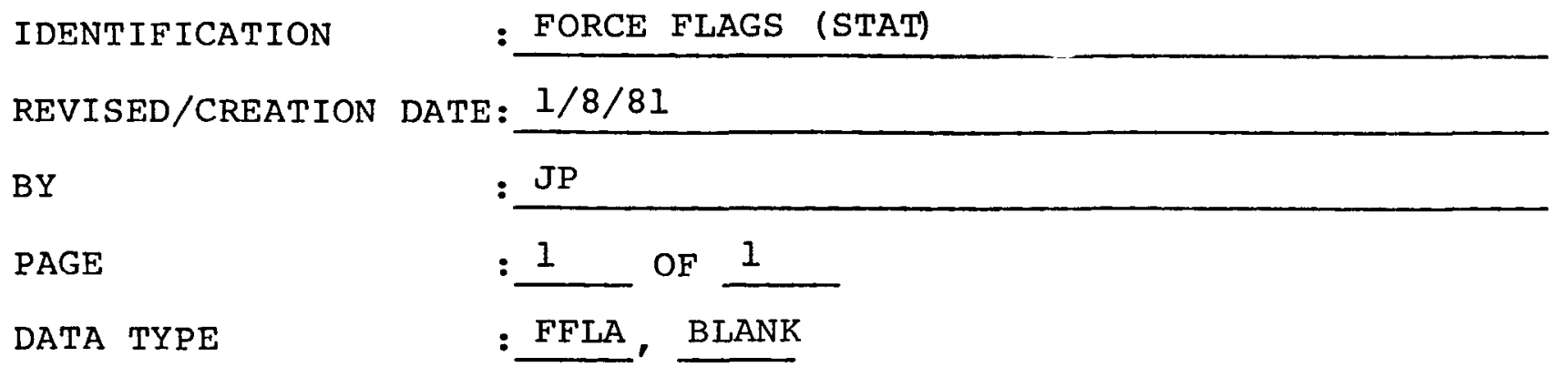

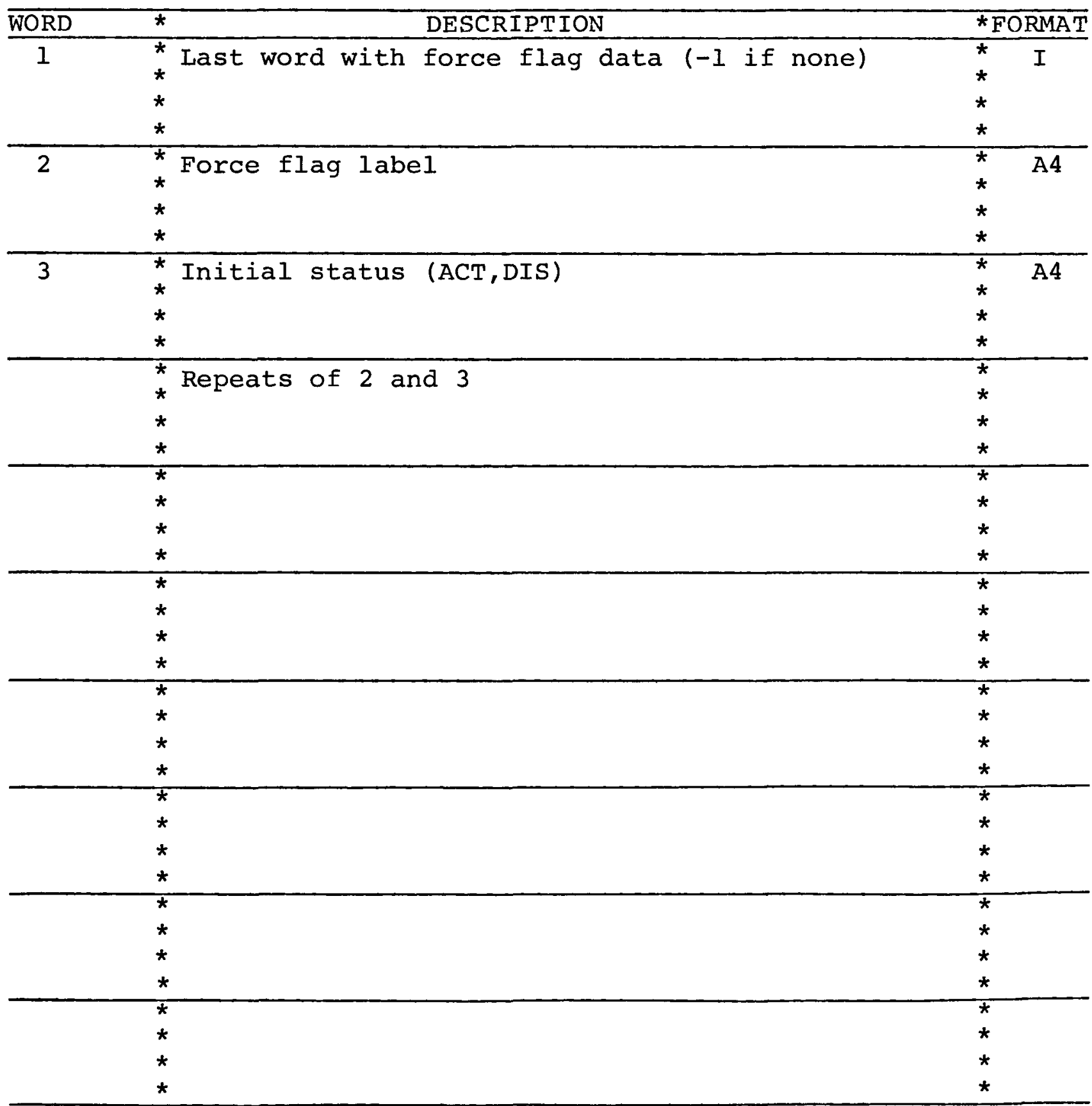


DATA LIST DESCRIPTION B-50

$\begin{array}{ll}\text { IDENTIFICATION } & : \text { GLOBAL VARIABLES (STAT) } \\ \text { REVISED/CREATION DATE } & \frac{1 / 8 / 81}{\text { JP }} \\ \text { BY } & : \frac{1}{\text { PAGE }} \\ \text { DATA TYPE } & : \text { GLOB }, \text { BLANK }\end{array}$

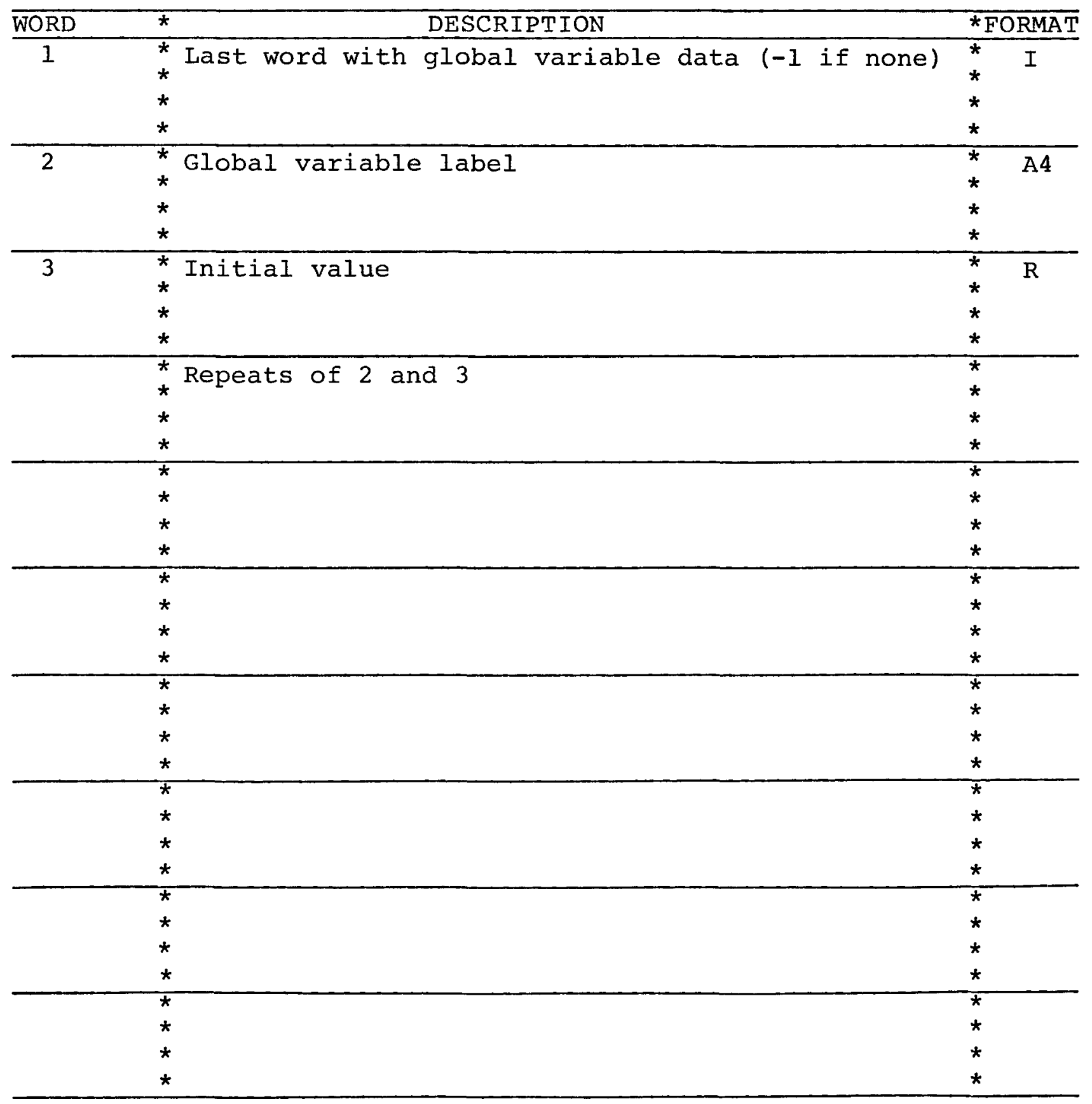


DATA LIST DESCRIPTION B-5I

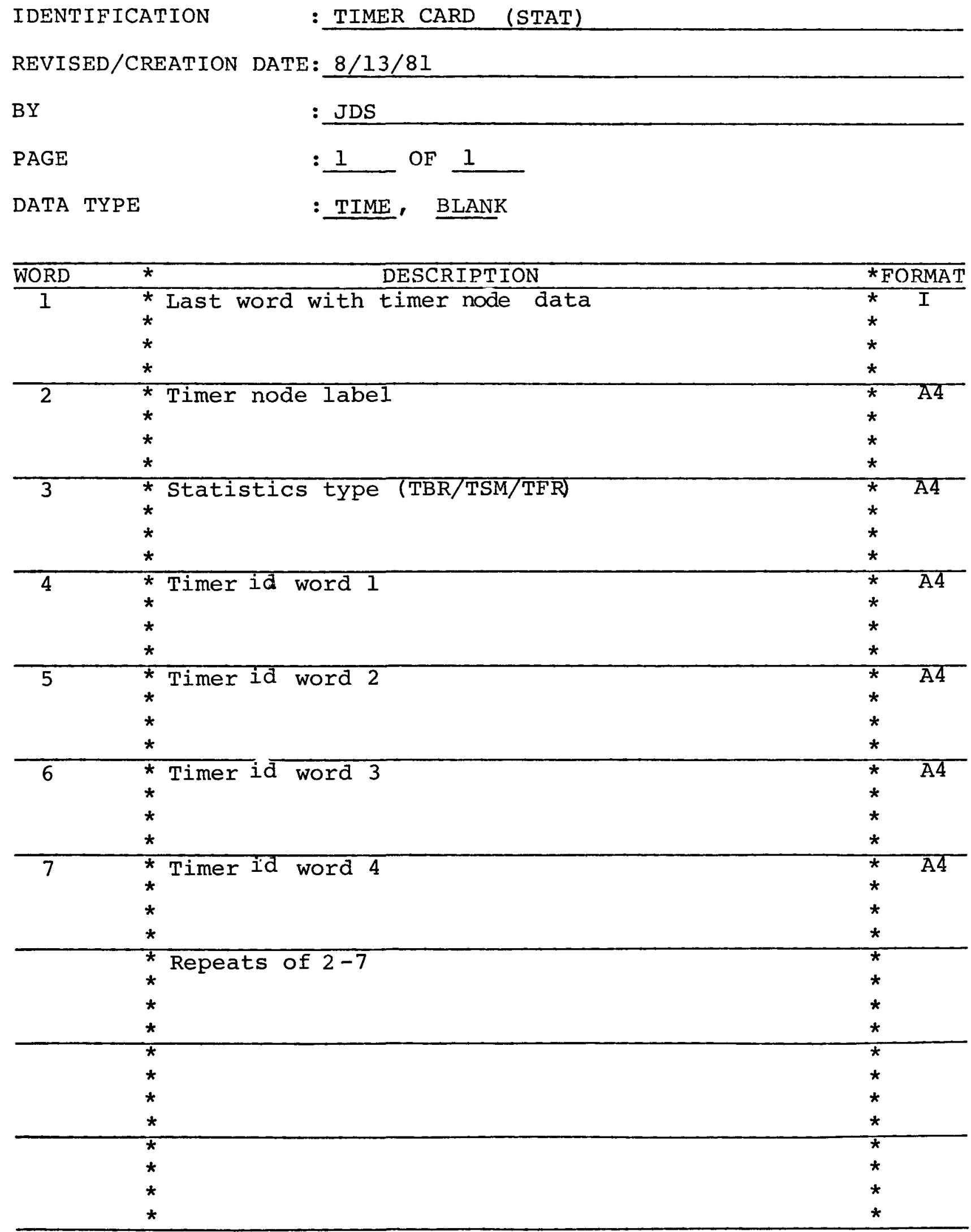




$\begin{array}{ll}\text { IDENTIFICATION } & : \text { MACRO (STAT) } \\ \text { REVISED/CREATION DATE: } & \frac{8 / 18 / 81}{\text { JDS }} \\ \text { BY } & : \frac{1}{\text { MACR }, ~ \text { LABEL }} \\ \text { PAGE } & : \text { MATA TYPE }\end{array}$

\begin{tabular}{|c|c|c|}
\hline WORD & DESCRIPTION & *FORMAT \\
\hline 1 & $\begin{array}{l}* \text { Label } \\
\star \\
\star \\
\star\end{array}$ & $\begin{array}{ll}* & \mathrm{~A} 4 \\
* & \\
* & \\
* & \end{array}$ \\
\hline 2 & $\begin{array}{l}\text { * Last word of data list }(-2 \text { if none }) \\
\star \\
\star\end{array}$ & $\begin{array}{l}* \\
\star \\
\star \\
\star\end{array}$ \\
\hline 3 & $\begin{array}{l}\text { * DOB action word (ACT/DIS/MARK/RECO/SET) } \\
\text { * } \\
\star\end{array}$ & $\begin{array}{l}* \\
* \\
* \\
*\end{array}$ \\
\hline 4 & $\begin{aligned} * & \text { Parameter 1: FLAG, F.FLAG, GV, TIMER, BARRIER } \\
& \text { node label } \\
* & \\
* & \end{aligned}$ & $\begin{array}{l}* \\
\star \\
* \\
\star\end{array}$ \\
\hline 5 & 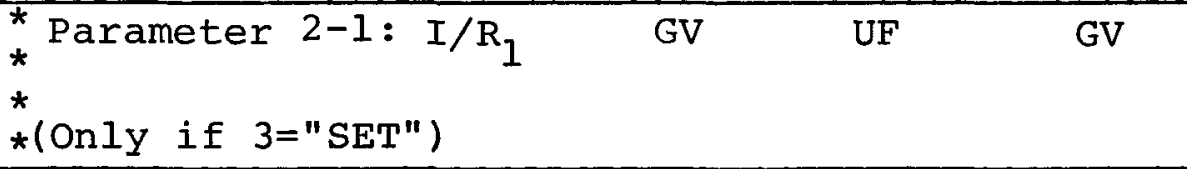 & $\begin{array}{l}* \\
\star \\
\star \\
\star\end{array}$ \\
\hline 6 & $\begin{array}{l}\text { * Parameter } 2-2\left(\mathrm{I} / \mathrm{R}_{2}\right) \\
* \\
*(\text { Only if } 3=" \mathrm{SET} ")\end{array}$ & $\begin{array}{l}* \\
* \\
* \\
*\end{array}$ \\
\hline 7 & $\begin{array}{l}* \text { Parameter } 2-3: \quad\left(I_{2}\right) \quad\left(I / R_{2}\right) \\
\star \\
*(\text { On } 1 \mathrm{y} \text { if } 3=" \mathrm{SET} ")\end{array}$ & $\begin{array}{l}* \\
* \\
* \\
*\end{array}$ \\
\hline 8 & $\begin{array}{l}\text { * Parameter } 2-4: \\
\star \text { (Only if } 3=" \mathrm{SET} "\end{array}$ & $\begin{array}{ll}* & \text { A4 } \\
\star & \\
\star & \\
\star & \end{array}$ \\
\hline & $\begin{array}{l}* \text { Repeats of } 3-8 \text { (6 words) } \\
\star \\
\star\end{array}$ & $\begin{array}{l}* \\
\star \\
\star \\
*\end{array}$ \\
\hline & $\begin{array}{l}\star \star \\
\star \\
\star \\
\star\end{array}$ & $\begin{array}{l}\star \\
\star \\
\star \\
\star\end{array}$ \\
\hline
\end{tabular}


DATA LIST DESCRIPTION B-53

$\begin{array}{ll}\text { IDENTIFICATION } & : \frac{\text { DATA LIST FOR TEXT FILES READ INTO SNAP LIBRARY }}{1 / 2 / 81} \\ \text { REVISED/CREATION DATE } & \frac{1 / \mathrm{JP}}{1} \\ \text { BY } & : \frac{1}{\text { READ }}, \text { BLANK } \\ \text { PAGE } & : \text { OF } \\ \text { DATA TYPE } & \end{array}$

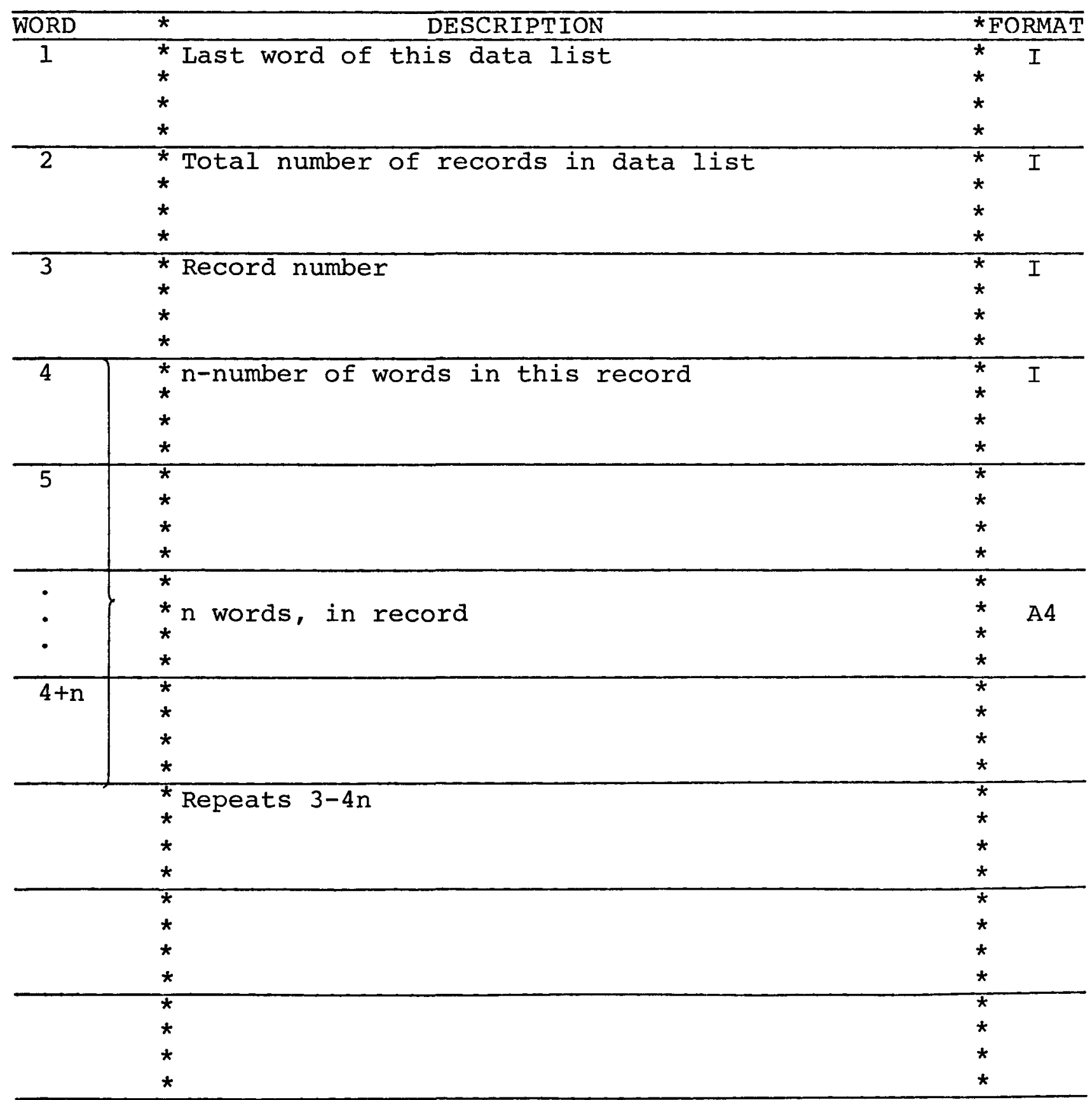




$\begin{array}{ll}\text { IDENTIFICATION } & : \text { ALPHA NUMERIC TRACE FILE } \\ \text { REVISED/CREATION DATE } & : \frac{4 / 1 / 81}{\mathrm{JP}} \\ \text { BY } & : \frac{1}{1} \text { OF } 1 \\ \text { PAGE } & : \text { TRAC }, \text { ALPHA } \\ \text { DATA TYPE } & \end{array}$

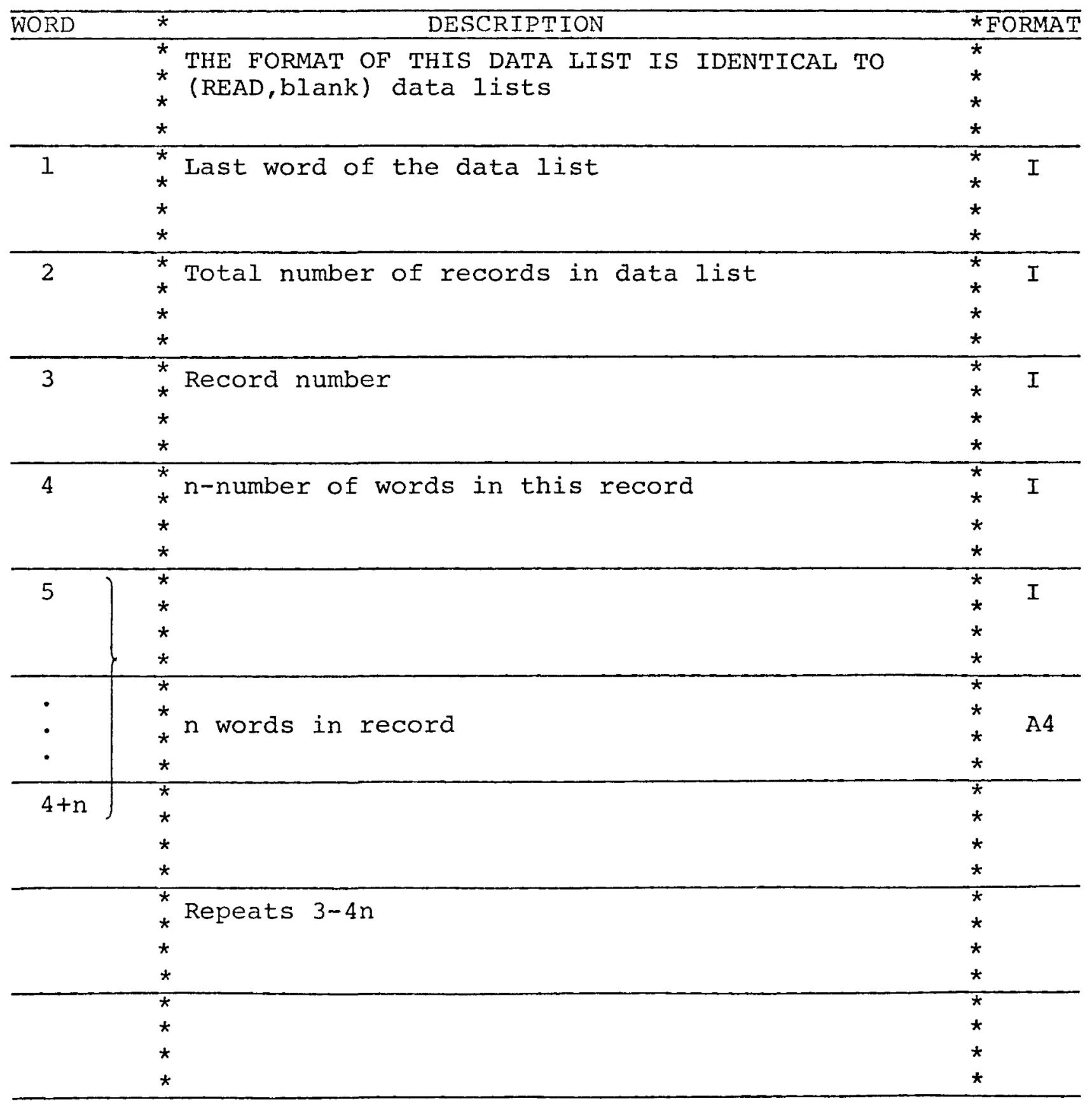


IDENTIFICATION

: GRAPHICS TRACE FILE

REVISED/CREATION DATE: 4/1/81

BY

PAGE

DATA TYPE

: JP

$: 1 \quad O F 1$

: TRAC, RUN NUMBER

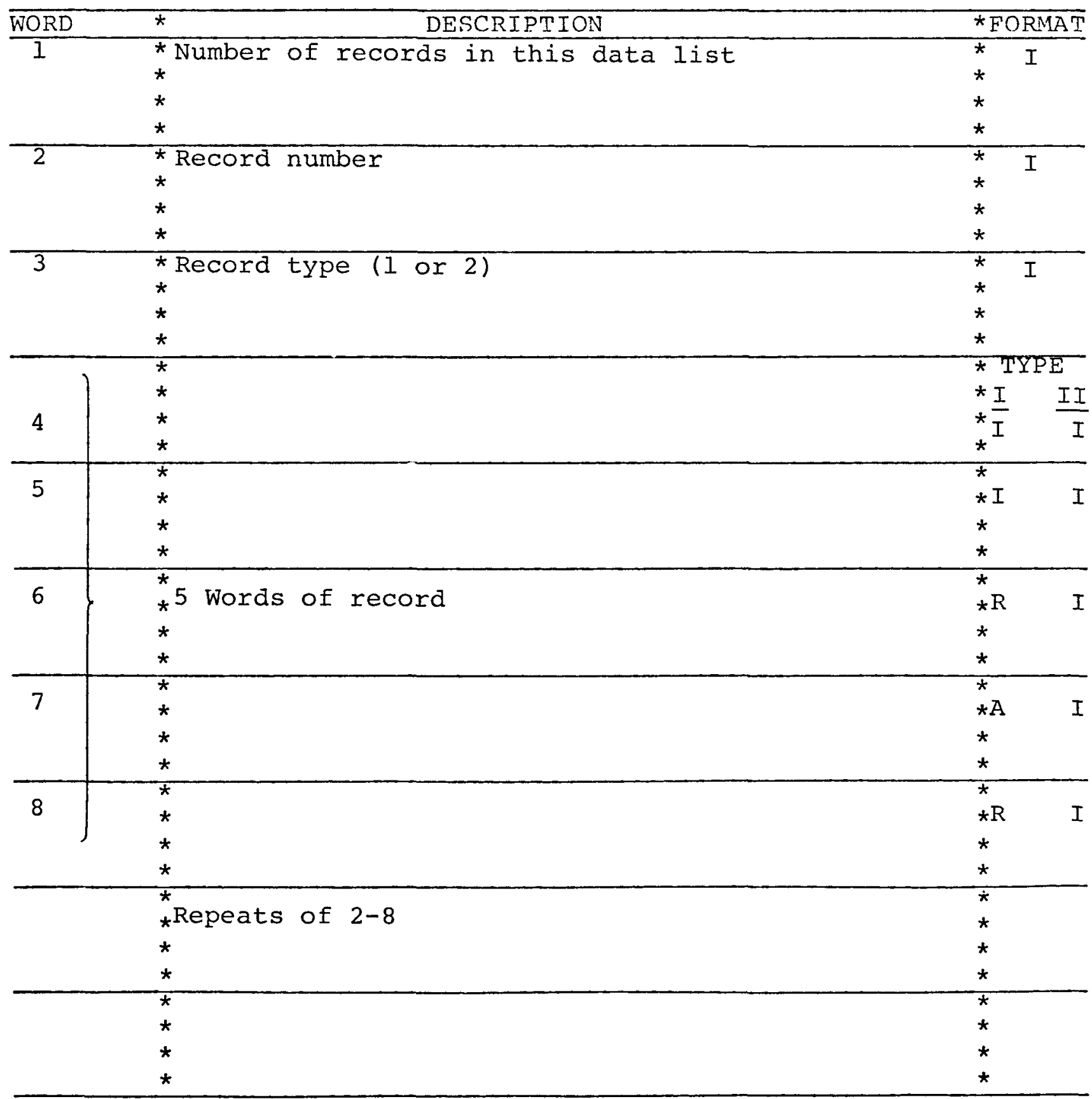




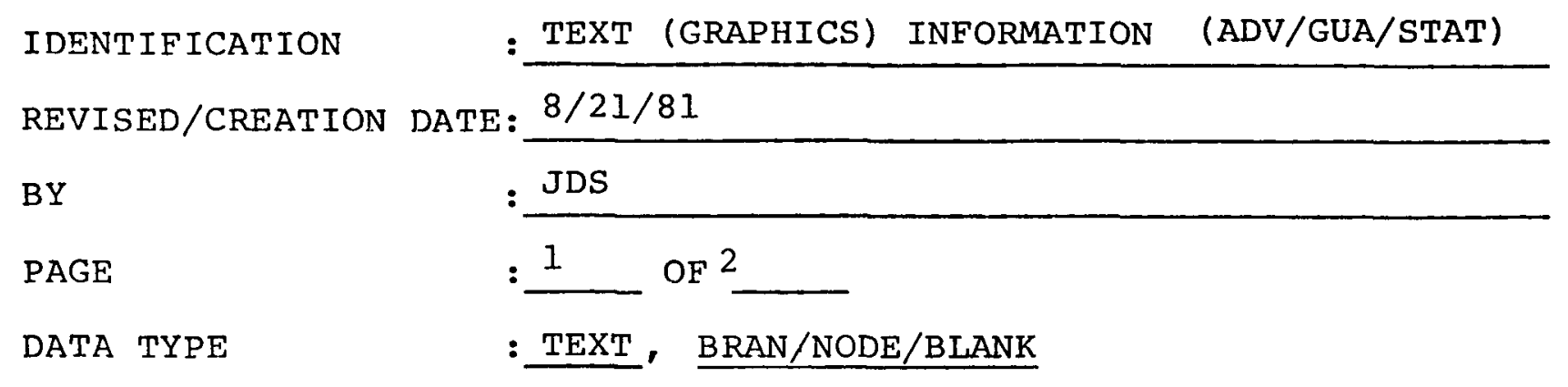

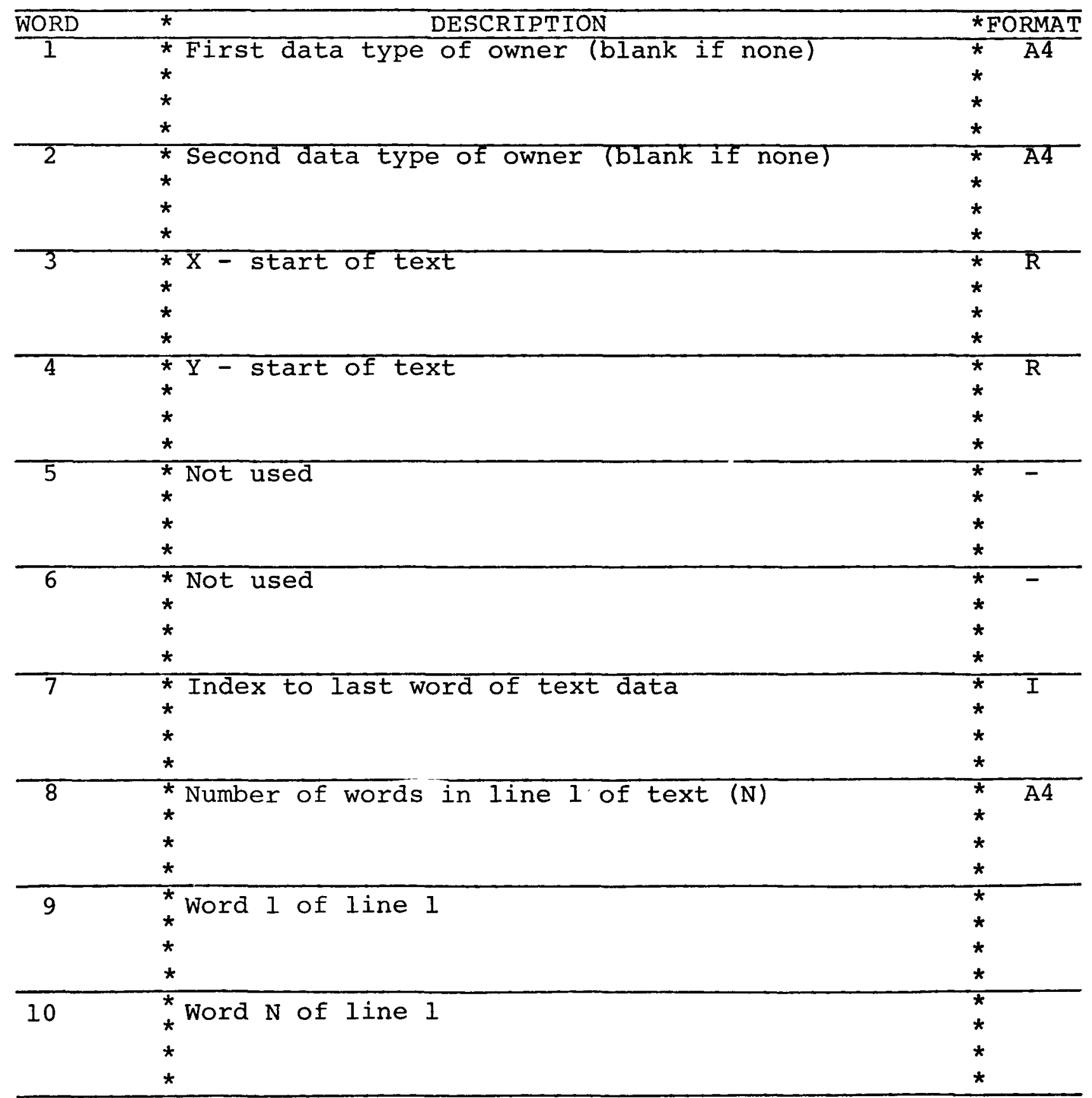


DATA LIST DESCRIPTION $\quad B-57$

IDENTIFICATION

:TEXT (GRAPHICS) - INFORMATION (ADV/GUA/STAT)

REVISED/CREATION DATE: $8 / 21 / 81$

BY

: JDS

PAGE

$: 2$

OF 2

DATA TYPE

: $\mathrm{TEXT}$, BRAN/NODE/BLANK

\begin{tabular}{|c|c|c|}
\hline WORD & * $\quad$ DESCRIPTION & ^FORMAT \\
\hline 11 & $\begin{array}{l}* \\
* \\
*\end{array}$ & $\begin{array}{l}* \\
\star \\
\star \\
\star\end{array}$ \\
\hline 12 & $\begin{array}{l}* \text { Word } 1 \text { of line } 2 \\
\star \\
\star\end{array}$ & $\begin{array}{l}* \\
\star \\
\star \\
\star\end{array}$ \\
\hline 13 & ${ }_{\star}^{*}$ Word $\mathrm{N}$ of line 2 & $\begin{array}{l}* \\
* \\
* \\
*\end{array}$ \\
\hline & $\begin{array}{l}* \text { Repeats } \\
\star \\
\star\end{array}$ & $\begin{array}{l}* \\
\star \\
\star \\
\star\end{array}$ \\
\hline & $\begin{array}{l}* \\
\star \\
\star \\
*\end{array}$ & $\begin{array}{l}* \\
\star \\
\star \\
\star\end{array}$ \\
\hline & $\begin{array}{l}* \\
\star \\
\star \\
\star\end{array}$ & $\begin{array}{l}* \\
* \\
* \\
*\end{array}$ \\
\hline & $\begin{array}{l}* \\
* \\
* \\
*\end{array}$ & $\begin{array}{l}* \\
* \\
* \\
*\end{array}$ \\
\hline & $\begin{array}{l}* \\
\star \\
* \\
\star\end{array}$ & $\begin{array}{l}* \\
* \\
* \\
*\end{array}$ \\
\hline & $\begin{array}{l}* \\
\star \\
* \\
*\end{array}$ & $\begin{array}{l}* \\
* \\
* \\
*\end{array}$ \\
\hline & $\begin{array}{l}* \\
\star \\
\star \\
\star\end{array}$ & $\begin{array}{l}* \\
* \\
* \\
*\end{array}$ \\
\hline
\end{tabular}

